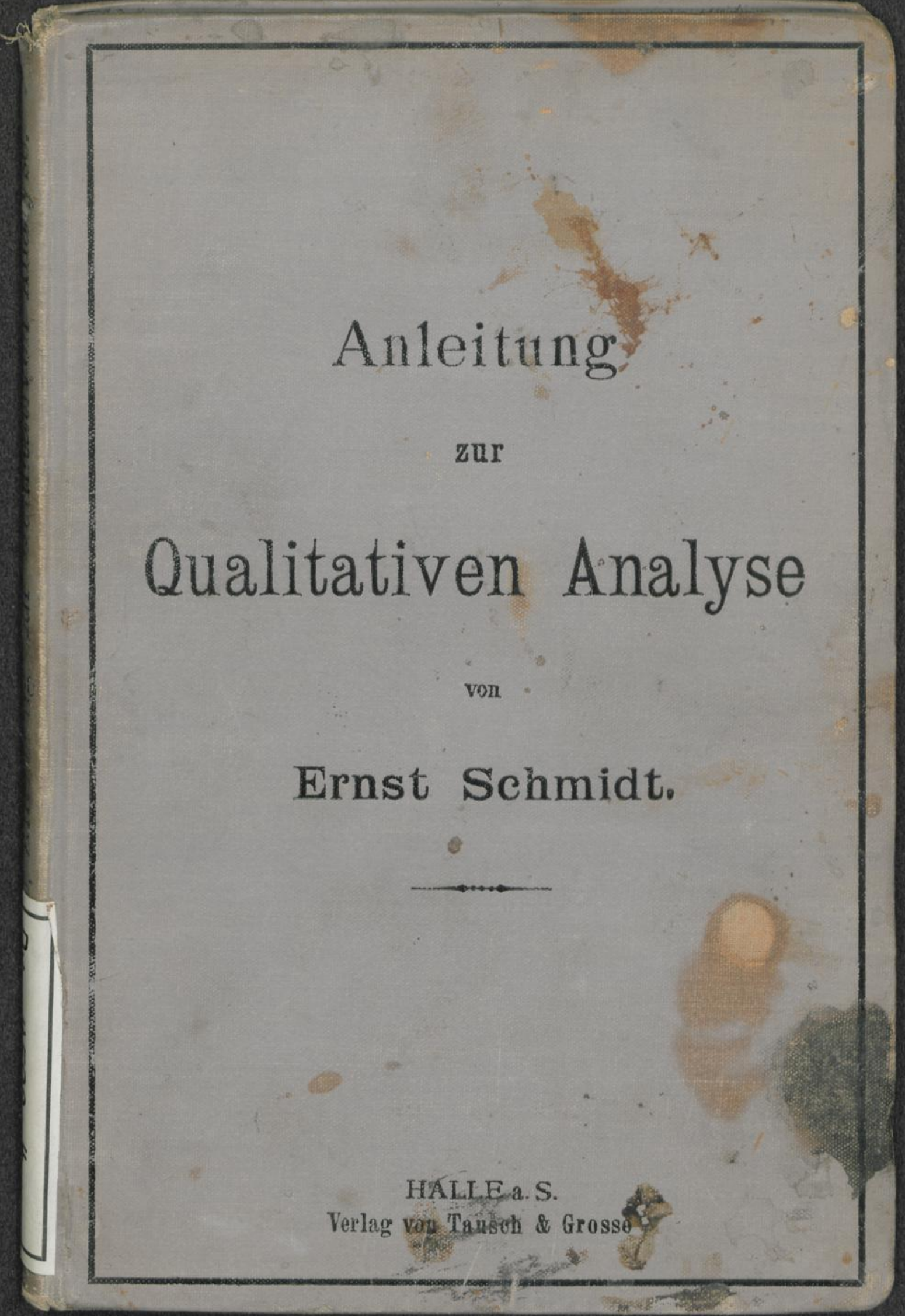





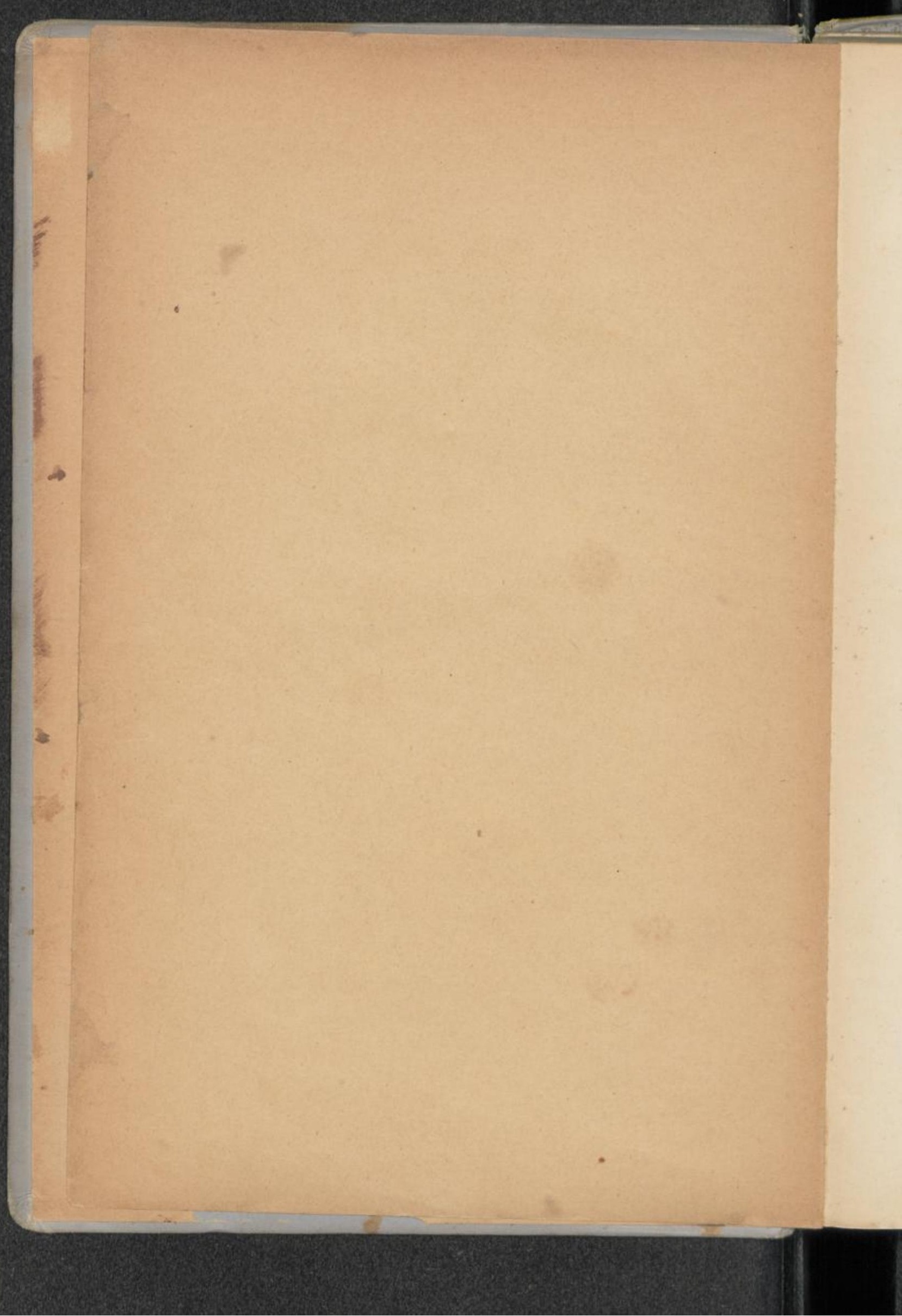




\title{
Anleitung
}

Zur

\section{Qualitativen Analyse}

bearbeitet von

\author{
Dr. Ernst Schmidt, \\ Geh. Regierungsrath, \\ o. Professor an der Universitat Marburg.
}

Vierte Auflage.

Halle a. S.,

Verlag von Tausch \& Grosse.

1896. 


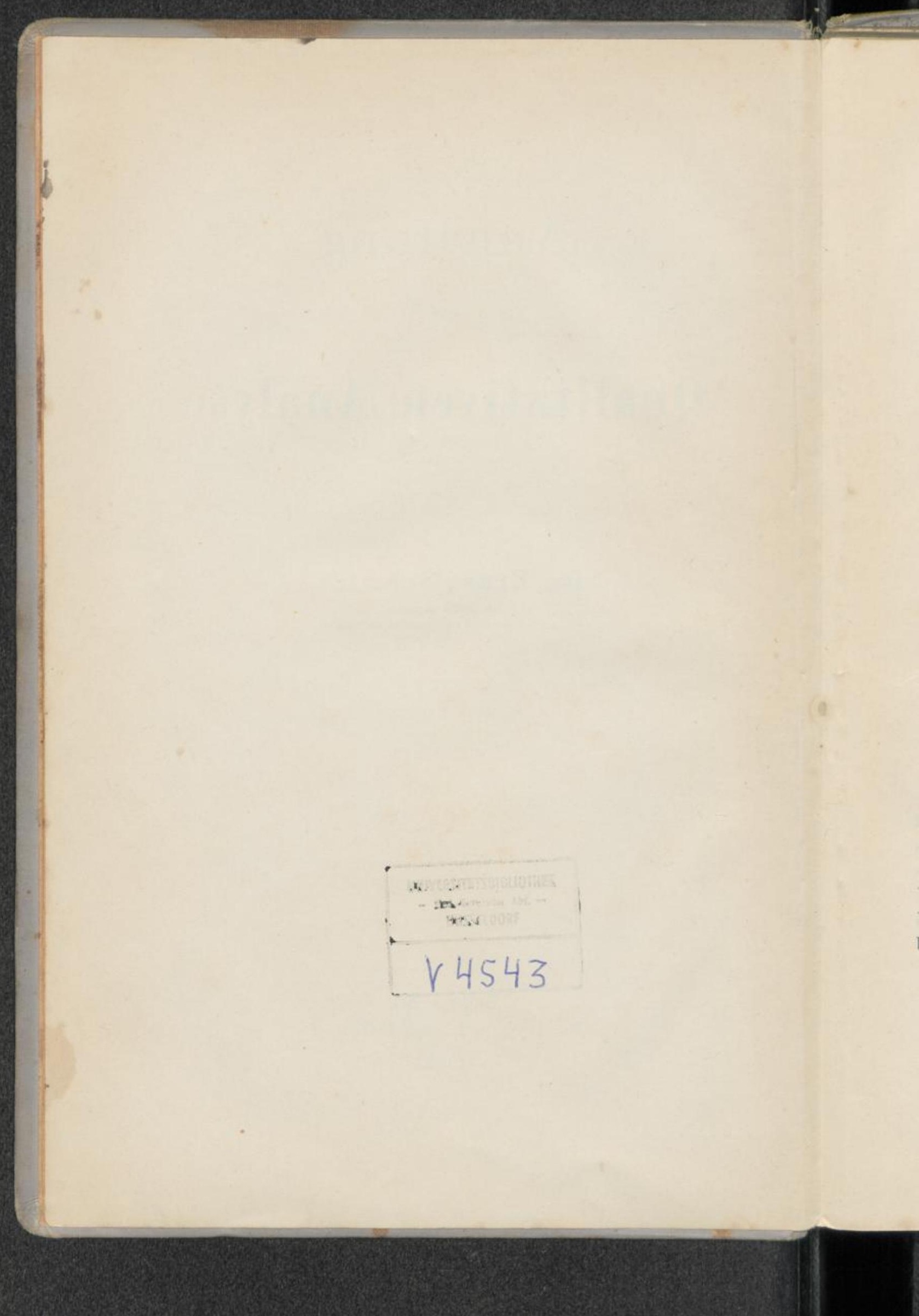




\section{Vorwort zur ersten Auflage.}

Die nachstehende Anleitung zur qualitativen chemischen Analyse macht keinen Anspruch darauf, neue Methoden in die analytische Chemie einzuführen, dieselbe beschränkt sich vielmehr auf eine übersichtliche, systematische Zusammenstellung derjenigen, meist zum Allgemeingut gewordenen Untersuchungsmethoden, welche beim langjährigen Unterricht in der qualitativen Analyse auch in der Hand des Anfängers als zuverlässig erkannt wurden.

Im Interesse der Uebersichtlichkeit ist in dieser Anleitung nur auf den Nachweis der bekannteren, in praxi häufiger vorkommenden Basen und Säuren, nicht dagegen auf seltenere Körper Rücksicht genommen. Trotzdem dürfte der aufmerksame Beobachter bei dem richtigen Verfolge des Gegebenen, sei es durch die Vorproben, sei es durch gewisse Abweichungen in dem Gesammtverhalten, leicht auch auf das Vorhandensein von selteneren Stoffen hingeführt werden, deren Natur alsdann mit Hilfe des Lehrers oder an der Hand ausführlicherer analytischer Werke festzustellen sein würde.

Die erste Abtheilung dieser Anleitung bezweckt eine Orientirung über das Verhalten der wichtigeren Basen und Säuren gegen Agentien überhaupt, die zweite Abtheilung dagegen eine Erörterung der anzuwendenden Methode der qualitativen Analyse. Die Begründung der angegebenen Untersuchungsmethoden bleibt der Thätigkeit des Lehrers, bezüglich dem eigenen Nachdenken des Arbeitenden vorbehal ten.

Halle a. S., Januar 1884.

Erust Schmidt. 


\section{Vorwort zur zweiten Auflage.}

Diese Anleitung zur qualitativen Analyse erscheint auf Wunsch mehrerer Fachgenossen zum ersten Male im Buchhandel, nachdem die erste, vor Jahresfrist als Manuscript gedruckte Auflage vergriffen ist. Die zweite Auflage dieses Werkchens hat gegen die erste nur in sofern eine Erweiterung erfahren, als anhangsweise auch die Reactionen einiger in der analytischen Praxis seltener vorkommenden Elemente und Verbindungen berücksichtigt sind.

Marburg, im Mai 1885.

\section{Ernst Sehmidt.}

\section{Vorwort zur dritten Auflage.}

Die dritte Auflage dieser Anleitung zur qualitativen Analyse hat gegen die zweite nur in sofern eine Erweiterung erfahren, als im Anhang, neben den Reactionen der in der analytischen Praxis seltener vorkommenden Elemente und Verbindungen, auch der im hiesigen Laboratorium gebräuchliche systematische Gang der Ausmittelung derselben eine Berücksichtigung erfahren hat. Im Uebrigen haben sich durch die Praxis nur kleine Aenderungen und Zusätze für dieses Werkchen als wünschenswerth herausgestellt.

Marburg, im Februar 1890.

\section{Ernst Schmidt.}

\section{Vorwort zur vierten Auflage.}

Die vierte Auflage dieser Anleitung zur qualitativen Analyse unterscheidet sich kaum von der dritten, da sich durch die Praxis nur geringfügige Aenderungen und $\mathrm{Zu}$ sätze als wünschenswerth herausgestellt haben.

Marburg, im Januar 1896.

Ernst Schmidt. 


\section{Erste Abtheilung.}

\section{Reactionen.}

\section{a. Reactionen der wichtigeren Basen.}

\section{Kaliumverbindungen.}

a) Platinchlorid (Platinchlorid-Chlorwasserstoff) erzeugt in nicht zu verdünnten, neutralen oder sauren Lösungen, entweder sofort, oder, nach einiger Zeit einen gelben, körnig-krystallinischen Niederschlag von Kaliumplatinchlorid; $\mathrm{K}^{2} \mathrm{PtCl}^{6}$. Verdünnte Lösungen sind behufs Abscheidung letzteren Niederschlags, nach Zusatz von Platinchlorid und etwas Salzsäure, zunächst auf ein kleines Volum einzudampfen und dann eventuell noch mit etwas Alkohol, worin das Kaliumplatinchlorid unlöslich ist, zu versetzen; alkalische Lösungen sind zuvor mit Salzsäure anzusäuren:

$$
2 \mathrm{KCl}+\mathrm{H}^{2} \mathrm{PtCl}^{6}=\mathrm{K}^{2} \mathrm{PtCl}^{6}+2 \mathrm{HCl} .
$$

b) Weinsäure oder besser noch saures Natriumtartrat scheiden aus nicht zu verdünnter, neutraler Lösung der Kaliumsalze, entweder sogleich, oder nach einiger Zeit einen körnigkrystallinischen Niederschlag von saurem Kaliumtartrat: $\mathrm{C}^{4} \mathrm{H}^{5} \mathrm{~K} \mathrm{O}^{6}$, ab. Alkalische Lösungen sind zuvor mit Essigsäure anzusäuren, freie Mineralsäuren enthaltende, zuvor mit Natriumacetatlösung $\mathrm{zu}$ versetzen.

$$
\begin{aligned}
\mathrm{KCl}+\mathrm{C}^{4} \mathrm{H}^{6} \mathrm{O}^{6} & =\mathrm{C}^{4} \mathrm{H}^{5} \mathrm{KO}^{6}+\mathrm{HCl} \\
\mathrm{KCl}+\mathrm{C}^{4} \mathrm{H}^{5} \mathrm{NaO}^{6} & =\mathrm{C}^{4} \mathrm{H}^{5} \mathrm{KO}^{6}+\mathrm{NaCl} .
\end{aligned}
$$

c) Kieselfluorwasserstoffsäure fällt allmälig durchscheinendes, dem Anschein nach amorphes Kieselfluorkalium: $\mathrm{K}^{2} \mathrm{SiF}^{6}$.

d) Ueberchlorsäure scheidet weisses, krystallinisches Kaliumperehlorat: $\mathrm{KClO}^{4}, \mathrm{ab}$.

e) Pikrinsäure erzeugt gelbes, krystallinisches Kaliumpikrat: $\mathrm{C}^{6} \mathrm{H}^{2}\left(\mathrm{NO}^{2}\right)^{3} \cdot \mathrm{OK}$.

f) Die nicht leuchtende Flamme des Bunsen'schen Brenners wird durch Kaliumsalze violett gefärbt, wenn dieselben am Oehr eines dünnen Platindrahtes in die Flamme eingeführt werden. Durch ein Kobaltglas oder ein mit Indigolösung gefülltes Prisma betrachtet, erscheint die Kaliumflamme carmoisinroth gefärbt; letztere Färbung tritt auch bei Gegenwart von Natriumsalzen auf, die andernfalls die Kaliumflamme leicht verdecken. Durch Befeuchten des zu prüfenden Salzes mit Salzsäure oder conc. Schwefelsäure wird häufig die Flammenfärbung verstärkt. 


\section{Natriumverbindungen.}

a) Kaliumpyroantimoniat scheidet aus nicht zu verdünnten, neutralen oder schwach alkalischen Lösungen sofort oder nach einiger Zeit einen körnig-krystallinischen Niederschlag von Natriumpyroantimoniat: $\mathrm{Na}^{2} \mathrm{H}^{2} \mathrm{Sb}^{2} \mathrm{O}^{7}+6 \mathrm{H}^{2} \mathrm{O}$, ab. Reiben der Wände des Reagensglases mit einem Glasstabe beschleunigt die Abscheidung.

$\mathrm{K}^{2} \mathrm{H}^{2} \mathrm{Sb}^{2} \mathrm{O}^{7}+2 \mathrm{NaCl}=\mathrm{Na}^{2} \mathrm{H}^{2} \mathrm{Sb}^{2} \mathrm{O}^{7}+2 \mathrm{KCl}$.

b) Platinchlorid, Weinsäure, saures Kaliumtartrat, Ueberchlorsäure und Pilerinsäure fällen die Lösungen der Natriumverbindungen nicht.

e) Die nicht leuchtende Flamme des Bunsen'schen Brenners wird durch Natriumsalze intensiv gelb gefärbt, wenn letztere am Oehr eines dünnen Platindrahtes in dieselbe eingeführt werden. Durch ein Kobaltglas oder ein Indigoprisma betrachtet, verschwindet die Färbung.

\section{Lithiumverbindungen.}

a) Platinchlorid und Weinsäurelösung verursachen in den $\mathrm{Lö-}$ sungen der Lithiumsalze keine Fällung.

b) Natrium -, Kalium - und Ammoniumearbonatlösung scheiden aus nicht $\mathrm{zu}$ verdünnten Lithiumsalzlösungen weisses Lithiumearbonat: $\mathrm{Li}^{2} \mathrm{CO}^{3}$, aus. $\quad 2 \mathrm{LiCl}+\mathrm{Na}^{2} \mathrm{CO}^{3}=\mathrm{Li}^{2} \mathrm{CO}^{3}+2 \mathrm{NaCl}$.

c) Natriumphosphat scheidet weisses Lithiumphosphat: $\mathrm{Li}^{3} \mathrm{PO}^{4}$, aus.

$$
3 \mathrm{LiCl}+\mathrm{Na}^{2} \mathrm{HPO}^{4}=\mathrm{Li}^{3} \mathrm{PO}^{4}+2 \mathrm{NaCl}+\mathrm{HCl} .
$$

d) Die Lithiumsalze ertheilen der Flamme eine earminrothe Fïrbung, welche nicht durch Kaliumsalze, wohl aber dureh Natriumsalze verdeckt wird. Bei Betrachtung durch eine dünne Schicht Indigolösung bleibt die Lithiumflamme sichtbar, während die Natriumflamme verschwindet. Durch dickere Schichten von Indigolösung oder dureh Kobaltglas betrachtet, verschwindet auch die Lithiumfärbung, wogegen die Kaliumflamme sichtbar bleibt.

\section{Ammoniumverbindungen.}

a) Die Ammoniumverbindungen kennzeichnen sich zunächst durch ihre Flüchtigkeit (Erhitzen auf dem Platinbleche oder in einem unten geschlossenen Glasröhrehen - Glühröhrchen -).

b) Beim Erwärmen mit Natronlauge entwickelt sich Ammoniakgas: $\mathrm{NH}^{3}$, kenntlich am Geruch, an der Blaufärbung des befeuchteten rothen Lackmuspapiers, an der Schwarzfärbung eines mit neutraler Mercuronitratlösung befeuchteten Papierstreifens, sowie an den weissen Nebeln, welche sich von einem über die Mischung gehaltenen, mit Salzsäure befeuchteten Glasstabe entwickeln.

$$
\begin{gathered}
\mathrm{NH}+\mathrm{Cl}+\mathrm{NaOH}=\mathrm{NH}^{3}+\mathrm{NaCl}+\mathrm{H}^{2} \mathrm{O} \\
2 \mathrm{NH}^{3}+\mathrm{Hg}^{2}\left(\mathrm{NO}^{3}\right)^{2}=\mathrm{NH}^{2} \cdot \mathrm{Hg}^{2} \cdot \mathrm{NO}^{3}+\mathrm{NH}^{4} \cdot \mathrm{NO}^{3} \\
\mathrm{NH}^{3}+\mathrm{HCl}=\mathrm{NH}^{4} \mathrm{Cl} .
\end{gathered}
$$


c) Platinchlorid erzeugt unter den gleichen Bedingungen wie bei den Kaliumverbindungen einen gelben, krystallinischen Niederschlag von Ammoniumplatinchlorid: $\left(\mathrm{NH}^{4}\right)^{2} \mathrm{PtCl}^{6}$.

$$
2 \mathrm{NH}^{4} \mathrm{Cl}+\mathrm{H}^{2} \mathrm{PtCl}^{6}=\left(\mathrm{NH}^{4}\right)^{2} \mathrm{PtCl}{ }^{6}+2 \mathrm{HCl} \text {. }
$$

d) Weinsäure verursacht unter den gleichen Bedingungen wie bei den Kaliumverbindungen allmälig eine Abscheidung von weissem, krystallinischem, saurem Ammoniumtartrat: $\mathrm{C}^{4} \mathrm{H}^{5}\left(\mathrm{NH}^{4}\right) \mathrm{O}^{6}$.

$$
\mathrm{NH} \mathrm{H}^{4} \mathrm{Cl}+\mathrm{C}^{4} \mathrm{H}^{6} \mathrm{O}^{6}=\mathrm{C}^{4} \mathrm{H}^{5}\left(\mathrm{NH}^{4}\right) \mathrm{O}^{6}+\mathrm{HCl} \text {. }
$$

e) Sehr geringe Mengen von Ammoniumverbindungen oder von Ammoniak (z. B. im Trinkwasser) lassen sich durch die gelbe bis braunrothe Färbung nachweisen, welche auf Zusatz von 10-20 Tropfen einer Lösung von Quecksilberjodid-Jodkalium in Kalilauge (Nessler'schem Reagens) ${ }^{1}$ eintritt.

$$
4\left(\mathrm{HgJ}^{2}+\mathrm{KJ}\right)+2 \mathrm{NH}^{3}+6 \mathrm{KOH}=2\left(\mathrm{NH}^{2} \cdot \mathrm{Hg} \cdot \mathrm{J}+\mathrm{HgO}\right)+10 \mathrm{KJ}+4 \mathrm{H}^{2} \mathrm{O} .
$$

\section{Calciumverbindungen.}

a) Ammonium-, Kalium- oder Natriumearbonat erzeugen weisse Niederschläge von Calciumcarbonat: $\mathrm{CaCO}^{3}$.

$$
\mathrm{CaCl}^{2}+\left(\mathrm{NH}^{1}\right)^{2} \mathrm{CO}^{3}=\mathrm{CaCO}^{3}+2 \mathrm{NH}^{4} \mathrm{Cl} \text {. }
$$

b) Verdünnte Schwefelsäure $(1: 5)$ und lösliche Sulfate fällen nur in concentrirteren Calciumsalzlösungen weisses, krystallinisches Calciumsulfat: $\mathrm{CaSO}^{4}+2 \mathrm{H}^{2} \mathrm{O}$; verdünnte Lösungen werden erst nach längerer Zeit oder gar nicht gefällt. Im letzteren Falle findet auf Zusatz von Alkohol allmälig eine Fällung statt. $\quad \mathrm{CaCl}^{2}+\mathrm{H}^{2} \mathrm{SO}^{4}=\mathrm{CaSO}^{4}+2 \mathrm{HCl}$.

c) Calciumsulfatlösung (Gypswasser) veranlasst in den Lösungen der Calciumsalze keine Fällung.

d) Oxalsäure und lösliche Oxalate scheiden aus neutralen, ammoniakalischen und essigsauren Calciumsalzlösungen weisses, pulveriges Calciumoxalat: $\mathrm{C}^{2} \mathrm{O}^{4} \mathrm{Ca}+\mathrm{H}^{2} \mathrm{O}$, ab, welches sich nicht in Essigsäure oder Oxalsäure, wohl aber in Salzsäure oder Salpetersäure löst.

$$
\begin{gathered}
\mathrm{CaCl}^{2}+\mathrm{C}^{2} \mathrm{O}^{4}\left(\mathrm{NH}^{4}\right)^{2}=\mathrm{C}^{2} \mathrm{O}^{4} \mathrm{Ca}+2 \mathrm{NH}^{4} \mathrm{Cl} . \\
\mathrm{C}^{2} \mathrm{O}^{4} \mathrm{Ca}+2 \mathrm{HCl}=\mathrm{C}^{2} \mathrm{O}^{4} \mathrm{H}^{2}+\mathrm{CaCl}^{2} .
\end{gathered}
$$

e) Kaliumdichromat, Kaliumehromat und Kieselfluorwasserstoffsëure fällen Calciumsalze nicht.

f) Die leicht zersetzbaren Calciumverbindungen (Chlorcalcium, Calciumnitrat) färben die nicht leuchtende Flamme gelbroth.

1) In eine Lösung von $2,0 \mathrm{KJ}$ in $5,0 \mathrm{H}^{2} \mathrm{O}$ werde so lange $\mathrm{HgJ}^{2}$ in kleinen Portionen eingetragen, bis dasselbe nicht mehr gelöst wird, sodann werden $20,0 \mathrm{H}^{2} \mathrm{O}$ und 40,0 Kalilauge $(1: 2)$ zugefügt, und die Flüssigkeit nach dem Absetzen klar abgegossen oder durch Asbest filtrirt. 


\section{Baryumverbindungen.}

a) Ammonium-, Kalium- oder Natriumearbonat erzeugen weisse Niederschläge von Baryumearbonat: $\mathrm{BaCO}^{3}$.

$$
\mathrm{BaCl}^{2}+\left(\mathrm{NH}^{4}\right)^{2} \mathrm{CO}^{3}=\mathrm{BaCO}^{3}+2 \mathrm{NH}^{4} \mathrm{Cl} \text {. }
$$

b) Verdünnte Schwefelsäure (1:5) und lösliche Sulfate, auch Calcium- und Strontiumsulfatlösung, fällen feinpulveriges, in verdünnten Säuren unlösliches Baryumsulfat: $\mathrm{BaSO}^{4}$.

$$
\mathrm{BaCl}^{2}+\mathrm{H}^{2} \mathrm{SO}^{4}=\mathrm{BaSO}^{4}+2 \mathrm{HCl} \text {. }
$$

c) Saures Kaliumoxalat verursacht in nentraler oder essigsaurer, nicht zu concentrirter Lösung keine Füllung; auf Zusatz von Ammoniak scheidet sich jedoch Baryumoxalat: $\mathrm{C}^{2} \mathrm{O}^{4} \mathrm{Ba}+\mathrm{H}^{2} \mathrm{O}$, aus, welches sich im frisch gefälten Zustande in Essigsäure und in Oxalsäure löst.

$\mathrm{BaCl}^{2}+\mathrm{C}^{2} \mathrm{O}^{4} \mathrm{HK}+\mathrm{NH}^{4} \cdot \mathrm{OH}=\mathrm{C}^{2} \mathrm{O}^{4} \mathrm{Ba}+\mathrm{KCl}+\mathrm{NH}^{4} \mathrm{Cl}+\mathrm{H}^{2} \mathrm{O}$.

d) Kaliumdichromat und Kaliumchromat seheiden aus neutraler oder aus essigsaurer Lösung gelbes Baryumehromat: $\mathrm{BaCrO}^{4}, \mathrm{ab}$, welches unlöslich in Essigsäure und in Natronlauge, leicht löslich in Salzsäure oder Salpetersäure ist.

$$
\begin{gathered}
\mathrm{BaCl}^{2}+\mathrm{K}^{2} \mathrm{CrO}{ }^{4}=\mathrm{BaCrO}^{4}+2 \mathrm{KCl} . \\
\mathrm{BaCrO}^{4}+2 \mathrm{HCl}=\mathrm{BaCl}^{2}+\mathrm{CrO}^{3}+\mathrm{H}^{2} \mathrm{O} .
\end{gathered}
$$

e) Kieselfluorwasserstoffsäure fällt krystallinisches Kieselfluorbaryum: $\mathrm{BaSiF}^{6}$, welches in Wasser und in verdünnten Säuren schwer löslich ist. In verdünnten Lösungen erfolgt die Abscheidung erst nach einiger Zeit; ein Zusatz von Alkohol beschleunigt dieselbe.

$$
\mathrm{BaCl}^{2}+\mathrm{H}^{2} \mathrm{SiF}^{6}=\mathrm{BaSiF}^{6}+2 \mathrm{HCl} .
$$

f) Die leicht zersetzbaren Baryumsalze (z. B. Chlorbaryum, Baryumnitrat) färben die nicht leuchtende Flamme gelbgrün.

\section{Strontiumverbindungen.}

a) Ammonium-, Kalium- oder Natriumcarbonat erzeugen weisse Niederschläge von Strontiumcarbonat: $\mathrm{SrCO}^{3}$.

$$
\mathrm{Sr}\left(\mathrm{NO}^{3}\right)^{2}+\left(\mathrm{NH}^{4}\right)^{2} \mathrm{CO}^{3}=\mathrm{SrCO}^{3}+2 \mathrm{NH}^{4} \cdot \mathrm{NO}^{3} .
$$

b) Verdünnte Schwefelsäure $(1: 5)$ und lösliche Sulfate, auch Calciumsulfat-, nicht aber Strontiumsulfatlösung, scheiden allmälig weisses, krystallinisches Strontiumsulfat: $\mathrm{SrSO}^{4}$, ab.

$$
\mathrm{Sr}\left(\mathrm{NO}^{3}\right)^{2}+\mathrm{H}^{2} \mathrm{SO}^{4}=\mathrm{SrSO}^{4}+2 \mathrm{HNO}^{3} \text {. }
$$

c) Saures Kaliumoxalat fällt allmälig weisses Strontiumoxalat: $\mathrm{C}^{2} \mathrm{O}^{4} \mathrm{Sr}+\mathrm{H}^{2} \mathrm{O}$, welches in Essigsäure und Oxalsäure schwer löslich ist; auf Zusatz von Ammoniak findet eine Vermehrung des Niedersehlags statt.

$$
\mathrm{Sr}\left(\mathrm{NO}^{3}\right)^{2}+\mathrm{C}^{2} \mathrm{O}^{4} \mathrm{HK}=\mathrm{C}^{2} \mathrm{O}^{4} \mathrm{Sr}+\mathrm{KNO}^{3}+\mathrm{HNO}^{3} .
$$


d) Kaliumchromat scheidet in neutraler Lösung allmälig gelbes Strontiumchromat: $\mathrm{SrCrO}^{4}$, ab, welches in Essigsäure und Salpetersäure löslich ist.

$$
\mathrm{Sr}\left(\mathrm{NO}^{3}\right)^{2}+\mathrm{K}^{2} \mathrm{CrO}{ }^{4}=\mathrm{SrCrO}^{4}+2 \mathrm{KNO}^{3} .
$$

e) Kaliumdichromat und Kieselfluorwasserstoffsäure fällen Strontiumsalzlösungen nicht.

f) Leicht zersetzbare Strontiumsalze (z. B. Strontiumnitrat, Chlorstrontium) färben die nicht leuchtende Flamme carminroth; durch Kobaltglas betrachtet, erscheint dieselbe purpurroth.

\section{Magnesiumverbindungen.}

a) Ammoniumcarbonatlösung $\left[\mathrm{NH}^{4} \mathrm{HCO}^{3},\left(\mathrm{NH}^{4}\right)^{2} \mathrm{CO}^{3}\right]$ erzeugt zunächst keine Fällung; erst beim längeren Stehen oder beim Erwärmen tritt eine solche ein. Bei Gegenwart von Ammoniaksalzen tritt auch im letzteren Falle keine Ausscheidung eines Niederschlags ein (vgl. d).

b) Concentrirte Lösung von neutralem Ammoniumcarbonat: $\left(\mathrm{NH}^{4}\right)^{2} \mathrm{CO}^{3}$, erzeugt, im Ueberschusse angewendet, in ammoniaksalzfreien Magnesiumsalzlösungen allmälig einen weissen, krystallinischen Niederschlag von Ammonium-Magnesiumcarbonat: $\mathrm{Mg}\left(\mathrm{NH}^{4}\right)^{2}\left(\mathrm{CO}^{3}\right)^{2}+4 \mathrm{H}^{2} \mathrm{O}$.

$$
\mathrm{MgSO}^{4}+2\left(\mathrm{NH}^{4}\right)^{2} \mathrm{CO}^{3}=\mathrm{Mg}\left(\mathrm{NH}^{4}\right)^{2}\left(\mathrm{CO}^{3}\right)^{2}+\left(\mathrm{NH}^{4}\right)^{2} \mathrm{SO}^{4} .
$$

c) Kalium- und Natriumcarbonat scheiden weisses BasischMagnesiumcarbonat ab, welches sich auf Zusatz von Chlorammonium wieder löst. Die Anwesenheit von Ammoniaksalzen verhindert die Fallung.

$$
\begin{gathered}
4 \mathrm{MgSO}^{4}+4 \mathrm{Na}^{2} \mathrm{CO}^{3}+\mathrm{xH}^{2} \mathrm{O}=\left[3 \mathrm{MgCO}{ }^{3}+\mathrm{Mg}(\mathrm{OH})^{2}+\mathrm{xH}^{2} \mathrm{O}\right]+4 \mathrm{Na}^{2} \mathrm{SO}^{4} \\
+\mathrm{CO}^{2} . \\
{\left[3 \mathrm{MgCO}{ }^{3}+\mathrm{Mg}(\mathrm{OH})^{2}+\mathrm{xH}^{2} \mathrm{O}\right]+16 \mathrm{NH}^{4} \mathrm{Cl}=4\left[\mathrm{MgCl}^{2}+2 \mathrm{NH}^{4} \mathrm{Cl}\right]+} \\
3\left(\mathrm{NH}^{4}\right)^{2} \mathrm{CO}^{3}+2 \mathrm{NH}^{4} \cdot \mathrm{OH}+\mathrm{xH}^{2} \mathrm{O} .
\end{gathered}
$$

d) Ammoniak scheidet aus neutralen Magnesiumsalzlösungen nur einen Theil des Magnesiums als Magnesiumhydroxyd: $\mathrm{Mg}(\mathrm{OH})^{2}$, ab, während der andere Theil mit dem bei der Umsetzung gebildeten Ammoniumsalze sich zu einem löslichen Doppelsalze vereinigt. Letztere Doppelsalze werden durch Ammoniak nicht zerlegt, ebensowenig in der Kälte von den Hydroxyden und Carbonaten der Alkalimetalle. Die letzteren Reagentien verursachen daher in Magnesiumsalzlösungen bei Gegenwart von Ammoniaksalzen keine Fällungen, bezüglich letztere verschwinden wieder, sobald man der Mischung Chlorammonium zusetzt.

$$
\begin{gathered}
2 \mathrm{MgSO}+2 \mathrm{NH}^{4} \cdot \mathrm{OH}=\mathrm{Mg}(\mathrm{OH})^{2}+\mathrm{Mg}\left(\mathrm{NH}^{4}\right)^{2}\left(\mathrm{SO}^{4}\right)^{2} . \\
\mathrm{Mg}(\mathrm{OH})^{2}+4 \mathrm{NH}^{4} \mathrm{Cl}=\mathrm{Mg}\left(\mathrm{NH}^{4}\right)^{2} \mathrm{Cl}^{4}+2 \mathrm{NH}^{4} \cdot \mathrm{OH} .
\end{gathered}
$$

e) Natriumphosphat erzeugt ohne Ammoniakzusatz nur in concentrirten Magnesiumsalzlösungen einen Niederschlag von Mag- 
nesiumphosphat: $\mathrm{MgHPO}^{4}+7 \mathrm{H}^{2} \mathrm{O}$. Setzt man der Magnesiumsalzlösung jedoch zunächst Chlorammoniumlösung (um die Abscheidung von Magnesiumhydroxyd durch Ammoniak zu verhüten) und dann Ammoniak zu, so bewirkt Natriumphosphat auch in sehr verdünnten Lösungen (in letzterem Falle erst nach einiger Zeit) einen körnig-krystallinischen Niederschlag von AmmoniumMagnesiumphosphat: $\mathrm{Mg}\left(\mathrm{NH}^{4}\right) \mathrm{PO}^{4}+6 \mathrm{H}^{2} \mathrm{O}$.

$$
\begin{gathered}
\mathrm{MgSO}^{4}+\mathrm{Na}^{2} \mathrm{HPO} \mathrm{HP}^{4}=\mathrm{MgHPO} \mathrm{Mg}^{4}+\mathrm{Na}^{2} \mathrm{SO}^{4} \\
\mathrm{MgSO}^{4}+\mathrm{NH}^{4} \cdot \mathrm{OH}+\mathrm{Na}^{2} \mathrm{HPO}^{4}=\mathrm{Mg}\left(\mathrm{NH}^{4}\right) \mathrm{PO}^{4}+\mathrm{Na}^{2} \mathrm{SO}^{4}+\mathrm{H}^{2} \mathrm{O} .
\end{gathered}
$$

f) Ammoniumoxalat ruft nur in concentrirten Lösungen der Magnesiumsalze einen Niederschlag von Magnesiumoxalat: $\mathrm{C}^{2} \mathrm{O}^{4} \mathrm{Mg}+2 \mathrm{H}^{2} \mathrm{O}$, hervor. Meist tritt diese Fällung erst nach längerem Stehen ein; Ammoniaksalze verzögern dieselbe oder verhindern sie bisweilen ganz.

\section{Aluminiumverbindungen.}

a) Kalium- und Natriumhydroxyd erzeugen einen weissen, gallertartigen Niederschlag von Aluminiumhydroxyd: $\left.\mathrm{Al}^{2}(\mathrm{OH})^{6},{ }^{1}\right)$ welcher sich in einem Ueberschusse des Fällungsmittels als $K a$ lium- und Natriumaluminat wieder löst. Aus letzterer Lösung wird das Aluminiumhydroxyd durch Zusatz von Chlorammonium, oder, nach der Neutralisation mit Salzsäure, durch Zusatz von Ammoniumcarbonatlösung wieder abgeschieden. Durch Kochen werden die Aluminate nicht zersetzt.

$$
\begin{gathered}
\mathrm{Al}^{2}\left(\mathrm{SO}^{4}\right)^{3}+6 \mathrm{NaOH}=\mathrm{Al}^{2}(\mathrm{OH})^{6}+3 \mathrm{Na}^{2} \mathrm{SO}^{4} \\
\mathrm{Al}^{2}(\mathrm{OH})^{6}+6 \mathrm{NaOH}=\mathrm{Al}^{2}(\mathrm{ONa})^{6}+6 \mathrm{H}^{2} \mathrm{O} \\
\mathrm{Al}^{2}(\mathrm{ONa})^{6}+6 \mathrm{NH}^{4} \mathrm{Cl}=\mathrm{Al}^{2}(\mathrm{OH})^{6}+6 \mathrm{NaCl}+6 \mathrm{NH}^{3} .
\end{gathered}
$$

b) Ammonial-, Ammoniumcarbonat- und Schwefelammoniumlösung scheiden ebenfalls gallertartiges Aluminiumhydroxyd: $\mathrm{Al}^{2}(\mathrm{OH})^{6}, \mathrm{ab}$, welches sich in einem Ueberschusse der Fällungsmittel wenig oder gar nicht löst.

$$
\begin{gathered}
\mathrm{Al}^{2} \mathrm{Cl}^{6}+3\left(\mathrm{NH}^{4}\right)^{2} \mathrm{CO}^{3}+3 \mathrm{H}^{2} \mathrm{O}=\mathrm{Al}^{2}(\mathrm{OH})^{6}+6 \mathrm{NH}^{4} \mathrm{Cl}+3 \mathrm{CO}^{2} \\
\mathrm{Al}^{2} \mathrm{Cl}^{6}+3\left(\mathrm{NH}^{4}\right)^{2} \mathrm{~S}+6 \mathrm{H}^{2} \mathrm{O}=\mathrm{Al}^{2}(\mathrm{OH})^{6}+6 \mathrm{NH}^{4} \mathrm{Cl}+3 \mathrm{H}^{2} \mathrm{~S} .
\end{gathered}
$$

c) Kalium - und Natriumcarbonat fällen ebenfalls weisses, gallertartiges, durch basisches Aluminiumsalz verunreinigtes $A l u$ miniumhydroxyd: $\mathrm{Al}^{2}(\mathrm{OH})^{6}$; letzteres ist nur in einem grossen Ueberschusse der conc. Lösungen dieser Fällungsmittel löslich.

$$
\mathrm{Al}^{2} \mathrm{Cl}^{6}+3 \mathrm{Na}^{2} \mathrm{CO}^{3}+3 \mathrm{H}^{2} \mathrm{O}=\mathrm{Al}^{2}(\mathrm{OH})^{6}+6 \mathrm{NaCl}+3 \mathrm{CO}^{2} \text {. }
$$

d) Natriumphosphat scheidet weisses, gallertartiges Aluminiumphosphat: $\mathrm{Al}^{2}\left(\mathrm{PO}^{4}\right)^{2}$, ab, welches in Kali- und Natronlauge, sowie in Essigsäure löslich ist. Chlorammonium scheidet

1) Verunreinigt durch basisches Aluminiumsalz. 
aus der Lösung in Kali- oder Natronlauge wieder Aluminiumphosphat aus.

$$
\begin{gathered}
\mathrm{Al}^{2} \mathrm{Cl}^{6}+2 \mathrm{Na}^{2} \mathrm{HPO} \mathrm{H}^{4}=\mathrm{Al}^{2}\left(\mathrm{PO}^{4}\right)^{2}+4 \mathrm{NaCl}+2 \mathrm{HCl} \\
\mathrm{Al}^{2}\left(\mathrm{PO}^{4}\right)^{2}+12 \mathrm{NaOH}=\mathrm{Al}^{2}(\mathrm{ONa})^{6}+2 \mathrm{Na}^{3} \mathrm{PO}^{4}+6 \mathrm{H}^{2} \mathrm{O}
\end{gathered}
$$

$\mathrm{Al}^{2}(\mathrm{ONa})^{6}+2 \mathrm{Na}^{3} \mathrm{PO}^{4}+12 \mathrm{NH}^{4} \mathrm{Cl}=\mathrm{Al}^{2}\left(\mathrm{PO}^{4}\right)^{2}+12 \mathrm{NaCl}+12 \mathrm{NH}^{3}+6 \mathrm{H}^{2} \mathrm{O}$.

e) Glüht man ein Aluminiumsalz vor dem Löthrohre auf der Kohle, befeuchtet die dabei entstehende weisse, unschmelzbare Masse mit Kobaltnitratlösung, und glüht dieselbe dann abermals, so nimmt der Rückstand eine schön blaue Farbe an (Thénard's Blau).

\section{Chromi- (Chromoxyd-) Verbindungen.}

a) Kalium- oder Natriumhydroxyd scheiden blau- oder graugrünes Chromhydroxyd: $\mathrm{Cr}^{2}(\mathrm{OH})^{6}$, ab, welches sich in einem Ueberschusse des Fällungsmittels mit grüner Farbe löst, durch Kochen der Lösung aber vollständig wieder ausgeschieden wird.

$$
\begin{gathered}
\mathrm{Cr}^{2}\left(\mathrm{SO}^{4}\right)^{3}+6 \mathrm{NaOH}=\mathrm{Cr}^{2}(\mathrm{OH})^{6}+3 \mathrm{Na}^{2} \mathrm{SO}^{4} \\
\mathrm{Cr}^{2}(\mathrm{OH})^{6}+6 \mathrm{NaOH}=\mathrm{Cr}^{2}(\mathrm{ONa})^{6}+6 \mathrm{H}^{2} \mathrm{O} \\
\mathrm{Cr}^{2}(\mathrm{ONa})^{6}+6 \mathrm{H}^{2} \mathrm{O}=\mathrm{Cr}^{2}(\mathrm{OH})^{6}+6 \mathrm{NaOH} .
\end{gathered}
$$

b) Ammonial fällt blau- oder graugrünes Chromhydroxyd: $\mathrm{Cr}^{2}(\mathrm{OH})^{6}$, welches sich in einem Ueberschusse des Fällungsmittels, namentlich bei Gegenwart von Ammoniaksalzen, zum Theil mit roth-violetter Farbe auflöst. Aus letzterer Lösung wird das Chromhydroxyd beim Kochen vollständig wieder abgeschieden.

$$
\mathrm{Cr}^{2} \mathrm{Cl}^{6}+6 \mathrm{NH}^{4} \cdot \mathrm{OH}=\mathrm{Cr}^{2}(\mathrm{OH})^{6}+6 \mathrm{NH}^{4} \mathrm{Cl} \text {. }
$$

c) Kalium- und Natriumcarbonat erzeugen einen grünen, bald bläulich werdenden Niederschlag von Chromhydroxyd: $\mathrm{Cr}^{2}(\mathrm{OH})^{6}$, welcher in einem Ueberschusse des Fallungsmittels löslich ist, sich beim Kochen der grünen Lösung aber wieder abscheidet.

$$
\mathrm{Cr}^{2}\left(\mathrm{SO}^{4}\right)^{3}+3 \mathrm{Na}^{2} \mathrm{CO}^{3}+3 \mathrm{H}^{2} \mathrm{O}=\mathrm{Cr}^{2}(\mathrm{OH})^{6}+3 \mathrm{Na}^{2} \mathrm{SO}^{4}+3 \mathrm{CO}^{2} \text {. }
$$

d) Schwefelammonium scheidet Chromhydroxyd: $\mathrm{Cr}^{2}(\mathrm{OH})^{6}$, ab. $\mathrm{Cr}^{2}\left(\mathrm{SO}^{4}\right)^{3}+3\left(\mathrm{NH}^{4}\right)^{2} \mathrm{~S}+6 \mathrm{H}^{2} \mathrm{O}=\mathrm{Cr}^{2}(\mathrm{OH})^{6}+3\left(\mathrm{NH}^{4}\right)^{2} \mathrm{SO}^{4}+3 \mathrm{H}^{2} \mathrm{~S}$.

e) Schmilzt man eine Chromverbindung auf dem Platinbleche oder in einem Porcellantiegel mit Natriumearbonat und Kaliumnitrat, so resultirt eine gelbe, Alkalichromat enthaltende Schmelze, die nach dem Ausziehen mit Wasser und Filtriren eine gelbgefärbte Lösung liefert; letztere zeigt nach der Neutralisation mit Essigsäure oder mit Salpetersäure die unter Chromsäure (s. S. 36) angegebenen Reactionen.

$\mathrm{Cr}^{2}\left(\mathrm{SO}^{4}\right)^{3}+5 \mathrm{Na}^{2} \mathrm{CO}^{3}+3 \mathrm{KNO}^{3}=2 \mathrm{Na}^{2} \mathrm{CrO}^{4}+3 \mathrm{Na}^{2} \mathrm{SO}^{4}+3 \mathrm{KNO}^{2}+5 \mathrm{CO}^{2}$.

f) Die Phosphorsalsperle wird durch Chromverbindungen in der oxydirenden und in der reducirenden Flamme grün gefärbt. 
g) Die Boraxperle zeigt in der reducirenden Flamme eine grüne, in der oxydirenden Flamme eine gelbe Farbe.

\section{Kobaltsalze.}

a) Schwefelwasserstoff scheidet aus neutralen Kobaltsalzlösungen nur einen Theil des Kobalts als schwarzes Schwefelkobalt: $\mathrm{CoS}$, ab; bei Gegenwart freier Mineralsäuren tritt keine Fällung ein; bei Gegenwart von Natriumacetat, namentlich beim Erwärmen der Flüssigkeit, findet dagegen vollständige Ausfällung als Schwefelkobalt statt.

$$
\mathrm{Co}\left(\mathrm{NO}^{3}\right)^{2}+\mathrm{H}^{2} \mathrm{~S}=\mathrm{CoS}+2 \mathrm{HNO}^{3}
$$

$\mathrm{Co}\left(\mathrm{NO}^{3}\right)^{2}+2 \mathrm{C}^{2} \mathrm{H}^{3} \mathrm{NaO}^{2}+\mathrm{H}^{2} \mathrm{~S}=\mathrm{CoS}+2 \mathrm{NaNO}^{3}+2 \mathrm{C}^{2} \mathrm{H}^{4} \mathrm{O}^{2}$.

b) Schwefelammonium fällt schwarzes Schwefelkobalt: CoS, welches in kalter verdünnter Salzsäure fast unlöslich ist, von Königswasser aber zu Kobaltchlorür: $\mathrm{CoCl}^{2}$, gelöst wird.

$$
\begin{gathered}
\mathrm{Co}\left(\mathrm{NO}^{3}\right)^{2}+\left(\mathrm{NH}^{4}\right)^{2} \mathrm{~S}=\mathrm{CoS}+2 \mathrm{NH}^{4} \cdot \mathrm{NO}^{3} \\
3 \mathrm{CoS}+6 \mathrm{HCl}+2 \mathrm{HNO}^{3}=3 \mathrm{CoCl}^{2}+\mathrm{S}^{3}+2 \mathrm{NO}+4 \mathrm{H}^{2} \mathrm{O} .
\end{gathered}
$$

c) Kalium- und Natriumhydroxyd fallen aus Kobaltoxydulsalzlösungen in der Kälte blaue basische Salze, welche sich beim Kochen in schmutzig rosenrothes Kobalthydroxydul: $\mathrm{Co}(\mathrm{OH})^{2}$, und bei längerem Stehen in schmutzig olivengrünes Kobalthydroxyduloxyd: $\mathrm{Co}^{3} \mathrm{O}^{4}+\mathrm{xH}^{2} \mathrm{O}$, verwandeln.

$$
\begin{aligned}
& \mathrm{Co}\left(\mathrm{NO}^{3}\right)^{2}+2 \mathrm{NaOH}=\mathrm{Co}(\mathrm{OH})^{2}+2 \mathrm{NaNO}^{3} \\
& 3 \mathrm{Co}(\mathrm{OH})^{2}+\mathrm{O}+\mathrm{xH}^{2} \mathrm{O}=\mathrm{Co}^{3} \mathrm{O}^{4}+\mathrm{xH}^{2} \mathrm{O} .
\end{aligned}
$$

d) Ammoniak ruft in neutralen, ammoniaksalzfreien Lösungen die gleichen Fällungen wie Kalium - und Natriumhydroxyd hervor, dieselben lösen sich jedoch in einem Ueberschusse des Fällungsmittels zu einer grünlichen, an der Luft durch Oxydation sich bräunenden Flüssigkeit: $\left[\mathrm{Co}^{2}(\mathrm{OH})^{6}+8 \mathrm{NH}^{3}\right]$, fast vollständig wieder auf. In saurer oder Ammoniaksalz enthaltender Lösung bewirkt Ammoniak keinen Niederschlag, sondern nur eine rothe, bald braun werdende Färbung.

e) Kalium- und Natriumcarbonat scheiden pfirsichblüthrothes Basisch-Kobaltoxydulcarbonat ab, welches im Ueberschusse des Fällungsmittels wenig löslich ist.

f) Ammoniumcarbonat fällt zunächst Basisch-Kobaltoxydulcarbonat, welches sich in einem Ueberschusse des Fällungsmittels leicht zu Ammonium-Kobaltoxydulcarbonat: $\mathrm{Co}\left(\mathrm{NH}^{4}\right)^{2}\left(\mathrm{CO}^{3}\right)^{2}+$ $4 \mathrm{H}^{2} \mathrm{O}$, auflöst.

g) Wird die sehr verdünnte mit Chlorammonium und wenig Ammoniak versetzte Kobaltlösung mit wenig Natriumhypochloritlösung gekocht, so nimmt die Flüssigkeit in Folge der Bildung von Roseokobaltchlorid: $\left(\mathrm{Co}^{2} \mathrm{Cl}^{6}+10 \mathrm{NH}^{3}\right)$, eine intensiv rothe Färbung an.

$2 \mathrm{CoCl}^{2}+2 \mathrm{NaClO}+10 \mathrm{NH}^{4} \cdot \mathrm{OH}=\left(\mathrm{Co}^{2} \mathrm{Cl}^{6}+10 \mathrm{NH}^{3}\right)+2 \mathrm{NaOH}+9 \mathrm{H}^{2} \mathrm{O}+0$. 
h) Kaliumnitrit im Ueberschusse, erzeugt in der Lösung eines neutralen Kobaltoxydulsalzes, nach Zusatz von Essigsäure, bei genügender Concentration sofort, in verdünnten Lösungen nach längerem Stehen, einen gelben, körnig-krystallinischen Niederschlag von Kobaltoxydkaliumnitrit: $\mathrm{Co}^{2}\left(\mathrm{NO}^{2}\right)^{6}+6 \mathrm{KNO}^{2}$. $\mathrm{Da}$ freie Mineralsäuren die Abscheidung des Niederschlags verhindern, so sind dieselben vor dem Essigsäurezusatz durch Neutralisation mit Natronlauge zu entfernen oder durch Zusatz von Natriumacetat zu binden.

$$
\begin{aligned}
2 \mathrm{Co}\left(\mathrm{NO}^{3}\right)^{2}+14 \mathrm{KNO}^{2}+4 \mathrm{C}^{2} \mathrm{H}^{4} \mathrm{O}^{2}=\left[\mathrm{CO}^{2}\left(\mathrm{NO}^{2}\right)^{6}+6 \mathrm{KNO}^{2}\right]+4 \mathrm{C}^{2} \mathrm{H}^{3} \mathrm{KO}^{2} \\
+4 \mathrm{KNO}^{3}+2 \mathrm{NO}+2 \mathrm{H}^{2} \mathrm{O} .
\end{aligned}
$$

i) Natriumhypochloritlösung scheidet aus neutralen Kobaltlösungen braunschwarzes Kobalthydroxyd: $\mathrm{Co}^{2}(\mathrm{OH})^{6}$, ab.

k) Cyankalium fällt bräunlich-weisses Kobaltcyanür: $\mathrm{Co}(\mathrm{CN})^{2}$, welches sich in einem Ueberschusse des Fälungsmittels zu Kobalteyanür-Cyankalium: $\mathrm{Co}(\mathrm{CN})^{2}+2 \mathrm{KCN}$, löst. Säuren scheiden aus letzterer Lösung $\mathrm{Co}(\mathrm{CN})^{2}$ wieder ab. Kocht man jedoch diese Lösung in überschüssigem Cyankalium, bei Gegenwart von etwas freier Cyanwasserstoffsäure (Zusatz von $1-2$ Tropfen Salzsäure), so bildet sich Kobaltcyanid-Cyankalium: $\mathrm{Co}^{2}(\mathrm{CN})^{6}$ $+6 \mathrm{KCN}$, in dessen Lösung Säuren, Chlor- und Bromwasser keine Fällung mehr bewirken (Untersehied vom Nickel).

1) Die Phosphorsalxperle und die Boraxperle werden durch Kobaltverbindungen, sowohl in der oxydirenden, wie auch in der reducirenden Flamme intensiv blau gefärbt.

\section{Nickelverbindungen.}

a) Schwefelwasserstoff verhält sich gegen die Nickelsalze ebenso wie gegen die Kobaltverbindungen.

b) Schwefelammonium fällt schwarzes Schwefelnickel: NiS, welches sich in überschüssigem gelbem Schwefelammonium in kleiner Menge mit brauner Farbe löst, in kalter, verdünnter Salzsäure dagegen fast unlöslich ist. Diese braune Lösung zersetzt sich beim Kochen, besonders nach Zusatz von etwas Essigsäure, unter Abscheidung des gelösten Schwefelnickels.

$$
\mathrm{NiSO}^{4}+\left(\mathrm{NH}^{4}\right)^{2} \mathrm{~S}=\mathrm{NiS}+\left(\mathrm{NH}^{4}\right)^{2} \mathrm{SO}^{4} \text {. }
$$

c) Kalium- oder Natriumhydroxyd scheiden apfelgrünes Nickelhydroxydul: $\mathrm{Ni}(\mathrm{OH})^{2}, \mathrm{ab}$, unlöslich in überschüssigem Alkali, löslich in Salmiaklösung.

$\mathrm{NiSO}^{4}+2 \mathrm{KOH}=\mathrm{Ni}(\mathrm{OH})^{2}+\mathrm{K}^{2} \mathrm{SO}^{4}$

$\mathrm{Ni}(\mathrm{OH})^{2}+4 \mathrm{NH}^{4} \mathrm{Cl}=\left[\mathrm{NiCl}^{2}+2 \mathrm{NH}^{4} \mathrm{Cl}\right]+2 \mathrm{NH}^{4} \cdot \mathrm{OH}$

d) Ammoniak bewirkt in neutralen, von Ammoniaksalzen freien Lösungen nur eine unvollkommene apfelgrüne Fällung von Nickelhydroxydul: $\mathrm{Ni}(\mathrm{OH})^{2}$, welches in überschüssigem Ammoniak mit blauer Farbe löslich ist: $\mathrm{Ni}\left(0 \cdot \mathrm{NH}^{4}\right)^{2}$. In sauren oder 
Ammoniaksalz enthaltenden Lösungen entsteht durch Ammoniak kein Niederschlag (Doppelsalzbildung z. B. " $\mathrm{NiCl}^{2}+2 \mathrm{NH}^{4} \mathrm{Cl}$ $+6 \mathrm{H}^{2} \mathrm{O}$ ).

e) Kalium- oder Natriumcarbonat scheiden apfelgrünes Basisch-Nickeloxydulcarbonat ab, welches im Ueberschusse der Fällungsmittel nicht löslich ist.

f) Ammoniumcarbonat scheidet zunächst apfelgrünes BasischNickeloxydulearbonat ab, welches sich in बinem Ueberschusse des Fällungsmittels mit grünlich-blauer $\mathrm{F}$ בede zu AmmoniumNickeloxydzulcarbonat: $\mathrm{Ni}\left(\mathrm{NH}^{4}\right)^{2}\left(\mathrm{CO}^{3}\right)^{2}+4 \mathrm{H}^{2} \mathrm{O}$, löst.

g) Kaliumnitrit fält Nickelsalze unter den unter Kobalt angegebenen Bedingungen nicht.

h) Oyankalium scheidet grünliches Nickelcyanü: $\mathrm{Ni}(\mathrm{CN})^{2}$, $\mathrm{ab}$, welches sich in einem Ueberschusse des Fallungsmittels zu einer bräunlich-gelben, $\mathrm{Ni}(\mathrm{CN})^{2}+2 \mathrm{KCN}$ enthaltenden Flüssigkeit löst. Säuren scheiden aus dieser Lösung, auch nach dem ' Kochen, wiederum $\mathrm{Ni}(\mathrm{CN})^{2}$ aus., Auf Zusatz von starker Natronlauge und etwas Bromwasser scheidet sich alles Nickel allmälig als schwarzes Hydroxyd: $\mathrm{Ni}^{2}(\mathrm{OH})^{6}$, aus.

i) Die Phosphorsalaperle färbt sich durch Nickelsalze in der oxydirenden und in der reducirenden Flamme röthlich, eine Färbung, die beim Erkalten blässer wird, bisweilen sogar ganz verschwindet.

k) Die Boraxperle erscheint in der oxydirenden Flamme ebenso, wie die Phosphorsalzperle gefärbt, in dér reducirenden Flamme nimmt sie in Folge einer Ausscheidung von metallischem Nickel ein graue Färbung an. Ein Zusater von etwas Zinnfolie bëgünstigt diese Reduction.

\section{Ferro- (Eisenoxydul-) Verbindungen.}

a) Schwefelwasserstoff verursacht in sauren Lösungen der Eisenoxydulsalze keine Fällung, nur Ferrosalze schwacher Säuren, wie z. B. der Essigsäure, werden theilweise in Gestalt von schwarzem Schwefeleisen: FeS, gefällt.

$\mathrm{Fe}\left(\mathrm{C}^{2} \mathrm{H}^{3} \mathrm{O}^{2}\right)^{2}+\mathrm{H}^{2} \mathrm{~S} \Rightarrow \mathrm{FeS}+2 \mathrm{C}^{2} \mathrm{H}^{4} \mathrm{O}^{2}$.

b) Schwefelammonium fällt schwarzes, in Schwefelammonium unlösliches, in Salzsäure leicht lösliches Schwefeleisen: FeS. $\mathrm{FeSO}^{4}+\left(\mathrm{NH}^{4}\right)^{2} \mathrm{~S}=\mathrm{FeS}+\left(\mathrm{NH}^{4}\right)^{2} \mathrm{SO}^{4}$.

c) Kalium- und Natriumhydroxyd, sowie auch Ammonalo scheiden aus reinen, oxydsalzfreien Ferrosalzen weisses*), schnell schmutzig grün**) und schliesslich rothbraun ${ }^{* * *}$ ) werdendes Eisenhydroxydul: $\mathrm{Fe}(\mathrm{OH})^{2}$, ab. 
d) Kalium-, Natrium- und Ammoniumcarbonat fällen aus oxydsalzfreien Ferrosalzlösungen zunächst weisses Ferrocarbonat: $\mathrm{FeCO}^{3}$, welehes sich an der Luft allmälig schmutzig grün $\left(\mathrm{Fe}^{3} \mathrm{O}^{4}+\mathrm{xHO}\right)$ und endlich rothbron $\left[\mathrm{Fe}^{2}(\mathrm{OH})^{6}\right]$ färbt.

$$
\begin{gathered}
\mathrm{FeSO}^{4}+\mathrm{K}^{2} \mathrm{CO}^{3}=\mathrm{FeCO}^{3}+\mathrm{K}^{2} \mathrm{SO}^{4} \\
3 \mathrm{FeCO}+\mathrm{O}+\mathrm{xH}^{2} \mathrm{O}=\left[\mathrm{Fe}^{3} \mathrm{O}^{4}+\mathrm{xH}^{2} \mathrm{O}\right]+3 \mathrm{CO}^{2} \\
2 \mathrm{Fe}^{3} \mathrm{O}^{4}+9 \mathrm{H}^{2} \mathrm{O}+\mathrm{O}=3 \mathrm{Fe}^{2}(\mathrm{OH})^{6} .
\end{gathered}
$$

e) Ferrocyankalium erzeugt in saurer oxydsalzfreier Lösung einen weissen, sich rasch hatr färbenden Niederschlag.

$$
\mathrm{FeSO} 0^{4}+\mathrm{K}^{4} \mathrm{Fe}(\mathrm{CN})^{6}=\mathrm{K}^{2} \mathrm{Fe}\left[\mathrm{Fe}(\mathrm{CN})^{6}\right]+\mathrm{K}^{2} \mathrm{SO}^{4} \text {. }
$$

f) Ferricyankalium giebt einen tiefblauen, in Salzsäure unlöslichen, in Kali- und Natronlauge unter Abscheidung von Eisenhydroxydul löslichen Niederschlag von Turnbull's Blau: $\mathrm{Fe}^{3}(\mathrm{CN})^{12}$.

$3 \mathrm{FeSO}+2 \mathrm{~K}^{3} \mathrm{Fe}(\mathrm{CN})^{6}=\mathrm{Fe}\left[\mathrm{Fe}(\mathrm{CN})^{6}\right]^{2}+3 \mathrm{~K}^{2} \mathrm{SO}^{4}$

$\left.\mathrm{Fe}^{3} \mathrm{Fe}(\mathrm{CN})^{6}\right]^{2}+6 \mathrm{NaOH}=2 \mathrm{Na} \mathrm{Fe}^{3}(\mathrm{CN})^{6}+3 \mathrm{Fe}(\mathrm{OH})^{2}$.

g) Gerbsäure - und Rhodankaliumlösung verändern die sungen der oxydsalzfreien Ferrosalze nicht.

h) Die Phosphorsalsperle färbt sich in der oxydirenden Flamme gelblich-roth bis dunkelroth; beim Erkalten verliert sich diese Färbung zum grossen Theil. In der reducirenden Flamme nimmt die Perle eine grünliche Färbung an, oder-wird-farblos,

\section{Ferri- (Eisenoxyd-) Verbindungen.}

a) Schwefelwasserstoff reducirt die Ferrisalze unter Abscheidung von Schwefel zu/Ferrosalzen; die gelbe oder braunnothe, Farbe der Lösung geht dabei in eine grüntiche über.

$$
\mathrm{Fe}^{2} \mathrm{Cl}^{6}+\mathrm{H}^{2} \mathrm{~S}=2 \mathrm{FeCl}^{2}+2 \mathrm{HCl}+\mathrm{S} .
$$

b) Schwefelammonium fällt schwarzes, sehwefelhaltiges Sehwefeleisen: FeS.

$$
\mathrm{Fe}^{2} \mathrm{Cl}^{6}+3\left(\mathrm{NH}^{4}\right)^{2} \mathrm{~S}=2 \mathrm{FeS}+\mathrm{S}+6 \mathrm{NH}^{4} \mathrm{Cl} .
$$

c) Kalium- und Natriumhydroxyd, sowíe Ammonial und Kalium-, Natrium- und Ammoniumcarbonat scheiden rothbraunes Eisenhydroxyd: $\mathrm{Fe}^{2}(\mathrm{OH})^{6}$, ab.

$$
\mathrm{Fe}^{2} \mathrm{Cl}^{6}+6 \mathrm{KOH}=\mathrm{Fe}^{2}(\mathrm{OH})^{6}+6 \mathrm{KCl} \text {. }
$$

$\mathrm{Fe}^{2} \mathrm{Cl}^{3}+3 \mathrm{Na}^{2} \mathrm{CO}^{3}+3 \mathrm{H}^{2} \mathrm{O}=\mathrm{Fe}^{2}(\mathrm{OH})^{6}+3 \mathrm{CO}^{2}+6 \mathrm{NaCl}$.

d) Ferrocyankatium fällt in Salzsäure unlosliches, in Kalioder Natronlauge, unter Abscheidung von Eisenhydroxyd, lösliches Berlinerblau: $\mathrm{Fe}^{7}(\mathrm{ON})^{18}$; Ferrieydankalium ruft nur eine braunrothe Färbung hervor.

$\left.2 \mathrm{Fe}^{2} \mathrm{Cl}^{6}+3 \mathrm{~K}^{4} \mathrm{Fe}(\mathrm{CN})^{6}=\mathrm{Fe}+\mathrm{Fe}(\mathrm{CN})^{9}\right]^{3}+12 \mathrm{KCl}$.

- $\mathrm{Fe}^{4}\left[\mathrm{Fe}(\mathrm{CN})^{6}\right]^{3}+12 \mathrm{NaOH}=3 \mathrm{Na}^{4} \mathrm{Fe}(\mathrm{CN})^{6}+2 \mathrm{Fe}^{2}(\mathrm{OH})^{6}$.

e) Gerbsëurelüsung verursacht eine blauschwarze, Rhodankalium eine blutrothe, beim Schütteln mit Aether in letzeren 
übergehende Färbung (Eisenrhodanid: $\mathrm{Fe}^{2}(\mathrm{CNS})^{6}$, bez. einer Doppelverbindung desselben: $\left.\mathrm{Fe}^{2}(\mathrm{CNS})^{6}+18 \mathrm{KCNS}+8 \mathrm{H}^{2} \mathrm{O}\right)$.

$$
\mathrm{Fe}^{2} \mathrm{Cl}^{6}+6 \mathrm{KCNS}=\mathrm{Fe}^{2}(\mathrm{CNS})^{6}+6 \mathrm{KCl} .
$$

f) Die Phosphorsalzperle verhält sich wie bei den Ferrosalzen.

\section{Zinkverbindungen.}

a) Schwefelwasserstoff fällt die Lösungen der neutralen Zinksalze nur unvollständig; ist die Lösung zuvor mit einer genügenden Menge von Salzsäure versetzt, so tritt überhaupt keine Fällung ein. Schwefelwasserstoff fällt die Zinksalze nur dann vollständig in Gestalt von weissem Schwefelzink aus, wenn die Säure, woran das Zink gebunden ist, eine schwache ist (z. B. Essigsäure), oder wenn die betreffende Lösung mit einer genügenden Menge Natriumacetat versetzt ist.

$$
\begin{gathered}
\mathrm{ZnSO}+\mathrm{H}^{2} \mathrm{~S}=\mathrm{ZnS}+\mathrm{H}^{2} \mathrm{SO}^{4} \\
\mathrm{H}^{2} \mathrm{SO}^{4}+2 \mathrm{C}^{2} \mathrm{H}^{2} \mathrm{NaO}^{2}=2 \mathrm{C}^{2} \mathrm{H}^{4} \mathrm{O}^{2}+\mathrm{Na}^{2} \mathrm{SO}^{4} .
\end{gathered}
$$

b) Schwefelammonium fällt weisses Schwefel:inle: $\mathrm{ZnS}$, welches unlöslich in ätzenden Alkalien, leicht löslich in Salzsäure ist.

$$
\mathrm{ZnSO}^{4}+\left(\mathrm{NH}^{4}\right)^{2} \mathrm{~S}=\mathrm{ZnS}+\left(\mathrm{NH}^{4}\right)^{2} \mathrm{SO}^{4} .
$$

c) Kalium - und Natriumhydroxyd, sowie Ammoniak scheiden weisses Zinkhydroxyd: $\mathrm{Zn}(\mathrm{OH})^{2}$, ab, welches sich in einem Ueberschusse des Fällungsmittels wieder auflöst.

$$
\begin{aligned}
& \mathrm{ZnSO}+2 \mathrm{KOH}=\mathrm{Zn}(\mathrm{OH})^{2}+\mathrm{K}^{2} \mathrm{SO}^{4} \\
& \mathrm{Zn}(\mathrm{OH})^{2}+2 \mathrm{KOH}=\mathrm{Zn}(\mathrm{OK})^{2}+2 \mathrm{H}^{2} \mathrm{O} .
\end{aligned}
$$

d) Kalium- und Natriumearbonat fallen weisses BasischZinkcarbonat, welches in einem Ueberschusse der Fällungsmittel unlöslich ist.

$5 \mathrm{ZnSO}^{4}+5 \mathrm{Na}^{2} \mathrm{CO}^{3}+3 \mathrm{H}^{2} \mathrm{O}=\left[2 \mathrm{ZnCO}^{3}+3 \mathrm{Zn}(\mathrm{OH})^{2}\right]+5 \mathrm{Na}^{2} \mathrm{SO}^{4}+3 \mathrm{CO}^{2}$.

e) Ammoniumcarbonat fällt ebenfalls Basisch-Zinkcarbonat, dasselbe wird jedoch von einem Ueberschusse des Fällungsmittels, namentlich unter Zusatz von Ammoniak, als Ammonium-Zinkcarbonat: $\mathrm{Zn}\left(\mathrm{NH}^{4}\right)^{2}\left(\mathrm{CO}^{3}\right)^{2}+$ aqu. wieder gelöst.

f) Ferrocyankalium scheidet weisses, in Salzsüure und in Ammoniak unlösliches, in Kalilauge lösliches Ferrocyanzinli: $\mathrm{Zn}^{2}\left[\mathrm{Fe}(\mathrm{CN})^{6}\right]$, ab.

$$
2 \mathrm{ZnSO}^{4}+\mathrm{K}^{4} \mathrm{Fe}(\mathrm{CN})^{6}=\mathrm{Zn}^{2}\left[\mathrm{Fe}(\mathrm{CN})^{6}\right]+2 \mathrm{~K}^{2} \mathrm{SO}^{4} .
$$

g) Mit Natriumcarbonat auf Kohle in der reducirenden Flamme geglüht, liefern die Zinksalze einen weissen, in der Hitze gelben Beschlag von Zinkoxyd: ZnO. Dieser Beschlag verschwindet wieder, wenn er mit der reducirenden Flamme angeblasen wird. Befeuchtet man denselben mit stark verdünnter Cobaltnitratlösung und glüht ihn alsdann nochmals, so färbt er sich grün: Rinmann's Grün. 


\section{Manganverbindungen.}

a) Schwefelwasserstoff fällt die Lösungen der Mangansalze nicht; Schwefelammonium scheidet fleischrothes, in Salzsäure und in Essigsäure leicht lösliches Schwefelmangan: MnS, ab.

$$
\mathrm{MnSO}^{4}+\left(\mathrm{NH}^{4}\right)^{2} \mathrm{~S}=\mathrm{MnS}+\left(\mathrm{NH}^{4}\right)^{2} \mathrm{SO}^{4} .
$$

b) Kalium- und Natriumhydroxyd scheiden aus den Lösungen der Manganoxydulsalze weisses, in einem Ueberschusse der Fällungsmittel unlösliches, in Salmiaklösung lösliches Manganhydroxydul: $\mathrm{Mn}(\mathrm{OH})^{2}$, ab. An der Luft nimmt letzterer Niederschlag allmälig eine braunrothe Farbe an, indem er sich theilweise zu Manganhydroxyd: $\mathrm{Mn}^{2}(\mathrm{OH})^{6}$, welches von Salmiaklösung nicht gelöst wird, oxydirt.

$$
\begin{gathered}
\mathrm{MnSO}+2 \mathrm{KOH}=\mathrm{Mn}(\mathrm{OH})^{2}+\mathrm{K}^{2} \mathrm{SO}^{4} \\
\mathrm{Mn}(\mathrm{OH})^{2}+4 \mathrm{NH} H^{4} \mathrm{Cl}=\left[\mathrm{MnCl}^{2}+2 \mathrm{NH}^{4} \mathrm{Cl}\right]+2 \mathrm{NH}^{4} \cdot \mathrm{OH} \\
2 \mathrm{Mn}(\mathrm{OH})^{2}+\mathrm{H}^{2} \mathrm{O}+\mathrm{O}=\mathrm{Mn}^{2}(\mathrm{OH})^{6} .
\end{gathered}
$$

c) Ammoniak scheidet aus neutralen, von Ammoniaksalzen freien Lösungen das Margan nur theilweise als Manganhydroxydul: $\mathrm{Mn}(\mathrm{OH})^{2}$, aus. Enthält die Manganlösung freie Säure oder Ammoniaksalze, so entsteht zunächst kein Niederschlag, indem das Mangan durch die gebildeten oder bereits vorhandenen Ammoniaksalze als Doppelsalz (z. B. $\mathrm{MnCl}^{2}+2 \mathrm{NH}^{4} \mathrm{Cl}$ ) in $\mathrm{Lö-}$ sung gehalten wird. Bei Luftzutritt färben sich jedoch die ammoniakalischen Manganlösungen unter Abscheidung von Manganhydroxyd: $\mathrm{Mn}^{2}(\mathrm{OH})^{6}$, allmälig braun.

$2\left[\mathrm{MnCl}^{2}+2 \mathrm{NH}^{4} \mathrm{Cl}\right]+4 \mathrm{NH}^{3}+5 \mathrm{H}^{2} \mathrm{O}+\mathrm{O}=\mathrm{Mn}^{2}(\mathrm{OH})^{6}+8 \mathrm{NH}^{4} \mathrm{Cl}$.

d) Kalium-, Natrium- und Ammoniumcarbonat fällen weisses, an der Luft sich kaum veränderndes Mangancarbonat: $\mathrm{MnCO}^{3}$. $\quad \mathrm{MnCl}^{2}+\mathrm{Na}^{2} \mathrm{CO}^{3}=\mathrm{MnCO}^{3}+2 \mathrm{NaCl}$.

e) Bromwasser scheidet nach Zusatz von Natriumacetat, namentlich beim Erwärmen, braunschwarzes Mangansuperoxydhydrat: $\mathrm{MnO}^{2}+\mathrm{H}^{2} \mathrm{O}$, aus.

$$
\mathrm{MnSO}^{4}+2 \mathrm{Br}+3 \mathrm{H}^{2} \mathrm{O}=\left(\mathrm{MnO}^{2}+\mathrm{H}^{2} \mathrm{O}\right)+2 \mathrm{HBr}+\mathrm{H}^{2} \mathrm{SO}^{4} \text {. }
$$

f) Mit Soda und Salpeter auf dem Platinbleche geschmolzen, liefern die Manganverbindungen eine grüne, Alkalimanganat enthaltende Schmelze; letztere Färbung tritt namentlich nach dem Erkalten auf.

$$
\mathrm{MnCl}^{2}+2 \mathrm{KNO}^{3}+2 \mathrm{Na}^{2} \mathrm{CO}^{3}=\mathrm{Na}^{2} \mathrm{MnO}^{4}+2 \mathrm{KNO}^{2}+2 \mathrm{NaCl}+2 \mathrm{CO}^{2} .
$$

g) Eine am Platindrahte befindliche Sodaperle färbt sich durch Mangansalz beim längeren Erhitzen in der oxydirenden Flamme grün (nach dem Erkalten).

$$
\mathrm{MnCl}^{2}+2 \mathrm{Na}^{2} \mathrm{CO}^{3}+20=\mathrm{Na}^{2} \mathrm{MnO}^{4}+2 \mathrm{NaCl}+2 \mathrm{CO}^{2} \text {. }
$$

h) Die Phosphorsalsperle und die Boraxperle werden durch Mangansalze in der oxydirenden Flamme amethystroth gefärbt; in der reducirenden Flamme verschwindet die Färbung wieder. 


\section{Mercuri- (Quecksilberoxyd-) Verbindungen.}

a) Sehwefelwasserstoff verursacht in geringer Menge zunächst einen weissen, aus einer Doppelverbindung des betreffenden Quecksilberoxydsalzes mit Quecksilbersulfid bestehenden Niederschlag. Bei weiterer Einwirkung von Schwefelwasserstoff wird dieser weisse Niederschlag allmälig gelb, bram und schliesslich schwarz gefärbt, indem als Endprodukt schwarzes Quecksilbersulfid: HgS, resultirt. Letzteres ist in Schwefelammonium, in Salzsäure und in Salpetersäure unlöslich; Königswasser löst es als Quecksilberchlorid auf.

$$
\begin{gathered}
3 \mathrm{HgCl}^{2}+2 \mathrm{H}^{2} \mathrm{~S}=\left(\mathrm{HgCl}^{2}+2 \mathrm{HgS}\right)+4 \mathrm{HCl} \\
\left(\mathrm{HgCl}^{2}+2 \mathrm{HgS}\right)+\mathrm{H}^{2} \mathrm{~S}=3 \mathrm{HgS}+2 \mathrm{HCl} \\
3 \mathrm{HgS}^{2}+6 \mathrm{HCl}^{2}+2 \mathrm{HNO}^{3}=3 \mathrm{HgCl}^{2}+2 \mathrm{NO}+4 \mathrm{H}^{2} \mathrm{O}+3 \mathrm{~S} .
\end{gathered}
$$

b) Schwefelammonium verhält sich wie Schwefelwasserstoff.

c) Kalium- und Natriumhydroxyd fallen gelbes Quecksilberoyd: $\mathrm{HgO}$.

$$
\mathrm{HgCl}^{2}+2 \mathrm{KOH}=\mathrm{HgO}+2 \mathrm{KCl}+\mathrm{H}^{2} \mathrm{O} .
$$

d) Ammoniak scheidet weisse, stickstoffhaltige Verbindungen ab, z. B.:

$$
\mathrm{HgCl}^{2}+\mathrm{NH}^{3}=\mathrm{NH}^{2} \cdot \mathrm{Hg} \cdot \mathrm{Cl}+\mathrm{HCl} .
$$

e) Ammoniumcarbonat verhält sich ähnlich wie Ammoniak.

f) Kalium- und Natriumcarbonat fällen rothbraunes $B a$ sisch-Mereuricarbonat, bez. Quecksilberoxychlorid.

g) Salzsäure und lösliche Chlormetalle fällen die Mercurisalze nicht.

h) Jodkalium erzeugt einen scharlachrothen Niederschlag von Quecksilberjodid: $\mathrm{HgJ}^{2}$, welches in einem Ueberschusse des Fällungsmittels farblos löslich ist.

$$
\begin{gathered}
\mathrm{HgCl}^{2}+2 \mathrm{KJ}=\mathrm{HgJ}^{2}+2 \mathrm{KCl} \\
\mathrm{HgJ}^{2}+\mathrm{KJ}=\left[\mathrm{HgJ}^{2}+\mathrm{KJ}\right] .
\end{gathered}
$$

i) Zinnchlorür scheidet zunächst weisses Queclsilberchlorür: $\mathrm{Hg}^{2} \mathrm{Cl}^{2}$, aus, welches sich durch Einwirkung eines Ueberschusses des Fällungsmittels, namentlich in der Wärme, grau färbt.

$$
\begin{gathered}
2 \mathrm{HgCl}^{2}+\mathrm{SnCl}^{2}=\mathrm{Hg}^{2} \mathrm{Cl}^{2}+\mathrm{SnCl}^{4} \\
\mathrm{Hg}^{2} \mathrm{Cl}^{2}+\mathrm{SnCl}^{2}=\mathrm{Hg}^{2}+\mathrm{SnCl}^{4} .
\end{gathered}
$$

k) Auf Kupferblech erzeugen die Quecksilberoxydsalze einen grauweissen, beim Reiben silberweiss werdenden Fleck.

1) Mit trocknem Natriumcarbonat in einem Glasröhrchen erhitzt, bildet sich ein Sublimat von metallischem Quecksilber.

$$
\mathrm{HgCl}^{2}+\mathrm{Na}^{2} \mathrm{CO}^{3}=2 \mathrm{NaCl}+\mathrm{Hg}+\mathrm{CO}^{2}+0 .
$$

m) Bei stärkerem Erhitzen (s. S. 2 ; 4a) verflüchtigen sich die Mereuriverbindungen vollständig. 


\section{Mercuro - (Quecksilberoxydul-) Verbindungen.}

a) Schwefelwasserstoff und Schwefelammonium fällen ein schwarzes Gemenge von Quecksilbersulfid und metallischem Quecksilber. Durch Kochen mit starker Salpetersäure entsteht die weisse, unlösliche Verbindung $2 \mathrm{HgS}+\mathrm{Hg}\left(\mathrm{NO}^{3}\right)^{2}$, während Mercurinitrat: $\mathrm{Hg}\left(\mathrm{NO}^{3}\right)^{2}$, in Lösung geht.

$$
\begin{aligned}
& \mathrm{Hg}^{2}\left(\mathrm{NO}^{3}\right)^{2}+\mathrm{H}^{2} \mathrm{~S}=\mathrm{HgS}+\mathrm{Hg}+2 \mathrm{HNO}^{3} \\
& 6[\mathrm{HgS}+\mathrm{Hg}]+16 \mathrm{HNO}=3\left[2 \mathrm{HgS}+\mathrm{Hg}\left(\mathrm{NO}^{3}\right)^{2}\right]+3 \mathrm{Hg}\left(\mathrm{NO}^{3}\right)^{2}+4 \mathrm{NO} \\
& +8 \mathrm{H}^{2} \mathrm{O} \text {. }
\end{aligned}
$$

b) Kalium- und Natriumhydroxyd scheiden schwarzes Quecksilberoxydul: $\mathrm{Hg}^{2} \mathrm{O}$, ab.

$$
\mathrm{Hg}^{2}\left(\mathrm{NO}^{3}\right)^{2}+2 \mathrm{KOH}=\mathrm{Hg}^{2} \mathrm{O}+2 \mathrm{KNO}^{3}+\mathrm{H}^{2} \mathrm{O} .
$$

c) Ammonials und Ammoniumcarbonat verursachen schwarze Fällungen, welche im Wesentlichen aus stickstoffhaltigen Verbindungen bestehen, z. B.:

$$
\mathrm{Hg}^{2}\left(\mathrm{NO}^{3}\right)^{2}+2 \mathrm{NH}^{3}=\mathrm{NH}^{2} \cdot \mathrm{Hg}^{2} \cdot \mathrm{NO}^{3}+\mathrm{NH}^{4} \cdot \mathrm{NO}^{3} .
$$

d) Kalium - und Natriumcarbonat erzeugen einen schmutzigweissen, durch einen Ueberschuss des Fällungsmittels, besonders beim Erwärmen, bald schwarz werdenden Niederschlag.

$$
\begin{gathered}
\mathrm{Hg}^{2}\left(\mathrm{NO}^{3}\right)^{2}+\mathrm{K}^{2} \mathrm{CO}^{3}=\mathrm{Hg}^{2} \mathrm{CO}^{3}+2 \mathrm{KNO}^{3} \\
\mathrm{Hg}^{2} \mathrm{CO}^{3}=\mathrm{Hg}^{2} \mathrm{O}+\mathrm{CO}^{2} .
\end{gathered}
$$

e) Salzsäure und lösliche Chlormetalle scheiden weisses, pulveriges Quecksilberchlorür: $\mathrm{Hg}^{2} \mathrm{Cl}^{2}$, aus, unlöslich in kalter Salzsäure und Salpetersäure, löslich in Chlorwasser und in Königswasser.

$$
\begin{gathered}
\mathrm{Hg}^{2}\left(\mathrm{NO}^{3}\right)^{2}+2 \mathrm{HCl}=\mathrm{Hg}^{2} \mathrm{Cl}^{2}+2 \mathrm{HNO}^{3} \\
3 \mathrm{Hg}^{2} \mathrm{Cl}^{2}+2 \mathrm{HNO}^{3}+6 \mathrm{HCl}=6 \mathrm{HgCl}^{2}+2 \mathrm{NO}+4 \mathrm{H}^{2} \mathrm{O} .
\end{gathered}
$$

f) Jodkalium scheidet grünlich-gelbes Quecksilberjodür: $\mathrm{Hg}^{2} \mathrm{~J}^{2}$, aus, welches sich in einem Ueberschusse des Fällungsmittels, unter Abscheidung von Quecksilber, farblos löst.

$$
\begin{aligned}
& \mathrm{Hg}^{2}\left(\mathrm{NO}^{3}\right)^{2}+2 \mathrm{KJ}=\mathrm{Hg}^{2} \mathrm{~J}^{2}+2 \mathrm{KNO}^{3} \\
& \mathrm{Hg}^{2} \mathrm{~J}^{2}+\mathrm{KJ}=\mathrm{Hg}+\left[\mathrm{HgJ}^{2}+\mathrm{KJ}\right] .
\end{aligned}
$$

g) Gegen Zinnchlorïr, Kupfer und trockenes Natriumcarbonat, sowie beim Erhitzen verhalten sich die Mercurosalze wie die Mercuriverbindungen.

\section{Silberverbindungen.}

a) Schwefelwasserstoff und Schwefelammonium fällen schwarzes Schwefelsilber: $\mathrm{Ag}^{2} \mathrm{~S}$, unlöslich in verdünnten Säuren und in Schwefelammonium, löslich in kochender Salpetersüure.

$$
\begin{aligned}
2 \mathrm{AgNO} \mathrm{S}^{3}+\mathrm{H}^{2} \mathrm{~S}=\mathrm{Ag}^{2} \mathrm{~S}+2 \mathrm{HNO}^{3} \\
+8 \mathrm{HNO}^{3}=6 \mathrm{AgNO}^{3}+2 \mathrm{NO}+4 \mathrm{H}^{2} \mathrm{O}+3 \mathrm{~S} .
\end{aligned}
$$

b) Kalium - und Natriumhydroxyd scheiden braunschwarzes Silberoxyd: $\operatorname{Ag}^{2} \mathrm{O}, \mathrm{ab}$.

$$
2 \mathrm{AgNO}^{3}+2 \mathrm{KOH}=\mathrm{Ag}^{2} \mathrm{O}+2 \mathrm{KNO}^{3}+\mathrm{H}^{2} \mathrm{O} .
$$


c) Ammoniak fällt in neutralen Lösungen zunächst braunes Silberoxyd, welches sich jedoch in einem Ueberschusse des Fällungsmittels farblos löst. In sauren Lösungen entsteht keine Fällung. $2 \mathrm{AgNO}^{3}+2 \mathrm{NH}^{4} \cdot \mathrm{OH}=\mathrm{Ag}^{2} \mathrm{O}+2 \mathrm{NH}^{4} \cdot \mathrm{NO}^{3}+\mathrm{H}^{2} \mathrm{O}$ $\mathrm{Ag}^{2} \mathrm{O}+2 \mathrm{NH}^{3}+\mathrm{H}^{2} \mathrm{O}=2\left(\mathrm{NH}^{3} \mathrm{Ag} \cdot \mathrm{OH}\right)$.

d) Kalium - und Natriumcarbonat fällen gelbweisses Silbercarbonat: $\mathrm{Ag}^{2} \mathrm{CO}^{3}$, Ammoniumcarbonat verhält sich ebenso, nur löst sich der Niederschlag in einem Ueberschusse des Fällungsmittels.

$$
\begin{gathered}
2 \mathrm{AgNO}{ }^{3}+\mathrm{K}^{2} \mathrm{CO}^{3}=\mathrm{Ag}^{2} \mathrm{CO}^{3}+2 \mathrm{KNO}^{3} \\
\mathrm{Ag}^{2} \mathrm{CO}^{3}+\left(\mathrm{NH}^{4}\right)^{2} \mathrm{CO}^{3}=\left[\mathrm{Ag}^{2}\left(\mathrm{NH}^{4}\right)^{2}\left(\mathrm{CO}^{3}\right)^{2}\right] .
\end{gathered}
$$

e) Salzsäure und löstiche Chlormetalle scheiden weisses, käsiges, am Licht violett werdendes Chlorsilber aus, welches unlöslich in verdünnten Säuren, löslich in Ammoniak-, Cyankalium- und Natriumthiosulfatlösung ist (in letzterer erst nach dem Auswaschen). Aus der ammoniakalischen Lösung wird das Chlorsilber durch Salpetersäure wieder abgeschieden.

$$
\begin{gathered}
\mathrm{AgNO} \mathrm{O}^{3}+\mathrm{HCl}=\mathrm{AgCl}+\mathrm{HNO}^{3} \\
\mathrm{AgCl}+\mathrm{NH} \mathrm{H}^{3}=\mathrm{NH} \mathrm{HgCl}^{3} \\
\mathrm{AgCl}+2 \mathrm{KCN}=[\mathrm{AgCN}+\mathrm{KCN}]+\mathrm{KCl} \\
\mathrm{AgCl}+\mathrm{Na} \mathrm{S}^{2} \mathrm{O}^{3}=\mathrm{NaAgS} \mathrm{O}^{3}+\mathrm{NaCl} \\
\mathrm{NH}^{3} \mathrm{AgCl}+\mathrm{HNO}^{3}=\mathrm{AgCl}+\mathrm{NH}^{4} \cdot \mathrm{NO}^{3} .
\end{gathered}
$$

f) Mit Natriumcarbonat auf der Kohle geglüht, liefern die Silberverbindungen ein weisses, ductiles Metallkorn ohne Beschlag. Letzteres wird durch erwärmte Chromsäurelösung roth gefärbt.

\section{Kupferverbindungen.}

a) Schwefelwasserstoff und Schwefelammonium fällen blauschwarzes Schwefellaupfer: CuS, unlöslich in Salzsäure, in Schwefelkalium und Schwefelnatrium. Gelbes Schwefelammonium löst es in geringer Menge als Kupfersulfid-Schwefelammonium: $2 \mathrm{CuS}$ $+\left(\mathrm{NH}^{4}\right)^{2} \mathrm{~S}^{5}$. Salpetersäure löst es zu Kupfernitrat: $\mathrm{Cu}\left(\mathrm{NO}^{3}\right)^{2}$, Cyankalium zu farblosen Kupfercyanür-Cyankalium.

$$
\mathrm{CuSO}^{4}+\mathrm{H}^{2} \mathrm{~S}=\mathrm{CuS}+\mathrm{H}^{2} \mathrm{SO}^{4}
$$

$3 \mathrm{CuS}+8 \mathrm{HNO}^{3}=3 \mathrm{Cu}\left(\mathrm{NO}^{3}\right)^{2}+2 \mathrm{NO}+4 \mathrm{H}^{2} \mathrm{O}+3 \mathrm{~S}$

$2 \mathrm{CuS}+6 \mathrm{KCN}=\left[\mathrm{Cu}^{2}(\mathrm{CN})^{2}+2 \mathrm{KCN}\right]+2 \mathrm{~K}^{2} \mathrm{~S}+\mathrm{C}^{2} \mathrm{~N}^{2}$.

b) Kalium- und Natriumhydroxyd erzeugen einen blauen Niederschlag von Kupferhydroxyd: $\mathrm{Cu}(\mathrm{OH})^{2}$, der beim Kochen schwarz wird. Zucker, Weinsäure, Glycerin und andere organische Substanzen hindern die Abscheidung des Kupferhydroxyds. $\mathrm{CuSO}^{4}+2 \mathrm{NaOH}=\mathrm{Cu}(\mathrm{OH})^{2}+\mathrm{Na}^{2} \mathrm{SO}^{4}$ $3 \mathrm{Cu}(\mathrm{OH})^{2}=\left[3 \mathrm{CuO}+\mathrm{H}^{2} \mathrm{O}\right]+2 \mathrm{H}^{2} \mathrm{O}$.

c) Ammonial scheidet zunächst blaugrünes, basisches Salz aus, welches sich in einem Ueberschusse des Fällungsmittels als Cupriammoniumsalz mit lasurblaner Farbe löst, z. B.:

$2 \mathrm{CuSO}^{4}+2 \mathrm{NH}^{4} \cdot \mathrm{OH}=\left[\mathrm{CuSO}^{4}+\mathrm{Cu}(\mathrm{OH})^{2}\right]+\left(\mathrm{NH}^{4}\right)^{2} \mathrm{SO}^{4}$

$\left[\mathrm{CuSO}^{4}+\mathrm{Cu}(\mathrm{OH})^{2}\right]+\left(\mathrm{NH}^{4}\right)^{2} \mathrm{SO}^{4}+6 \mathrm{NH}^{4} \cdot \mathrm{OH}=2\left[\mathrm{CuSO}^{4}+4 \mathrm{NH}^{3}+\mathrm{H}^{2} \mathrm{O}\right]$

$$
+6 \mathrm{H}^{2} \mathrm{O} \text {. }
$$


d) Natrium- und Kaliumcarbonat fällen blaugrünes BasischKupfercarbonat.

$2 \mathrm{CuSO}^{4}+2 \mathrm{Na}^{2} \mathrm{CO}^{3}+\mathrm{H}^{2} \mathrm{O}=\left[\mathrm{CuCO}^{3}+\mathrm{Cu}(\mathrm{OH})^{2}\right]+2 \mathrm{Na}^{2} \mathrm{SO}^{4}+\mathrm{CO}^{2}$.

e) Ammoniumcarbonat scheidet blaugrünes, in einem Ueberschusse des Fällungsmittels als Kupfer-Ammoniumcarbonat: $\left(\mathrm{NH}^{3}\right)^{2} \mathrm{Cu} \cdot \mathrm{Co}^{3}$, mit lasurblauer Farbe lösliches Basisch-Kupfercarbonat ab.

f) Cyankalium ruft in neutralen Kupfersalzlösungen einen gelbgrünen Niederschlag von Kupfercyanürcyanid: $\mathrm{Cu}^{3}(\mathrm{CN})^{4}$, hervor, welcher sich jedoch in einem Ueberschusse des Fällungsmittels zu farblosem Kupfercyanür-Cyankalium: $\mathrm{Cu}^{2}(\mathrm{CN})^{2}+$ $2 \mathrm{KCN}$, auflöst. Aus letzterer Lösung ist das Kupfer durch Schwefelwasserstoff nicht fällbar.

g) Ferrocyankalium scheidet rothbraunes, in Salzsäure unlösliches Ferrocyankupfer: $\mathrm{Cu}^{2} \mathrm{Fe}(\mathrm{CN})^{6}, \mathrm{ab}$.

$$
2 \mathrm{CuSO}^{4}+\mathrm{K}^{4} \mathrm{Fe}(\mathrm{CN})^{6}=\mathrm{Cu}^{2} \mathrm{Fe}(\mathrm{CN})^{6}+2 \mathrm{~K}^{2} \mathrm{SO}^{4} .
$$

h) Metallisches Eisen überzieht sich in schwach angesäuerter Kupfersalzlösung allmälig mit einem rothen Ueberzuge von metallischem Kupfer.

i) Die Phosphorsalsperle nimmt in der oxydirenden Flamme eine schön grüne Färbung an, in der reducirenden Flamme wird die Perle nach anhaltendem Blasen mit dem Löthrohre undurchsichtig und nimmt beim Erkalten in Folge der Ausscheidung von metallischem Kupfer eine rothbraune Farbe an. Durch Zusatz von etwas Zinnfolie wird letztere Erscheinung beschleunigt.

k) Die Boraxperle zeigt in der oxydirenden Flamme, heiss eine grüne, kalt eine blaue Färbung; in der reducirenden Flamme treten dieselben Erscheinungen wie in der Phosphorsalzperle auf.

1) Mit Natriumcarbonat auf der Kohle in der reducirenden Löthrohrflamme geglüht, liefern die Kupferverbindungen kupferrothe Metallflitter oder Körner, ohne Beschlag.

\section{Bleiverbindungen.}

a) Schwefelwasserstoff und Schwefelammonium fällen schwarzes Schwefelblei: $\mathrm{PbS}$, in kalten verdünnten Säuren und in Schwefelammonium unlöslich. Kochende verdünnte Salpetersäure löst es als Bleinitrat, erwärmte rauchende Salpetersäure oxydirt es zu unlöslichem Bleisulfat: $\mathrm{PbSO}^{4}$. In verdünnten, salzsäurehaltigen Bleisalzlösungen scheidet Schwefelwasserstoff zunächst rothes Bleisulfochlorid: $\mathrm{PbS}+\mathrm{PbCl}^{2}$, ab, welches bei weiterer Einwirkung in schwarzes Schwefelblei: PbS, übergeht.

$$
\begin{gathered}
\mathrm{Pb}\left(\mathrm{NO}^{3}\right)^{2}+\mathrm{H}^{2} \mathrm{~S}=\mathrm{PbS}+2 \mathrm{HNO}^{3} \\
3 \mathrm{PbS}+8 \mathrm{HNO}^{3}=3 \mathrm{~Pb}\left(\mathrm{NO}^{3}\right)^{2}+2 \mathrm{NO}+4 \mathrm{H}^{2} \mathrm{O}+3 \mathrm{~S} \\
\mathrm{PbS}+4 \mathrm{HNO}^{3}=\mathrm{PbSO}^{4}+2 \mathrm{H}^{2} \mathrm{O}+2 \mathrm{NO}^{2}+2 \mathrm{NO} .
\end{gathered}
$$


h) Kalium- und Natriumhydroxyd fällen weisses Bleihydroxyd: $\mathrm{Pb}(\mathrm{OH})^{2}$, welches sich in einem Ueberschusse des Fällungsmittels wieder auflöst.

$$
\begin{gathered}
\mathrm{Pb}\left(\mathrm{NO}^{3}\right)^{2}+2 \mathrm{KOH}=\mathrm{Pb}(\mathrm{OH})^{2}+2 \mathrm{KNO}^{3} \\
\mathrm{~Pb}(\mathrm{OH})^{2}+2 \mathrm{KOH}=\mathrm{Pb}(\mathrm{OK})^{2}+2 \mathrm{H}^{2} \mathrm{O} .
\end{gathered}
$$

c) Ammoniak scheidet basisches, im Ueberschusse des Fällungsmittels fast unlösliches Bleisalz ab (aus Bleiacetatlösung erst nach einiger Zeit).

d) Kalium-, Natrium- und Ammoniumcarbonat fällen weisses Basisch-Bleicarbonat. $3 \mathrm{~Pb}\left(\mathrm{NO}^{3}\right)^{2}+3 \mathrm{Na}^{2} \mathrm{CO}^{3}+\mathrm{H}^{2} \mathrm{O}=\left[2 \mathrm{PbCO}^{3}+\mathrm{Pb}(\mathrm{OH})^{2}\right]+6 \mathrm{NaNO}^{3}+\mathrm{CO}^{2}$.

e) Salzsäure und lösliche Chlormetalle fällen weisses, krystallinisches, in viel kochendem Wasser lösliches Chlorblei: $\mathrm{PbCl}^{2}$; in sehr verdünnten Lösungen entsteht kein Niederschlag. $\mathrm{Pb}\left(\mathrm{NO}^{3}\right)^{2}+2 \mathrm{HCl}=\mathrm{PbCl}^{2}+2 \mathrm{HNO}^{3}$.

f) Verdünnte Schwefelsäure und lösliche Sulfate scheiden weisses, fast unlösliches Bleisulfat ab; letzteres ist in Kali- oder Natronlauge, sowie in Ammoniumtartrat bei Gegenwart von Ammoniak löslich.

$$
\begin{gathered}
\mathrm{Pb}\left(\mathrm{NO}^{3}\right)^{2}+\mathrm{H}^{2} \mathrm{SO}^{4}=\mathrm{PbSO}^{4}+2 \mathrm{HNO}^{3} \\
\mathrm{PbSO}^{4}+4 \mathrm{KOH}=\mathrm{Pb}(\mathrm{OK})^{2}+\mathrm{K}^{2} \mathrm{SO}^{4}+2 \mathrm{H}^{2} \mathrm{O} .
\end{gathered}
$$

g) Kaliumchromat und Kaliumdichromat fällen gelbes, in Essigsäure unlösliches, in Natronlauge lösliches Bleichromat: $\mathrm{PbCrO}^{4}$.

$2 \mathrm{~Pb}\left(\mathrm{NO}^{3}\right)^{2}+\mathrm{K}^{2} \mathrm{Cr}^{2} \mathrm{O}^{7}+\mathrm{H}^{2} \mathrm{O}=2 \mathrm{PbCrO}^{4}+2 \mathrm{KNO}^{3}+2 \mathrm{HNO}^{3}$

$$
\mathrm{PbCrO}^{4}+4 \mathrm{NaOH}=\mathrm{Pb}(\mathrm{ONa})^{2}+\mathrm{Na}^{2} \mathrm{CrO}^{4}+2 \mathrm{H}^{2} \mathrm{O} \text {. }
$$

h) Jodkalium scheidet gelbes, in siedender Essigsäure lösliches Jodblei: $\mathrm{PbJ}^{2}$, ab.

$$
\mathrm{Pb}\left(\mathrm{NO}^{3}\right)^{2}+2 \mathrm{KJ}=\mathrm{PbJ}^{2}+2 \mathrm{KNO}^{3} .
$$

i) Mit Natriumcarbonat auf der Kohle in der reducirenden Löthrohrflamme geglüht, liefern die Bleiverbindungen ein ductiles Metallkorn und einen gelben, aus Bleioxyd bestehenden Beschlag.

\section{Wismuthverbindungen.}

a) Schwefelwasserstoff und Schwefelammonium fallen braunschwarzes Schwefelwismuth: $\mathrm{Bi}^{2} \mathrm{~S}^{3}$, unlöslich in verdünnten Säuren und in Schwefelammonium, löslich in kochender Salpetersäure zu Wismuthnitrat: $\mathrm{Bi}\left(\mathrm{NO}^{3}\right)^{3}$.

$$
2 \mathrm{Bi}\left(\mathrm{NO}^{3}\right)^{3}+3 \mathrm{H}^{2} \mathrm{~S}=\mathrm{Bi}^{2} \mathrm{~S}^{3}+6 \mathrm{HNO}^{3}
$$

$\mathrm{Bi}^{2} \mathrm{~S}^{3}+8 \mathrm{HNO}^{3}=2 \mathrm{Bi}\left(\mathrm{NO}^{3}\right)^{3}+2 \mathrm{NO}+4 \mathrm{H}^{2} \mathrm{O}+3 \mathrm{~S}$.

b) Kalium - und Natriumhydroxyd, sowie Ammoniak fällen weisses, im Ueberschusse der Fällungsmittel unlösliches Wismuthhydroxyd: $\mathrm{BiO} \cdot \mathrm{OH}$.

$$
\mathrm{Bi}\left(\mathrm{NO}^{3}\right)^{3}+3 \mathrm{KOH}=\mathrm{BiO} \cdot \mathrm{OH}+3 \mathrm{KNO}^{3}+\mathrm{H}^{2} \mathrm{O} .
$$

c) Kalium-, Natrium- und Ammoniumcarbonat scheiden weisses Basisch-Wismuthcarbonat ab. 
d) Salwäure und verdünnte Schwefelsäure (1:5) fällen Wismuthsalzlösungen nicht.

e) Kaliumchromat fällt gelbes, in Natronlauge unlösliches Wismuthehromat: $\mathrm{Bi}^{2}\left(\mathrm{CrO}^{4}\right)^{3}$.

$$
2 \mathrm{Bi}\left(\mathrm{NO}^{3}\right)^{3}+3 \mathrm{~K}^{2} \mathrm{CrO}^{4}=\mathrm{Bi}^{9}\left(\mathrm{CrO}^{4}\right)^{3}+6 \mathrm{KNO}^{3} .
$$

f) Jodkalium fällt braunrothes Jodwismuth: $\mathrm{BiJ}^{3}$, bez. Oxyjodid: $\mathrm{BiOJ} . \quad \mathrm{Bi}\left(\mathrm{NO}^{3}\right)^{3}+3 \mathrm{KJ}=\mathrm{BiJ}^{3}+3 \mathrm{KNO}^{3}$

$$
\mathrm{Bi}\left(\mathrm{NO}^{3}\right)^{3}+\mathrm{KJ}+\mathrm{H}^{2} \mathrm{O}=\mathrm{BiOJ}+\mathrm{KNO}^{3}+2 \mathrm{HNO}^{3} .
$$

g) Wasser fällt aus den Lösungen der Wismuthsalze in möglichst wenig Säure schwer- oder unlösliche basische Salze. Chlorammonium befördert deren Abscheidung. Diese basischen Salze sind unlöslich in Weinsäure und in Kalilauge; Schwefelammonium schwärzt dieselben.

$$
\mathrm{Bi}\left(\mathrm{NO}^{3}\right)^{3}+2 \mathrm{H}^{2} \mathrm{O}=\mathrm{Bi}(\mathrm{OH})^{2} \mathrm{NO}^{3}+2 \mathrm{HNO}^{3}
$$

$$
\mathrm{Bi}\left(\mathrm{NO}^{3}\right)^{3}+\mathrm{NH} \mathrm{H}^{4} \mathrm{Cl}+\mathrm{H}^{2} \mathrm{O}=\mathrm{BiOCl}+\mathrm{NH}^{4} \cdot \mathrm{NO}^{3}+2 \mathrm{HNO}^{3} .
$$

h) Eine Lösung von Zinnchlorür in Kali- oder Natronlauge, im Ueberschuss zu einer Wismuthsalzlösung zugesetzt, scheidet schwarzes Wismuthoxydul: $\mathrm{BiO}$, aus.

i) Mit Natriumcarbonat auf der Kohle in der reducirenden Löthrohrflamme geglüht, liefern die Wismuthverbindungen ein sprödes Metallkorn mit gelbem, aus Wismuthoxyd bestehendem Beschlage.

\section{Cadmiumverbindungen.}

a) Schwefelwasserstoff und Schwefelammonium fällen gelbes, in Schwefelammonium und in kalten verdünnten Säuren unlösliches Schwefelcadmium: CdS. Conc. Salzsäure und kochende verdünnte Schwefelsäure $(1: 5)$ lösen es auf.

$$
\begin{aligned}
& \mathrm{CdSO}^{4}+\mathrm{H}^{2} \mathrm{~S}=\mathrm{CdS}+\mathrm{H}^{2} \mathrm{SO}^{4} \\
& \mathrm{CdS}+2 \mathrm{HCl}=\mathrm{CdCl}^{2}+\mathrm{H}^{2} \mathrm{~S} .
\end{aligned}
$$

b) Kalium- und Natriumhydroxyd scheiden weisses, im Ueberschusse des Fällungsmittels unlösliches Cadmiumhydroxyd: $\mathrm{Cd}(\mathrm{OH})^{2}$, ab. $\quad \mathrm{CdSO}^{4}+2 \mathrm{KOH}=\mathrm{Cd}(\mathrm{OH})^{2}+\mathrm{K}^{2} \mathrm{SO}^{4}$.

c) Ammoniak fällt weisses, im Ueberschusse des Fällungsmittels lösliches Cadmiumhydroxyd: $\mathrm{Cd}(\mathrm{OH})^{2}$.

$$
\begin{aligned}
& \mathrm{CdSO}^{4}+2 \mathrm{NH}^{4} \cdot \mathrm{OH}=\mathrm{Cd}(\mathrm{OH})^{2}+\left(\mathrm{NH}^{4}\right)^{2} \mathrm{SO}^{4} \\
& \mathrm{Cd}(\mathrm{OH})^{2}+2 \mathrm{NH}^{4} \cdot \mathrm{OH}=\mathrm{Cd}\left(\mathrm{ONH}^{4}\right)^{2}+2 \mathrm{H}^{2} \mathrm{O} .
\end{aligned}
$$

d) Kalium-, Natrium- und Ammoniumearbonat scheiden weisses Cadmiumcarbonat: $\mathrm{CdCO}^{3}$, aus, welches in einem Ueberschusse der Fällungsmittel nicht löslich ist.

$$
\mathrm{CdSO}^{4}+\mathrm{K}^{2} \mathrm{CO}^{3}=\mathrm{CdCO}^{3}+\mathrm{K}^{2} \mathrm{SO}^{4} .
$$

e) Cyankalium erzeugt in neutraler oder ammoniakalischer Lösung einen weissen, in einem Ueberschusse des Fällungsmittels zu Cadmiumcyanid-Cyankalium: $\mathrm{Cd}(\mathrm{CN})^{2}+2 \mathrm{KCN}$, löslichen 
Niederschlag. Schwefelwasserstoff scheidet aus dieser Lösung gelbes Schwefelcadmium: CdS, ab.

$$
\begin{gathered}
\mathrm{CdSO}^{4}+4 \mathrm{KCN}=\left[\mathrm{Cd}(\mathrm{CN})^{2}+2 \mathrm{KCN}\right]+\mathrm{K}^{2} \mathrm{SO}^{4} \\
{\left[\mathrm{Cd}(\mathrm{CN})^{2}+2 \mathrm{KCN}\right]+\mathrm{H}^{2} \mathrm{~S}=\mathrm{CdS}+2 \mathrm{KCN}+2 \mathrm{HCN} .}
\end{gathered}
$$

f) Mit Natriumcarbonat auf der Kohle in der reducirenden Flamme geglüht, liefern die Cadmiumverbindungen, ohne Metallkorn, einen braunen Beschlag von Cadmiumoxyd.

\section{Arsenverbindungen.}

a) Mit Natriumcarbonat und Cyankalium im Glühröhrchen erhitzt, liefern die Arsenverbindungen einen glänzenden Spiegel von Arsen.

b) Auf der Kohle in der Reductionsflamme erhitzt, liefern die Arsenverbindungen Knoblauchgeruch und häufig auch einen weissen Beschlag von Arsenigsäureanhydrid: $\mathrm{As}^{2} \mathrm{O}^{3}$.

Weitere Reactionen siehe S. 28 und S. 29 unter arseniger Säure und Arsensäure.

\section{Antimonverbindungen.}

a) Sehwefelwasserstoff fällt aus Antimonoxydsalzlösungen orangerothes Antimonsulfür: $\mathrm{Sb}^{2} \mathrm{~S}^{3}$, aus Antimonsäurelösungen orangerothes Antimonsulfid: $\mathrm{Sb}^{2} \mathrm{~S}^{5}$. Antimonsulfür ist ganz, Antimonsulfid nahezu unlöslich in Ammoniumearbonat und in kalten verdünnten Säuren; beide sind löslich in kochender Salzsäure, in Schwefelammonium und in Kalilauge.

$$
\begin{gathered}
2 \mathrm{SbCl}^{3}+3 \mathrm{H}^{2} \mathrm{~S}=\mathrm{Sb}^{2} \mathrm{~S}^{3}+6 \mathrm{HCl} \\
2 \mathrm{SbCl}^{5}+5 \mathrm{H}^{2} \mathrm{~S}=\mathrm{Sb}^{2} \mathrm{~S}^{5}+10 \mathrm{HCl} \\
\mathrm{Sb}^{2} \mathrm{~S}^{3}+6 \mathrm{HCl}=2 \mathrm{SbCl}^{3}+3 \mathrm{H}^{2} \mathrm{~S} \\
\mathrm{Sb}^{2} \mathrm{~S}^{5}+6 \mathrm{HCl}=2 \mathrm{SbCl}^{3}+3 \mathrm{H}^{2} \mathrm{~S}+2 \mathrm{~S} \\
\mathrm{Sb}^{2} \mathrm{~S}^{3}+6\left(\mathrm{NH} \mathrm{H}^{4}\right) \mathrm{HS}=2\left(\mathrm{NH}^{4}\right)^{3} \mathrm{SbS}^{3}+3 \mathrm{H}^{2} \mathrm{~S} \\
\mathrm{Sb}^{2} \mathrm{~S}^{5}+3\left(\mathrm{NI} \mathrm{I}^{4}\right)^{2} \mathrm{~S}=2\left(\mathrm{NH}^{4}\right)^{3} \mathrm{SbS}^{4} \\
2 \mathrm{Sb}^{2} \mathrm{~S}^{3}+4 \mathrm{KOH}=3 \mathrm{KSbS}^{2}+\mathrm{KSbO}^{2}+2 \mathrm{H}^{2} \mathrm{O} \\
4 \mathrm{Sb}^{2} \mathrm{~S}^{5}+18 \mathrm{KOH}=3 \mathrm{KSbO}^{3}+5 \mathrm{~K}^{3} \mathrm{SbS}^{4}+9 \mathrm{H}^{2} \mathrm{O} .
\end{gathered}
$$

Salzsäure scheidet aus den Lösungen des $\mathrm{Sb}^{2} \mathrm{~S}^{3}$ oder $\mathrm{Sb}^{2} \mathrm{~S}^{5}$ in Kalilauge oder Schwefelammonium wieder $\mathrm{Sb}^{2} \mathrm{~S}^{3}$ oder $\mathrm{Sb}^{2} \mathrm{~S}^{5} \mathrm{ab}$.

b) Schwefelammonium verhält sich wie Schwefelwasserstoff, der Niederschlag löst sich jedoch in einem Ueberschusse des Fällungsmittels wieder auf.

c) Kalium - und Natriumhydroxyd fällen aus Antimonoxydsalzen weisse metantimonige Säure: $\mathrm{SbO} \cdot \mathrm{OH}$, welche sich in einem Ueberschusse des Fällungsmittels wieder löst.

$$
\begin{gathered}
\mathrm{SbCl}^{3}+3 \mathrm{KOH}=\mathrm{SbO} \cdot \mathrm{OH}+3 \mathrm{KCl}+\mathrm{H}^{2} \mathrm{O} \\
\mathrm{SbO} \cdot \mathrm{OH}+\mathrm{KOH}=\mathrm{SbO} \cdot \mathrm{OK}+\mathrm{H}^{2} \mathrm{O} .
\end{gathered}
$$


d) Zink, Eisen und auch Zinn scheiden aus salzsäurehaltigen Antimonlösungen schwarzes Antimonpulver aus. Bringt man die Antimonlösung auf ein Platinblech und legt alsdann in die Lösung ein kleines Zink- oder Zinnkorn (Zinnfolie, die zu einer kleinen Kugel zusammengedreht ist), so bekleidet sich das Platinblech durch die ganze Flüssigkeit mit einem schwarzen, festhaftenden, in Salzsäure unlöslichen Ueberzuge von Antimon.

e) Zink und verdünnte Schwefelsäure erzeugen (im Marshschen Apparate) Antimonwasserstoff: $\mathrm{SbH}^{3}$. Das entweichende Gas brennt mit bläulich-grüner Flamme zu Antimonoxyd. Kühlt man die Flamme jedoch durch Hineinhalten einer Porzellanschale $a b$, so beschlägt letztere mit einem tiefschwarzen, matten Flecke von Antimon, welcher sich in Natriumhypochloritlösung nicht auflöst (Unterschied vom Arsen, s. S. 28).

$$
\begin{aligned}
2 \mathrm{SbH}^{3}+6 \mathrm{O} & =\mathrm{Sb}^{2} \mathrm{O}^{3}+3 \mathrm{H}^{2} \mathrm{O} \\
2 \mathrm{SbH}^{3}+3 \mathrm{O} & =2 \mathrm{Sb}+3 \mathrm{H}^{2} \mathrm{O} .
\end{aligned}
$$

f) Die Lösung der Antimonverbindungen in Salzsäure wird durch Wasser weiss gefallt; in Weinsäure und in Natronlauge ist der entstandene Niederschlag löslich, z. B.:

$$
\mathrm{SbCl}^{3}+\mathrm{H}^{2} \mathrm{O}=\mathrm{SbOCl}+2 \mathrm{HCl}
$$

$\mathrm{SbOCl}+\mathrm{C}^{4} \mathrm{H}^{6} \mathrm{O}^{6}=\mathrm{C}^{4} \mathrm{H}^{5}(\mathrm{SbO}) \mathrm{O}^{6}+\mathrm{HCl}$

$\mathrm{SbOCl}+2 \mathrm{NaOH}=\mathrm{NaSbO}^{2}+\mathrm{NaCl}+\mathrm{H}^{2} \mathrm{O}$.

g) Mit Natriumcarbonat oder besser mit Cyankalium auf der Kohle in der Reductionsflamme geglüht, liefern die Antimonverbindungen rauchende, spröde Metallkörner und einen weissen, aus Antimonoxyd bestehenden Beschlag. Bisweilen bekleiden sich die Metallkörner beim Erkalten mit einem Krystallnetze von Antimonoxyd.

\section{Stanno - (Zinnoxydul-) Verbindungen.}

a) Schwefelwasserstoff erzeugt einen dunkelbraunen Niederschlag von Zinnsulfür: SnS, unlöslich in farblosem, löslich in gelbem Schwefelammonium. Aus letzterer Lösung fällt Salzsäure gelbes Zinnsulfid: $\mathrm{SnS}^{2}$.

$$
\mathrm{SnCl}^{2}+\mathrm{H}^{2} \mathrm{~S}=\mathrm{SnS}+2 \mathrm{HCl}
$$

$\mathrm{SnS}+\left(\mathrm{NH}^{4}\right)^{2} \mathrm{~S}^{2}=\left(\mathrm{NH}^{4}\right)^{2} \mathrm{SnS}$

$\left(\mathrm{NH}^{4}\right)^{2} \mathrm{SnS}^{3}+2 \mathrm{HCl}=\mathrm{SnS}^{2}+2 \mathrm{NH}^{4} \mathrm{Cl}+\mathrm{H}^{2} \mathrm{~S}$.

b) Kalium- und Natriumhydroxyd, sowie Ammoniak, Kalium-, Natrium- und Ammoniumcarbonat fällen weisses Zinnhydroxydul: $\mathrm{Sn}(\mathrm{OH})^{2}$, im Ueberschusse der ersteren Fällungsmittel löslich. $\quad \mathrm{SnCl}^{2}+2 \mathrm{KOH}=\mathrm{Sn}(\mathrm{OH})^{2}+2 \mathrm{KCl}$

$$
\mathrm{Sn}(\mathrm{OH})^{2}+2 \mathrm{KOH}=\mathrm{Sn}(\mathrm{OK})^{2}+2 \mathrm{H}^{2} \mathrm{O} .
$$

c) Quecksilberchlorid erzeugt einen weissen Niederschlag von Quecksilberchlorür: $\mathrm{Hg}^{2} \mathrm{Cl}^{2}$, der bei Gegenwart von überschüssigem Zinnoxydulsalz, namentlich in der Wärme, grau wird. 


\section{$\mathrm{SnCl}^{2}+2 \mathrm{HgCl}^{2}=\mathrm{Hg}^{2} \mathrm{Cl}^{2}+\mathrm{SnCl}^{4}$ \\ $\mathrm{SnCl}^{2}+\mathrm{Hg}^{2} \mathrm{Cl}^{2}=2 \mathrm{Hg}+\mathrm{SnCl}^{4}$.}

d) Zink scheidet graues, schwammiges, das Zink einhüllendes Zinn ab; auf dem Platinbleche selbst (vgl. 25, d.) entsteht kein schwarzer, anhaftender Ueberzug, sondern nur obige Abscheidung. Letztere ist in Salzsäure löslich. Zinn ruft keine derartige Ausscheidung hervor.

e) Mit Natriumcarbonat oder besser mit Natriumcarbonat und Cyankalium in der reducirenden Flamme auf Kohle geglüht, liefern die Zinnverbindungen weisse, ductile Metallkörner und einen weissen Beschlag von Zinnoxyd.

\section{Stanni- (Zinnoxyd-) Verbindungen.}

a) Schwefelwasserstoff fällt gelbes Zinnsulfid: $\mathrm{SnS}^{2}$, unlöslich in Ammoniumcarbonat, löslich in farblosem und in gelbem Schwefelammonium, sowie in erwärmter starker Salzsäure.

$$
\begin{gathered}
\mathrm{SnCl}^{4}+2 \mathrm{H}^{2} \mathrm{~S}=\mathrm{SnS}^{2}+4 \mathrm{HCl} \\
\mathrm{SnS}^{2}+\left(\mathrm{NH}^{4}\right)^{2} \mathrm{~S}=\left(\mathrm{NH}^{4}\right)^{2} \mathrm{SnS}^{3} \\
\mathrm{SnS}^{2}+4 \mathrm{HCl}=\mathrm{SnCl}^{4}+2 \mathrm{H}^{2} \mathrm{~S} .
\end{gathered}
$$

b) Schvefelammonium fällt zunächst gelbes Zinnsulfid: $\mathrm{SnS}^{2}$, welches sich alsdann in einem Ueberschusse des Fällungsmittels wieder löst.

c) Kalium- und Natriumhydroxyd scheiden weisses, im Ueberschusse des Fällungsmittels lösliches Zinnhydroxyd: $\operatorname{Sn}(\mathrm{OH})^{4}$, aus.

$$
\begin{gathered}
\mathrm{SnCl}^{4}+4 \mathrm{KOH}=\mathrm{Sn}(\mathrm{OH})^{4}+4 \mathrm{KCl} \\
\mathrm{Sn}(\mathrm{OH})^{4}+2 \mathrm{KOH}=\mathrm{K}^{2} \mathrm{SnO}^{3}+3 \mathrm{H}^{2} \mathrm{O} .
\end{gathered}
$$

d) Ammoniak - und Ammoniumcarbonat fällen weisses Zinnhydroxyd: $\mathrm{Sn}(\mathrm{OH})^{4}$, welches in einem Ueberschusse des Fällungsmittels unlöslich ist.

$$
\mathrm{SnCl}^{4}+2\left(\mathrm{NH}^{4}\right)^{2} \mathrm{CO}^{3}+2 \mathrm{H}^{2} \mathrm{O}=\mathrm{Sn}(\mathrm{OH})^{4}+4 \mathrm{NH}^{4} \mathrm{Cl}+2 \mathrm{CO}^{2} .
$$

e) Kalium- und Natriumcarbonat scheiden ebenfalls weisses Zinnhydroxyd: $\operatorname{Sn}(\mathrm{OH})^{4}, a b$, letzteres löst sich in überschüssigem Kaliumcarbonat vollständig, in Natriumearbonat nur theilweise auf.

f) Natriumsulfat und Ammoniumnitrat fällen weisses Zinnhydroxyd: $\mathrm{Sn}(\mathrm{OH})^{4}$.

$\mathrm{SnCl}^{4}+4 \mathrm{Na}^{2} \mathrm{SO}^{4}+4 \mathrm{H}^{2} \mathrm{O}=\mathrm{Sn}(\mathrm{OH})^{4}+4 \mathrm{NaCl}+4 \mathrm{NaHSO}^{4}$
$\mathrm{SnCl}^{4}+4 \mathrm{NH}^{4} \mathrm{NO}^{3}+4 \mathrm{H}^{2} \mathrm{O}=\mathrm{Sn}(\mathrm{OH})^{4}+4 \mathrm{NH}^{4} \mathrm{Cl}+4 \mathrm{HNO}^{3}$.

g) Quecksilberchlorid ruft keine Fällung hervor.

h) Gegen Zink, Eisen und Zinn, sowie auf der Kolle verhalten sich die Stanniverbindungen wie die Stannoverbindungen. 


\section{Platinverbindungen.}

a) Schwefehcasserstoff erzengt anfänglich nur eine braune Färbung, allmälig, besonders beim Erwärmen, entsteht jedoch ein braunschwarzer Niederschlag: $\mathrm{PtS}^{2}$, welcher unlöslich in Salzsäure, löslich in starker Salpetersäure und in Königswasser ist.

$$
\mathrm{H}^{2} \mathrm{PtCl}^{6}+2 \mathrm{H}^{2} \mathrm{~S}=\mathrm{PtS}^{2}+6 \mathrm{HCl} \text {. }
$$

b) Schwefelammonium scheidet ebenfalls Platinsulfid: PtS, ab, welches jedoch in einem Ueberschusse des Fällungsmittels, namentlich, wenn letzteres Polysulfid enthält, theilweise löslich ist.

$$
\mathrm{H}^{2} \mathrm{PtCl}^{6}+2\left(\mathrm{NH}^{4}\right)^{2} \mathrm{~S}=\mathrm{PtS}^{2}+4 \mathrm{NH}^{4} \mathrm{Cl}+2 \mathrm{HCl} \text {. }
$$

c) Kaliumhydroxyd erzeugt einen gelben Niederschlag von Kaliumplatinchlorid: $\mathrm{K}^{2} \mathrm{PtCl}^{6}$, welcher in einem grossen Ueberschusse des Fällungsmittels, namentlich beim Erwärmen, löslich ist.

$$
\begin{gathered}
\mathrm{H}^{2} \mathrm{PtCl}+2 \mathrm{KOH}=\mathrm{K}^{2} \mathrm{PtCl}^{6}+2 \mathrm{H}^{2} \mathrm{O} \\
\mathrm{K}^{2} \mathrm{PtCl}^{6}+8 \mathrm{~K} \mathrm{OH}=\mathrm{Pt}(\mathrm{OK})^{4}+6 \mathrm{KCl}+4 \mathrm{H}^{2} \mathrm{O} .
\end{gathered}
$$

d) Natriumhydroxyd-und Natriumcarbonatlösung bewirken in der Kälte keine Fällung, beim Erwärmen scheidet sich braungelbes Platinoxydnatrium: $\mathrm{Pt}(\mathrm{ONa})^{4}(?)$, aus.

e) Ammoniak ruft in geringer Menge zu Platinchloridlösung gegeben, einen gelben Niederschlag von Ammoniumplatinchlorid: $\left(\mathrm{NH}^{4}\right)^{2} \mathrm{PtCl}^{6}$, hervor, der im Ueberschusse des Fallungsmittels löslich ist.

f) Chlorkalium und Chlorammonium, nicht dagegen Chlornatrium scheiden aus nicht zu verdünnter Platinlösung gelbe, körnig-krystallinische Niederschläge $a b, z$. B.:

$$
\mathrm{H}^{2} \mathrm{PtCl}^{6}+2 \mathrm{KCl}=\mathrm{K}^{2} \mathrm{PtCl}^{6}+2 \mathrm{HCl} \text {. }
$$

g) Zinnchloriö färbt die Lösung des Platinchlorids dunkel braunroth; Eisenvitirol - und Eisenchloriirlösung bewirken keine Fällung, erst bei langem Kochen damit findet eine Reduction zu Platin statt.

h) Versetzt man die Lösung des Platinchlorids zunächst mit Eisenvitriol-, dann mit Natriumhydroxydlösung und endlich mit Salnsäure, so scheidet sich Platinmohr aus.

i) Auf der Kohle hinterlassen die Platinverbindungen beim Erhitzen mittelst des Löthrohrs eine graue, schwammige Masse von metallischem Platin, welche sich nur in Königswasser, und zwar mit gelber Farbe löst.

\section{Goldverbindungen.}

a) Schwefelwasserstoff scheidet in der Kälte aus Goldchloridlösung schwarzbraunes Goldsulfid: $\mathrm{Au}^{2} \mathrm{~S}^{3}$, ans, unlöslich in Salpetersäure und farblosem Schwefelammonium, löslich in Königswasser, Cyankaliumlösung und zum Theil auch in gelbem Schwefelammonium. Aus heisser Lösung wird das Goldchlorid durch Schwefelwasserstoff theilweise $\mathrm{zu}$ Metall reducirt.

$$
\begin{gathered}
2 \mathrm{HAuCl}^{4}+3 \mathrm{H}^{2} \mathrm{~S}=\mathrm{Au}^{2} \mathrm{~S}^{3}+8 \mathrm{HCl} \\
2 \mathrm{HAuCl}+3 \mathrm{H}^{2} \mathrm{~S}=\mathrm{Au}^{2}+8 \mathrm{HCl}+\mathrm{S}^{3} .
\end{gathered}
$$

b) Schwefelammonium fällt aus Goldlösung braunschwarzes Goldsulfid: $\mathrm{Au}^{2} \mathrm{~S}^{3}$, welches sich bei Gegenwart von Ammoniumpolysulfid, in einem Ueberschusse des Fällungsmittels, besonders in der Wärme, zum Theil wieder löst. 
c) Kalium - und Natriumhydroxyd erzeugen einen röthlich-gelben, in einem Uebersohusse des Fällungsmittels löslichen Niederschlag von Goldhydroxyd: $\mathrm{Au}(\mathrm{OH})^{3}$.

$$
\begin{gathered}
\mathrm{HAuCl}+4 \mathrm{KOH}=\mathrm{Au}(\mathrm{OH})^{3}+4 \mathrm{KCl}+\mathrm{H}^{2} \mathrm{O} \\
\mathrm{Au}(\mathrm{OH})^{3}+\mathrm{KOH}=\mathrm{KAuO} \mathrm{O}^{2}+2 \mathrm{H}^{2} \mathrm{O} .
\end{gathered}
$$

d) Alkalicarbonate bewirken in der Kälte keine Fällung, in der Siedehitze scheidet sich röthlich-gelbes Goldhydroxyd: $\mathrm{Au}(\mathrm{OH})^{3}, \mathrm{ab}$.

$$
2 \mathrm{HAuCl}^{4}+4 \mathrm{Na}^{2} \mathrm{CO}^{3}+2 \mathrm{H}^{2} \mathrm{O}=2 \mathrm{Au}(\mathrm{OH})^{3}+8 \mathrm{NaCl}+4 \mathrm{CO}^{2} \text {. }
$$

e) Ammonialo- und Ammoniumearbonatlösung fallen braungelbes Knallgold: $\mathrm{AuN}+\mathrm{NH}^{3}$.

f) Eisenvitriol- und Eisenchlorïrlösung scheiden in der, Wärme rothbraunes Gold ab.

$$
2 \mathrm{HAuCl}^{4}+6 \mathrm{FeSO}^{4}=2 \mathrm{Au}+2 \mathrm{Fe}^{2}\left(\mathrm{SO}^{4}\right)^{3}+\mathrm{Fe}^{2} \mathrm{Cl}^{6}+2 \mathrm{HCl} .
$$

g) Oxalsäure ruft beim Erwärmen mit stark verdünnter Goldlösung zunächst nur eine blaue Färbung hervor, welche allmälig in einen rothbraunen Niederschlag von metallischem Gold übergeht.

$$
2 \mathrm{HAuCl}^{4}+3 \mathrm{C}^{2} \mathrm{H}^{2} \mathrm{O}^{4}=2 \mathrm{Au}+6 \mathrm{CO}^{2}+8 \mathrm{HCl} \text {. }
$$

h) Verdünnte, etwas Zinnchlorid enthaltende Lösung von Zinnchlorïr ruft, selbst in sehr verdünnten Lösungen, eine purpurrothe bis rothbraune Färbung hervor (Cassius'seher Goldpurpur).

i) Auf der Kohle mit Soda geschmolzen, liefern die Goldverbindungen gelbe, ductile Flitter oder Körnchen von metallischem Golde.

\section{ק. Reactionen der wichtigeren Säuren.}

\section{Schwefelsäure, Sulfate.}

a) Chlorbaryum, Baryumnitrat und andere lösliche Baryumsalze scheiden in saurer Lösung weisses, in verdünnten Säuren unlösliches Baryumsulfat: $\mathrm{BaSO}^{4}, \mathrm{ab}$.

$$
\begin{gathered}
\mathrm{BaCl}^{2}+\mathrm{Na}^{2} \mathrm{SO}^{4}=\mathrm{BaSO}^{4}+2 \mathrm{NaCl} \\
\mathrm{Ba}\left(\mathrm{NO}^{3}\right)^{2}+\mathrm{H}^{2} \mathrm{SO}^{4}=\mathrm{BaSO}^{4}+2 \mathrm{HNO}^{3} .
\end{gathered}
$$

b) Bleiacetat fällt weisses Bleisulfat: $\mathrm{PbSO}^{4}$, vgl. S. 18 .

c) Mit Natriumcarbonat auf der Kohle anhaltend geglüht, liefern die Sulfate eine gelbe Schmelze von Schwefelnatrium (Hepar). Bringt man diese Schmelze auf eine Silbermünze und fügt etwas Wasser zu, so entsteht ein schwarzer Fleck von Schwefelsilber.

$$
\begin{gathered}
\mathrm{Na}^{2} \mathrm{SO}^{4}+4 \mathrm{C}=\mathrm{Na}^{2} \mathrm{~S}+4 \mathrm{CO} \\
\mathrm{Na}^{2} \mathrm{~S}+2 \mathrm{Ag}+2 \mathrm{H}^{2} \mathrm{O}=\mathrm{Ag}^{2} \mathrm{~S}+2 \mathrm{NaOH}+2 \mathrm{H} .
\end{gathered}
$$

\section{Unterschweflige Säure, Thiosulfate.}

a) Salzsäure zerlegt die Thiosulfate unter Abscheidung von Schwefel und Entwickelung von Schwefligsäureanhydrid.

$$
\mathrm{Na}^{2} \mathrm{~S}^{2} \mathrm{O}^{3}+2 \mathrm{HCl}=2 \mathrm{NaCl}+\mathrm{SO}^{2}+\mathrm{S}+\mathrm{H}^{2} \mathrm{O} .
$$


b) Silbernitrat fällt weisses Silberthiosulfat: $\mathrm{Ag}^{2} \mathrm{~S}^{2} \mathrm{O}^{3}$, welches in einem Ueberschusse des Thiosulfats löslich ist. Das Silberthiosulfat wird rasch gelb, braun und endlich unter Bildung von Schwefelsilber schwarz.

$$
\begin{gathered}
\mathrm{Na}^{2} \mathrm{~S}^{2} \mathrm{O}^{3}+2 \mathrm{AgNO} \mathrm{A}^{3}=\mathrm{Ag}^{2} \mathrm{~S}^{2} \mathrm{O}^{3}+2 \mathrm{NaNO}^{3} \\
\mathrm{Ag}^{2} \mathrm{~S}^{2} \mathrm{O}^{3}+\mathrm{Na}^{2} \mathrm{~S}^{2} \mathrm{O}^{3}=2 \mathrm{NaAg \textrm {S } ^ { 3 }} \\
\mathrm{Ag}^{2} \mathrm{~S}^{2} \mathrm{O}^{3}+\mathrm{H}^{2} \mathrm{O}=\mathrm{Ag}^{2} \mathrm{~S}+\mathrm{H}^{2} \mathrm{SO}^{4} .
\end{gathered}
$$

c) Bleiacetat fallt weisses Bleithiosulfat, welches in einem Ueberschusse von Thiosulfat löslich ist, sich aber beim Erwärmen unter Bildung von Sehwefelblei schwärzt.

$$
\begin{gathered}
\mathrm{Na}^{2} \mathrm{~S}^{2} \mathrm{O}^{3}+\left(\mathrm{C}^{2} \mathrm{H}^{3} \mathrm{O}^{2}\right)^{2} \mathrm{~Pb}=\mathrm{PbS}^{2} \mathrm{O}^{3}+2 \mathrm{C}^{2} \mathrm{H}^{3} \mathrm{NaO}^{2} \\
\mathrm{PbS}^{2} \mathrm{O}^{3}+\mathrm{H}^{2} \mathrm{O}=\mathrm{PbS}+\mathrm{H}^{2} \mathrm{SO}^{4} .
\end{gathered}
$$

d) Jod wird von übersehüssiger Thiosulfatlösung unter Entfärbung gelöst.

$$
2 \mathrm{Na}^{2} \mathrm{~S}^{2} \mathrm{O}^{3}+2 \mathrm{~J}=\mathrm{Na}^{2} \mathrm{~S}^{4} \mathrm{O}^{6}+2 \mathrm{NaJ} .
$$

e) Neutrale Eisenchloridlösung färbt die Lösung der Alkalithiosulfate zunächst violett $\left[\mathrm{Fe}^{2}\left(\mathrm{~S}^{2} \mathrm{O}^{3}\right)^{3}\right]$, nach einiger Zeit, rascher beim gelinden Erwärmen, verschwindet diese Färbung vollständig $\left[\mathrm{FeS}^{2} \mathrm{O}^{3}\right]$.

$$
\begin{gathered}
3 \mathrm{Na}^{2} \mathrm{~S}^{2} \mathrm{O}^{3}+\mathrm{Fe}^{2} \mathrm{Cl}^{6}=\mathrm{Fe}^{2}\left(\mathrm{~S}^{2} \mathrm{O}^{3}\right)^{3}+6 \mathrm{NaCl} \\
\mathrm{Fe}^{2}\left(\mathrm{~S}^{2} \mathrm{O}^{3}\right)^{3}=\mathrm{FeS}^{2} \mathrm{O}^{3}+\mathrm{FeS}^{4} \mathrm{O}^{6} .
\end{gathered}
$$

f) Beim Glühen in einem Glühröhrchen werden die Thiosulfate in Sulfate und Polysulfide verwandelt. Der erkaltete Rückstand entwickelt daher auf Zusatz von Salzsäure Schwefelwasserstoff.

$$
\begin{gathered}
4 \mathrm{Na}^{2} \mathrm{~S}^{2} \mathrm{O}^{3}=3 \mathrm{Na}^{2} \mathrm{SO}^{4}+\mathrm{Na}^{2} \mathrm{~S}^{5} \\
\mathrm{Na}^{2} \mathrm{~S}^{5}+2 \mathrm{HCl}=2 \mathrm{NaCl}+\mathrm{H}^{2} \mathrm{~S}+4 \mathrm{~S} .
\end{gathered}
$$

g) Mit Natriumcarbonat auf der Kohle geglüht, verhalten sich die Thiosulfate wie die Sulfate.

\section{Schweflige Säure, Sulfite.}

a) Salrsäure oder verdünnte Schwefelsäure entwickeln stechend riechendes Schwefligsäureanhydrid: $\mathrm{SO}^{2}$; Jodsüure-Stärkepapier ${ }^{1}$ ) färbt sich durch das entweichende Gas blau; durch einen Ueberschuss von Schwefligsäureanhydrid versehwindet die Blaufärbung wieder.

$$
\begin{aligned}
& \mathrm{Na}^{2} \mathrm{SO}^{3}+2 \mathrm{HCl}=\mathrm{SO}^{2}+2 \mathrm{NaCl}+\mathrm{H}^{2} \mathrm{O} \\
& 2 \mathrm{HJO}^{3}+5 \mathrm{SO}^{2}+4 \mathrm{H}^{2} \mathrm{O}=\mathrm{J}^{2}+5 \mathrm{H}^{2} \mathrm{SO}^{4} \\
& 2 \mathrm{~J}+\mathrm{SO}^{2}+2 \mathrm{H}^{2} \mathrm{O}=\mathrm{H}^{2} \mathrm{SQ}^{4}+2 \mathrm{HJ} .
\end{aligned}
$$

b) Schwefelwasserstoff wird durch schweflige Säure unter Abscheidung von Schwefel zersetzt.

$$
\mathrm{SO}^{2}+2 \mathrm{H}^{2} \mathrm{~S}=2 \mathrm{H}^{2} \mathrm{O}+3 \mathrm{~S} .
$$

c) Chlorbaryum erzeugt nach vorherigem Zusatz von Chlorwasser oder von Jodlösung einen weissen, in verdünnten Säuren unlöslichen Niederschlag von Baryumsulfat.

$$
\mathrm{H}^{2} \mathrm{SO}^{3}+\mathrm{H}^{2} \mathrm{O}+2 \mathrm{Cl}=\mathrm{H}^{2} \mathrm{SO}^{4}+2 \mathrm{HCl} \text {. }
$$

d) Zink und verdünnte Schwefelsäure reduciren die schweflige Säure zu Schwefelwasserstoff: $\mathrm{H}^{2} \mathrm{~S}$, zu erkennen durch den Geruch und die Schwärzung von Bleipapier.

$$
\mathrm{H}^{2} \mathrm{SO}^{3}+6 \mathrm{H}=\mathrm{H}^{2} \mathrm{~S}+3 \mathrm{H}^{2} \mathrm{O} \text {. }
$$

e) Mit Natriumearbonat auf der Kohle geglüht, verhalten sich die Sulfite wie die Sulfate.

1) Papier, welches mit Starkekleister, dem etwas Jodstururelösung zugesetzt ist, befeuchtet ist. 


\section{Schwefelwasserstoff, Schwefelmetalle.}

a) Schwefelwasserstoff kennzeichnet sich durch den Geruch, durch die Braun- oder Schwarzfärbung von Filtrirpapier, welches mit Bleiacetat - oder mit Silbernitratlösung imprägnirt, und durch die Violettfärbung von Filtrirpapier, welches mit ammoniakalischer Nitroprussidnatriumlösung befeuchtet ist.

b) Sal:säure löst, namentlich in der Wärme, viele Schwefelmetalle unter Entwickelung von Schwefelwasserstoff; einige Schwefelmetalle sind dagegen nur in Salpetersäure oder in Königswasser löslich. Häufig findet bei der Auflösung (besonders in den beiden letzten Fallen) eine Abscheidung von Schwefel in Gestalt von zusammengeballten Massen, bisweilen auch eine Bildung von Schwefelsäure statt.

c) Nitroprussidnatrium färbt die Lösungen wasserlöslicher Schwefelmetalle blauviolett; Schwefelwasserstoff ruft keine Färbung hervor; letztere tritt erst ein nach Zusatz von Ammoniak.

d) Im Glühröhrchen erhitzt, geben viele Schwefelmetalle ein Sublimat von Schwefel.

e) In einem schräg liegenden, an beiden Seiten offenen Röhrchen erhitzt, werden die Schwefelmetalle unter Bildung von schwefliger Säure (vgl. S. 25) zersetzt.

f) Mit Natriumearbonat in der reducirenden Löthrohrflamme auf Kohle erhitzt, verhalten sich die Schwefelmetalle wie die Sulfate (Heparbildung).

\section{Salpetersäure, Nitrate.}

a) Giesst man zu dem in Wasser gelösten oder darin suspendirten Nitrate ein der Flüssigkeitsmenge gleiches Volum cone. Schwefelsäure und überschichtet alsdann die heisse Mischung mit Eisenvitriollösung, so macht sich an der Berührungsfläche entweder sofort oder nach einiger Zeit eine braune Zone (Lösung von Stickoxyd: NO, in Eisenvitriollösung) bemerkbar.

$$
6 \mathrm{FeSO}^{4}+2 \mathrm{HNO}^{3}+3 \mathrm{H}^{2} \mathrm{SO}^{4}=3 \mathrm{Fe}^{2}\left(\mathrm{SO}^{4}\right)^{3}+2 \mathrm{NO}+4 \mathrm{H}^{2} \mathrm{O} .
$$

b) Die mit Schwefelsäure stark angesüuerte Nitratlösung entfärbt Indigolösung beim Erwärmen.

c) Mit einem gleichen Volum Brucinlösung (1 Theil Brucin, 5 Theile verdünnter Schwefelsäure, 100 Theile Wasser) gemischt und mit chemisch reiner cone. Schwefelsäure unterschichtet, rufen Nitrate an der Berührungsfläche eine schönrothe Zone hervor.

d) Mit etwas Diphenylaminlösung (1 Theil Diphenylamin, 100 Theile reiner conc. Schwefelsäure) versetzt und mit chemisch reiner conc. Sehwefelsäure unterschichtet, rufen Spuren von Nitraten an der Berührungsfläche eine sehr beständige blaue Zone hervor. 
e) Beim Erwärmen der Nitrate mit Natronlauge, Zink- und Eisenfeile, findet Entwickelung von Ammonial: $\mathrm{NH}^{3}$, statt.

f) Feingeraspeltes Zink mit Salpetersäure oder Nitrate enthaltenden Flüssigkeiten erwärmt, veranlasst eine Reduction zu salpetriger Säure, bezüglich zu Nitriten; letztere werden nach Zusatz von etwas verdünnter Schwefelsäure an der Blaufärbung zugefügten Jodkaliumstärkekleisters erkannt (siehe 6).

g) Auf Kohle erhitzt, verpuffen die Nitrate.

\section{Salpetrige Säure, Nitrite.}

a) Die Nitrite liefern ebenfalls die im Vorstehenden angegebenen Nitratreactionen.

b) Jodkaliumstärkekleister (1 g. jodsäurefreien Jodkaliums, $500 \mathrm{~g}$. dünnen Stärkekleisters) wird in der durch Sehwefelsäure angesäuerten Nitritlösung sofort blau gefärbt.

$$
2 \mathrm{HNO}^{2}+2 \mathrm{KJ}=2 \mathrm{~J}+2 \mathrm{NO}+2 \mathrm{KOH} \text {. }
$$

c) Metadiamidobenxollösung (1 g. salzsauren Metadiamidobenzols: $\mathrm{C}^{e} \mathrm{H}^{4}\left(\mathrm{NH}^{2}\right)^{2}, 100 \mathrm{~g}$. Wasser) verursacht sofort oder nach wenigen Minuten eine gelbe bis braune Fïrbung in der mit Schwefelsäure angesäuerten Nitritlösung. $\quad 2 \mathrm{C}^{6} \mathrm{H}^{8} \mathrm{~N}^{2}+\mathrm{HNO}^{2}=\mathrm{C}^{12} \mathrm{H}^{13} \mathrm{~N}^{5}+2 \mathrm{H}^{2} \mathrm{O}$.

\section{Phosphorsäure, Phosphate.}

a) Silbernitrat erzeugt in neutralen Phosphatlösungen einen gelben Niederschlag von Silberphosphat: $\mathrm{Ag}^{3} \mathrm{PO}^{4}$, farblos löslich in Ammoniak und in Salpetersäure.

$$
\begin{gathered}
\mathrm{Na}^{2} \mathrm{HPO}^{4}+3 \mathrm{AgNO}^{3}=\mathrm{Ag}^{3} \mathrm{PO}^{4}+2 \mathrm{NaNO}^{3}+\mathrm{HNO}^{3} \\
\mathrm{Ag}^{3} \mathrm{PO}^{4}+3 \mathrm{HNO}^{3}=\mathrm{H}^{3} \mathrm{PO}^{4}+3 \mathrm{AgNO}^{3} .
\end{gathered}
$$

b) Eisenchlorid fällt gelblich-weisses Ferriphosphat: $\mathrm{Fe}^{2}\left(\mathrm{PO}^{4}\right)^{2}$, löslich in Salzsäure und in überschüssigem Eisenchlorid, unlöslich in Essigsäure.

$$
\mathrm{Fe}^{2} \mathrm{Cl}^{6}+2 \mathrm{Na}^{2} \mathrm{HPO}^{4}=\mathrm{Fe}^{2}\left(\mathrm{PO}^{4}\right)^{2}+4 \mathrm{NaCl}+2 \mathrm{HCl} .
$$

c) Blei-, Baryum-, Calcium- und andere Metallsalze geben mit neutralen Phosphatlösungen Niederschläge, die in Salzsäure und Salpetersäure löstich sind.

d) Magnesiumsellfat ruft in mit Salmiak und Ammoniak versetzten Phosphatlösungen sofort oder nach einiger Zeit eine Fällung von krystallinischem Ammonium-Magnesiumphosphat: $\mathrm{Mg}\left(\mathrm{NH}^{4}\right) \mathrm{PO}^{4}+6 \mathrm{H}^{2} \mathrm{O}$, hervor; letzterer Niederschlag ist in Essigsäure löslich.

$$
\mathrm{Na}^{2} \mathrm{HPO}^{4}+\mathrm{NH}^{4} \cdot \mathrm{OH}+\mathrm{MgSO}^{4}=\mathrm{Mg}\left(\mathrm{NH}^{4}\right) \mathrm{PO}^{4}+\mathrm{Na}^{2} \mathrm{SO}^{4}+\mathrm{H}^{2} \mathrm{O} .
$$

e) Salpetersäurehaltige Ammoniummolybdatlösung ruft im Veberschuss angewendet in salpetersäurehaltiger Phosphat- oder Phosphorsäurelösung bei gew öhnlicher Temperatur allmälig einen gelben, körnig-krystallinischen Niederschlag von Ammoniumphosphomolybdat hervor: $\left.2\left(\mathrm{NH}^{4}\right)^{3} \mathrm{PO}^{4}+22 \mathrm{MoO}^{3}+12 \mathrm{H}^{2} \mathrm{O}\right)$ (vgl. Arsensäure). 


\section{Arsenige Säure, Arsenite.}

a) Schwefelwasserstoff ruft in der wässerigen Lösung der arsenigen Säure und der Arsenite zunächst nur eine gelbe Fürbung hervor; ein Zusatz von Salzsäure bewirkt jedoch sofortige Abscheidung von gelbem Schwefelarsen: $\mathrm{As}^{2} \mathrm{~S}^{3}$, unlöslich in Salzsäure, löslich in Schwefelammonium, Ammoniak und Ammoniumcarbonatlösung.

$$
\begin{gathered}
\mathrm{As}^{2} \mathrm{O}^{3}+3 \mathrm{H}^{2} \mathrm{~S}=\mathrm{As}^{2} \mathrm{~S}^{3}+3 \mathrm{H}^{2} \mathrm{O} \\
\mathrm{As}^{2} \mathrm{~S}^{3}+6\left(\mathrm{NH} \mathrm{H}^{4}\right) \mathrm{HS}=2\left(\mathrm{NH}^{4}\right)^{3} \mathrm{AsS}^{3}+3 \mathrm{H}^{2} \mathrm{~S} \\
\mathrm{As}^{2} \mathrm{~S}^{3}+6 \mathrm{NH}^{4} \cdot \mathrm{OH}=\left(\mathrm{NH}^{4}\right)^{3} \mathrm{AsS}^{3}+\left(\mathrm{NH}^{4}\right)^{3} \mathrm{AsO}^{3}+3 \mathrm{H}^{2} \mathrm{O} \\
\mathrm{As}^{2} \mathrm{~S}^{3}+3\left(\mathrm{NH}^{4}\right)^{2} \mathrm{CO}=\left(\mathrm{NH}^{4}\right)^{3} \mathrm{AsS}^{3}+\left(\mathrm{NH}^{4}\right)^{3} \mathrm{AsO}^{3}+3 \mathrm{CO}^{2} .
\end{gathered}
$$

Salzsäure scheidet aus diesen Lösungen wieder gelbes Schwefelarsen aus.

b) Silbernitrat bewirkt in der wässerigen Lösung der arsenigen Säure keine Fällung, fügt man aber vorsichtig tropfenweise Ammoniak zu, so entsteht ein gelber Niederschlag von Silberarsenit: $\mathrm{Ag}^{3} \mathrm{AsO}^{3}$, welcher in überschüssigem Ammoniak und in Salpetersäure farblos löslich ist.

$\mathrm{As}^{2} \mathrm{O}^{3}+6 \mathrm{AgNO}^{3}+6 \mathrm{NH}^{4} \cdot \mathrm{OH}=2 \mathrm{Ag}^{3} \mathrm{AsO}^{3}+6 \mathrm{NH}^{4} \cdot \mathrm{NO}^{3}+3 \mathrm{H}^{2} \mathrm{O}$.

c) Kocht man die ammoniakalische Lösung des Silberarsenits längere Zeit, unter Ersatz des entweichenden Ammoniaks, so findet, unter Abscheidung von metallischem Silber, Bildung von Arsensäure statt. Das Filtrat liefert daher nach der Neutralisation mit Salpetersäure mit Silbernitratlösung einen rothbraunen Niederschlag von Silberarsenat: $\mathrm{Ag}^{3} \mathrm{AsO}^{4}$.

d) Kupfersulfatlösung erzeugt nach vorsichtigem Zusatz von verdünnter Kalilauge einen gelblich-grünen Niederschlag von Kupferarsenit: $\mathrm{CuHAsO}$.

$$
\mathrm{As}^{2} \mathrm{O}^{3}+4 \mathrm{KOH}+2 \mathrm{CuSO}^{4}=2 \mathrm{CuHAsO}^{3}+2 \mathrm{~K}^{2} \mathrm{SO}^{4}+\mathrm{H}^{2} \mathrm{O} .
$$

e) Erwärmt man eine salzsaure Lösung von Arsenigsäureanhydrid oder eines Arsenits auf einem blanken Kupferbleche, so entsteht ein grauer Fleck von Arsenkupfer.

f) Wird der Dampf des Arsenigsäureanhydrids in einem Glühröhrchen über einen glühenden Kohlesplitter getrieben, so bildet sich ein braunschwarzer, glänzender Spiegel von Arsen.

g) Zink und verdünnte Schwefelsäure erzeugen (im Marshsehen Apparate) Arsenwasserstoff: $\mathrm{AsH}^{3}$. Das entweichende Gas brennt mit bläulich-weisser Flamme zu Arsenigsäureanhydrid. Kühlt man jedoch die Flamme durch Hineinhalten einer Porzellanschale $\mathrm{ab}$, so beschlägt letztere mit einem braunschwarzen Flecke von Arsen, welcher sich in Natriumhypochloritlösung leicht auflöst (Unterschied vom Antimon, s. S. 21).

$$
\begin{gathered}
2 \mathrm{AsH}^{3}+6 \mathrm{O}=\mathrm{As}^{2} \mathrm{O}^{3}+3 \mathrm{H}^{2} \mathrm{O} \\
2 \mathrm{AsH}+30=\mathrm{As}^{2}+3 \mathrm{H}^{2} \mathrm{O} \\
\mathrm{As}^{2}+3 \mathrm{NaClO}=\mathrm{As}^{2} \mathrm{O}^{3}+3 \mathrm{NaCl} .
\end{gathered}
$$

h) Ueber das Verhalten auf der Kohle s. S. 20. 


\section{Arsensäure, Arsenate.}

a) Schwefelwasserstoff ruft zunächst keinen Niederschlag hervor, erst bei längerem Stehen oder beim Erwärmen auf 60 bis $70^{\circ} \mathrm{C}$. scheidet sich je nach den Versuchsbedingungen Arsenpentasulfid: $\mathrm{As}^{2} \mathrm{~S}^{5}$, oder ein Gemisch von Arsenpentasulfid: $\mathrm{As}^{2} \mathrm{~S}^{5}$, Arsentrisulfid: $\mathrm{As}^{2} \mathrm{~S}^{3}$ und Schwefel ab.

Wirkt Schwefelwasserstoff im raschen Strome auf Arsensäure ein, so entsteht langsam $\mathrm{As}^{2} \mathrm{~S}^{5}$, jedoch ausschliesslich nur, wenn die Lösung freie Salzsäure enthält und erwärmt wird.

$$
2 \mathrm{H}^{3} \mathrm{AsO}^{4}+5 \mathrm{H}^{2} \mathrm{~S}=\mathrm{As}^{2} \mathrm{~S}^{5}+8 \mathrm{H}^{2} \mathrm{O} \text {. }
$$

Beim langsamen Einleiten von Schwefelwasserstoff in Arsensäurelösung oder in die saure Lösung von Arsenaten verläuft neben obiger Reaction noch nachstehender Process.

$$
\begin{gathered}
2 \mathrm{H}^{3} \mathrm{AsO} \mathrm{O}^{4}+2 \mathrm{H}^{2} \mathrm{~S}=2 \mathrm{H}^{3} \mathrm{AsO} \mathrm{O}^{3}+2 \mathrm{~S}+2 \mathrm{H}^{2} \mathrm{O} \\
2 \mathrm{H}^{3} \mathrm{AsO}^{3}+3 \mathrm{H}^{2} \mathrm{~S}=\mathrm{As}^{2} \mathrm{~S}^{3}+6 \mathrm{H}^{2} \mathrm{O} .
\end{gathered}
$$

b) Silbernitrat fällt aus der Lösung neutraler Arsenate rothbraunes Silberarsenat: $\mathrm{Ag}^{3} \mathrm{AsO}^{4}$, farblos löslich in Ammoniak und in Salpetersäure.

$$
\mathrm{Na}^{2} \mathrm{HAsO} \mathrm{H}^{4}+3 \mathrm{AgNO}^{3}=\mathrm{Ag}^{3} \mathrm{AsO}^{4}+2 \mathrm{NaNO}^{3}+\mathrm{HNO}^{3} .
$$

c) Kupfersulfat scheidet aus neutralen Arsenatlösungen blaugrünes Kupferarsenat: $\mathrm{CuHAsO}^{4}$, ab, löslich in Ammoniak und in Säuren.

$$
\mathrm{Na}^{2} \mathrm{HAsO}^{4}+\mathrm{CuSO}^{4}=\mathrm{CuHAsO}^{4}+\mathrm{Na}^{2} \mathrm{SO}^{4} .
$$

d) Magnesiumsulfat fallt aus ammoniakalischer, Chlorammonium enthaltender Lösung der Arsensäure oder der Arsenate sofort oder nach einiger Zeit weisses, krystallinisches AmmoniumMagnesiumarsenat: $\mathrm{Mg}\left(\mathrm{NH}^{4}\right) \mathrm{AsO}^{4}+6 \mathrm{H}^{2} \mathrm{O}$.

$$
\mathrm{H}^{3} \mathrm{AsO}^{4}+\mathrm{MgSO}^{4}+3 \mathrm{NH}^{4} \cdot \mathrm{OH}=\mathrm{Mg}\left(\mathrm{NH}^{4}\right) \mathrm{AsO}^{4}+\left(\mathrm{NH}^{4}\right)^{2} \mathrm{SO}^{4}+3 \mathrm{H}^{2} \mathrm{O} .
$$

Arsenige Säure oder Arsenite werden hierdurch nicht gefält.

e) Salpetersäurehaltige Ammoniummolybdatlösung ruft im Ueberschusse angewendet erst bei gelindem Erwärmen (40 bis $50^{\circ}$ C.) in salpetersäurehaltiger Arsensäurelösung die Abscheidung eines gelben, krystallinischen Niederschlags hervor $\left[2\left(\mathrm{NH}^{4}\right)^{3} \mathrm{AsO}^{4}+22 \mathrm{MoO}^{3}+12 \mathrm{H}^{2} \mathrm{O}\right]$. In der Kälte tritt keine Reaction ein (vgl. Phosphorsäure).

f) Auf Kupferblech, im Marsh'schen Apparate und auf Kohle verhält sich die Arsensäure wie die arsenige Säure.

\section{Borsäure, Borate.}

a) Versetzt man Borsäure mit Alkohol oder Borate mit Alkohol und conc. Schwefelsäure, und zündet nach einiger Zeit den Alkohol an, so erscheint die Flamme beim Umrühren der Mischung, namentlich kurz vor dem Erlöschen, grün gefärbt. 
Kupfersalze, die ebenfalls die Flamme grün färben, sind zuvor durch Schwefelwasserstoff $\mathrm{zu}$ entfernen. Die Grünfürbung der Borsäureflamme wird bedingt durch Bildung von Borsäureaethyläther, zum Theil auch durch Borsäure, die sich verflüchtigt.

b) Taucht man Curcumapapier in die salssäurehaltige Lösung eines Borats oder die der Borsäure, und trocknet dasselbe, so nimmt es eine braunrothe Fürbung an. Betupft man dieses gebräunte Papier mit Natronlauge, so färbt sich diese Stelle grünschwarz.

c) Calcium-, Baryum-, Silber-, Blei-, Eisen-, Quecksilbersalze werden durch conc. Alkaliboratlösung gefällt. Die Niederschläge sind in Säuren und in Ammoniaksalzlösung löslich.

\section{Kohlensäure, Carbonate.}

Salwsäure, Salpetersäure etc. treiben aus den Carbonaten bei gewöhnlicher Temperatur oder beim Erwärmen damit, unter Aufbrausen, Kohlensäureanhydrid: $\mathrm{CO}^{2}$, aus. Das entwickelte Gas ist geruchlos; beim Einleiten in Kalk- oder Barytwasser oder in Berührung mit einem durch Barytwasser befeuchteten Glasstab gebracht, ruft es sofort eine weisse Trübung hervor.

$$
\begin{gathered}
\mathrm{CaCO}^{3}+2 \mathrm{HCl}=\mathrm{CaCl}^{2}+\mathrm{H}^{2} \mathrm{O}+\mathrm{CO}^{2} \\
\mathrm{CO}^{2}+\mathrm{Ba}(\mathrm{OH})^{2}=\mathrm{BaCO}^{3}+\mathrm{H}^{2} \mathrm{O} .
\end{gathered}
$$

\section{Kieselsäure, Silicate.}

a) Die Lösungen der Alkalisilicate werden durch Säuren und durch Chlorammonium zersetzt. Bei genügender Concentration oder beim Eindampfen scheidet sich in Folge dessen die Kieselsäure als gallertartige Masse $a b$.

$$
\mathrm{Na}^{2} \mathrm{SiO}^{3}+2 \mathrm{HCl}=\mathrm{H}^{2} \mathrm{SiO}^{3}+2 \mathrm{NaCl}
$$

$\mathrm{Na}^{2} \mathrm{SiO}^{3}+2 \mathrm{NH}^{4} \mathrm{Cl}=\mathrm{H}^{2} \mathrm{SiO}^{3}+2 \mathrm{NaCl}+2 \mathrm{NH}^{3}$.

b) Calcium-, Baryum-, Blei- und Silbersalze scheiden aus Alkalisilicatlösungen weisse Metallsilicate ab.

c) Schmilzt man Kieselsäure oder ein Silicat mit der Phosphorsalzperle am Platindrahte zusammen, so bleibt die Kieselsäure ungelöst und schwimmt in der sonst klaren, glühenden Perle als undurchsichtiges Wölkchen - Kieselsäureskelett herum.

$$
\mathrm{CaSiO}^{3}+\mathrm{NaPO}^{3}=\mathrm{SiO}^{2}+\mathrm{NaCaPO}^{4}
$$

\section{Chlorwasserstoff'säure, Chloride.}

a) Silbernitrat veranlasst eine weisse, käsige, am Licht violett werdende Fällung von Chlorsilber: AgCl. Der Niederschlag ist unlöslich in Salpetersäure, löslich in Ammoniak-, Cyankalium- und Natriumthiosulfatlösung (vgl. S. 16).

b) Mercuronitratlösung fällt weisses, in verdünnten Säuren unlösliches Quecksilberchlorür: $\mathrm{Hg}^{2} \mathrm{Cl}^{2}$.

$$
\mathrm{Hg}^{2}\left(\mathrm{NO}^{3}\right)^{2}+2 \mathrm{NaCl}=\mathrm{Hg}^{2} \mathrm{Cl}^{2}+2 \mathrm{NaNO}^{3} \text {. }
$$


c) Bleiacetat fällt weisses, krystallinisches, in kaltem Wasser schwer lösliches, in viel kochendem Wasser lösliches Chlorblei. $\left(\mathrm{C}^{2} \mathrm{H}^{3} \mathrm{O}^{2}\right)^{2} \mathrm{~Pb}+2 \mathrm{NaCl}=\mathrm{PbCl}^{2}+2 \mathrm{C}^{2} \mathrm{H}^{3} \mathrm{NaO}^{2}$.

d) Mit Mangansuperoxyd und conc. Schwefelsäure erwärmt, entwickeln die Chloride freies Chlor, kenntlich am Geruch und an der Blaufärbung des Jodkaliumstärkepapieres.

$\mathrm{MnO}^{2}+2 \mathrm{NaCl}+3 \mathrm{H}^{2} \mathrm{SO}^{4}=2 \mathrm{NaHSO}^{4}+\mathrm{MnSO}^{4}+2 \mathrm{H}^{2} \mathrm{O}+2 \mathrm{Cl}$.

e) Mit Kaliumdichromat (1 Theil) und conc. Schwefelsäure (3 Theile) in einer Retorte destillirt, liefern die Chloride (1 Theil) ein dunkel rothbraunes, öliges Destillat von Chlorchromsäure: $\mathrm{CrO}^{2} \mathrm{Cl}^{2}$; fügt man zu dem Destillate Ammoniak im Ueberschusse, so löst sich die Chlorchromsäure mit gelber Farbe zu Ammoniumchromat: $\left(\mathrm{NH}^{4}\right)^{2} \mathrm{CrO}^{4}$ (Unterschied von den Bromiden und Jodiden).

$$
\begin{gathered}
4 \mathrm{KCl}+\mathrm{K}^{2} \mathrm{Cr}^{2} \mathrm{O}^{7}+6 \mathrm{H}^{2} \mathrm{SO}^{4}=2 \mathrm{CrO}^{2} \mathrm{Cl}^{2}+6 \mathrm{KHSO}^{4}+3 \mathrm{H}^{2} \mathrm{O} \\
\mathrm{CrO}^{2} \mathrm{Cl}^{2}+4 \mathrm{NH}^{4} \cdot \mathrm{OH}=\left(\mathrm{NH}^{4}\right)^{2} \mathrm{CrO}^{4}+2 \mathrm{NH}^{4} \mathrm{Cl}+2 \mathrm{H}^{2} \mathrm{O} .
\end{gathered}
$$

\section{Unterchlorige Säure, Hypochlorite.}

Die Hypochlorite sind gewöhnlich in Folge ihrer Bereitungsweise: durch Einwirkung von Chlor auf basische Hydroxyde, mit Chloriden gemengt, z. B.:

$$
2 \mathrm{Cl}+2 \mathrm{NaOH}=\mathrm{NaClO}+\mathrm{NaCl}+\mathrm{H}^{2} \mathrm{O} .
$$

a) Silbernitrat fallt in Folge der leichten Zersetzbarkeit des zunächst gebildeten Silberhypochlorits: AgClO, nur Chlorsilber.

b) Bleiacetat erzeugt zunächst einen weissen Niederschlag von Chlorblei: $\mathrm{PbCl}^{2}$, der jedoch in Folge der Bildung von Bleisuperoxyd: $\mathrm{PbO}^{2}$, bald gelb und schliesslich braun wird.

c) Salrsäure etc. entwickeln freies Chlor, kenntlich am Geruch und an der Blaufärbung des Jodkaliumstärkepapiers.

$$
\mathrm{NaClO}+\mathrm{NaCl}+2 \mathrm{HCl}=2 \mathrm{NaCl}+\mathrm{H}^{2} \mathrm{O}+\mathrm{Cl}^{2} \text {. }
$$

d) Lackmus - und Indigolösung werden entfärbt.

\section{Chlorsäure, Chlorate.}

a) Silbernitrat und Bleiacetat rufen keine Fällung hervor; wird das Chlorat jedoch vorher geglüht, so wird durch das hierdurch gebildete Chlorid Chlorsilber: $\mathrm{AgCl}$, bezüglich Chlorblei: $\mathrm{PbCl}^{2}$, gefällt.

$$
\mathrm{KClO}=\mathrm{KCl}+0^{3} \text {. }
$$

b) Durch Salısäure werden die Chlorate, besonders in der Wärme, unter Entwickelung von Chlor zersetzt, kenntlich an der grünlichgelben Färbung, am Geruch und an der Blaufärbung des Jodkaliumstärkepapiers.

$$
\mathrm{KClO}^{3}+6 \mathrm{HCl}=\mathrm{KCl}+3 \mathrm{H}^{2} \mathrm{O}+6 \mathrm{Cl} .
$$

c) Cone. Schwefelsäure entwickelt aus den festen Chloraten grüngelbes, explosibles Chlordioxyd.

$$
3 \mathrm{KClO}^{3}+2 \mathrm{H}^{2} \mathrm{SO}^{4}=2 \mathrm{KHSO}^{4}+\mathrm{KClO}^{4}+2 \mathrm{ClO}^{2}+\mathrm{H}^{2} \mathrm{O} .
$$

d) Mit der gleichen Menge Zucker vorsichtig gemischt, verpuffen die festen Chlorate mit grosser Heftigkeit, wenn das Gemisch mit einem Tropfen cone. Schwefelsäure befeuchtet wird.

e) Auf glühende Kohle geworfen, verpuffen die Chlorate. 
f) Im Glühröhrchen erhitzt, entwickeln die Chlorate Sauerstoff, kenntlich an der Wiederentzündung eines glimmenden Hölzchens.

$$
\mathrm{KClO}^{3}=\mathrm{KCl}+\mathrm{O}^{3} .
$$

g) Lackmus - und Indigolösung werden erst dann durch Chlorate entfärbt, wenn die Lösung mit Salzsäure erwärmt wird.

\section{Bromwasserstoff, Bromide.}

a) Silbernitrat fällt gelbliches, in Salpetersäure unlösliches, in Ammoniak schwerer als Chlorsilber lösliches Bromsilber; von Natriumthiosulfat- und von Cyankaliumlösung wird es leicht gelöst (vgl. S. 16).

$$
\mathrm{KBr}+\mathrm{AgNO}^{3}=\mathrm{AgBr}+\mathrm{KNO}^{3} .
$$

b) Mercuronitrat scheidet gelblich-weisses Quecksilberbromür: $\mathrm{Hg}^{2} \mathrm{Br}^{2}$, aus.

$$
\mathrm{Hg}^{2}\left(\mathrm{NO}^{2}\right)^{2}+2 \mathrm{KBr}=\mathrm{Hg}^{2} \mathrm{Br}^{2}+2 \mathrm{KNO}^{3} .
$$

c) Bleiacetat fällt weisses, krystallinisches, in Wasser sehr schwer lösliches Bromblei: $\mathrm{PbBr}^{2}$.

$2 \mathrm{KBr}+\left(\mathrm{C}^{2} \mathrm{H}^{3} \mathrm{O}^{2}\right)^{2} \mathrm{~Pb}=\mathrm{PbBr}^{2}+2 \mathrm{C}^{2} \mathrm{H}^{3} \mathrm{~K} 0^{2}$.

d) Mangansuperoxyd und conc. Schwefelsäure, ebenso Chlorwasser, conc. Salpetersäure und cone. Schwefelsäure machen aus den Bromiden Brom frei, kenntlich am Geruch, der braunen Farbe und an der Blaufärbung des Jodkaliumstärkepapieres.

$\mathrm{MnO}^{2}+2 \mathrm{KBr}+3 \mathrm{H}^{2} \mathrm{SO}^{4}=2 \mathrm{KHSO}^{4}+\mathrm{MnSO}^{4}+2 \mathrm{H}^{2} \mathrm{O}+2 \mathrm{Br}$ $2 \mathrm{KBr}+3 \mathrm{H}^{2} \mathrm{SO}^{4}=2 \mathrm{KHSO}^{4}+\mathrm{SO}^{2}+2 \mathrm{Br}+2 \mathrm{H}^{2} \mathrm{O}$.

e) Mit Kaliumdichromat und cone. Sehwefelsäure destillirt, liefern die Bromide ein braunes, chromfreies Destillat von Brom; auf Zusatz von Ammoniak verschwindet daher die Färbung (vgl. 13. e).

$6 \mathrm{KBr}+\mathrm{K}^{2} \mathrm{Cr}^{2} \mathrm{O}^{7}+7 \mathrm{H}^{2} \mathrm{SO}^{4}=6 \mathrm{Br}+\mathrm{Cr}^{2}\left(\mathrm{SO}^{4}\right)^{3}+4 \mathrm{~K}^{2} \mathrm{SO}^{4}+7 \mathrm{H}^{2} \mathrm{O}$

$$
3 \mathrm{Br}+4 \mathrm{NH}^{4} \cdot \mathrm{OH}=3 \mathrm{NH}^{4} \mathrm{Br}+4 \mathrm{H}^{2} \mathrm{O}+\mathrm{N} \text {. }
$$

\section{Bromsäure, Bromate.}

a) Silbernitrat scheidet weisses, in Salpetersäure schwer, in Ammoniak leicht lösliches Silberbromat: $\mathrm{AgBrO}^{3}$, ab.

b) Mercuronitrat erzeugt sofort einen weissen Niederschlag, wogegen Chlorbaryum und Bleiacetat nur in conc. Bromatlösung, und zwar erst nach längerem Stehen, eine krystallinische Abscheidung hervorrufen.

c) Schwefelsäure, Salzsäure und Salpetersëure scheiden aus Bromatlösung Brom aus.

$$
\begin{gathered}
\mathrm{KBrO}^{3}+\mathrm{HCl}=\mathrm{KCl}+\mathrm{HBrO}^{3} \\
2 \mathrm{HBrO}^{3}=\mathrm{H}^{2} \mathrm{O}+2 \mathrm{Br}+\mathrm{O}^{5} .
\end{gathered}
$$

d) Schwefelvasserstoff führt die Bromate unter Abscheidung von Schwefel in Bromide über.

$$
2 \mathrm{KBrO}^{3}+6 \mathrm{H}^{2} \mathrm{~S}=2 \mathrm{KBr}+6 \mathrm{H}^{2} \mathrm{O}+6 \mathrm{~S} \text {. }
$$
Sauerstoff.

e) Beim Glühen liefern die Bromate im Allgemeinen Bromid und

$$
\mathrm{KBrO}{ }^{3}=\mathrm{KBr}+0^{3} .
$$

f) Auf der Kohle erhitzt, verpuffen die Bromate mit Heftigkeit. 


\section{Jodwasserstoff, Jodide.}

a) Silbernitrat scheidet gelbes, in Salpetersäure und in Ammoniak unlösliches, in Natriumthiosulfat- und in Cyankaliumlösung lösliches Jodsilber: AgJ, ab.

$$
\mathrm{KJ}+\mathrm{AgNO}^{3}=\mathrm{AgJ}+\mathrm{KNO}^{3} .
$$

b) Merlouronitratlösung fällt grüngelbes, in überschüssiger Jodkaliumlösung unter Abscheidung von Quecksilber farblos lösliches Quecksilberjodür: $\mathrm{Hg}^{2} \mathrm{~J}^{2}$ (vgl. S. 15).

c) Quecksilberchlorid scheidet scharlachrothes, in einem Ueberschusse von Jodkalium- und von Quecksilberchloridlösung lösliches Quecksilberjodid: $\mathrm{HgJ}^{2}$, ab.

$$
\begin{gathered}
\mathrm{HgCl}^{2}+2 \mathrm{KJ}=\mathrm{HgJ}^{2}+2 \mathrm{KCl} \\
\mathrm{HgJ}^{2}+\mathrm{KJ}=\left[\mathrm{HgJ}^{2}+\mathrm{KJ}\right] \\
\mathrm{HgJ}^{2}+2 \mathrm{HgCl}^{2}=\left[\mathrm{HgJ}^{2}+2 \mathrm{HgCl}^{2}\right] .
\end{gathered}
$$

d) Bleiacetat fällt pomeranzengelbes Jodblei: $\mathrm{PbJ}^{2}$.

$$
\left(\mathrm{C}^{2} \mathrm{H}^{3} \mathrm{O}^{2}\right)^{2} \mathrm{~Pb}+2 \mathrm{KJ}=\mathrm{PbJ}^{2}+2 \mathrm{C}^{2} \mathrm{H}^{3} \mathrm{KO}^{2} .
$$

e) Mangansuperoxyd und Schwefelsäure, Chlorwasser, Bromwasser, Eisenchlorid, cone. Salpetersäure, conc. Schwefelsüure scheiden aus den Jodiden freies Jod ab, kenntlich an der violetten Farbe des Dampfes, der Blaufärbung eines, mit diesem Dampfe in Berührung gebrachten feuchten Stärkepapiers oder des der jodhaltigen, mit Wasser verdünnten Mischung zugefügten Stärkekleisters, sowie endlich an der Violettfärbung, die es Schwefelkohlenstoff oder Chloroform ertheilt, welche mit der jodhaltigen Mischung geschüttelt werden.

f) Mit Kaliumdichromat und cone. Schwefelsäure destillirt, liefern die Jodide nur freies Jod; das Destillat wird daher durch überschüssiges Ammoniak oder überschüssige Natronlauge entfärbt.

$$
\begin{gathered}
6 \mathrm{KJ}+\mathrm{K}^{2} \mathrm{Cr}^{2} \mathrm{O}^{7}+7 \mathrm{H}^{2} \mathrm{SO}^{4}=6 \mathrm{~J}+\mathrm{Cr}^{2}\left(\mathrm{SO}^{4}\right)^{3}+4 \mathrm{~K}^{2} \mathrm{SO}^{4}+7 \mathrm{H}^{2} \mathrm{O} \\
6 \mathrm{~J}+6 \mathrm{NaOH}=5 \mathrm{NaJ}+\mathrm{NaJO}^{3}+3 \mathrm{H}^{2} \mathrm{O} .
\end{gathered}
$$

g) Palladiumoxydulnitrat erzeugt einen schwarzen Niederschlag von Palladiumjodür: PdJ².

$$
\mathrm{Pd}\left(\mathrm{NO}^{3}\right)^{2}+2 \mathrm{KJ}=\mathrm{PdJ}^{2}+2 \mathrm{KNO}^{3} \text {. }
$$

\section{Jodsäure, Jodate.}

a) Silbernitrat scheidet weisses, in Salpetersäure schwer, in Ammoniak leicht lösliches Silberjodat: $\mathrm{AgJO}^{3}, \mathrm{ab}$.

$$
\mathrm{KJO}^{3}+\mathrm{AgNO}^{3}=\mathrm{AgJO}^{3}+\mathrm{KNO}^{3} \text {. }
$$

b) Chlorbaryum, Bleiacetat und Mereuronitrat erzeugen weisse, in Wasser wenig lösliche Niederschläge.

c) Schwefelwasserstoff und schweflige Säure scheiden, in geringer Menge der Lösung der Jodsäure oder der angesäuerten Lösung der Jodate zugesetzt, Jod ab; auf Zusatz eines Ueberschusses dieser Reductionsmittel verschwindet das abgeschiedene Jod wieder.

$$
\begin{gathered}
2 \mathrm{HJO}^{3}+5 \mathrm{H}^{2} \mathrm{SO}^{3}=2 \mathrm{~J}+5 \mathrm{H}^{2} \mathrm{SO}^{4}+\mathrm{H}^{2} \mathrm{O} \\
2 \mathrm{HJO}^{3}+5 \mathrm{H}^{2} \mathrm{~S}=2 \mathrm{~J}+6 \mathrm{H}^{2} \mathrm{O}+5 \mathrm{~S} .
\end{gathered}
$$

Schmidt, Anleit. z. qualitativen Analyse. 
d) Bei Gegenwart von Jodlkalium wird durch Zusatz von verdünnter Schwefelsäure, Salzsäure, Essigsäure etc. Jod abgeschieden: Braunfärbung; Blaufärbung auf Zusatz von Stärkekleister. $\mathrm{KJO}^{3}+5 \mathrm{KJ}+3 \mathrm{H}^{2} \mathrm{SO}^{4}=6 \mathrm{~J}+3 \mathrm{~K}^{2} \mathrm{SO}^{4}+3 \mathrm{H}^{2} \mathrm{O}$.

e) Beim Glühen zerfallen die Jodate in Jodmetall und Sauerstoff oder in Metalloxyd, Sauerstoff und Jod; die Jodsäure zerfällt hierbei in Jod und Sauerstoff.

$$
\begin{gathered}
\mathrm{KJO}^{3}=\mathrm{KJ}+\mathrm{O}^{3} \\
\mathrm{~Pb}\left(\mathrm{JO}^{3}\right)^{2}=\mathrm{PbO}+2 \mathrm{~J}+\mathrm{O}^{5} .
\end{gathered}
$$
die Chlorate.

f) Auf Kohle erhitzt, verpuffen die Jodate, jedoch schwächer als

\section{Fluorwasserstoff, Fluoride.}

a) Silbernitrat liefert mit löslichen Fluoriden keinen Niederschlag.

b) Bleiacetat fällt weisses, in Salpetersäure lösliches Fluorblei: $\mathrm{PbF}^{2}$.

$$
2 \mathrm{NH}^{4} \mathrm{~F}+\left(\mathrm{C}^{2} \mathrm{H}^{3} \mathrm{O}^{2}\right)^{2} \mathrm{~Pb}=\mathrm{PbF}^{2}+2 \mathrm{C}^{2} \mathrm{H}^{3}\left(\mathrm{NH}^{4}\right) \mathrm{O}^{2} .
$$

c) Chlorbaryum fällt weisses, in Salzsäure lösliches Fluorbaryum: $\mathrm{BaF}^{2}$; Chlorcalcium scheidet gallertartiges, in verdünnten Mineralsäuren schwierig lösliches Fluorcalcium: $\mathrm{CaF}^{2}$, ab.

$$
2 \mathrm{NH}^{4} \mathrm{~F}+\mathrm{CaCl}^{2}=\mathrm{CaF}^{2}+2 \mathrm{NH}^{4} \mathrm{Cl} \text {. }
$$

d) Conc. Schwefelsüure entwickelt in der Wärme Fluorwasserstoff, welcher Glas ätzt, d. h. sich mit der Kieselsäure desselben zu Fluorsilicium: $\mathrm{SiF}^{4}$, verbindet. Wird das Erhitzen in einem Reagensglase vorgenommen, so findet eine Entwicklung von Gasblasen statt, welche die Form von Oeltröpfchen zeigen.

$$
\begin{gathered}
\mathrm{CaF}^{2}+\mathrm{H}^{2} \mathrm{SO}^{4}=\mathrm{CaSO}^{4}+2 \mathrm{HF} \\
\mathrm{SiO}^{2}+4 \mathrm{HF}=\mathrm{SiF}^{4}+2 \mathrm{H}^{2} \mathrm{O} .
\end{gathered}
$$

e) Conc. Schwefelsäure bewirkt bei Gegenwart von Kieselsäure die Bildung von Fluorsilicium: SiF4; leitet man letzteres Gas in Wasser oder durch ein feuchtes Glasrohr oder über einen befeuchteten Glasstab, so findet Abscheidung von gallertartiger Kieselsäure statt, während Kieselfluorwasserstoff: $\mathrm{H}^{2}{ }^{\mathrm{SiF}}{ }^{6}$, in Lösung geht.

$$
\begin{gathered}
2 \mathrm{CaF}^{2}+\mathrm{SiO}^{2}+2 \mathrm{H}^{2} \mathrm{SO}^{4}-2 \mathrm{CaSO}^{4}+2 \mathrm{H}^{2} \mathrm{O}+\mathrm{SiF}^{4} \\
3 \mathrm{SiF}^{4}+3 \mathrm{H}^{2} \mathrm{O}=2 \mathrm{H}^{2} \mathrm{SiF}^{6}+\mathrm{H}^{2} \mathrm{SiO}^{3} .
\end{gathered}
$$

\section{Cyanwasserstoff, Cyanide.}

Salzsäure entwickelt aus der Mehrzahl der Cyanide schon bei gewöhnlicher Temperatur Cyanwasserstoff, welcher sich durch den bittermandelölartigen Geruch kennzeichnet. Einige Cyanide, wie z. B. Quecksilbercyanid, werden erst beim Kochen mit Salzsäure unter Cyanwasserstoffentwickelung zersetzt.

a) Silbernitrat fällt weisses, käsiges Cyansilber: $\mathrm{AgCN}$, welches unlöslich in Wasser und Salpetersäure, löslich in Ammoniak-, Cyankalium- und Natriumthiosulfatlösung, sowie in 
einem kochenden Gemische gleicher Volume conc. Schwefelsäure und Wasser ist.

$$
\begin{gathered}
\mathrm{AgNO}+\mathrm{KCN}=\mathrm{AgCN}+\mathrm{KNO}^{3} \\
\mathrm{AgCN}+\mathrm{NH} \mathrm{H}^{3}=\mathrm{AgCN} \cdot \mathrm{NH}^{3} \\
\mathrm{AgCN}+\mathrm{KCN}=[\mathrm{AgCN}+\mathrm{KCN}] \\
\mathrm{AgCN}+\mathrm{Na}^{2} \mathrm{~S}^{2} \mathrm{O}^{3}=\mathrm{AgNaS} \mathrm{K}^{3}+\mathrm{NaCN} \\
2 \mathrm{AgCN}+\mathrm{H}^{2} \mathrm{SO}^{4}=\mathrm{Ag}^{2} \mathrm{SO}^{4}+2 \mathrm{HCN} .
\end{gathered}
$$

b) Mercuronitrat scheidet, besonders in der Wärme, graues Quecksilber ab.

$$
\mathrm{Hg}^{2}\left(\mathrm{NO}^{3}\right)^{2}+2 \mathrm{KCN}=\mathrm{Hg}+\mathrm{Hg}(\mathrm{CN})^{2}+2 \mathrm{KNO}^{3} .
$$

c) Bleiacetat fällt weisses, in Salpetersäure lösliches Cyanblei: $\mathrm{Pb}(\mathrm{CN})^{2}$.

d) Fügt man zu einer cyanwasserstoffhaltigen oder cyanidhaltigen Lösung zunächst Natronlauge, dann Eisenvitriollösung, nach gelindem Erwärmen etwas Eisenchlorid und endlich Salzsäure im Ueberschusse, so verbleibt ein blauer Niederschlag von Berlinerblau: $\mathrm{Fe}^{7}(\mathrm{CN})^{18}$, während das zunächst gefällte Eisenoxyduloxyd wieder in Lösung geht.

$$
\begin{gathered}
6 \mathrm{NaCN}+\mathrm{FeSO}^{4}=\mathrm{Na}^{4} \mathrm{Fe}(\mathrm{CN})^{6}+\mathrm{Na}^{2} \mathrm{SO} \mathrm{O}^{4} \\
3\left[\mathrm{Na}{ }^{4} \mathrm{Fe}(\mathrm{CN})^{6}\right]+2 \mathrm{Fe}^{2} \mathrm{Cl}^{6}=\mathrm{Fe} e^{4}\left[\mathrm{Fe}(\mathrm{CN})^{6}\right]^{3}+12 \mathrm{NaCl} .
\end{gathered}
$$

e) Mit gelbem Schwefelammonium im Wasserbade eingedampft liefern die Cyanide Rhodanide; letztere kennzeichnen sich durch die blutrothe Färbung, welche Eisenoxydsalze in der mit Salzsäure angesäuerten Lösung des Verdampfungsrückstandes hervorrufen.

$$
\begin{gathered}
\mathrm{KCN}+\left(\mathrm{NH}^{4}\right)^{2} \mathrm{~S}^{2}=\mathrm{KCNS}+\left(\mathrm{NH}^{4}\right)^{2} \mathrm{~S} \\
6 \mathrm{KCNS}+\mathrm{Fe}^{2} \mathrm{Cl}^{6}=\mathrm{Fe}^{2}(\mathrm{CNS})^{6}+6 \mathrm{KCl} .
\end{gathered}
$$

\section{Ferrocyanwasserstoff, Ferrocyanide.}

a) Silbernitrat fällt weisses, in verdünnter Salpetersäure unlösliches, in Ammoniak schwer lösliches, in Cyankalium leicht lösliches Ferrocyansilber: $\mathrm{Ag}^{4} \mathrm{Fe}(\mathrm{CN})^{6}$. Auch in einem siedenden Gemisch gleicher Volume conc. Schwefelsäure und Wasser ist das Ferrocyansilber löslich.

$$
4 \mathrm{AgNO}^{3}+\mathrm{K}^{4} \mathrm{Fe}(\mathrm{CN})^{6}=\mathrm{Ag}^{4} \mathrm{Fe}(\mathrm{CN})^{6}+4 \mathrm{KNO}^{3} .
$$

b) Bleiacetat scheidet weisses Ferrocyanblei: $\mathrm{Pb}^{2} \mathrm{Fe}(\mathrm{CN})^{6}$, welches in verdünnter Salpetersäure unlöslich ist, ab.

c) Kupfersulfal fällt rothbraunes Ferrocyankupfer: $\mathrm{Cu}^{2} \mathrm{Fe}(\mathrm{CN})^{6}$.

d) Eisenoxydsalze scheiden Berlinerblau: $\mathrm{Fe}^{7}(\mathrm{CN})^{18}$, ab.

$$
3 \mathrm{~K}^{4} \mathrm{Fe}(\mathrm{CN})^{6}+2 \mathrm{Fe}^{2} \mathrm{Cl}^{6}=\mathrm{Fe}^{4}\left[\mathrm{Fe}(\mathrm{CN})^{6}\right]^{3}+12 \mathrm{KCl} \text {. }
$$

\section{Ferricyanwasserstoff, Ferricyanide.}

a) Silbernitrat fällt braun-gelbes, in verdünnter Salpetersäure unlösliches, in Ammoniak- und in Cyankaliumlösung, sowie in einem siedenden Gemisch gleicher Volume conc. Schwefelsäure und Wasser lösliches Ferricyansilber: $\mathrm{Ag}^{3} \mathrm{Fe}(\mathrm{CN})^{6}$.

$$
3 \mathrm{AgNO}^{3}+\mathrm{K}^{3} \mathrm{Fe}(\mathrm{CN})^{6}=\mathrm{Ag}^{3} \mathrm{Fe}(\mathrm{CN})^{6}+3 \mathrm{KNO}^{3} \text {. }
$$


b) Bleiacetat ruft keine Fällung hervor; auf Zusatz von Ammoniak findet Abscheidung von gelb-braunem Basisch-Ferricyanblei statt.

c) Kupfersulfat fällt grün-gelbes Ferricyanloup fer: $\mathrm{Cu}^{3} \mathrm{Fe}^{2}(\mathrm{CN})^{12}$

d) Eisenoxydulsalze scheiden Turnbull's Blau: $\mathrm{Fe}^{5}(\mathrm{CN})^{12}$, ab; Eisenoxydsalze verursachen nur eine braun-rothe Färbung. $2 \mathrm{~K}^{3} \mathrm{Fe}(\mathrm{CN})^{6}+3 \mathrm{FeSO}^{4}=\mathrm{Fe}^{3}\left[\mathrm{Fe}(\mathrm{CN})^{6}\right]^{2}+3 \mathrm{~K}^{2} \mathrm{SO}^{4}$.

24. Rhodanwasserstoff, Rhodanide.

a) Silbernitrat fällt weisses, in verdünnter Salpetersäure unlösliches, in Ammoniak schwer lösliches Rhodansilber: AgCNS. $\mathrm{KCNS}+\mathrm{AgNO}^{3}=\mathrm{AgCNS}+\mathrm{KNO}^{3}$.

In einem kochenden Gemisch gleicher Volume conc. Schwefelsäure und Wasser ist das Rhodansilber löslich.

b) Bleiacetat fällt weisses Rhodanblei: $(\mathrm{CNS})^{2} \mathrm{~Pb}$. $2 \mathrm{KCNS}+\left(\mathrm{C}^{2} \mathrm{H}^{3} \mathrm{O}^{2}\right)^{2} \mathrm{~Pb}=(\mathrm{CNS})^{2} \mathrm{~Pb}+2 \mathrm{C}^{2} \mathrm{H}^{3} \mathrm{KO}^{2}$.

c) Eisenoxydsalre bewirken eine blutrothe, durch verdünnte Mineralsäuren nicht verschwindende, beim Schütteln mit Aether in letzteren übergehende Färbung: Eisenrhodanid: $\mathrm{Fe}^{2}(\mathrm{CNS})^{6}$. $6 \mathrm{KCNS}+\mathrm{Fe}^{2} \mathrm{Cl}^{6}=\mathrm{Fe}^{2}(\mathrm{CNS})^{6}+6 \mathrm{KCl}$

25. Chromsäure, Chromate.

a) Silbernitrat fällt rothes Silberchromat: $\mathrm{Ag}^{2}{ }^{2} \mathrm{CrO}^{4}$, löslich in Ammoniak und in erwärmter Salpetersäure.

$\mathrm{K}^{2} \mathrm{CrO}^{4}+2 \mathrm{AgNO}^{3}=\mathrm{Ag}^{2} \mathrm{CrO}^{4}+2 \mathrm{KNO}^{3}$.

b) Bleiacetat scheidet gelbes, in Salpetersäure und in Natronlauge lösliches Bleichromat: $\mathrm{PbCrO}^{4}$, ab. Mit Kallowasser gekocht, nimmt dieser Niederschlag in Folge der Bildung von Basisch-Bleichromat eine rothe Färbung an.

$\left(\mathrm{C}^{2} \mathrm{H}^{3} \mathrm{O}^{2}\right)^{2} \mathrm{~Pb}+\mathrm{K}^{2} \mathrm{CrO}^{4}=\mathrm{PbCrO}^{4}+2 \mathrm{C}^{2} \mathrm{H}^{3} \mathrm{KO}^{2}$

$\mathrm{PbCrO}^{4}+4 \mathrm{NaOH}=\mathrm{Pb}(\mathrm{ONa})^{2}+\mathrm{Na}^{2} \mathrm{CrO}^{4}+2 \mathrm{H}^{*} \mathrm{O}$.

c) Chlorbaryum fallt gelbes Baryumehromat: $\mathrm{BaCrO}^{4}$, unlöslich in Natronlange und in Essigsäure, löslich in Salzsäure und Salpetersäure.

d) Mercuronitrat scheidet ziegelrothes, in Salpetersäure lösliches Mercurochromat: $\mathrm{Hg}^{2} \mathrm{CrO}^{4}$, ab.

e) Mit conc. Salzsäure erhitzt, entwiekeln die Chromate Chlor; gleichzeitig entsteht eine grüne Lösung von Chromchlorid: $\mathrm{Cr}^{2} \mathrm{Cl}^{6}$. $\mathrm{K}^{2} \mathrm{Cr}^{2} \mathrm{O}^{7}+14 \mathrm{HCl}=6 \mathrm{Cl}+\mathrm{Cr}^{2} \mathrm{Cl}^{6}+2 \mathrm{KCl}+7 \mathrm{H}^{2} \mathrm{O}$.

f) Wasserstoffsuperoxyd ruft mit sehr verdünnter Chromsäurelösung oder Chromatlösung, die mit Schwefelsäure angesäuert ist, eine tief blaue Färbung hervor; beim Schütteln mit Aether wird letzterer intensiv blau gefärbt $\left(\mathrm{CrO}^{3}+\mathrm{H}^{2} \mathrm{O}^{2}\right.$ ?).

g) Schwefelwasserstoff reducirt die mit Salzsäure versetzte Chromatlösung unter Abscheidung von Schwefel zu grün gefärbtem Chromoxydsals.

$$
2 \mathrm{~K}^{2} \mathrm{CrO}^{4}+3 \mathrm{H}^{2} \mathrm{~S}+10 \mathrm{HCl}=\mathrm{Cr}^{2} \mathrm{Cl}^{6}+4 \mathrm{KCl}+3 \mathrm{~S}+8 \mathrm{H}^{2} \mathrm{O} .
$$


h) Alkohol und verdiünte Schwefelsäure oder Salssäure reduciren beim Kochen die Chromate unter Grünfärbung zu Chromoxydsalzen. In gleicher Weise wirken schweflige Säure, Oxalsüure, Weinsäure, Zucker ete.

$\mathrm{K}^{2} \mathrm{Cr}^{2} \mathrm{O}^{7}+4 \mathrm{H}^{2} \mathrm{SO}^{4}+3 \mathrm{C}^{2} \Pi^{6} \mathrm{O}=\mathrm{K}^{2} \mathrm{Cr}^{2}\left(\mathrm{SO}^{4}\right)^{4}+3 \mathrm{C}^{2} \mathrm{H}^{4} \mathrm{O}+7 \mathrm{H}^{2} \mathrm{O}$.

i) Vor dem Löthrohre und in der Phosphorsalzperle zeigen die Chromate die Reactionen der Chromoxydsalze (s. S. 7).

\section{Essigsäure, Acetate.}

a) Silbernitrat ruft nur in conc. Lösung der Essigsäure und der Acetate eine weisse, krystallinische Fälung von Silberacetat: $\mathrm{C}^{2} \mathrm{H}^{3} \mathrm{AgO}{ }^{2}$, hervor; letzteres ist in viel Wasser löslich.

$$
\mathrm{AgNO}^{3}+\mathrm{C}^{2} \mathrm{H}^{3} \mathrm{NaO}^{2}=\mathrm{C}^{2} \mathrm{H}^{3} \mathrm{AgO}^{2}+\mathrm{NaNO}^{3} \text {. }
$$

b) Eisenchlorid ruft in der Lösung der noutralen Acetate eine dunkelrothe Färbung hervor, welche auf Zusatz von Salzsäure verschwindet. Beim Kochen wird die dunkelrothe Lösung entfärbt, indem sich Basisch-Ferriacetat als braunrother Niederschlag ausscheidet.

$$
\begin{array}{r}
6 \mathrm{C}^{2} \mathrm{H}^{3} \mathrm{NaO}^{2}+\mathrm{Fe}^{2} \mathrm{Cl}^{6}=\mathrm{Fe}^{2}\left(\mathrm{C}^{2} \mathrm{H}^{3} \mathrm{O}^{2}\right)^{6}+6 \mathrm{NaCl} . \\
\mathrm{Fe}^{2}\left(\mathrm{C}^{2} \mathrm{H}^{3} \mathrm{O}^{2}\right)^{6}+6 \mathrm{HCl}=\mathrm{Fe}^{2} \mathrm{Cl}^{6}+6 \mathrm{C}^{2} \mathrm{H}^{4} \mathrm{O}^{2} \\
\mathrm{Fe}^{2}\left(\mathrm{C}^{2} \mathrm{H}^{3} \mathrm{O}^{2}\right)^{6}+4 \mathrm{H}^{2} \mathrm{O}=\mathrm{Fe}^{2}\left\{\begin{array}{l}
(\mathrm{OH})^{4} \\
\left(\mathrm{C}^{2} \mathrm{H}^{3} \mathrm{O}^{2}\right)^{2}+4 \mathrm{C}^{2} \mathrm{H}^{4} \mathrm{O}^{2} .
\end{array}\right.
\end{array}
$$

c) Mit conc. Schwefelsäure und etwas Alkohol erwärmt, entwickelt sich der Geruch nach Essigäther: $\mathrm{C}^{2} \mathrm{H}^{3}\left(\mathrm{C}^{2} \mathrm{H}^{5}\right) \mathrm{O}^{2}$.

$$
\mathrm{C}^{2} \mathrm{H}^{5} \cdot \mathrm{OH}+\mathrm{H}^{2} \mathrm{SO}^{4}=\mathrm{C}^{2} \mathrm{H}^{5} \cdot \mathrm{HSO}^{4}+\mathrm{H}^{2} \mathrm{O}
$$

$\mathrm{C}^{2} \mathrm{H}^{5} \cdot \mathrm{HSO}^{4}+\mathrm{C}^{2} \mathrm{H}^{3} \mathrm{NaO}^{2}=\mathrm{C}^{2} \mathrm{H}^{3}\left(\mathrm{C}^{2} \mathrm{H}^{5}\right) \mathrm{O}^{2}+\mathrm{NaHSO}^{4}$.

d) Arsenigsäureanhydrid mit vollständig entwässertem Acetat und etwas wasserfreiem Natriumearbonat im Glühröhrchen erhitzt, erzeugt Kakodyloxyd (Arsendimethyloxyd: $\mathrm{As}^{2}\left(\mathrm{CH}^{3}\right)^{4} \mathrm{O}$, kenntlich an dem heftigen, unangenehmen Geruche.

e) Beim Glühen werden die Acetate meist ohne Abscheidung von Kohle zersetzt. Unter Entwickelung von Aceton: $\mathrm{C}^{3} \mathrm{H}^{6} \mathrm{O}$, zum Theil auch von Essigsäure, verbleiben Carbonate, Oxyde oder Metalle als Rückstand.

\section{0xalsäure, 0xalate.}

a) Lösliche Calciumsalze fällen aus wässeriger, essigsaurer oder ammoniakalischer Lösung der Oxalsäure und der Oxalate weisses Calciumoxalat: $\mathrm{C}^{2} \mathrm{O}^{4} \mathrm{Ca}+\mathrm{H}^{2} \mathrm{O}$, löslich in Salzsäure und Salpetersäure, unlöslich in Essigsäure und in Ammoniaksalzlösung.

$$
\mathrm{C}^{2} \mathrm{O}^{4} \mathrm{~K}^{2}+\mathrm{CaCl}^{2}=\mathrm{C}^{2} \mathrm{O}^{4} \mathrm{Ca}+2 \mathrm{KCl} \text {. }
$$

b) Die meisten Metallsalze liefern mit Oxalsäure und den Oxalaten Niederschläge, welche in stärkeren Mineralsäuren löslich sind. 
c) Durch conc. Schwefelsäure werden Oxalsäure und die Oxalate in der Wärme, unter Entwickelung von Kohlensäureanhydrid und Kohlenoxyd, ohne Schwärzung, zersetzt.

$$
\mathrm{H}^{2} \mathrm{C}^{2} \mathrm{O}^{4}+\mathrm{H}^{2} \mathrm{SO}^{4}=\mathrm{H}^{2} \mathrm{SO}^{4}+\mathrm{H}^{2} \mathrm{O}+\mathrm{CO}^{2}+\mathrm{CO} \text {. }
$$

d) Beim Glühen werden die Oxalate unter Entwickelung von Kohlenoxyd, meist ohne erhebliche Schwärzung, in Carbonate verwandelt; einige hinterlassen anch Metalloxyd oder Metall als Rückstand.

\section{Weinsäure, Tartrate.}

a) Lösliche Calciumsalze verursachen in Weinsäurelösung keine Fällung; letztere tritt jedoch ein, sobald die Weinsäure durch eine Base, z. B. Ammoniak, gesättigt wird. Die lösliehen Tartrate geben daher mit Calciumsalzen Fällungen von weissem Calciumtartrat: $\mathrm{C}^{4} \mathrm{H}^{4} \mathrm{CaO}^{6}$. Das Calciumtartrat ist fast unlöslich in Wasser, leicht löslich in Essigsäure, Chlorammoniumlösung, Kali- und Natronlauge.

$$
\begin{gathered}
\mathrm{C}^{4} \mathrm{H}^{4} \mathrm{~K}^{2} \mathrm{O}^{6}+\mathrm{CaCl}^{2}=\mathrm{C}^{4} \mathrm{H}^{4} \mathrm{CaO}+2 \mathrm{KCl} . \\
\mathrm{C}^{4} \mathrm{H}^{4} \mathrm{CaO}^{6}+2 \mathrm{C}^{2} \mathrm{H}^{4} \mathrm{O}^{2}=\mathrm{C}^{4} \mathrm{H}^{6} \mathrm{O}^{6}+\left(\mathrm{C}^{2} \mathrm{H}^{3} \mathrm{O}^{2}\right)^{2} \mathrm{Ca} \\
\mathrm{C}^{4} \mathrm{H}^{4} \mathrm{CaO}^{6}+2 \mathrm{NH} \mathrm{H}^{4} \mathrm{Cl}=\mathrm{C}^{4} \mathrm{H}^{4}\left(\mathrm{NH}^{4}\right)^{2} \mathrm{O}^{6}+\mathrm{CaCl}^{2} \\
\mathrm{C}^{4} \mathrm{H}^{4} \mathrm{CaO}^{6}+2 \mathrm{NaOH}=\mathrm{C}^{4} \mathrm{H}^{2} \mathrm{Na}^{2} \mathrm{CaO}^{6}+2 \mathrm{H}^{2} \mathrm{O} .
\end{gathered}
$$

b) Kallwwasser scheidet, wenn überschüssig zugesetzt, Calciumtartrat: $\mathrm{C}^{4} \mathrm{H}^{4} \mathrm{CaO}^{6}$, ab.

c) Chlorkalium-, geeigneter noch Kaliumacetatlösung, scheidet aus Weinsäurelösung oder der mit Essigsäure angesäuerten Lösung eines Tartrats sofort oder nach einiger Zeit weisses, krystallinisches saures Kaliumtartrat: $\mathrm{C}^{4} \mathrm{H}^{5} \mathrm{KO}^{6}$, ab. In sehr verdünnten Lösungen tritt keine Fällung ein; Reiben der Gefässwände, sowie Zusatz von Alkohol, befördern die Abscheidung.

d) Bleiacetat fällt weisses, in Salpetersäure und in Ammoniak lösliches Bleitartrat: $\mathrm{C}^{4} \mathrm{H}^{4} \mathrm{PbO}^{6}$.

$$
\mathrm{C}^{4} \mathrm{H}^{4} \mathrm{~K}^{2} \mathrm{O}^{6}+\left(\mathrm{C}^{2} \mathrm{H}^{3} \mathrm{O}^{2}\right)^{2} \mathrm{~Pb}=\mathrm{C}^{4} \mathrm{H}^{4} \mathrm{PbO}^{6}+2 \mathrm{C}^{2} \mathrm{H}^{3} \mathrm{KO} \mathrm{O}^{2} \text {. }
$$

e) Silbernitrat scheidet aus der Lösung der Tartrate, nicht dagegen aus der der freien Weinsäure, weisses, in Salpetersäure und in Ammoniak lösliches Silbertartrat: $\mathrm{C}^{4} \mathrm{H}^{4} \mathrm{Ag}^{2} \mathrm{O}^{6}$, ab.

f) Beim Glühen scheiden Weinsäure und die Tartrate, unter Entwickelung eines charakteristischen Geruches nach Caramel, Kohle ab.

g) Erhitzt man eine geringe Menge Weinsäure oder eines Tartrats mit $1 \mathrm{ccm}$ einer Lösung von 1 Thl. Resorcin in etwa 100 Thln. conc. Schwefelsäure auf $125-130^{\circ}$ C., so tritt eine intensiv violettrothe Fürbung auf. Die Gegenwart von Nitraten oder von Nitriten, sowie von Jodiden hindert diese Reaction. 


\section{Zweite Abtheilung.}

Methode der qualitativen Untersuchung von Substanzen, in welchen enthalten sind:

$\begin{array}{ll}\text { Wasser, } & \text { Gold, } \\ \text { Kalium, } & \text { Schwefel, } \\ \text { Natrium, } & \text { Schwefelsäure, } \\ \text { Lithium, } & \text { Salpetersäure, } \\ \text { Ammonium, } & \text { Phosphorsäure, } \\ \text { Calcium, } & \text { Borsäure, } \\ \text { Baryum, } & \text { Kohlensäure, } \\ \text { Strontium, } & \text { Kieselsäure, } \\ \text { Magnesium, } & \text { Chlorwasserstoff, } \\ \text { Aluminium, } & \text { Bromwasserstoff, } \\ \text { Chrom, } & \text { Jodwasserstoff, } \\ \text { Kobalt, } & \text { Fluorwasserstoff, } \\ \text { Nickel, } & \text { Cyanwasserstoff, } \\ \text { Eisen, } & \text { Ferrocyanwasserstoff, } \\ \text { Zink, } & \text { Ferricyanwasserstoff, } \\ \text { Mangan, } & \text { Rhodanwasserstoff, } \\ \text { Quecksilber, } & \text { Essigsäure, } \\ \text { Silber, } & \text { Oxalsäure, } \\ \text { Kupfer, } & \text { Weinsäure, } \\ \text { Blei, } & \text { Kohle, } \\ \text { Wismuth, } & \text { Schweflige Säure, } \\ \text { Cadmium, } & \text { Unterschweflige Säure, } \\ \text { Arsen, } & \text { Salpetrige Säure, } \\ \text { Antimon, } & \text { Unterchlorige Säure, } \\ \text { Zinn, } & \text { Chlorsäure, } \\ \text { Platin, } & \text { Bromsäure, } \\ & \text { Jodsäure, } \\ & \end{array}$

Bei der Ausführung einer qualitativen Analyse suche man sich zunächst durch eine Vorprüfung über die Natur der betreffenden Substanz zu orientiren. Die Resultate dieser Vorprüfung sind in den meisten Fällen geeignet, Anhaltspunkte und Fingerzeige für die Ausführung der eigentlichen Analyse zu liefern. Liegen Lösungen zur Untersuchung vor, so dampfe man einen kleinen Theil derselben bei mässiger Wärme ein und verwende den Rückstand zur Vorprüfung. 


\section{Vorprüfung.}

1. Prüfung im Glühröhrchen.

Ein erbsengrosses Stück der zu untersuchenden Substanz werde in einem engen, dünnwandigen, unten zugeschmolzenen, etwa $12 \mathrm{~cm}$ langen Röhrchen zunächst gelinde ${ }^{1}$ ), dann stärker, bis zum Glühen, erhitzt und werden die dabei auftretenden Erscheinungen beobachtet:

a) Abgabe von Wasser: Krystallwasser und hygroskopische Feuchtigkeit entweichen und setzen sich als Hauch oder in Tröpfchen an den oberen, kälteren Theilen des Röhrchens ab. Häufig tritt gleichzeitig eine Farbenver:̈nderung der Substanz, bisweilen auch ein Aufschwellen, Schmelzen, Verknistern etc. ein.

b) Abscheidung von Kohle: organische Verbindungen; gleichzeitig findet Entwickelung empyreumatischer Dämpfe statt.

c) Entwickelung von Dämpfen:

a. Farblose Dämpfe sind mit feuchtem Lackmuspapier auf ihre Reaction zu prüfen; Sauerstoff (Superoxyde, Chlorate, Quecksilberoxyd) ist durch Entflammung eines glimmenden Spans zu kennzeichnen. Brom.

ß. Rothbraune Dämpfe: Untersalpetersäure (Nitrate),

$\gamma$. Violette Dämpfe: Jod.

d) Geruch:

$\alpha$. Nach Ammoniak: Ammoniaksalze, Cyanverbindungen.

B. Nach schweflig. Säure: Sulfide, Sulfite u. ev. Sulfate.

$\gamma$. Nach Knoblauch: Arsenverbindungen.

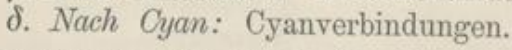

e) Sublimate sind durch Zerschneiden des Glühröhrchens von dem Glührückstande zu trennen und näher zu charakterisiren:

$\alpha$. Weisses Sublimat: Mercuro-, Mercurisalze, Ammoniaksalze, Arsenigsäureanhydrid, Antimonoxyd. Das Sublimat werde mit Natronlauge befeuchtet. Mercurosals: Schwärzung; Mercurisalx: gelbrothe Färbung; Ammoniaksals: Ammoniakentwickelung; Arsenigsäureanhydrid und Antimonoxyd erleiden kaum eine Veränderung (weitere Kennzeichnung auf der Kohle).

$\beta$. Gelbes Sublimat: Quecksilberjodid (bei der Berührung mit einem Glasstab roth werdend); Arsensulfid (in Ammoniak, Natronlauge etc. löslich).

1) Sollten sich hierbei Wassertröpfchen an den kälteren Theilen des. Röhrchens absetzen, so sind dieselben vor dem stärkeren Erhitzen mit Fliesspapier sorgfältig zu entfernen. 
$\gamma$. Rothgelbes Sublimat: Antimonsulfid (in Salzsäure und Schwefelammonium löslich); basische Quecksilbersalze (Schwefelammonium schwärzt).

d. Braungelbes Sublimat: Schwefel (in der Wärme braune Tröpfehen bildend).

e. Schwarzes Sublimat: Quecksilber (Kügelchen); Arsen (braunschwarzer, glänzender Spiegel); Antimon (schwarzer, glänzender Spiegel); Jod (violetter Dampf).

\section{Prüfung auf der Kohle.}

Eine erbsengrosse Menge der zu untersuchenden Substanz, innig gemengt mit der $2-3$ fachen Menge entwässerten Natriumcarbonats und mit wenig Wasser zu einer plastischen Masse angefeuchtet, werde in einem Grübchen eines flachen Stückes Holzkohle mittelst des Löthrohrs einige Zeit in der reducirenden Flamme zum Schmelzen erhitzt ${ }^{1}$ ). Regulinische Metalle sind ohne Natriumcarbonatzusatz zu erhitzen. Die Schwermetallverbindungen werden hierbei zu Metallen (theils mit, theils ohne Oxydbeschlag) reducirt; die Erdmetallverbindungen liefern weisse, ungeschmolzene Massen; die Alkaliverbindungen ziehen sich während des Schmelzens in die Kohle ein.

\section{a. Metallkörner.}

Blei: weiss, ductil; gelber Beschlag.

Wismuth: weiss, spröde; gelber Beschlag.

Zinn: weiss, ductil; weisser Beschlag.

Silber: weiss, ductil; kein Beschlag.

Antimon: weiss, häufig von einem Krystallnetz $\left(\mathrm{Sb}^{2} \mathrm{O}^{3}\right)$

umgeben, spröde; starker weisser Beschlag, in der oxydirenden Flamme verschwindend ${ }^{2}$ ).

Gold: gelb, ductil; kein Beschlag.

Kupfer: roth, ductil; kein Beschlag.

ק. Graue, ungeschmolzene Massen, ohne Beschlag.

Platin, Eisen, Mangan, Kobalt, Nickel.

$$
\gamma \text {. Beschläge ohne Metallkorn. }
$$

Zink: weisser Beschlag, in der Hitze gelb; in der oxydirenden Flamme beständig, in der reducirenden Flamme verschwindend. Mit Kobaltnitratlösung durchfeuchtet und

1) Die Holzkohle ist unter einem Winkel von $45^{\circ}$ derartig zu halten, dass ein event. sich bildender Beschlag auf der Kohle ablagern kann.

2) Bei Anwendung von Natriumearbonat tritt meist nur ein starker weisser Beschlag auf; durch Schmelzen mit Cyankalium kann dagegen leicht ein Metallkorn erhalten werden. 
von Neuem mit der Löthrohrflamme erhitzt, färbt sich der Beschlag grün.

Cadmium: braunrother Beschlag.

$\delta$. Weder Metallkorn, noch Beschlag.

Arsen: Knoblauchgeruch.

Quecksilber.

ع. Weisse, ungeschmolzene Massen (Erden).

Bleibt auf der Kohle eine weisse, ungeschmolzene Masse zurück, so pflegt man zur weiteren Charakterisirung diese weissen Massen oder eine neue Probe der Substanz mit Kobaltnitrat zu durchfeuchten und von Neuem in der Oxydationsflamme zu glühen. Es liefert hierbei:

Thonerde: blaue Massen ${ }^{1}$ ); Magnesia: fleischfarbene Massen; Calcium-, Baryum- und Strontiumverbindungen: graue Massen.

Von anderen Oxyden (Beschlägen) färben sich bei obiger Behandlung:

Zinkoxyd: grün; Zinnoxyd: blaugrün; Antimonoxyd: schmutzig-grün.

\section{ל. Farbe der Schmelze.}

Grïne Schmelze: Chromverbindungen;

Gelbe bis braune Schmelze (Hepar): schwefelhaltige Verbindungen; auf einer Silbermünze zu prüfen (s. S. 24).

3. Prüfung in der Phosphorsalzperle.

Ein wenig Natrium-Ammoniumphosphat werde am Oehre eines dünnen Platindrahtes zunächst in dem untersten Theil des Flammensaumes, schliesslich in der Flammenspitze bis zum ruhigen Schmelzen erhitzt, alsdann eine sehr kleine Menge der zu untersuchenden Substanz an die aus Natriummetaphosphat: $\mathrm{NaPO}^{3}$, bestehende klare Perle gebracht, letztere alsdann in der Oxydationsflamme, und nachdem die hierbei auftretenden Erscheinungen beobachtet sind, schliesslich in der reducirenden Flamme (mittelst des Löthrohres) anhaltend erhitzt. Durch Zusatz von etwas Stanniol wird die Reduction sehr erleichtert.

Die charakteristische Färbung der Phosphorsalzperlen tritt häufig erst beim vollständigen Erkalten hervor.

1) Diese Reaction ist jedoch nicht beweisend, da auch manche Silicate und Phosphate, sowie auch Borate und Arsenate unter obigen Bedingungen blaue Massen liefern können. 
$\alpha$. Färbung in der Oxydationsflamme.

Farblos: Zink, Cadmium, Blei, Wismuth, Antimon, Zinn, die alkalischen Erden und Erdmetallsalze (bei starker Sättigung häufig trübe), Molybdän, Wolfram, Tantal, Niob, Titan.

Gelb: Eisenoxyd (in der Hitze rothgelb, in der Kälte gelb bis farblos), Nickel (ähnlich wie Eisen), Uran (beim Erkalten gelbgrün), Cer, Vanadin.

Grün: Kupfer (blaugrün), Chrom, Uran (jedoch nur in der Kälte, und zwar gelbgrün).

Blau: Kobalt, Kupfer (besonders nach dem Erkalten).

Violett: Mangan, Didym.

$\beta$. Färbung in der Reductionsflamme.

Farblos: Die alkalischen Erden und Erdmetallsalze (bei starker Sättigung häufig trübe), Mangan, Zinn, Cer.

Gelb: Eisenoxyd (in der Hitze), Titan (in der Hitze).

Grün: Chrom, Uran, Vanadin, Molybdän.

Blau: Kobalt, Wolfram (besonders auf Zusatz von etwas Stanniol), Niob (blauviolett).

Violett: Titan, Niob, Didym.

Roth: Kupfer (trübe, undurchsichtig), Titan, Niob, Wolfram und Didym bei Gegenwart von Eisen.

Grau, ) Cadmium, Silber, Blei, Wismuth, Antimon, Zink, trübe: J Nickel (besonders auf Zusatz von Stanniol).

Bei Anwesenheit mehrerer, die Phosphorsalzperle färbender Metallverbindungen verdecken sich die Einzelfärbungen mehr oder minder vollständig.

Die Phosphorsalzperle dient ferner zum Nachweise der Kieselsäure und der Silicate. Kieselsäure wird von der glühenden Phosphorsalzperle nicht gelöst, sondern bewegt sich in derselben als ein durchscheinendes Wölkchen - Kieselsäurcskelett - In gleicher Weise verhalten sich die Silicate, da aus denselben Kieselsäure in der schmelzenden Phosphorsalzperle ausgeschieden wird.

Aehnliche Erscheinungen wie in der Phosphorsalzperle treten auch im Allgemeinen in der Boraxperle $\left(\mathrm{Na}^{2} \mathrm{~B}^{4} \mathrm{O}^{7}\right)$ auf.

\section{Färbung der Flamme.}

Eine kleine Menge der zu untersuchenden Substanz werde mit Salzsäure oder Schwefelsäure durchfeuchtet und am Oehre eines frisch ausgeglühten, dünnen Platindrahts in den Schmelzraum der Flamme gebracht. Die Flamme wird gefärbt durch die Salze des 


\section{4}

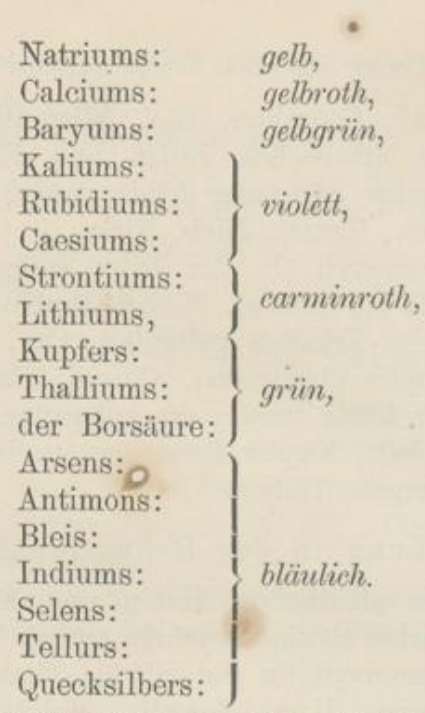

Bei Anwesenheit mehrerer obiger Verbindungen verdecken sich die Einzelfärbungen mehr oder minder.

\section{Prüfung auf Fluor.}

a) Eine Probe der zu untersuchenden Substanz werde in einem trockenen Reagensglase mit der $5-6$ fachen Menge conc. Schwefelsäure erwärmt. Bei Gegenwart eines Fluormetalls findet • Entwicklung von Gasblasen statt, die grosse Aehnlichkeit mit Oeltröpfchen zeigen. Das entwickelte Gas, welches sich langsam an den Wandungen des Reagensglases emporzieht, ruft auf einem eingesenkten, mit Wasser befeuchteten Glasstab einen weissen Ueberzug von ausgeschiedener Kieselsäure hervor.

b) Eine Probe der zu untersuchenden Substanz werde in einem Platin- oder Bleitiegel mit cone. Schwefelsäure zum dünnen Brei angerührt, der Tiegel mit einer Glasplatte bedeckt, in deren Wachsüberzug mittelst eines gespitzten Hölzchens Schriftzüge eingegraben sind, und die Mischung hierauf einige Zeit gelinde erwärmt. Bei Anwesenheit von Fluormetallen erseheinen die Schriftzüge, nach Entfernung des Wachses, in das Glas eingeätzt.

\section{Prüfung auf Cyanverbindungen.}

Fine Probe der zu untersuchenden Substanz werde mit überschüssiger Natronlauge von etwa 10 Proc., der einige Tropfen Chlornatriumlösung zugefügt sind, unter Ergänzung des verdampfenden Wassers einige Zeit in einem Porzellanschälchen gekocht und ein Theil des heissen alkalischen Filtrats (F) mit 
einigen Tropfen Ferrosulfatlösung (bis zur bleibenden grünschwarzen Färbung), dann mit einigen Tropfen Ferrichloridlösung, sowie endlich die noch alkalisch reagirende Mischung mit Salzsäure bis zur stark sauren Reaction versetzt. Entsteht eine blutrothe Färbung ${ }^{1}$ ), so sind Rhodanverbindungen, entsteht eine blaugrüne Färbung oder beim Stehen ein blauer Niederschlag, so sind Cyanverbindungen irgend welcher Art vorhanden, und umgekehrt.

Sollte auf Zusatz der Salzsäure keine Klärung obiger Mischung eintreten, bez. durch Salzsäure allein bereits eine Ausscheidung (Schwefelantimon etc.) aus dem alkalischen Filtrate (F) erfolgen, so säure man, zur Prüfung auf Rhodan- und Cyanverbindungen im Allgemeinen, einen anderen Theil dieses Filtrates (F) (nach dem Erkalten) mit Salzsäure an, filtrire den entstandenen Niederschlag $a b$ und prüfe dann dieses Filtrat auf Cyanverbindungen. $\mathrm{Zu}$ diesem Zwecke mache man dasselbe mit Natronlauge wieder stark alkalisch, erwärme es mit einigen Tropfen Ferrosulfatlösung, füge hierauf etwas Eisenchloridlögung und schliesslich Salzsäure im Ueberschuss hinzu (vgl. oben).

Zur Auffindung der verschiedenen Arten von Cyanverbindungen verwende man den Rest des alkalischen Filtrats (F) oder man koche eine neue Probe der zu untersuchenden Substanz mit Natronlauge, der etwas Chlornatriumlösung zugefügt ist, -filtrire, theile das Filtrat (F) in 4 Theile und prüfe diese in folgender Weise:

a) Ferrocyanide: Eisentchloridlösung ruft in der zuvor mit Salzsäure angesänerten und nöthigenfalls filtrirten, klaren Flüssigkeit (F) eine Blaufärbung oder einen blauen Niederschlag hervor.

b) Ferricyanide: Ferrosulfatlösung veranlasst in der zuvor mit Salzsäure angesäuerten und nöthigenfalls filtrirten, klaren Flüssigkeit (F) eine Blaufärbung oder einen blauen Niederschlag. Sind Ferrocyanverbindungen gefunden, so lasse man den durch überschüssiges Eisenchlorid entstandenen Niederschlag absetzen, filtrire und prüfe dann erst das Filtrat hiervon auf Ferricyanverbindungen mittelst Ferrosulfat.

c) Rhodanide: Eisenchloridlösung ruft in der zuvor mit Salzsäure angesäuerten und nöthigenfalls filtrirten, klaren Flüssigkeit (F) eine blutrothe Färbung hervor. Sind Ferroeyanverbindungen gefunden, so lasse man den durch überschüssiges Eisenchlorid entstandenen Niederschlag absetzen, filtrire und beobachte die Färbung, des Filtrats.

1) Die bei längerem Kochen der Flüssigkeit nicht verschwindet, bezüglich auf erneuten Zusatz von Eisenchloridlösung wiederkehrt und beim Sehütteln mit Aether meist in den letzteren übergeht (Untersehied von gelöstem Jod). 
d) Cyanide: Man füge zu der stark alkalischen Flüssigkeit (F) etwas Ferrosulfatlösung hinzu, erwärme einige Zeit, setze dann einige Tropfen Eisenchloridlösung zu und säure endlich die schwarzbraune Mischung mit Salzsäure stark an: Blaufärbung oder blauer Niederschlag. - Sind Rhodanide neben Cyaniden vorhanden, so lasse man die schliesslich mit Salzsäure angesänerte, in diesem Falle tief roth gefärbte Flüssigkeit absetzen, filtrire alsdann und wasche das Filter mit Wasser aus. Das bei Gegenwart von Cyan gebildete Berlinerblau bleibt dann als blaner Anflug auf dem Filter zurück. Sind Ferro- oder Ferricyanide gefunden, so sind dieselben durch einen Ueberschuss von Eisenchlorid- bezw. Ferrosulfatlösung zuvor zu entfernen; man benutze daher zum Nachweis der Cyanide die Filtrate von den Proben a oder b, mache diese mit Natronlauge wieder stark alkalisch und verfahre wie unter $d$ angegeben ist.

Ueber den Nachweis von Cyan bei Gegenwart von Quecksilber s. Prüfung auf Säuren S. 63. 


\section{Eigentliche Analyse.}

\section{Auflösung oder Aufsehliessung der Substanz.}

Nach beendeter Vorprüfung ist die zu untersuchende Substanz zunächst in Lösung zu bringen. Je nach der Natur der Substanz (gekennzeichnet durch die Vorproben) ist die Art der Auflösung eine verschiedene; sie geschieht nach den unter 1,2, $3,4,5,6,7,8$ und 9 angegebenen Verfahren.

\section{Oxyde, Salze ete.}

(Gewöhnliche Art der Auflösung.)

a) Eine erbsengrosse Menge der Substanz werde in einem Reagensglase mit etwa $1-1,5 \mathrm{~cm}$ Wasser geschüttelt und falls nicht sofortige Lösung eintritt, damit gekocht. Wird auf die eine oder die andere Weise eine vollständige Auflösung erzielt, so behandle man $2-3 \mathrm{~g}$ der $\mathrm{zu}$ untersuchenden Substanz in der gleichen Weise und prüfe die Lösung nach II (S. 53).

b) War durch Kochen mit Wasser keine Lösung erzielt, so füge man zu der gleichen Probe etwas Salısüure und erhitze eventuell abermals zum Kochen. Findet hierbei eine vollständige Lösung statt, so behandle man $2-3 \mathrm{~g}$ der zu untersuchenden Substanz in der gleichen Weise nnd prüfe die Lösung nach Gruppe B (Tab. I). Flüchtige Säuren werden hierbei entweichen:

Kohlensäure: geruchlos; braust auf, trübt sofort Barytwasser (Glasstab, der in Barytwasser eingetaucht ist).

Schwefelwasserstoff: am Geruch und an der Schwärzung von Bleipapier zu erkennen.

Cyanwasserstoff: am Geruch nach Bittermandelöl, sowie durch die Vorproben (S. 44) zu erkennen.

Sehweflige Säure: am Geruch und an der Bläuung des Jodsäurestärkepapiers zu erkennen (s. S. 25).

Chlor, Brom, Jod können ebenfalls unter Umständen entweichen; durch Farbe, Geruch etc. leicht zu erkennen.

c) Wurde durch Kochen mit verdünnter Salzsäure keine Lösung erzielt, so versuche man eine neue Probe der zu untersuchenden Substanz in verdünnter Salpetersäure zu lösen. 
Die Abscheidung eines gelben oder grauen, zusammengeballten Rückstandes: Schwefel, deutet auf die Anwesenheit eines Schwefelmetalls hin. Derartig abgeschiedener Schwefel kennzeichnet sich nach dem Auswaschen dadurch, dass er beim Erhitzen auf einem Porzellanscherben ganz oder theilweise, unter Entwickelung von Schwefligsäureanhydrid, mit blauer Flamme verbrennt.

Besteht das Ungelöste im Wesentlichen nur aus Schwefel, so ist die Substanz als gelöst zu betrachten. Ist somit durch verdünnte Salpetersäure eine vollständige Lösung der zu untersuchenden Substanz bewirkt worden, so behandle man $2-3 \mathrm{~g}$ davon in der gleichen Weise, dampfe alsdann die ervielte Lösung auf ein leleines Volum ein, verdünne den hierdurch von Salpetersüureüberschuss möglichst befreiten Rückstand mit Wasser und untersuche diese Lösung nach Gruppe A (S. 56). Eine durch den Wasserzusatz etwa eintretende Trübung ist zuvor durch Erwärmen, nöthigenfalls unter nochmaligem Zusatz von wenig Salpetersäure, zu beseitigen.

d) Ist weder durch Wasser, noch durch verdünnte Salzsäure oder Salpetersäure eine vollständige Lösung erzielt, so erwärme man $2-3 \mathrm{~g}$ der zu untersuchenden Substanz mit Königswasser (3 Theile Salzsäure, 1 Theil Salpetersäure). Wird hierdurch eine vollständige Lösung bewirkt, so dampfe man dieselbe auf ein lleines Volum ein, verdünne den hierdurch von Süureüberschuss möglichst befreiten Rückstand mit Wasser und untersuche diese Lösung, ohne auf eine durch den Wasserzusatz entstandene Trübung besondere Rücksicht $\mathrm{zu}$ nehmen, nach Gruppe B (Tab. I). erzielt,

Wird auch durch Königswasser keine vollständige Lösung

die Abscheidung eines gelben oder grauen Rückstandes deutet auch hier auf das Vorhandensein eines Schwefelmetalles hin. Sollte dieser abgeschiedene Schwefel noch andere Substanzen einschliessen, so wasche man denselhen aus, verflüchtige ihn nach dem Trocknen durch Erhitzen auf einem Porzellanscherben und behandle den Rüekstand abermals mit Königswasser. Die hierdurch noch erzielte Lösung füge man zu der früher erhaltenen, das etwa ungelöst bleibende untersuehe man nach III (Tab. VI),

so lasse man die Mischung absetzen, giesse die Flüssigkeit möglichst klar von dem Ungelösten durch ein Filter ab und behandle den Rückstand von Neuem mit Königswasser.. Nach dem Absetzen filtrire man abermals, sammele das Ungelöste auf dem nämlichen Filter, wasche es zunächst mit salzsäurehaltigem, dann mit reinem Wasser aus und untersuche es als ,unlöslichen Rïckstand" nach III (Tab. VI).

Die von dem unlöslichen Rückstand abfiltrirten, mit einander gemischten Lösungen werden auf ein kleines Volum ein- 
gedampft, der hierdurch von Säureüberschuss möglichst befreite Rückstand mit Wasser verdünnt und die Lösung, ohne auf eine durch den Wasserzusatz entstandene Trübung (ev. von BasischChlorwismuth, Basisch-Chlorantimon, Chlorblei herrührend) Rücksicht zu nehmen, nach Gruppe B (Tab. I) untersucht.

\section{Metalle, Legirungen, Schwefelmetalle, Kiese, Blenden.}

Obige Untersuchungsmaterialien, welche sich meist schon in ihrem Aeusseren, sowie auch durch die Vorproben kennzeichnen, werden in möglichst zerkleinertem Zustande mittelst Königswasser nach dem unter $1 \mathrm{~d}$. angegebenen Verfahren (entweder ganz oder zum Theil) in Lösung gebracht.

\section{Fluormetalle.}

Hat die Fluorreaction bei den Vorproben ein positives Resultat ergeben, so rühre man die Menge der fein gepulverten Substanz, welche zur Prüfung auf die Basen dienen soll $(2-3 \mathrm{~g})$, in einem Platintiegel mit conc. Schwefelsäure zu einem dünnen Breie an und erhitze die Mischung anfänglich gelinde, schliesslich einige Zeit so stark, dass dichte weisse Nebel von Schwefelsäurehydrat entweichen. Der auf diese Weise von Fluor befreite Rückstand werde hierauf behufs Auflösung nach den unter $1 \mathrm{a}$, $\mathrm{b}$, c oder d angegebenen Methoden behandelt.

\section{Cyanide, Rhodanide.}

Sind Cyanide oder Rhodanide bei den Vorproben gefunden worden, so muss die Substanz, welche zur Untersuchung auf die Basen dienen soll $(2-3 \mathrm{~g})$, vor der Auflösung, zur Entfernung der Cyan- oder Rhodanwasserstoffsäure, einige Zeit lang mit Salpetersäure oder mit Königswasser gekocht werden. Sollte hierdurch die Substanz nicht bereits vollständig in Lösung gegangen sein, so werde das Ungelöste nach dem unter $1 \mathrm{~d}$ erörterten Verfahren weiter behandelt. Die erzielte Lösung ist durch Eindampfen von Säureüberschuss möglichst zu befreien und alsdann in der üblichen Weise nach Gruppe $\mathbf{A}$ bezüglich Gruppe B zu untersuchen.

\section{Ferrocyanide, Ferricyanide.}

Ist durch die Vorproben die Anwesenheit eines Ferrocyanids oder Ferricyanids constatirt worden, so rühre man die Menge der feingepulverten Substanz, welche zur Prüfung auf die Basen dienen soll $(2-3 \mathrm{~g})$, mit conc. Schwefelsäure in einem Porzellan- 
oder Platinschälchen zu einem dünnen Brei an und erhitze die Mischung so lange, bis weisse Nebel von Schwefelsäurehydrat zu entweichen beginnen ${ }^{1}$ ) und bis eine herausgenommene, mit Wasser verdünnte Probe, auf Zusatz von Ferrichlorid- bezw. Ferrosulfatlösung, nicht mehr blau gefärbt wird. Der auf diese Weise von Ferro- und Ferricyaniden befreite Rückstand ist alsdann nach $1 \mathrm{a}, \mathrm{b}$, $\mathrm{c}$ oder $\mathrm{d}$ in Lösung überzuführen und diese nach Gruppe $\mathbf{A}$ bezüglich Gruppe $\mathbf{B}$ zu untersuchen.

\section{Silicate.}

Silicate kennzeichnen sich durch ihr Verhalten in der Phosphorsalzperle (Kieselsäureskelett, s. S. 43), sowie häufig auch schon durch ihre physikalischen Eigenschaften.

Die Trennung der Kieselsäure von den betreffenden Basen, mit denen sie in künstlichen und natürlichen Silicaten vereinigt ist, kann je nach der Natur derselben verschieden geschehen. Alle Silicate müssen jedoch vor der Aufschliessung auf das Feinste gepulvert sein.

$\alpha$. Ein Theil der wasserhaltigen Silicate (Zeolithe), der Orthound Metasilicate (z. B. Olivin, Wollastonit), sowie die meisten Schlacken und alle in Wasser löslichen kieselsauren Salze lassen sich schon durch Säuren vollständig zerlegen. Zu diesem Zwecke erwärme man das fein gepulverte Silicat so lange mit cone. Salzsäure, bis eine vollständige Zerlegung eingetreten, die sandige Beschaffenheit also verschwunden ist. Hierauf dampfe man, zur Ueberführung der theilweise löslichen galleitartigen Kieselsäure in unlösliche amorphe Kieselsäure, die Flüssigkeit unter Umrühren im Wasserbade oder auf der Asbestpappe zur staubigen Trockne ein, befeuchte dann den Rückstand gleichmässig mit conc. Salzsäure (um basische Salze wieder zu lösen), lasse die Masse kurze Zeit stehen und ziehe sie endlich mit Wasser aus. Die von der abgeschiedenen Kieselsäure abfiltrirte Lösung ist hierauf in der üblichen Weise zu untersuchen.

Bei bleihaltigen Silicaten ist die Anwendung der Salpetersäure an Stelle der Salzsäure vorzuziehen.

$\beta$. Die durch die Säuren nur unvollkommen oder gar nicht aufschliessbaren Silicate werden gewöhnlich durch Schmelzen mit Natriumcarbonat zerlegt. $\mathrm{Zu}$ diesem Behufe mische man 1 Thl. des feinen Silicatpulvers in einem Platintiegel mit 4 Thln.

1) Ein $z u$ starkes und $z u$ langes Erhitzen mit Schwefelsäure ist zur Verhütung einer eventuelien Verflüchtigung von Quecksilberchlorid, Arsenchlorid' ete. zu vermeiden. 
eines Gemenges aus wasserfreiem Natrium- und Kalcinmearbonat zu gleichen Theilen, erhitze die Mischung bis zum ruhigen Schmelzen und erhalte sie hierin $10-15$ Minuten lang. Die erkaltete Schmelze werde hierauf zerrieben, mit Wasser aufgeweicht und mit Salzsäure im Ueberschuss, wie unter $\alpha$. angegeben ist, eingedampft.

$\gamma$. Sind in dem zu untersuchenden Silicate Alkalien enthalten (häufig schon durch die Flammenfärbung zu erkennen, welche das mit Salzsäure oder Schwefelsäure durchfeuchtete Silicatpulver am Platindrahte hervorruft), so schliesse man zu deren Auffindung eine besondere Probe durch Glühen mit Baryum- oder Calciumcarbonat oder durch Behandeln mit Fluorammonium auf.

$\mathrm{Zu}$ diesem Zwecke erhitze man das mit der 6-8fachen Menge alkalifreien Baryum- oder Caleiumcarbonats innig gemengte Silicat eine halbe Stunde lang im Gebläse oder im Hempel'schen Glühofen, zerreibe hierauf die erkaltete, zusammengesinterte Masse, digerire dieselbe mit Ammoniumcarbonatlösung und verwende alsdann das Filtrat zur Prüfung auf Alkalien. Dasselbe werde zu diesem Behufe eingedampft, der Rückstand durch Glühen von Ammoniaksalzen befreit und letzterer schliesslich in der üblichen Weise auf Alkalimetalle geprüft.

Zur Aufschliessung mit Fluorammonium menge man das feine Silicatpulver in einem Platintiegel mit der 8fachen Menge Fluorammonium, füge einige Tropfen Wasser zu, um die Mischung in einen gleichmässigen Brei zu verwandeln, und erwärme im Wasserbade. Ist die Masse wieder trocken geworden, so werde sie vorsichtig auf directer Flamme bis zur beginnenden schwachen (dunklen) Rothgluth erhitzt und darin so lange erhalten, als noch Dämpfe von Ammoniaksalz etc. entweichen. Die als Fluoride zurückbleibenden Metalle sind alsdann durch Erhitzen mit conc. Schwefelsäure von Fluor zu befreien (siehe 3., S. 49) und der Rückstand hierauf in der üblichen Weise zur Prüfung auf die Basen zu verwenden.

An Stelle des Fluorammoniums kann auch conc. Flusssäure zur Aufschliessung der Silicate dienen. Zu diesem Zwecke übergiesse man das feine Silicatpulver in einem Platintiegel mit einem Gemisch gleicher Volume Wasser und conc. Schwefelsäure, setze dann reine conc. Flusssäure zu und erwärme unter Umrühren mit einem Plätinspatel im Wasserbade. Sollte nach einiger Zeit noch keine vollständige Lösung erzielt sein, so lasse - man erkalten, füge von Neuem Flusssäure zu und erwärme bis sich alles löst. Hierauf erhitze man stärker, um die Schwefelsäure zum grossen Theil zu verjagen und untersuche endlich den aus Sulfaten bestehenden Rückstand in der üblichen Weise. 


\section{Chromoxyd, Chromeisenstein, Eisenoxyd, Aluminiumoxyd.}

Chromoxyd und Chromeisenstein kennzeichnen sich durch die Grünfärbung der Phosphorsalzperle, Eisenoxyd durch die physikalischen Eigenschaften, Aluminiumoxyd durch die blaue unschmelzbare Masse, welche nach dem Befeuchten mit Kobaltnitratlösung und dem darauffolgenden Glühen auf der Kohle resultirt.

Um vorstehende Oxyde, die im geglühten Zustande in Säuren unlöslich sind, in Lösung überzuführen, schmelze man dieselben im feingepulverten Zustande im Platintiegel mit der 10 fachen Menge sauren Kaliumsulfats und löse dann die aus Sulfaten bestehende Schmelze nach dem Erkalten in Wasser oder in Salzsäure auf.

Chromeisenstein wird am besten derartig aufgeschlossen, dass man obiger Schmelze mit saurem Kaliumsulfat noch eine solche mit Natriumcarbonat und Salpeter folgen lässt. Zu diesem Zwecke lasse man die Schmelze mit saurem Kaliumsulfat, nachdem sie sich längere Zeit, unter häufigem Umrühren mit einem Platindrahte, im glühenden Flusse befunden hat, erkalten, füge wasserfreies Natriumcarbonat (die Hälfte vom angewendeten $\left.\mathrm{KHSO}^{4}\right) \mathrm{zu}$, schmelze von Neuem und trage nach und nach eine dem Natriumcarbonat gleiche Menge Salpeter ein. Die nach längerem Schmelzen resultirende Masse giebt an Wasser das gebildete Kaliumchromat ab, während das Eisenoxyd im Rückstande verbleibt, dem es durch Salzsäure entzogen werden kann.

\section{Die natürlichen Sulfate, \\ $\left(\mathrm{BaSO}^{4}, \mathrm{CaSO}^{4}, \mathrm{SrSO}^{4}, \mathrm{PbSO}^{4}\right)$,}

welche sich bei den Vorproben durch Heparbildung beim Schmelzen mit Soda auf-der Kohle kennzeichnen, werden durch Schmelzen mit der vierfachen Menge eines Gemisches gleicher Theile wasserfreien Natriumcarbonats und Kaliumcarbonats aufgeschlossen. Nach dem Behandeln der erkalteten Schmelze mit Wasser enthält die Lösung das gebildete Natriumsulfat, der mit Wasser gut ausgewaschene Rückstand die Basen als Carbonate (nach dem Auswaschen in Essigsäure oder verdünnter Salpetersäure löslich).

\section{Zinnoxyd (Zinnstein) und Antimonsäure,}

(bei den Vorproben, durch Schmelzen mit Soda auf der Kohle kenntlich) werden durch Schmelzen mit der 4 fachen Menge Aetznatron in eine in Säuren lösliche Form übergeführt. Auch durch längere Digestion mit gelbem Schwefelammonium werden beide Verbindungen bisweilen als Sulfosalze gelöst; Salzsäure scheidet aus letzterer Lösung die Basen als Sulfide ab. 


\section{Untersuchung der nach I. (S. 48 u, f.) erhaltenen Lösungen.}

a) Liegt eine Lösung der zu untersuchenden Substanz in Wasser vor, so prüfe man dieselbe zunächst mittelst Lackmuspapier auf ihre Reaction. Neutral oder sauer reagirende Lösungen sind nach A. (S. 56) zu untersuchen. Alkalisch reagirende Lösungen sind vor der weiteren Untersuchung nach A. mit Salpetersäure anzusäuern; hierbei beobachte man, ob sich Niederschläge ausscheiden, oder ob sich Gase entwickeln. Scheidet sich beim Ansäuern mit Salpetersäure ein Niederschlag aus, so untersuche man das Filtrat davon nach B. (Tab. I).

Als Niederschläge können sich ausscheiden: Schwefel, ArsenAntimon- und Zinnsulfid, Chlorsilber, Cyansilber sowie Kieselsäure. Als Gase können entweichen: Schwefelwasserstoff, schweflige Säure, Kohlensäureanhydrid und Cyanwasserstoff.

Schwefel scheidet sich meist unter gleichzeitiger Entwickelung von Schwefelwasserstoff (aus Sulfiden und Sulfosalzen), seltener von Schwefligsäureanhydrid (aus Thiosulfaten) $a b$, und zwar entweder als milchige Trübung oder in zusammengeballten Massen. Derselbe kennzeichnet sich nach dem Abfiltriren und Auswaschen durch die Brennbarkeit (blaue Flamme, $\mathrm{SO}^{2}$-Entwicklung) und durch die Heparbildung beim Zusammenschmelzen mit Soda auf der Kohle.

Arsen-, Antimon- und Zinnsulfid scheiden sich unter Entwicklung von Schwefelwasserstoff als flockige, gelbe oder orangefarbene Niederschläge aus. Man erwärme die angesäuerte Flüssigkeit gelinde bis der Geruch nach Schwefelwasserstoff nahezu verschwunden ist, sammle den Niederschlag auf einem Filter, wasche ihn aus und untersuche ihn nach B. b. (Tab. II).

Chlorsilber scheidet sich als weisser, käsiger, sich am Lichte violett färbender Niederschlag aus, der nach $\boldsymbol{A}$. (S. 56) und beim Schmelzen mit Soda auf der Kohle (s. S. 16 f.) leicht gekennzeichnet werden kann. Cyansilber ist in gleicher Weise auf der Kohle, sowie durch die Cyanreaction (s. S. 44) und das auf S. 34 a angegebene Verhalten $\mathrm{zu}$ eharacterisiren.

Kieselsäure, welche sich gallertartig, besonders in der Wärme abscheidet, ist weiter durch die Phosphorsalzperle (s. S. 30) zu kennzeichnen. In letzterem Falle verdampfe man die Lösung sammt dem Niederschlage im Wasserbade zur staubigen Trockne, durchfeuchte den Verdampfungs- 
rückstand mit Salpetersäure, ziehe ihn nach kurzem Stehen mit Wasser aus und prüfe den Auszug (derselbe kann im Wesentlichen nur Alkalien enthalten) weiter.

Schwefelwasserstoff, Schwefligsäureanhydrid, Kohlensäureanhydrid und Cyanwasserstoff kennzeichnen sich durch den Geruch, bezüglich durch die auf S. $26,25,30$ und 35 angegebenen Reactionen.

b) Liegt eine Lösung der zu untersuchenden Substanz in Salpetersäure vor, so beginne man die weitere Untersuchung bei A. (S. 56); handelt es sich dagegen um eine Lösung des Untersuchungsobjectes in Salrsäure oder in Königswasser, so beginne man die weitere Untersuchung derselben bei B. (Tab. I).

Zur Trennung der Basen bedient man sich nach einander folgender Gruppenreagentien: Salwsüure, Schwefelwasserstoff, Schwefelammonium und Ammoniumcarbonat.

Entsteht durch eines der genannten Reagentien in einer Probe der Auflösung ein Niederschlag, so versetze man alsdann die ganze Menge derselben mit einem zur vollständigen Ausfällung erforderlichen Quantum des betreffenden Reagens, sammle hierauf den Niederschlag auf einem Filter, wasche ihn sorgfältig aus und prüfe alsdann das Filtrat [nachdem man sich überzeugt hat, dass die Ausfällung auch eine vollständige war, d. h., dass durch weiteren Zusatz des angewendeten Gruppenreagens in dem Filtrate kein Niederschlag mehr entsteht] mit dem nächstfolgenden Gruppenreagens. Die einzelnen Niederschläge sind nach den unter Gruppe A., B., C., D. etc. angegebenen Verfahren weiter zu untersuchen.

\section{Uebersicht des Verhaltens der Basen gegen die Gruppenreagentien.}

Gruppe A. Durch Salzsäure werden als Chloride gefällt, die sich in einem Ueberschusse des Fällungsmittels nicht wieder lösen:

Silber: weiss, käsig, | vollständig

Quecksilberoxydul: weiss, pulverig, f fällbar.

Blei: weiss, krystallinisch, unvollständig fällbar.

Gruppe B. Durch Schwefelwasserstoff werden aus saurer Lösung als Sulfide gefällt:

Quecksilberoxyd: schwarz,

Blei: schwarz,

Arsen: gelb,

Wismuth: schwarz,

Kupfer: blauschwarz,

Cadmium: gelb,

Antimon: orangeroth,

Zinnoxydul: braun,

Zinnoxyd: gelb,

Platin: schwarzbraun,

Gold: schwarzbraun. 
a) Von diesen durch Schwefelwasserstoff gefällten Metallen sind in Schuefelammonium löslich: Arsen-, Antimon-, Zinn-, Platin- und Goldsulfid.

b) In Schwefelammonium sind unlöslich: Quecksilber-, Blei-, Wismuth-, Kupfer- und Cadmiumsulfid.

Gruppe C. Bei Gegenwart von Chlorammonium werden durch Schwefelwasserstoff aus alkalischer Lösung (Schwefelammonium) gefällt (nicht dagegen aus saurer Lösung):

$$
\text { als Sulfide: }
$$

Kobalt: schwarz, Eisenoxyd: schwarz,

Nickel: schwarz, Zink: weiss,

Eisenoxydul: schwarz, Mangan: fleischroth, an der Luft in braunschwarz übergehend.

\section{Als Hydroxyde:}

Aluminium: weiss, | Chrom: graublau.

event. als Phosphate und Oxalate:

Calcium, Baryum, Strontium, Magnesium: weiss.

Gruppe D. Durch Schwefelwasserstoff und Schwefelammonium (bei Gegenwart von Chlorammonium) werden nicht gefällt, wohl aber durch Ammoniumcarbonat als Carbonate:

Calcium, Baryum, Strontium: weiss.

Gruppe E. Lösungen, welche durch Salzsäure, Schwefelwasserstoff, Schwefelammonium und Ammoniumearbonat nicht gefällt werden oder von den dadurch entstandenen Niederschlägen abfiltrirt sind, können von Basen noch enthalten:

Magnesium, Kalium, Natrium, Lithium, Ammonium. 


\section{Gruppe A.}

\section{Salzsäureniederschlag ${ }^{1)}$.}

Entsteht durch Salzsäure in einer Probe der neutralen oder schwach sauren Lösung des Untersuchungsobjects kein Niederschlag, so gehe man behufs weiterer Prüfung zu B. (Tab. I) über. Entsteht dagegen durch Salzsäure ein Niederschlag, der sich in einem Ueberschuss des Fällungsmittels nicht wieder löst ${ }^{2}$ ), so behandle man die ganze Menge der Lösung in gleicher Weise. Es werden gefällt: Quecksilberoxydul als $\mathrm{Hg}^{2} \mathrm{Cl}^{2}$, Silber als $\mathrm{AgCl}$, Blei als $\mathrm{PbCl}^{2}$ (unvollständig). Der Niederschlag werde abfiltrirt, mit wenig kaltem Wasser ausgewaschen und alsdann mit viel Wasser ausgekocht:

In Lösung geht: Chlorblei.

Ungelöst bleiben: Chlorsilber, Quecksilberchlorïr

Kaliumchromat fällt daraus gelbes Bleichromat; verdünnte Schwefelsäure scheidet weisses Bleisulfat aus.

mit Ammoniak digerirt, geht Chlorsilber in Lösung und kann aus der ev. filtrirten Lösung durch Salpetersäure wieder gefällt werden; Quecksilberchlorür wird durch Ammoniak geschwärzt und bleibt ungelöst.

Das Filtrat von obigem Salzsäureniederschlage werde zur Prüfung nach B. (Tab. I) verwendet, nachdem es ev. durch Eindampfen von Säureüberschuss befreit ist.

Ist die concentrirte Auflösung der Substanz ungefärbt, so enthält dieselbe weder Kupfer-, noch Platin-, noch Gold-, noch Kobalt-, noch Nickel-, noch Eisenoxyd-, noch Chromoxydsalz, noch Chromsäure.

1) Liegt eine Lösung der zu untersuchenden Substanz in Salzsïure oder in Königswasser vor, so ist es überflüssig, auf Gruppe A. Rücksicht zu nehmen; man beginne daher die Prüfung bei Gruppe B.

2) Aus Brechweinsteinlösung entsteht durch Salzsäure auch ein Niederschlag, der sich jedoch in einem Ueberschusse der Sïtre wieden

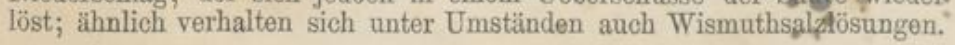




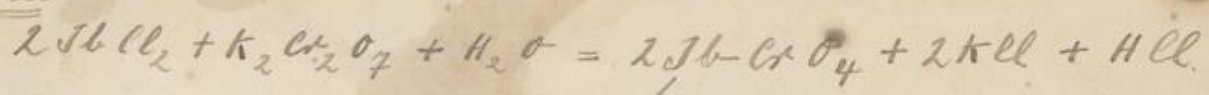

$$
\begin{aligned}
& \text { eislich in CHgCOOH m. NaOH } \\
& \mathrm{ObCHO}+4 \mathrm{NaON}=\mathrm{Cb}(\mathrm{ONO})^{2}+\mathrm{Nm}_{2} \mathrm{CrOH}_{4}+2 \mathrm{H}_{2} \mathrm{O} \text {, } \\
& \mathrm{NaCl}+112 \mathrm{SOO}_{4}=\mathrm{bb} 4 \mathrm{OO}_{4}+2 \mathrm{HeC}
\end{aligned}
$$

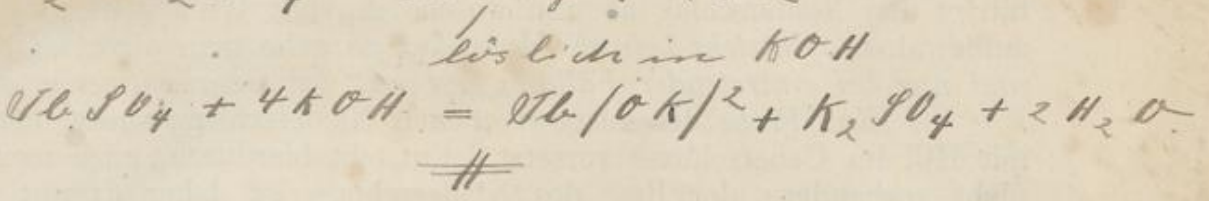

$$
\begin{aligned}
& \frac{\text { Qurechsillbers }}{H_{2} C_{2}+2 N H_{3}}=N H^{2} H_{j} 2 C l+N H_{4} C l
\end{aligned}
$$

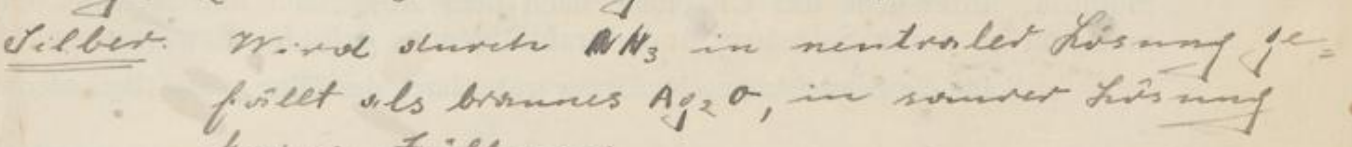

$$
\begin{aligned}
& \text { heive fireenzy } \\
& \mathrm{xyCl}+\mathrm{HNO}=\mathrm{Ly} \mathrm{NO}_{3}+\mathrm{HCl}
\end{aligned}
$$

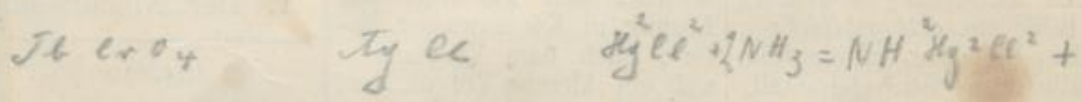




\section{Schwefelwasserstoffiniederschlag.}

Das saure Filrat von dem Niederschlag der Gruppe A, nder diet Fltssigkeit, in welehor Salzsäure keinen Niedersohtag hervorgehracht hat, oder endlich die Lasung der ursprüinglichen Substanz in Salzsiure oder in K önigswasser (nachdern sie durch Eindampfen möglichst von Säureiberschuse befreit ist, vgl. S. 48) werde mit His vollständig gesattigt. Entsteht cin Vicderschlag, so tiberzeuge man sich, dass durch HS Alles ausgefallt ist I), filtrire den Niederschlag ab und wasche ihn mit Wasser bis zur neutralen Reaction ans. Das Filtrat werde zur weiteren Prufung nach Gruppe C. aufbewahrt. Entsteht kein Niedersehlag, so gehe man digect zu Gruppe C. Aber\%). Obige Operationen sind sunächst mit einer Probe der Löszng und nur bei eintretender Fallung erst mit der Gesammimenge derselben auszuführen.

Eine Probe des ausgewaschenen Niederschlags werde hierauf mit selbem Schwefelammonium digerirt $\left(40-50^{\circ} \mathrm{C}\right.$.), die Lösung abfiltrirt und mit $\mathrm{HCl}$ im Ueberschusse versetst. Entstelat hierdurch, auch nach gelindem Erwärmen, nur eine milehige Trübung, so sind As, Sb, Sn, Pt und An nicht vorhanden; der Rest des Ntederschlags ist daher direct nach it. zu untersuchen. Löst sich dagegen in Schwefelammonium der gesammie H²S-Niederschlag, so sind $\mathrm{Hg}, \mathrm{Pb}, \mathrm{Bi}$, Cu und $\mathrm{Cd}$ nicht vorhandent der Rest des H8-Niederschlags ist daher direct nach b. (Tab. II) zu untersuchen. Hat sich in Schwefolammonimm nur ein Theil des H'S-Niederchlags gelöst (der durch HCl in der Schwefelammoniumläsung entstandene Niederschlag ist flockig und selb, orangeroth oder bramsehwarz gefirht), so digerire man den Rest des H'S-Niederschlags mit gelbem Schwefelammonium, nntersuche das Ungelöste nach dem Abfiltriren und Answaschen Ipit etwas Schwefelammonium enthaliendem Wasser nach a., das Gelöste. nachdem es durch' Salzsäure und daraffolgendes gelindes Erwirmen wieder abgeschieden ist, nach b. (Tab. II).

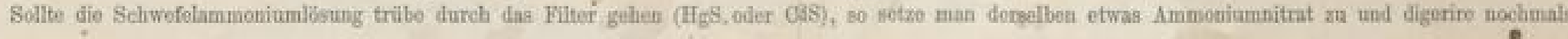

a. In Sehwefelammonium unlöslieher Theil: $\mathrm{H}_{\mathrm{g}}, \mathrm{PbS}, \mathrm{Bi}^{2} \mathrm{~S}^{3}, \mathrm{Cu} 8, \mathrm{CdS}$.

\begin{tabular}{|c|c|c|c|c|c|}
\hline \multirow{2}{*}{\multicolumn{2}{|c|}{ 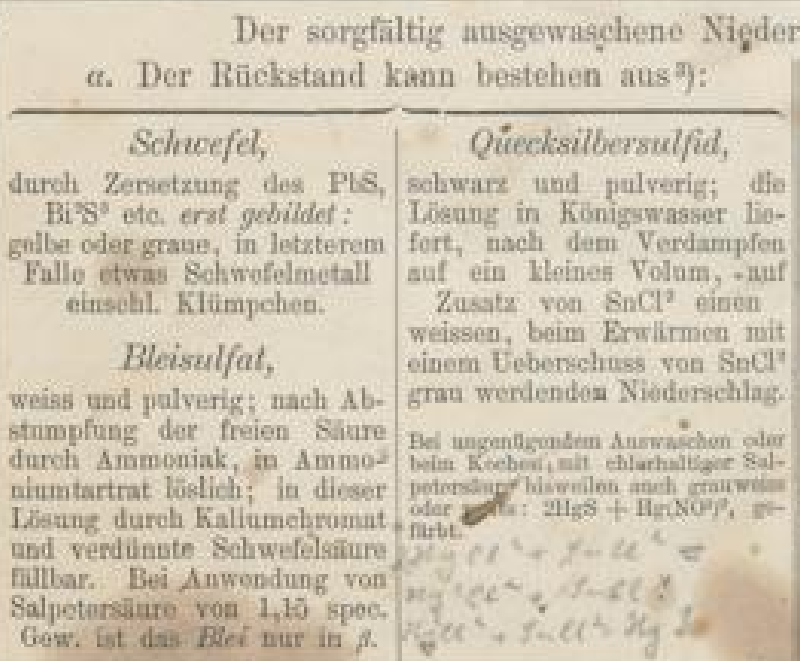 }} & \multirow{2}{*}{\multicolumn{2}{|c|}{ 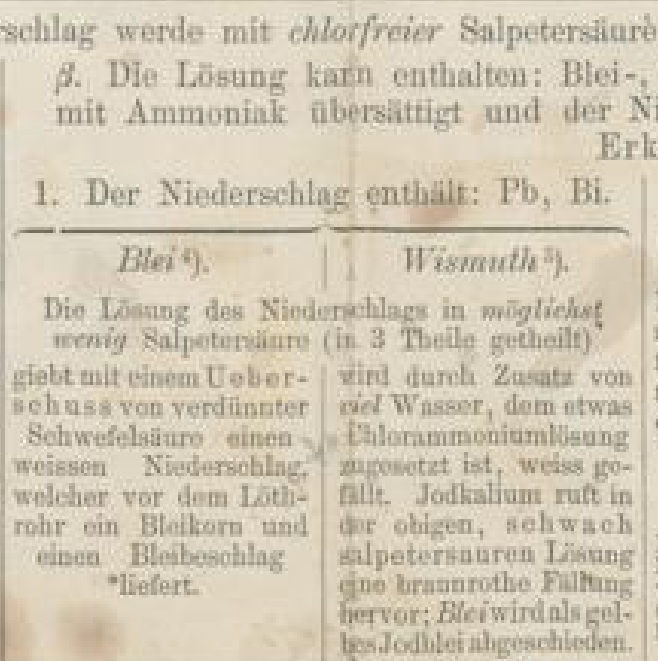 }} & \multicolumn{2}{|c|}{$\begin{array}{l}\text { von etwa } 1,15 \text { spec. Gewielit gekocht: } \\
\text { Wismuth-, Kupfer-, Cadmamnitrat; dieselbe wird } \\
\text { Viedersehlag 1. von der Flissigkeit 2., nach dem } \\
\text { kalten, abfiltrirt. } \\
\text { 2. Die Flussigkeit enthilt: } \mathrm{Cu}, \mathrm{Cd} \text {. }\end{array}$} \\
\hline & & & & & \\
\hline
\end{tabular}

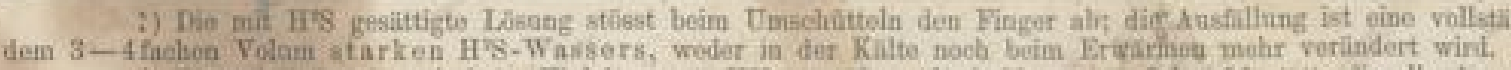

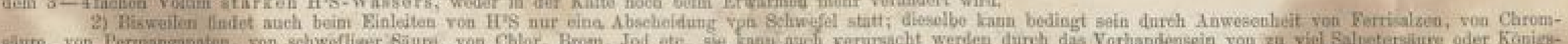

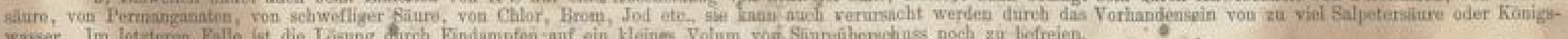

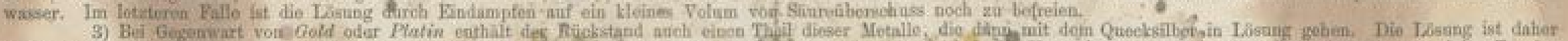

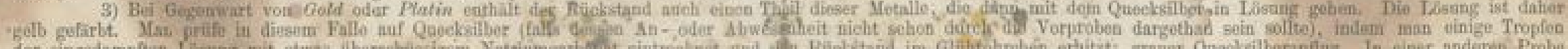

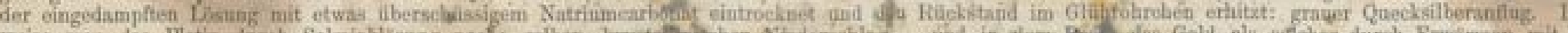

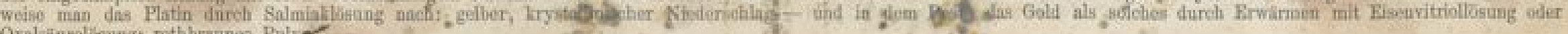

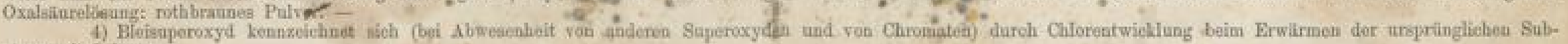
stanx mit Salnature

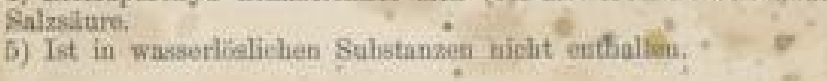




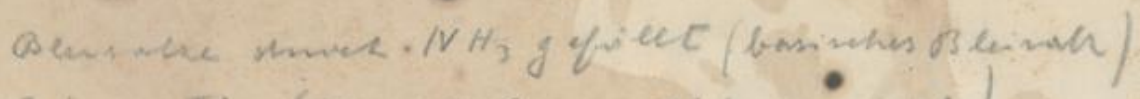

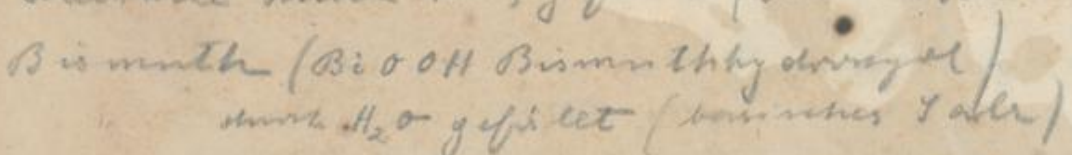

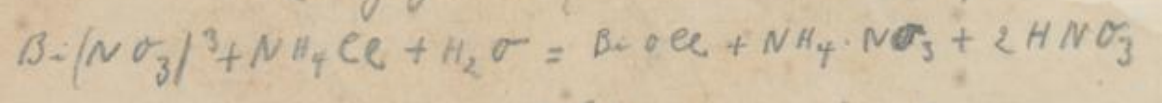

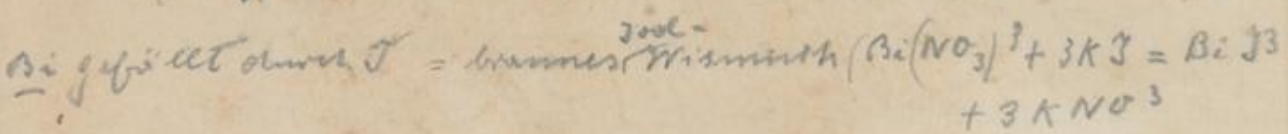

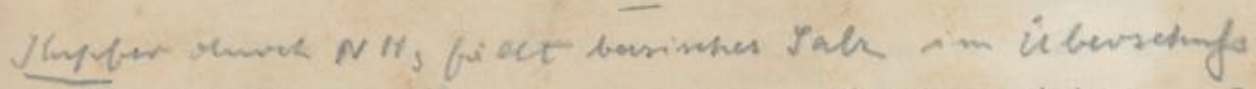

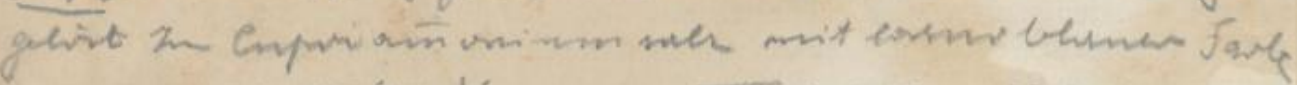

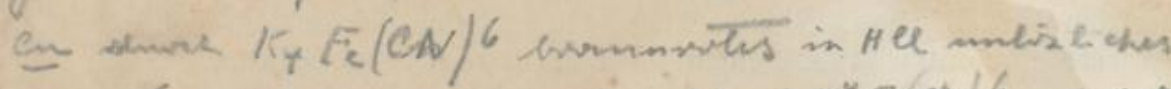

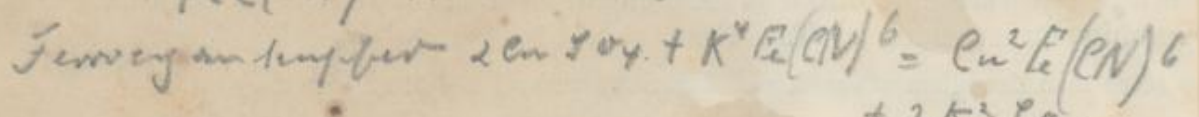

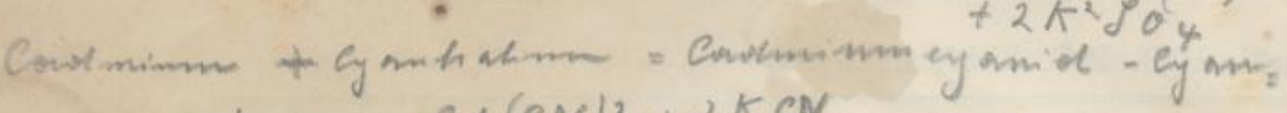

$$
\begin{aligned}
& \text { hubim } \operatorname{Col}(\mathrm{CN})^{2}+2 \mathrm{KCN} \\
& \text { Ertilärung our Grappe B }
\end{aligned}
$$

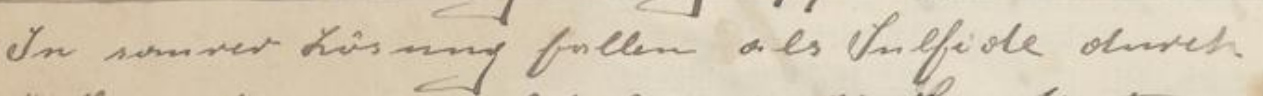

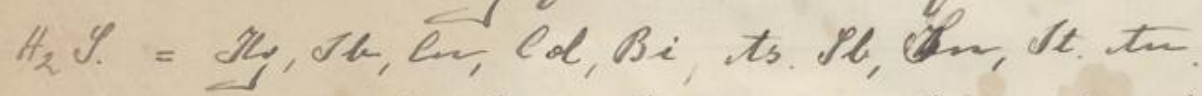

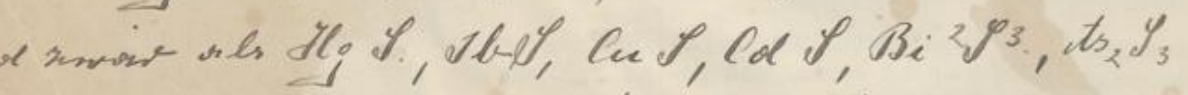

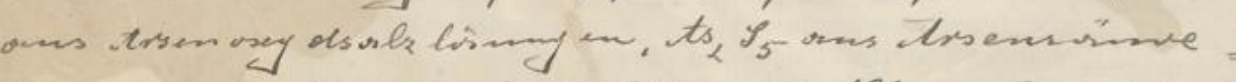

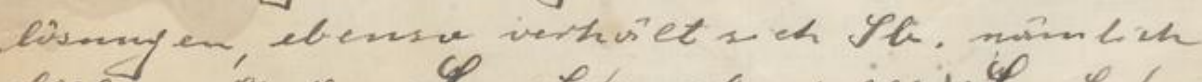

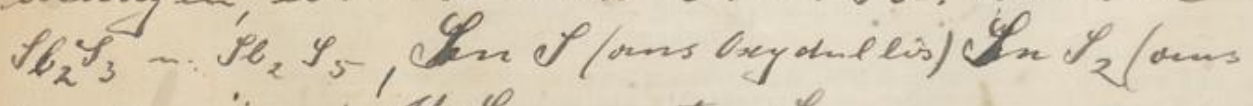

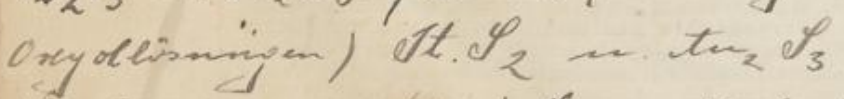

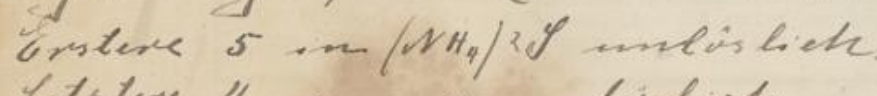
Letilere 4" lisbeh

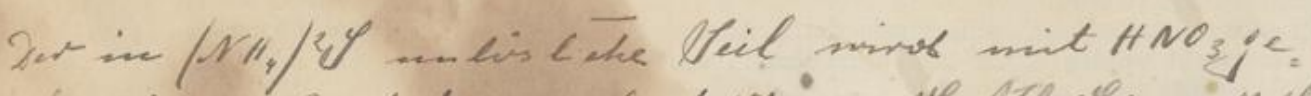

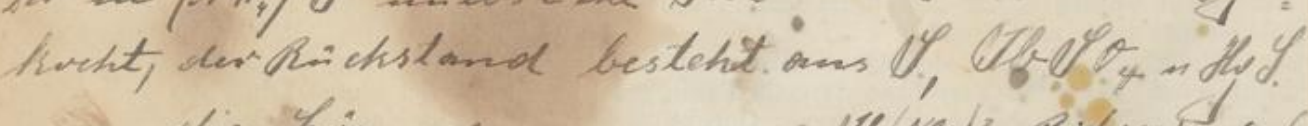

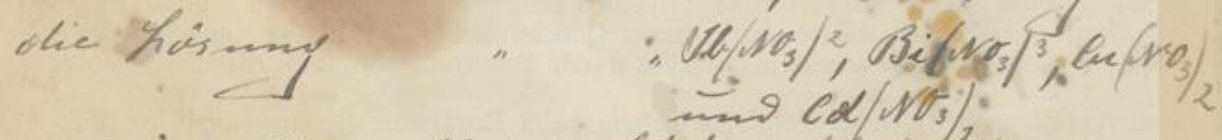

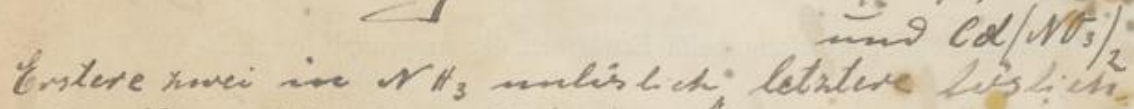

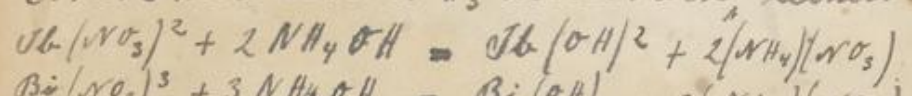
$\mathrm{Bi} /\left(\mathrm{NO}_{3}\right)^{3}+3 \mathrm{NH}_{4} \mathrm{OH}=\mathrm{Bi}(\mathrm{OH})_{3}+3\left(\mathrm{NH}_{4}\right)\left(\mathrm{NO}_{3}\right)$. 


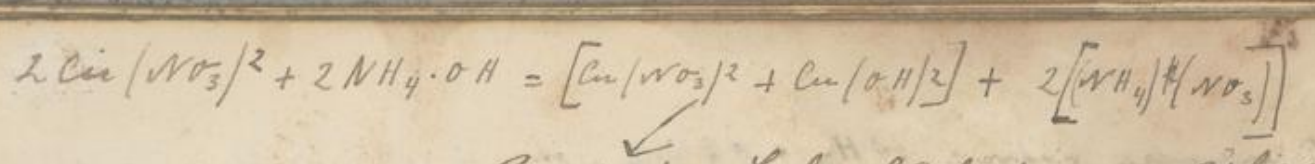
Brssisches Yula lislich ind viber

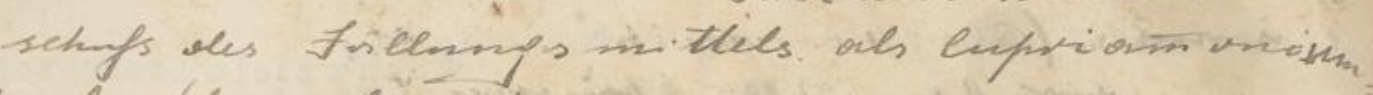
is als. (losurblines

$$
\begin{aligned}
& \text { - }\left[\operatorname{con}\left(N v_{3}\right)^{2}+\cos (\sigma N)^{2}\right]+\left[\left(N H_{4}\right)^{2}\left[N v_{3}\right]^{2}\right]+6 N H_{4} O H= \\
& \left.2\left[\mathrm{CL} / \mathrm{NO}_{3}\right]^{2}+4 \mathrm{NH}^{3}+\mathrm{H}_{2} \mathrm{O}\right]+\mathrm{CH}_{2} \mathrm{O}
\end{aligned}
$$

Beri: Norctimajo siche Gorffue $A$.

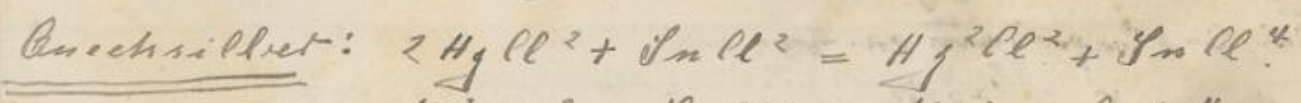

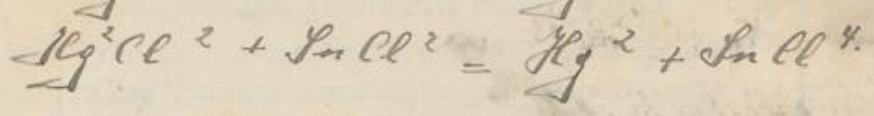

Nismeth: $\mathrm{Bi}_{i}\left(\mathrm{NOB}^{3}\right) 3+2 \mathrm{H}_{2} \mathrm{O}=\mathrm{Bi}(\mathrm{OH})^{2} \mathrm{NO}^{3}+2 \mathrm{HNO}_{3}$ $\mathrm{Bi}_{i}\left(\mathrm{NO}^{3}\right)^{3}+\mathrm{NH}_{4} \mathrm{Cl}+\mathrm{H}_{2} \mathrm{O}=\mathrm{BiOCO}+\mathrm{NH}_{4} \mathrm{NO}_{3}+2 \mathrm{HNO}_{3}$.

Htuffer : $2\left[\mathrm{em}_{2}\left(N \sigma_{5}\right)^{2}+4 N H_{3}+H_{2} \sigma\right]+K_{4} F_{2} C N_{6}=\mathrm{Cu}_{2} \mathrm{Fe}_{\mathrm{e}} C N^{2}+$ $2\left[\mathrm{~K}_{2}\left(\mathrm{NO}_{3}\right)^{2}+4 \mathrm{NH}_{3}+\mathrm{H}_{2} \mathrm{OH}\right]$.

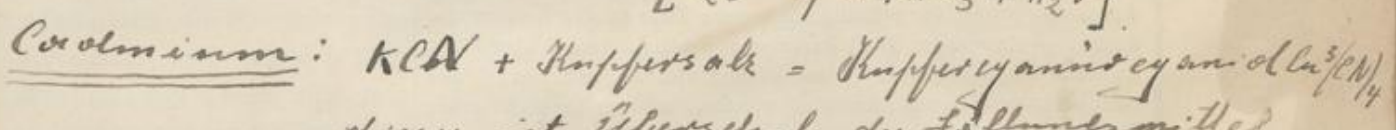
dieses ist Liberschars des follengenithel

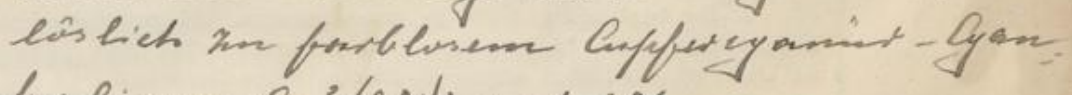
holime are $/(C N)^{2}+2 K C N$ 
Gruppe B.

Tab. II.

Schwefelwasserstoffniedersohlag (2. Theil).

b) In Schwefelammonimm löslieher Theil.

L Der aus der Lossung in Sehwefelammonium durh Salzsalure ausgeschiedene Niederschlag ist gelb oder orangegelb gefilirbt: Gemenge von $\mathrm{As} 2 \mathrm{~s} 3$, 'SbะS', $\mathrm{SnS}^{2}$, bei Gegenwart von Kupfer lossung im Ueberschuss digerirt $\left(40-50^{\circ} \mathrm{C}\right.$.), nachdem er zuxor durch Auswaschen soryfaltig von H'S befreit ist.

$$
\text { (ra.). } x_{1}
$$

a. Die Likung kann enthalten: Schuefelarsen. Sie wird mit Salzshlure ïbersittint und dann ev. mit etwas Schwefelwasserstoffwasser vensetxt: gelber, flockiger Niedersohlag von As 8 :

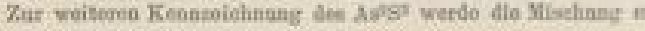

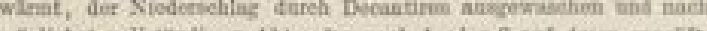

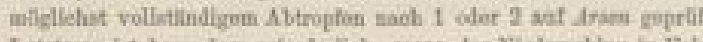

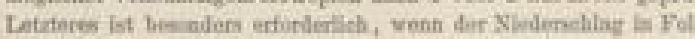

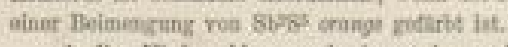

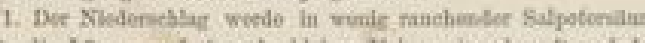

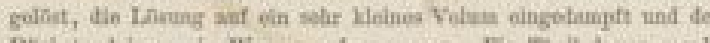

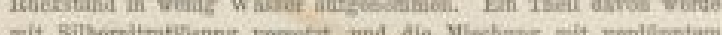

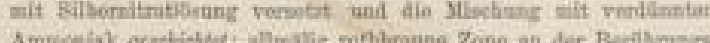

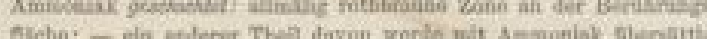

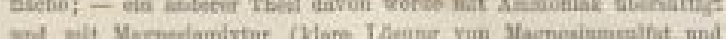

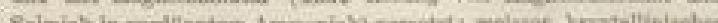

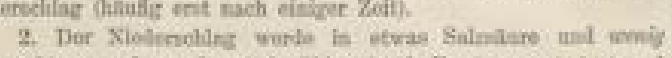

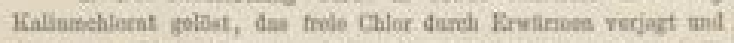

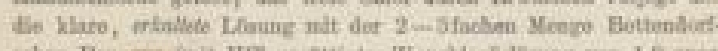

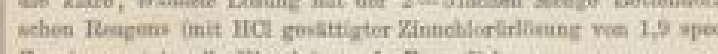

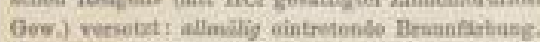

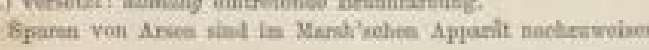

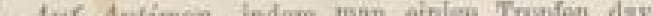
zeigt dieser Niederschlag hïufig eine rothbraune Fürbung. - Er werde mit Ammoniumearbonat-

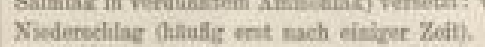

3. Der von $A s^{2} S^{\square}$ befreite Rückstand kamn enthaiten: Schucefelantimon und Schucefelsinn.

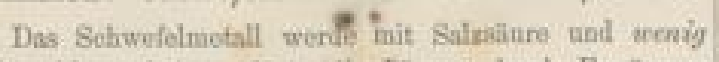
Knliumchlomt holss gelsst, * dite Bsoung durch Erwirmen von Cilor rollstindig befreit und geprint: Iuf PlatinHeoh mit einem Ylánon Zinkkom oder teinen Stanniolliüpolchen in Berilhung bringt: tief sehoorzer, an Platin buteoder, in Sultwidure unilialicher Yleok") fon der Grüsse des Filizsiglecitstinopfous.

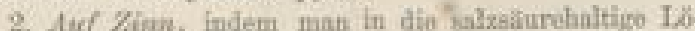
sung oinige Stricko Eisendrabt bringt und sie damit litnger Zeit digerirt, Das farblese, bestiglich blaxa-grüntiche Fi. trat mit menig Quochsilberchitorillianng erwilrmt, liefert

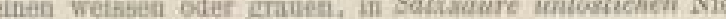

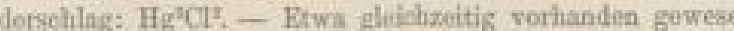
nes Antimon wird durch das Rimut als schwarzes Pulver abgeschicden; lotxteres lamn nach dem Answaschen durch

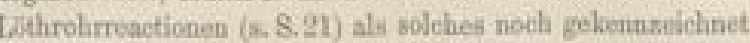
wortan.
II. Der aus der Lösung in Schwefelammonium durch Salzsiture abgeschiedene Niederschlag ist braunschucar gefarbt: Gemenge von $\mathrm{As}^{2} \mathrm{~S}^{3}, \mathrm{Sb}^{2} \mathrm{~S}$, $\mathrm{SnS}^{2}, \mathrm{PtS}^{2}, \mathrm{Au}^{2} \mathrm{~S}^{3}$ und ev, CuS.

Die Schwefelmetalle werden mit conc. Salyzäure gekocht: Die Lösung enthailt: Antimon und Zinn, deren Nachweis nach $I_{\beta} \beta \mathrm{zu}$ bewirken ist.

Der Rückstand enthilit: Arien-, Platin- und GoldsulFid; ar werde zetrocknet und im Glíhröbrchen der Subtimation unterworfen. Es snblimirt Selwwefelarsen nnd Bchwefel, aut dem Boden des Röhrehens verbleiben Plutin und Goll Das Glübrührchen worde daon zerschnitten und das Sablimat mit Ammoniumearbonatbisung bach If geprutet.

Dor ana Platin und fold bestehendo Raichstand worko

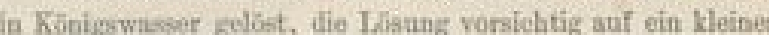
Votum verdampft und die räckstindigo Flassighkeit, nach den Vendilusen mit wenig Wasser, in 2 Theilo getheilt. Win Thei werde mit Salmiaklósung versotzt: nllmalis gelber, krystal finischer Niesterschlag von (NHFPtCl, - ein anderer Theil

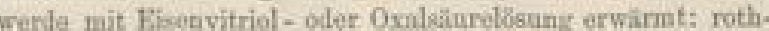
bnuner Niodersechlag rou mutalliscben Gold - V fL. Tab. I, Anm. 3.)

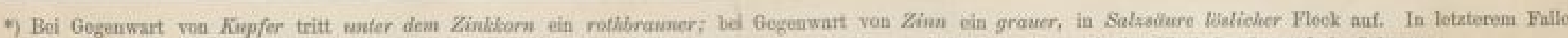

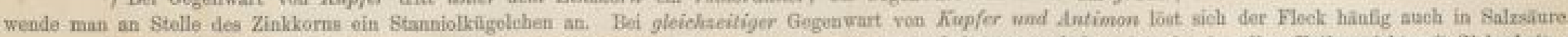

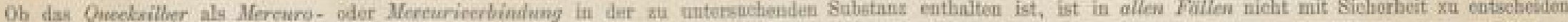

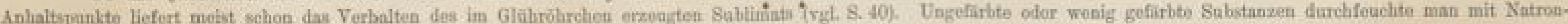

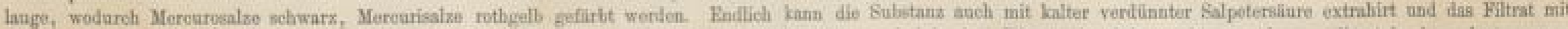

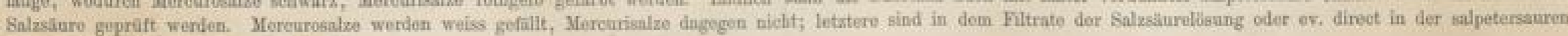
Lisang durch Zinnchlorir min ermitteln.

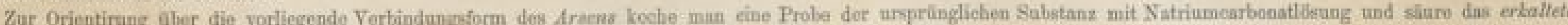

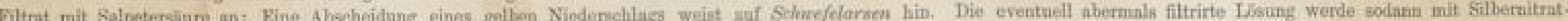

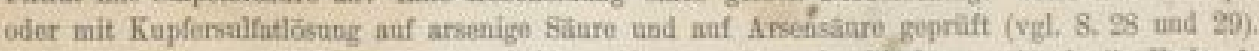

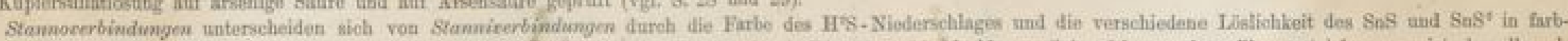

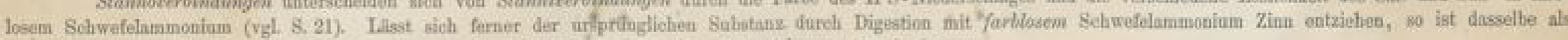
Stanniverbindung vorhnnden; Stannosalze gehen nur durch Digestion mit gelbeen Schwefelammonium in Lisumg. 
Eshloirang der qunffe $B b$

trsenige $t_{S_{2}} \mathrm{O}_{3}+3 \mathrm{H}_{2} \mathscr{I}=t_{3} \mathscr{J}_{3}+3 \mathrm{H}_{2} \mathrm{a}$

Prinre $\left.t_{s_{2}} \mathscr{J}_{3}+6\left(N H_{H}\right) H \mathscr{I}=2 / N H_{4}\right)^{3} t_{s} \mathscr{Y}_{3}+3 H_{2} \mathscr{I}$

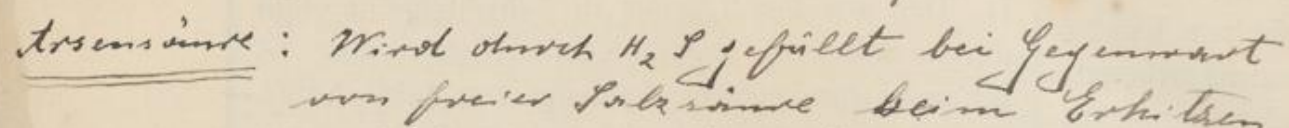
$2 \mathrm{H}^{3} d_{0} \mathrm{O}_{4}+5 \mathrm{H}_{2} \mathrm{Y}=\mathrm{t}_{2} Y_{5}+8 \mathrm{H}_{2} \mathrm{O}$

2 er witere Nothrecis nom $\pi_{s_{2}} \rho_{3}$.

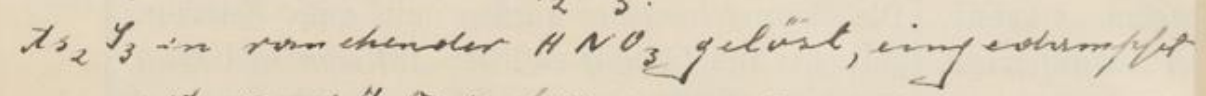

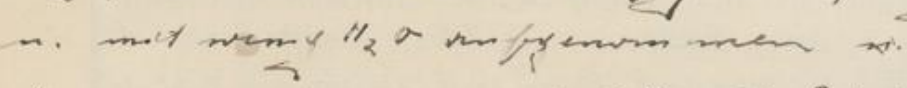

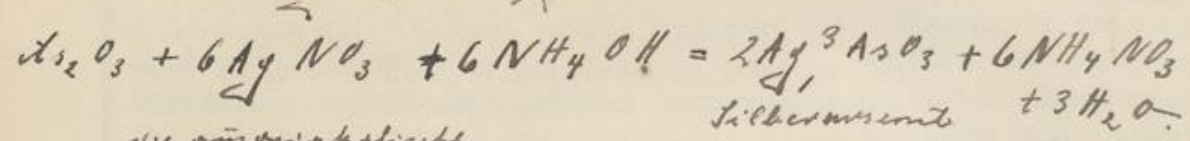

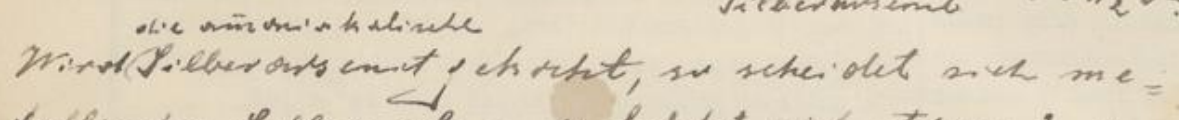

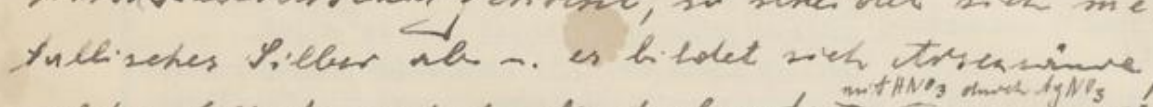

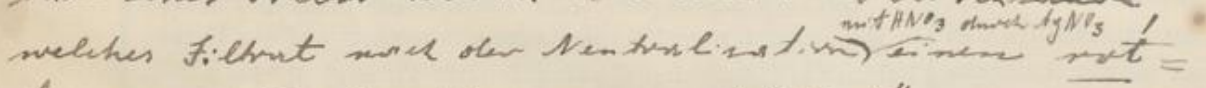

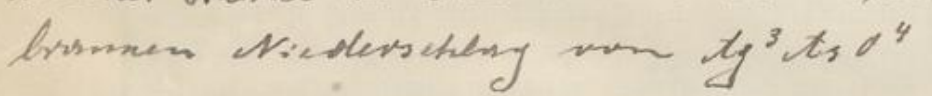

1. Nonemocis:

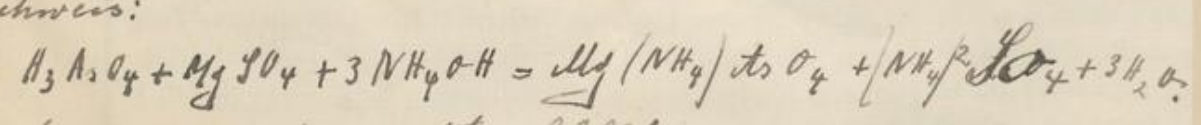

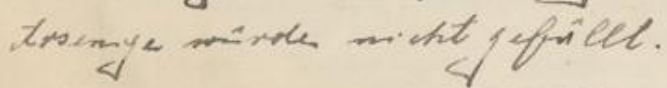



Schwefelammoniumniederschlag.

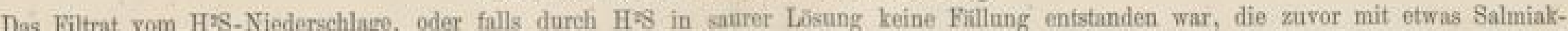
lösung versotzte Lōsung der ursprūnglichen 'Substanz (falls sie vorher nicht sauer gemacht sein sollte), werde mit Ammoniak alkalisch gernacht und alsdann mit H'S gesittigt. War durch $\mathrm{H}^{2 \mathrm{~S}}$ in saurer Lösung (Gruppe B.) kein Niederschlag entstanden, so ist bei Gelbfärbung der Lösung auf cvent Anwesenheit von Clromsäure bez. Chromaten insofern Rücksicht zu nehmen, als letztere vor dem Uedergange zu Gruppe C. durch Kochen mit Alkohol und Salzsiure in Chromoxydealz zu verwandeln sind. Den durch Sehwefelammonium entstandenen Niederschlag filtrire man ab und mit Wusser, dem einige Tropfen Schwefelammonium zugesetzt sind, aus; das Filtrat*) ist zur Untersuchung nach Gruppe D. aufzu-

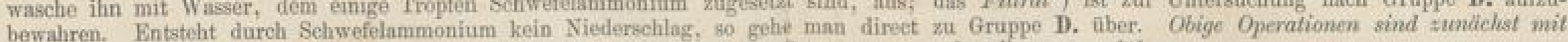
einer Probe der Lusung und nur bei eintretender Fälung erst mit der Gesammimenge derselben aus:ufilhen.

Der gut ausgewaschene Schwefelammoniumniederschlag werde mit kalter Salzsïure (von 5 Proc. HCl) in Uebersohuss geschuattolt und der ungelöste Theil a) (doch nur, wenn er rein schwarz gefirbt ist) von der erzielten Lösung b) durch Filtration und Auswaschen getrennt.

a) Der schucarze Rückstand (a) kann enthalten CoS u. NiS. Kabalt: Eine kleine Mengo der Niederschlags worlo in dur Phosphorsalzperle goprüf: Blaufirbang, begonders der noch warmen Perle.

Nielnl: Den Rest des Niednrschlagn lise man beiss in Königswassor, verdample đie filtrirto Lösung bia auf ein sehr bleines Volum, nehme den Fïlokstand mit etwas Wasser auf und priffo in folgender Weise:

Man setze Cyankaliumlósung in Eehensehass zit, koche dîn klan Lösung auf, fugo das doppelto Volum starkor Natronlaugo zi und sehichte die warme Mischung mit Bromwasser im Uebenschuss; Nicke? scheidet sich allmilizy sls sehwarye Zone oder alu schwaryer. Nieder schling: $\mathrm{Ni}^{2}(\mathrm{OH})^{4}$, aus.

d) Die Lossung (d) ***) kann enthalten: $\mathrm{Mn}(\mathrm{OH})^{2}, \mathrm{Zn}(\mathrm{OH})^{2}$.

Bri. Aberesenheit con Co oder $\mathrm{Ni}$ prúfe man zunliehst eino Probec, dasou mit HS; entsteht (auch nach einiger Zeit) leine Fintung, so weis von $\mathrm{Yfn}$ und $\mathrm{Zn}$ koche man den Best der Lörung mit Natron laugo in Boberschuss bif sim Verscherinden des Ammontiakgonich In schejdet bich sus der noch starl allowlisch reagirenden Flssigheit in hraunscbrarzor Fiocken $\mathrm{nb}$, de beim schmedzen mit soda und Salpoter nef tem Platinbicobos, oder Erhitxon mit soda in dor Oxy. fatiobstamme des Bansen scben Brenuers (am Funtindrahto) nach dew

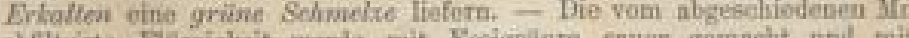

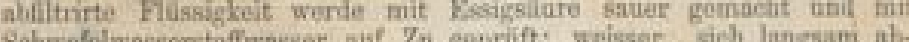
solwefelwasserstofitwass

Bei Ansesentwit kon Co oder $N i$ koche man die Lbsug 4 d direct

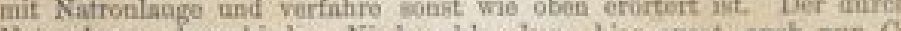

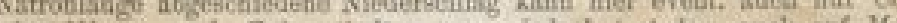

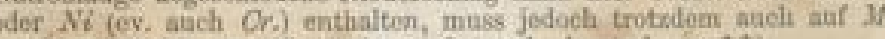

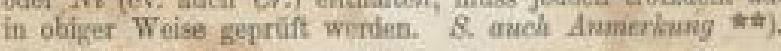

b) Die Losung (b) kann enthalten die Chlorïre des Fe, Gr, Al, Mritg sowie die Phosphute und Oxalate des $\mathrm{Ca}, \mathrm{Ba}, \mathrm{Sr}$ und $\mathrm{Mg}$.

Bine kleine Probe dieser Losung werde zunächst, nach Entfernung des Has durch Erwärmen, uuf Phosphorsïure (mit dem doppolten Volum Ammoniummolybdatlösmg oinigo Zeit bei Soite gusetat: gelber, kryatallinischer Niederschlag $\rightarrow$ ) und eine saceile Probe auf Oxalscüre

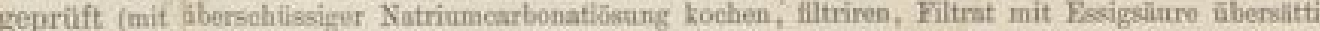

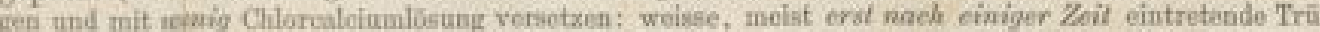
bung) Lijete sieh das Entersiechangsobject in Wasser, so ist die Anwesenheit voa Phosphinten und Oxulatan in Lasung (b) mangosoblossen.

I. Bei Abwesenheit von Phosphorsüure und Oxalsilure.

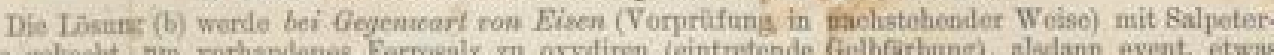

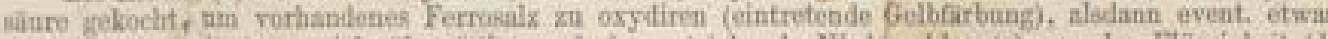
eingedampft, mit Ammonialk alveselittigt und der entstebendo Niedersching (c) von der Muissigkeit (d)

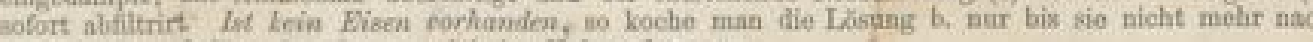
HS riecht und fuge dann Ammoniak im Uebersohuss xa. c) Der Nicderschlag (c) kann enthalten: $\mathrm{Al}^{2}(\mathrm{OH})^{6}$, $\mathrm{Fe}^{2}(\mathrm{OH})^{6}, \mathrm{Cr}^{2}(\mathrm{OH})^{6}$ *

$$
\text { Aluminium. } \pm 4 \text { forif Eisen. Chrom. }
$$

Der Niedernchlag werde mit Eine Probe des von Natroti- Den Rest des von Natronlatuge Satronlage yoige Zeit gokocht, lange nicht Gelosten 1000 man in nicht Gelöiten schmelte man mit

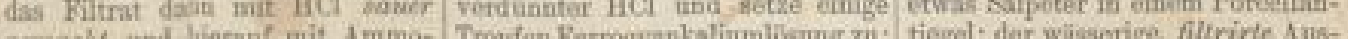

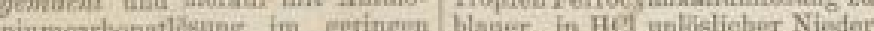
Ederichinss Penetzt: gillortarti- schlag.

gar sich hulufo eret allimälig absoheidender Nedertichlag. zug der Schmelzo ist golb gefarbt, Bei Gegenwats ven Mangan heht dio crlalieto Selumelze zo nichst gritu ans.

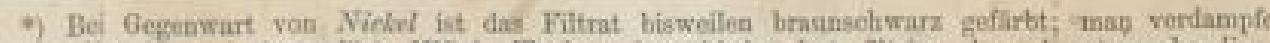
Aann dassedbo, buh sich das golbete Nis in Flocken abgeschinden hat, filtrite ab und untersucho dies

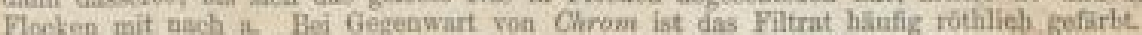

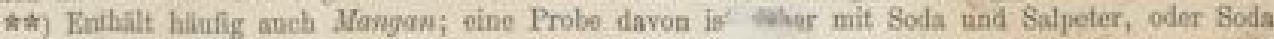
allein (vil, d.) darnaf rut priflen.

क**) Be Gononwart yon Clirom besitzt diesethe moist

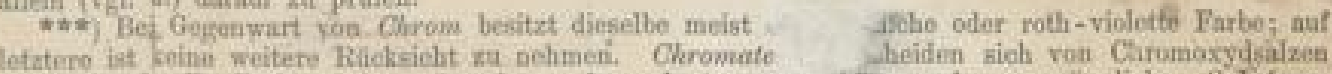

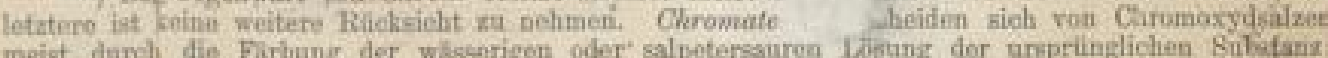
Chromates celb oder rothigh b; Chromorylsalte: grün oder violott. 


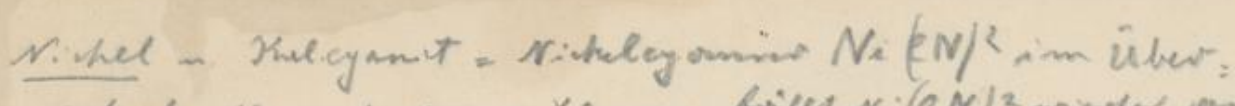

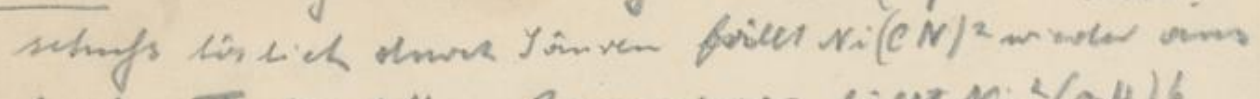

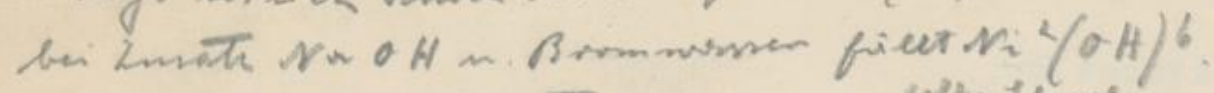

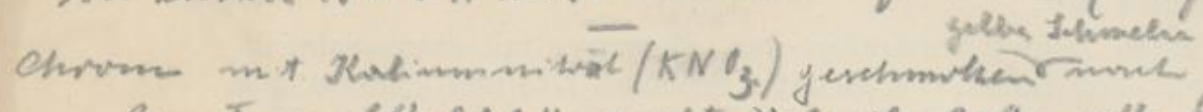

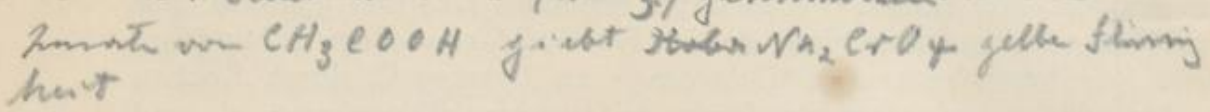

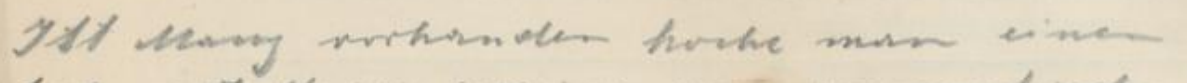

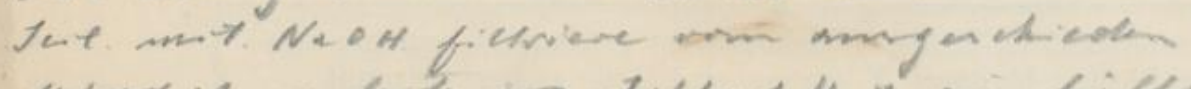

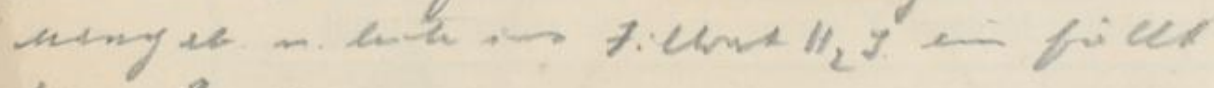
dinn he ans. 

Schwefelammoniumniederschlag (2. Theil).

\section{Bei Aurfendeng von Plosphorsämre und Oxalsäure.}

Die salzsaure, von CoS und NiS ev, abfiltrirte Lösung des Schwefelammoninmniederschlags (vgl. Tab. III) werde bei Gegenurart ron Eisen mit etwas Salpetersăure gekocht [um vorhandenes Ferrosalz zu oxydiren, eintretende Gelbfarbung], oder bei Abocesenheit von Eisen nur bis zur Verjagung des H*S gekocht, alsdann mit Ammonink übersittigt und der entstebende. Niederschlag (c) von der Flüssigkeit (d) sofort abfiltrirt. Die Flüssigkeit (d) ist auf Mangan und Zink zn prufen (vgl. Tab. III); der Niedersehlag (c) nach $c$. oder $\beta$. weiter zu untersachen.

a. Der Niedersching (o) wenle in wenig Salzaliure golöst, die Lösung mit $2-3 \mathrm{~g}$ cone. Schwefelsiuro und $2-3 \mathrm{~g}$ gesittigter Kaliumsulfatlisang versetzt und die

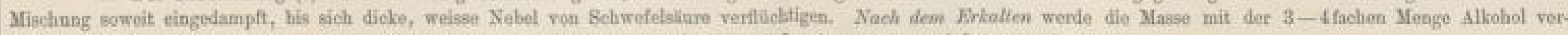
riebon, der Rilohstand abflitrirt, mit Alkohol sorgfältig amegeraschan") wnd schlleselich mit verdfinnter Salzsliure gokocht.

Die salzsaure Lüsung kann enthalten die Sulfate des $\mathrm{Fe}, \mathrm{Or}$,

$$
\mathrm{Al}, \mathrm{Ca}, \mathrm{Mg} \text {. }
$$

Dieselbe wird mit Ammoniak abersittigt:

Der Niederschlag kann enthalten:

$\mathrm{Fe}^{2}(\mathrm{OH})^{2}, \mathrm{Cr}^{2}(\mathrm{OH})^{a}, \mathrm{Al}^{2}(\mathrm{OH})^{2}$

(ev. axch Mangan, s. Tab. III, Anm. *n).

Dersolbe werle auf obige Körper geprüft, wie untor c. auf Tab. III angegebop ist. (Bei ungenügondem Auswaschen mit Alkobol [s obeo] enthalt der Niodensehlag auch noch heine Mengen der Phosphate des $\mathrm{Ca}, \mathrm{Ba}, \mathrm{Sr}$.)

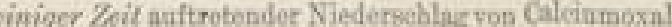

ent nach eimiger Zeit entstehender Niodesschlas:
Das in Salssäure nicht Geluste kann enthulten die Sulfate des (Ca), Ba, Sr.

Die gut ansgewaschenen Sulfute des $(\mathrm{Ca})$, Ba und $\mathrm{Sr}$ werden mit conc. Natriumearbonatlösung einigo Zeit gokocht, wach dom Absetzen die uberstehende Flissigkeit müglichst klar durch ein Fitor gogossen, der Rilokstand in der gleichen Weise noch $2-3 \mathrm{mal}$ mit Natriumearbonatlisung behandelt und endich auf dom nilmliches Filter gesan-

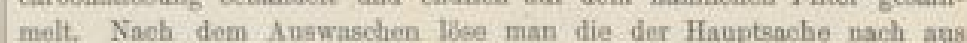
Carbonaten bestehende Masse in verdlinater. Essigsilure und untersuche die flltrite Ihaung auf $(\mathrm{Ca})$, Ba und $\mathrm{Sr}$, wie unter Groppe D. erôrtert ist.

Kilumoxalatlöaung versetzt: weisser, hidfig erat med

Magnesium: Die ex. vom Caleiumoxalat aneh volltilndigorKl larungablitrirto Flusigigkeit werde mit Natriumphoophattlosung vorsotat: weisser, krystallirischer, hinflig

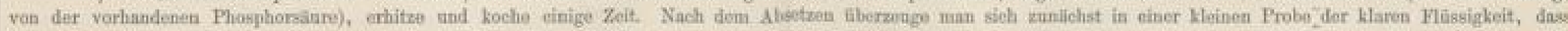
allo Phosphorsliaro abpeschieden ist (Prüfung mit Ammoniummolybdat); andernfalla ist noch mohr Zinnfolie zuzusetzen und von Nenem zu kochen. Der sus Metazinnsluro

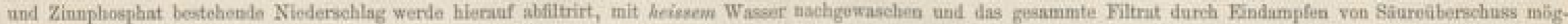

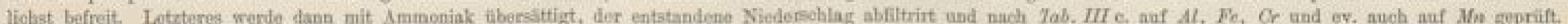

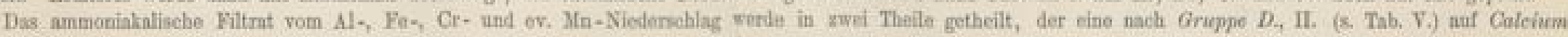

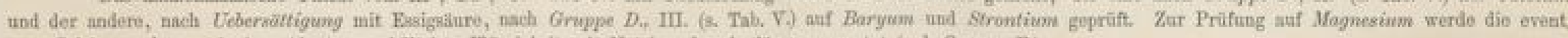
vom Calciumoxalat, nach dem Absetzen, abfiltrirte Flíssigkeit mit Natrimmphesphntlosung versotzt (vpl. Gruppo E.).

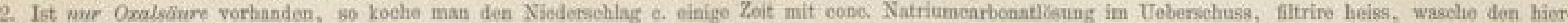

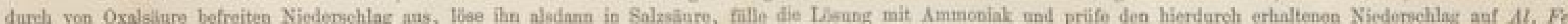
Cr (ev. $\mathrm{A}(n)$ ), das Filtrat dagegen auf $\mathrm{Ca}, \mathrm{Ba}, \mathrm{Sr}, \mathrm{Mg}$, wio os unter $\beta$. 1 . erörtert ist.

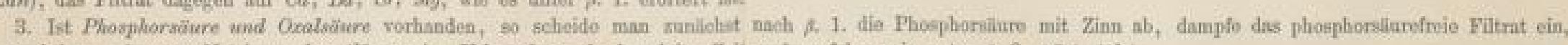

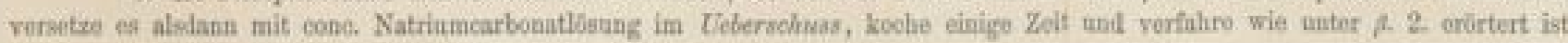

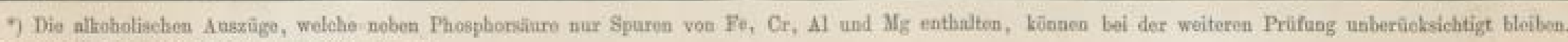
Die Oxalature wird bei obiger Behandlungwwoise zerstïrt.

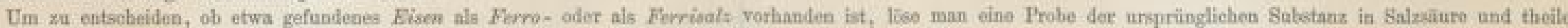

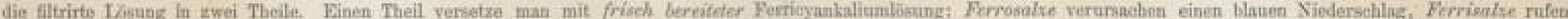
eine rothbraune Firbang bervor; - den andern Theil versetze man mit Ferrocyankalitumlisung: Ferrisalve verursachen einen blanen Niedersohlag 


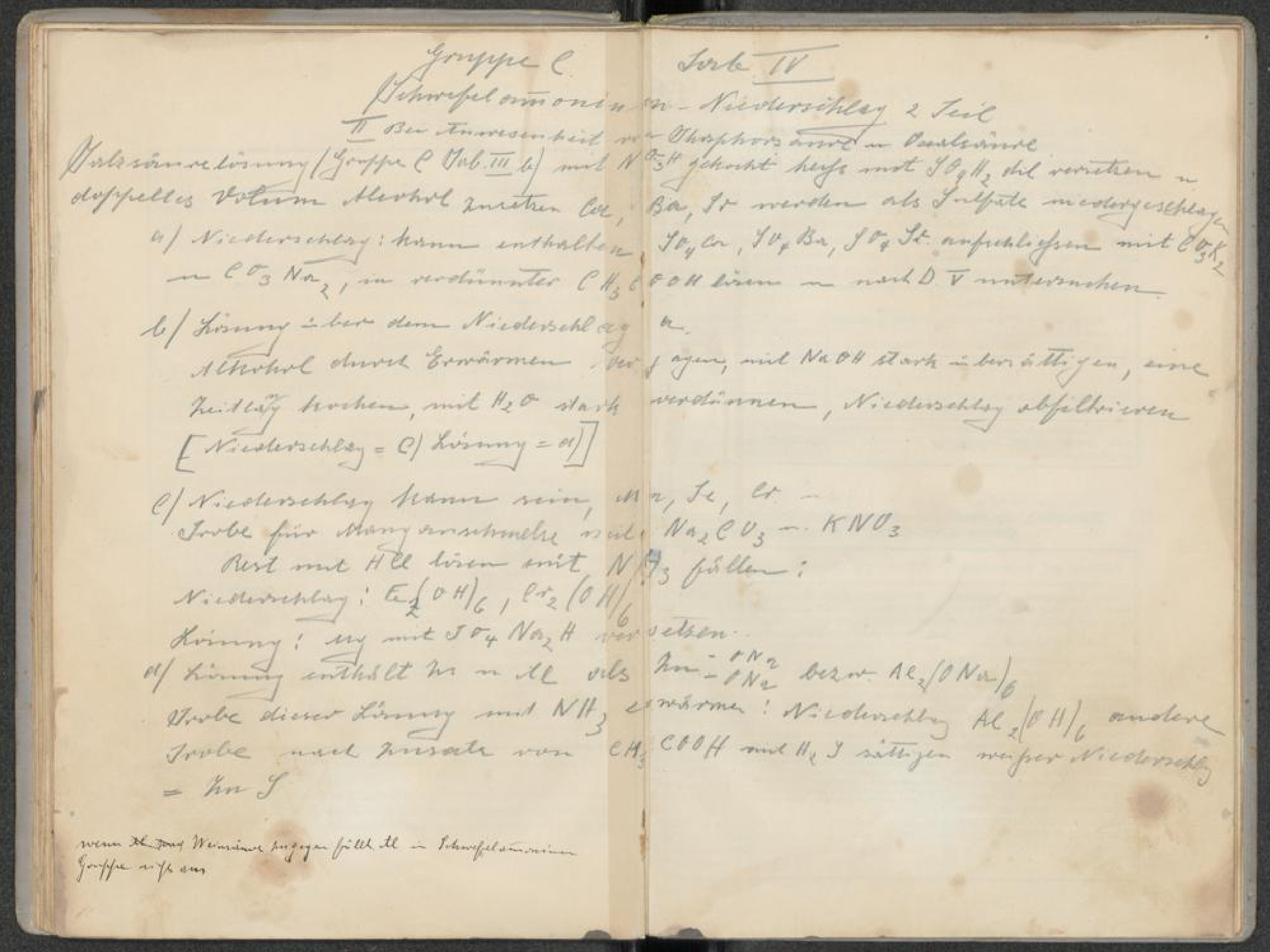




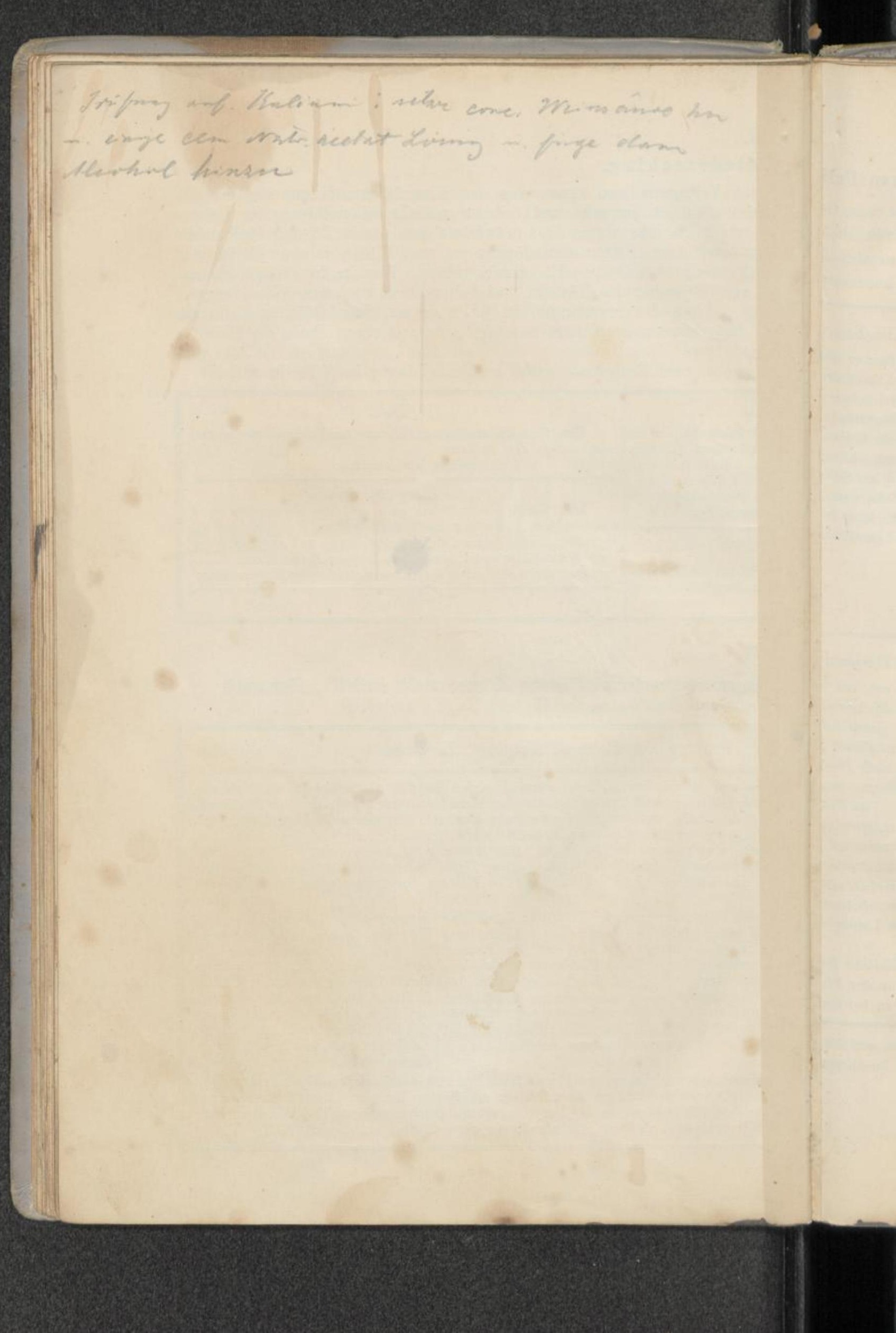



III. Untersuchung des in Săuren Unlosłlichen, „des unlöslichen Rückstandes".

Tab. VI.

Der bei der Untersuchung von Oxyden, Salzen etc, oder von Getnengen derselben (s. S, 48) verbleibende, in Säuren (Königswasser) unlösliche Rïckstand kann, wenn alles Lösliche durch sorgfiltiges Auskochen mit Säuren und Answaschen entfernt ist, enthalten: Kohle, Kïeselsäure (Silicate), Chlorsilber, Chlorblei, Bleisulfat, Zinn- und Antimonoxyde, Baryum-, Calcium-, Strontiumsulfat und ev, anch Eisen-, Aluminium und Chromoxyd. Derselbe werde nach sorgfiiltigem Auswaschen successive nach a, b, c, d, e und $f$ geprüft.

\begin{tabular}{|c|c|c|}
\hline 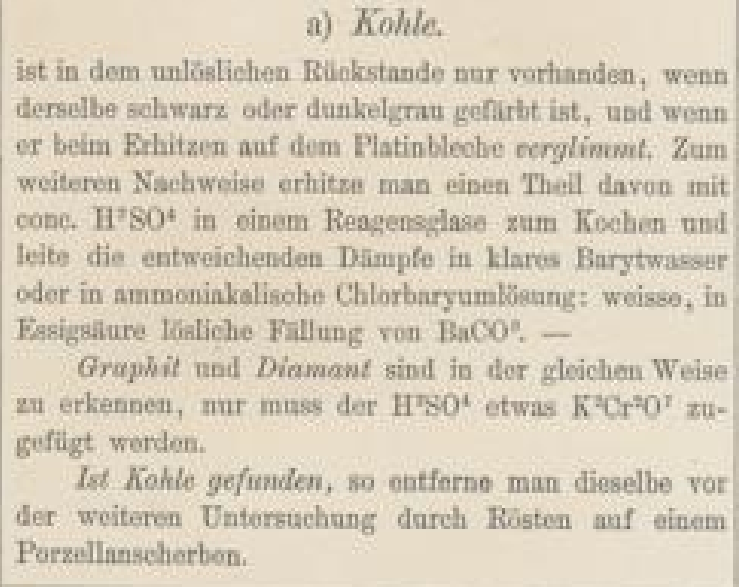 & 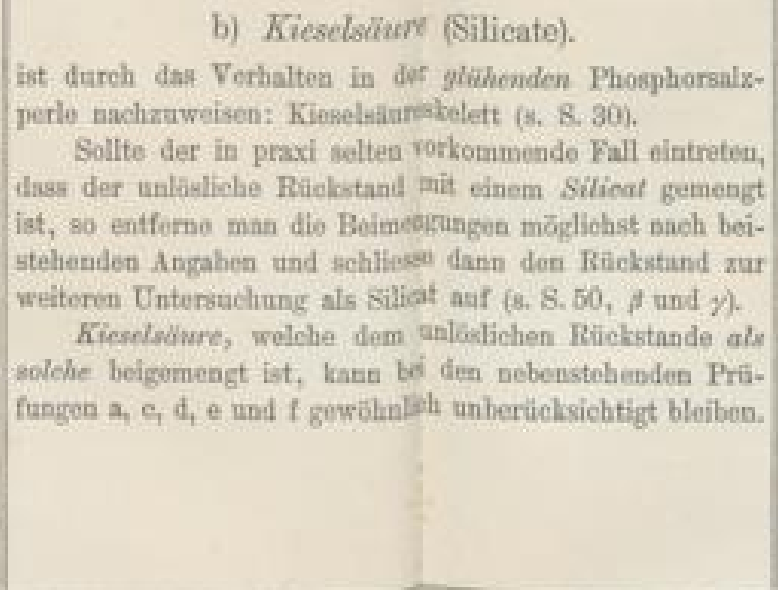 & 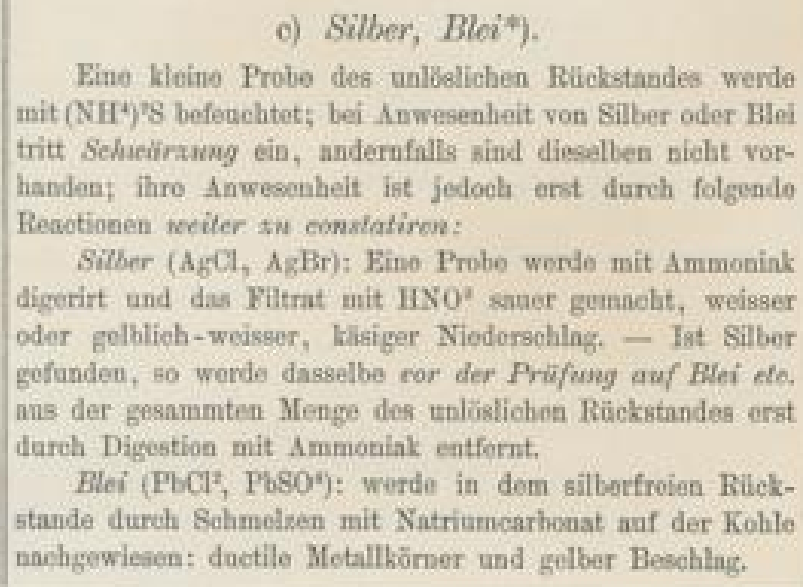 \\
\hline 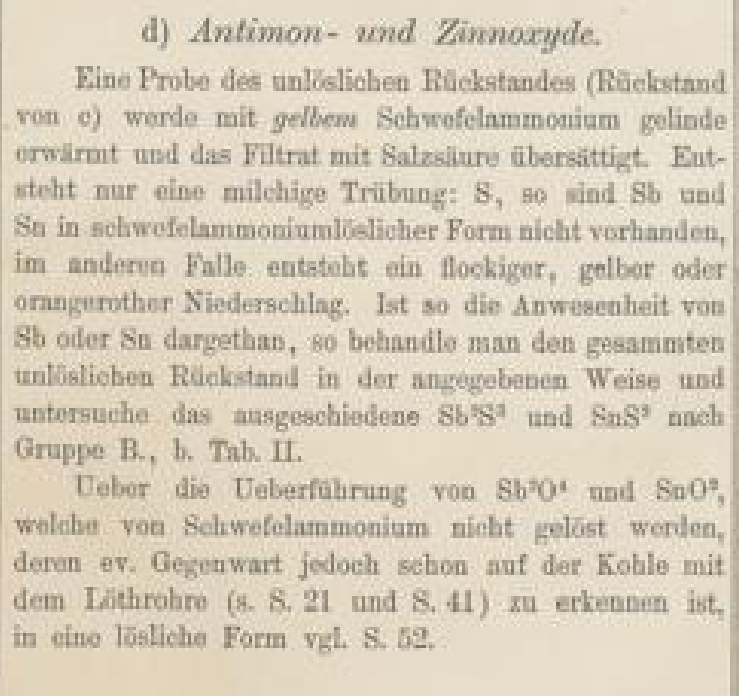 & 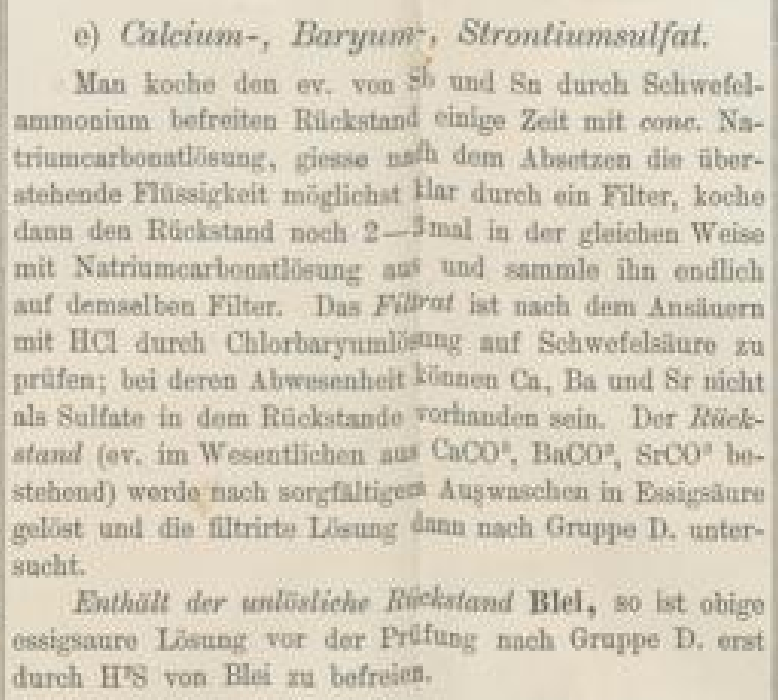 & 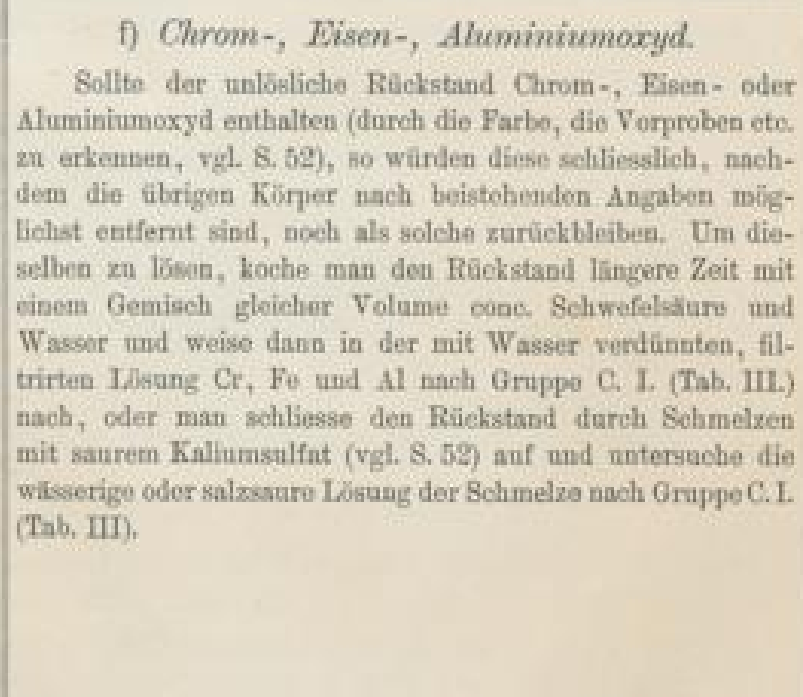 \\
\hline
\end{tabular}

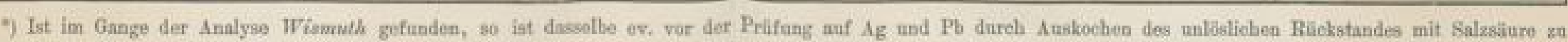

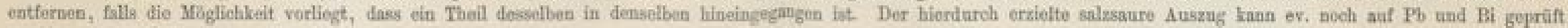
werden, wie aut Tab. $I$ angegeben ist. 


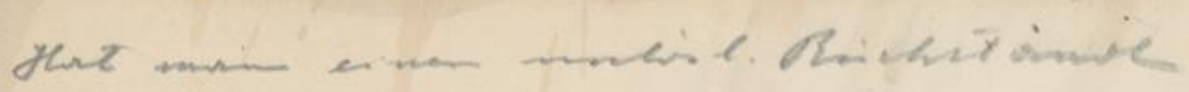

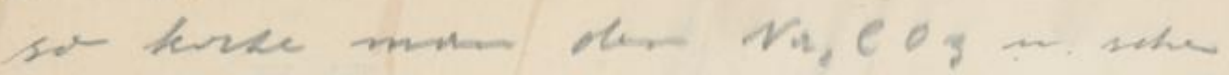

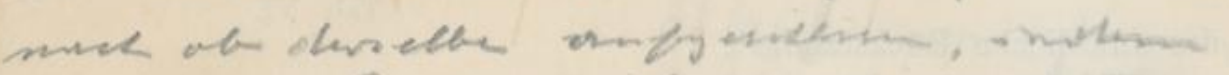

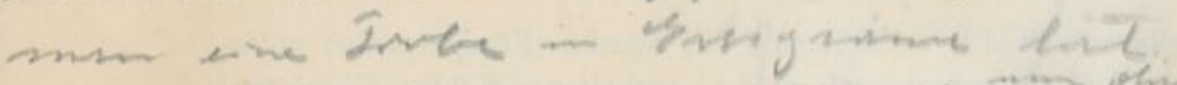

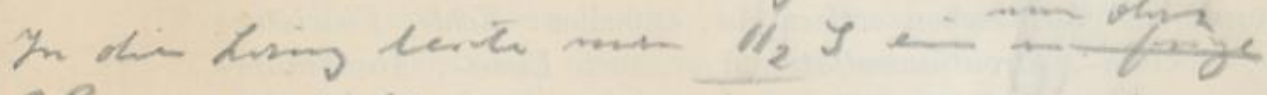

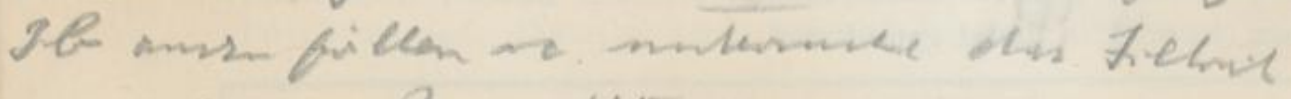
and Cuk., Bay. Ytions

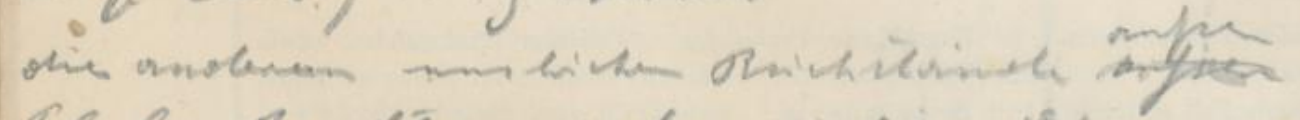

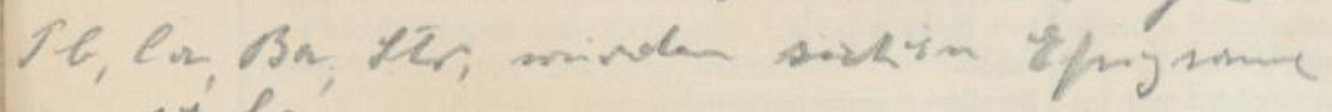
mrees hise. 


\section{Untersuchung der Säuren.}

$\mathrm{Da}$ bei Berücksichtigung der Löslichkeitsverhältnise die Anwesenheit gewisser Basen die gleichzeitige Anwesenheit gewisser Säuren in dem Untersuchungsobjecte ausschliesst, so überlege man, ehe man zur Prüfung auf die Säuren schreitet, welche Säuren, bei Berücksichtigung der gefundenen Basen, überhaupt vorhanden sein können.

a) Löst sich die Substanะ in Wasser ohne saure Reaction: so kann bei Gegenwart einer andern Base als Alkalion weder Kieselsäure, noch Kohlensüure, noch Phosphorsäure, noch Fluor vorhanden sein, und umgekehrt.

b) Löst sich die Substanz in Wasser olne alkalische Reaction: so kann bei Gegenwart eines Schwermetalls kein Schwefelmetall in der Substanz enthalten sein, ebensowenig kann sich bei Anwesenheit von Blei gleichzeitig Schwefelsäure vorfinden.

c) Zeigt die Lösung neutrale oder saure Reaction:

so kann bei Anwesenheit von Baryum oder Strontium keine Schwefelsäure vorhanden sein, ebensowenig bei Anwesenheit von Silber- oder Queclesilberoxydulsalz gleichzeitig Chlor, Brom oder Jod.

\section{Vorprüfung auf Säuren.}

In einem trocknen Reagensglase werde eine kleine Messerspitze voll der ursprünglichen, trocknen Substanz mit dem 3 bis 4 fachen Volum conc. Schwefelsäure übergossen und gelinde erwärmt. Man beobachte, ob sich Dämpfe entwickeln und welche Eigenschaften dieselben haben. Findet keine Entwicklung von Dämpfen statt, so ist die Gegenwart flüchtiger, bezüglich durch $\mathrm{H}^{2} \mathrm{SO}^{4}$ abscheidbarer oder zersetzbarer Säuren ausgeschlossen.

\section{a) Farblose Gase oder Dämpfe.}

Chlorwasserstoff: stechend riechend, Nebel bildend, Wasser am Glasstab nicht trübend.

Fluonvasserstoff: stechend riechend, bei Anwesenheit von Kieselsäure (auch von Glas) Wasser am Glasstab trübend (vgl. S. 34).

Salpetersäure: fast farblose Dämpfe, auf Zusatz von Ferrosulfat oder von Kupfer roth werdend. 
Kohlensëure: geruchlos, Barytwasser am Glasstab trübend (ev. auch von Oxalsäure oder anderen organischen Säuren herrührend).

Oxalsäure: Kohlensäure und Kohlenoxyd entwickelnd.

Ameisensäure: Kohlenoxyd (mit blauer Flamme brennbar) entwickelnd.

Cyanwasserstoff, Ferrocyanwasserstoff, Ferrieyanwasserstoff: Kohlenoxyd entwickelnd.

Schweflige Säure: durch den Geruch und durch das Verhalten gegen Jodsäurestärkepapier (vgl. S. 25) kenntlich.

Schwefelwasserstoff: durch den Geruch und durch das Verhalten gegen Bleipapier kenntlich.

b) Gefärbte Gase oder Dämpfe.

\section{Rothbraun.}

Brom, von Bromiden oder Bromaten herrührend, besonders nach Zusatz von Braunstein.

Chromsäure, bei Gegenwurt von Chloriden, in Folge Bildung von $\mathrm{CrO}^{2} \mathrm{Cl}^{2}$.

Salpetrige Säure, von Nitriten oder Nitraten herrührend.

$$
\text { Gelb-grün. }
$$

Unterchlorige Süure, Chlor entwickelnd.

Chlorsäure, explosible Unterchlorsäure entwickelnd; die Verbindung verpufft auf Kohle.

\section{Violett.}

Jod, von Jodiden herrührend.

\section{Einzelprüfung auf Säuren.}

Chlor-, Brom- und Jodwasserstoff.

«. Bei Abwesenheit von Cyanverbindungen.

1. Chlorwasserstoff. Eine Probe der ursprünglichen Substanz werde mit verdünnter Salpetersäure gelinde erwärmt, ev. filtrirt und mit wenig Silbernitratlösung versetzt: weisser, käsiger, nach dem Auswaschen in Ammoniak leicht löslicher Niederschlag: AgCl.

Ist der durch wenig Silbernitratlösung hervorgerufene Niederschlag, nach dem Umschütteln der Mischung und darauffolgendem Absetzenlassen derselben, rein weiss gefärbt, so ist nur 
Chlorwasserstoff zugegen, ist der entstandene Niederschlag dagegen gelblich oder gelb gefärbt, so ist auch Brom-oder Jodwasserstoff vorhanden, und prüfe man alsdann auf Chlorwasserstoff nach $4 \mathrm{~g}$ ) oder $\mathrm{h}$ ).

Bei Gegenwart von Silber (ev, auch von Quecksilber und Blei) digerire man zur Prüfung auf Chlor-, Brom oder Jod eine Probe des ursprünglichen Untersuchungsobjectes erst einige Zeit mit Zinkpulver und verdünnter Schwefelsäure, filtrire alsdann und untersuche das Filtrat nach 1, 2 und 3, bez. 4.

2. Bromwasserstoff. Prüfung wie auf Chlorwasserstoff: gelblicher, in Ammoniak schwer löslicher Niederschlag: AgBr.

Zur weiteren Charakterisirung vorhandenen Brommetalls werde:

a) Das gefallte Bromsilber: $\mathrm{AgBr}$, durch Decantiren ausgewaschen, etwas Schwefelkohlenstoff zugefügt und tropfenweise starkes Chlorwasser zugesetzt. Nach Zusatz jedes Tropfens Chlorwasser werde die Mischung umgeschüttelt: Gelb- bis Braunfärbung des Schwefelkohlenstoffs. Vgl. auch $4 \mathrm{e}$.

b) Eine Probe der ursprünglichen Substanz mit der gleichen Menge Braunsteinpulver gemischt und das Gemisch mit der $2-3$ fachen Menge conc. Schwefelsäure erwärmt: Entwickelung von braunen Bromdämpfen.

3. Jodwasserstoff. Prüfung wie auf Chlorwasserstoff: gelber, in Ammoniak unlöslicher Niederschlag: AgJ.

Zur weiteren Charakterisirung vorhandenen Jodmetalls werde:

a) Das gefällte Jodsilber: AgJ, durch Decantiren ausgewaschen, etwas Schwefelkohlenstoff zugefügt und tropfenweise starkes Chlorwasser zugesetzt. Nach Zusatz jedes Tropfens Chlorwasser werde die Mischung umgeschüttelt: Violettfürbung des Schwefelkohlenstoff's. Vgl. auch $4 \mathrm{e}$.

b) Eine Probe der ursprünglichen Substanz mit Eisenchloridlösung gelinde erwärmt, die Mischung mit Wasser verdünnt und mit Stärkelösung versetzt: Blaufärbung.

4. Chlor-, Brom- und Jodwasserstoff nebeneinander. Ist der durch wenig Silbernitrat in salpetersaurer Lösung erzeugte Niederschlag gelb oder gelblich gefärbt, so enthält er Bromoder Jodsilber, mithin ist Brom- oder Jodwasserstoff, ev. neben Chlorwasserstoff vorhanden. In letzterem Falle werde der durch überschüssiges Silbernitrat erzeugte gelbe Niederschlag durch Decantiren ausgewaschen und mit Ammoniak im Ueberschuss gelinde erwärmt:

a) Es löst sich der ganze Niederschlag, so ist kein Jodsilber, mithin auch kein Jodwasserstoff vorhanden. 
b) Es löst sich der Niederschlag nur theilweise, so kann Chlor-, Brom- und Jodwasserstoff gleichzeitig vorhanden sein. In diesem Falle werde die ammoniakalische Lösung abfiltrirt und das Filtrat mit Salpetersäure übersättigt. Es entsteht hierdurch:

a. liein Niederschlag:

Abwesenheit von $\mathrm{HCl}$ und $\mathrm{HBr}$.

\section{$\beta$. ein rein weisser Niederschlag:}

Anwesenheit nur von $\mathrm{HCl}$. $\gamma$. ein gelblicher Niederschlag: ev. Anwesenheit von $\mathrm{HCl}$ und $\mathrm{HBr}$.

Zur weiteren Charakterisirung der einzelnen Halogene benutze man die unter $4 \mathrm{c}, \mathrm{d}, \mathrm{e}, \mathrm{f}, \mathrm{g}$ und $\mathrm{h}$ angegebenen Reactionen.

c) Bromwasserstoff neben Chlorwasserstoff. Der nach $\gamma$ erhaltene gelbliche Niederschlag ist nach dem Auswaschen durch Decantiren nach 2a auf Brom zu prüfen. Der Nachweis des Broms kann ev. auch nach $2 b$ geführt werden.

d) Bromwasserstoff neben Jodwasserstoff. Die Scheidung des Silberniederschlags ist, wie oben erörtert, durch Ammoniak zu bewirken und die weitere Charakterisirung nach $2 \mathrm{a}$ bez. $3 \mathrm{a}$ auszuführen.

e) Bromwasserstoff kann neben Jodwasserstoff meist auch in der Weise nachgewiesen werden, dass man den mit salpetersäurehaltigem Wasser gemachten Auszug der ursprünglichen Substanz, oder letztere selbst, nach dem Anschütteln mit Wasser, mit Schwefelkohlenstoff und alsdann tropfenweise mit starkem Chlorwasser versetzt. Nach Zusatz jedes Tropfens Chlorwasser werde die Mischung umgeschüttelt. Bei Gegenwart von Jodwasserstoff tritt hierbei zunächst eine Violettfärbung des Schwefelkohlenstoffs ein, die bei weiterem vorsichtigem Zusatz von Chlorwasser allmälig verschwindet, um bei Gegenwart von Bromwasserstoff schliesslich einer gelbbraunen oder braunen Färbung Platz zu machen ${ }^{1}$ ). Diese Reaction kann auch zum Einzelnachweis von Brom- und Jodwasserstoff dienen.

f) Jodwasserstoff neben Chlor- oder Bromwasserstoff. Der in Ammoniak unlösliche Theil des Silberniederschlags (vgl. oben) werde nach 3a geprüft. Der Nachweis des Jods kann ev. auch nach $3 \mathrm{~b}$ oder $4 \mathrm{e}$ geführt werden.

g) Chlorwasserstoff neben Brom- und ev. auch neben Jodwasserstoff. Eine Probe der ursprünglichen Substanz werde mit der gleichen Menge Kaliumdichromat gemischt und mit der drei-

1) Bei Gegenwart von leicht oxydirbaren Substanzen [z. B. $\mathrm{SnCl}^{2}$, $\left.\mathrm{K}^{4} \mathrm{Fe}(\mathrm{CN})^{6}\right]$ treten die Jod-oder Bromfärbungen des Schwefelkohlenstoffes erst dann ein, wenn jene Substanzen durch das Chlor oxydirt sind. 
fachen Menge reiner conc. Schwefelsäure in einer trocknen Retorte destillirt. Das Destillat zeigt bei Gegenwart von Chlor, nach dem Uebersättigen mit Ammoniak, eine gelbe Farbe. (Vgl. S. 31.)

h) Chlorwasserstoff kann neben Brom- und Jodwasserstoff meist auch derartig nachgewiesen werden, dass man den mit verdümnter Salpetersäure hergestellten und ev. filtrirten Auszug der ursprünglichen Substanz tropfenweise mit Silbernitratlösung versetzt und die Mischung nach jedem Zusatz tüchtig durchschüttelt. Es scheidet sich hierbei zunächst gelbes Jodsilber, dann blassgelbes Bromsilber und schliesslich rein-weisses Chlorsilber aus.

\section{$\beta$. Bei Anwesenheit von Cyanverbindungen.}

5. Um Chlor-Brom-Jodwasserstoff neben Cyanverbindungen nachzuweisen, werde der durch überschüssige Silbernitratlösung in salpetersaurer Lösung erhaltene Niederschlag durch Decantiren ausgewaschen, noch feucht mit einer Mischung gleicher Volume conc. Schwefelsäure und Wasser übergossen und die Mischung dann nach Zusatz einiger Tropfen Salpetersäure gekocht:

a) löst sich der Niederschlag (namentlich nachdem das Auskochen mit Schwefelsäure wiederholt ist) vollständig, so ist weder Chlor-, noch Brom-, noch Jodwasserstoff vorhanden.

b) löst sich der Niederschlag nur theilweise, so koche man das Ungelöste dem Decantiren der darüber stehenden Lösung abermals mit obiger Schwefelsüuremischung aus, lasse erkalten, verdünne mit Wasser, wasche das Ungelöste durch Decantiren aus und untersuche es, wie oben erörtert ist, auf Chlor, Brom und Jod.

* 6. Schwefel. Der Schwefel scheidet sich beim Auflösen der Substanz in verdünnten Säuren entweder als solcher in zusammengeballten Massen ab, oder er entweicht als Schwefelwasserstoff beim Uebergiessen und Erwärmen der Substanz mit Salzsäure.

7. Schwefelsäure. Eine Probe der Substanz werde mit verdünnter Salzsäure digerirt und die ev. filtrirte Lösung mit Chlorbaryum versetzt: weisser, in Säuren unlöslicher Niederschlag. - Schwer- oder unlösliche Sulfate $\left(\mathrm{PbSO}^{4}, \mathrm{BaSO}^{4}\right.$ etc.) koche man anhaltend mit einer conc. Lösung von Natriumcarbonat, filtrire, mache das Filtrat mit Salzsäure sauer und prüfe dann mit Chlorbaryum.

8. Salpetersäure. Eine Probe der fein gepulverten Substanz werde mit Wasser angeschüttelt, das Gemisch (ohne zu filtriren) mit dem gleichen Volum conc. Schwefelsäure gemischt und die heisse Mischung alsdann mit Eisenvitriollösung überschichtet: 
Braune, bisweilen erst allmälig auftretende Zone an der Berührungsfläche.

Bei sehr dunkel gefürbten, namentlich unlöslichen Substanzen, verwende man einen salzsauren Auszug derselben zur Prüfung.

Bei Gegenwart von Jod-, ev. auch Brommetallen, sowie von Chromaten versetze man den wässerigen oder schwach salzsauren Auszug der Substanz mit Bleiessig, lasse einige Zeit stehen, filtrire und prüfe dann das Filtrat, wie oben erörtert ist.

Bei Gegenwart von Ferro - oder Ferricyaniden oder von Rhodaniden, versetze man den wässerigen oder schwach salzsauren Auszug der Substanz zunächst mit einer genügenden Menge Bleiacetatlösung und hierauf mit Ammoniak bis zur schwach alkalischen Reaction. Nach dem Absetzen werde die Misehung filtrirt und das Filtrat, wie oben erörtert ist, mit Schwefelsäure und Eisenvitriollösung geprüft.

9. Kohlensäure. Eine Probe der Substanz werde mit Wasser angeschüttelt, das Gemisch aufgekocht und alsdann mit Salzsäure vorsichtig versetzt: Entwickelung eines geruchlosen Gases (Aufbrausen), welches beim Annähern eines mit Barytwasser befeuchteten Glasstabes denselben sofort weiss beschlägt.

\section{Phosphorsäure.}

a) Bei wasserlöslichen Substanzen, welche nur Alkalimetalle als Base enthalten ( $\mathrm{K}-, \mathrm{Na}-, \mathrm{Li}_{-}, \mathrm{NH}^{4}$-Verbindungen). Die Lösung werde mit Chlorammonium, dann mit Ammoniak und endlich die klare Mischung mit Magnesiumsulfatlösung versetat: sofort oder nach einiger Zeit weisser, körnig-krystallinischer Niederschlag.

b) Bei säurelöslichen Substanzen. Die Phosphorsäure findet sich nach dem analytischen Gange entweder im Schwefelammonium-Niederschlage oder in der davon abfiltrirten [ [ $\mathrm{H}^{2} \mathrm{~S}$ und $\left(\mathrm{NH}^{4}\right)^{2} \mathrm{~S}$ freien] Flüssigkeit. Eine Probe dieses Niederschlags oder jener Flüssigkkeit oder auch der ursprünglichen Substanz (bei Abwesenheit von Arsen) werde in Salpetersäure gelöst, die ev. filtrirte Lösung mit dem 2 fachen Volum Ammoniummolybdatlösung versetzt und'die Mischung einige Zeit bei Seite gestellt: gelber, körniger Niederschlag.

11. Borsüure. Eine Probe der ursprünglichen Substanz werde in einem Schälchen mit der 2 fachen Menge conc. Schwefelsäure übergossen und die Mischung nach Zusatz von Alkohol angezündet. Beim Umrühren mit einem Glasstabe erscheint die Flamme grün gefärbt (besonders kurz vor dem Erröschen). 
Bei Gegenwart von Kupfer ist letzteres erst durch Schwefelwasserstoff aus der salzsauren Lösung der ursprünglichen Substanz zu entfernen, das Filtrat einzudampfen und der Rückstand dann, wie oben angegeben, zu prüfen.

12. Oxalsäure. Eine Probe der ursprünglichen Substanz werde mit Natriumcarbonatlösung im Ueberschusse gekocht, das Filtrat mit Essigsäure sauer gemacht und mit wenig Chlorcalciumlösung versetzt: allmälig weisse Trübung oder Fällung.

\section{Essigsäure.}

a) Eine Probe der ursprünglichen Substanz werde mit dem gleichen Volum Alkohol und conc. Schwefelsäure in einem Reagensglase bis nahe zum Kochen erhitzt: Geruch nach Essigäther, besonders nachdem die Mischung einige Zeit gestanden hat.

b) Eine Probe der ursprünglichen Substanz werde in einem Porzellanschälchen mit überschüssiger verdünnter Schwefelsäure gelinde erwärmt und die Mischung bedeckt einige Zeit bei Seite gestellt: Geruch nach Essigsäure.

c) In zweifelhaften Fällen sind zum Vergleiche diese Reactionen mit einem essigsauren Salze auszuführen, oder ist ev. die Kakodylreaction (s. S. 37) zur Anwendung zu bringen.

14. Weinsäure.

a) Bei Gegenwart von Weinsäure tritt Schwärzung und Geruch nach Caramel auf, wenn man eine Probe der Substanz auf dem Platinbleche erhitzt.

b) Kocht man eine Probe der ursprünglichen Substanz mit Kaliumcarbonatlösung, filtriirt, übersättigt das Filtrat mit Essigsäure und dampft dasselbe auf ein kleines Volum ein, so scheiden sich nach einiger Zeit kleine, weisse Krystalle von Weinstein ab (beim Erhitzen auf dem Platinblech schwarz werdend).

c) Erhitzt man eine Probe der ursprünglichen Substanz mit einer Lösung von Resorcin in conc. reiner Schwefelsäure (etwa $1: 100)$ auf $125-130^{\circ}$ C., so tritt bei Gegenwart von Weinsäure eine intensiv violett-rothe Färbung ein.

Durch die Gegenwart von Nitraten, Nitriten und Jodiden wird diese Reaction unbrauchbar gemacht; man prüfe in diesem Falle die nach $14 \mathrm{~b}$ erhaltenen Weinsteinkryställehen in obiger Weise.

15. Cyan-, Ferrocyan-, Ferricyan- und Rhodanwasserstoff. Ueber den Nachweis dieser Säuren s. S. 44. Enthält die untersuchte Substanz Quecksilber, so ist für den Nachweis des Cyanwasserstoffs eine Probe derselben mit Wasser auszukochen, die filtrirte Lösung durch Schwefelwasserstoff von Quecksilber zu befreien und alsdann das Filtrat in der üblichen Weise (s. S. 46) auf Cyanwasserstoff zu prüfen. 
16. Fluor. Ueber den Nachweis von Fluor s. S. 44. Zur Erkennung von Fluor in fluorhaltigen Silicaten (Glimmer, Topas, Lepidolith etc.) schmelze man die feingepulverte Substanz mit der dreifachen Menge Kalium-Natriumcarbonat im Platintiegel, weiche die Schmelze mit heissem Wasser auf, füge Ammoniumcarbonatlösung zu und digerire damit einige Zeit. Der entstehende, die Kieselsäure etc. enthaltende Niederschlag werde abfiltrirt, das Filtrat davon zur Trockne verdampft und der Rückstand in der üblichen Weise auf Fluor geprüft.

Bei nicht $z u$ geringen Mengen von Fluor gelingt der Nachweis desselben neben Kieselsäure auch, wenn man das fluorhaltige Silicat mit conc. Schwefelsäure in einem Reagensglase erhitzt und das entweichende Gas (SiF$\left.{ }^{4}\right)$ durch ein angefeuchtetes Glasrohr in Wasser leitet. Enthalt das Gas Fluorsilicium: $\mathrm{SiF}^{4}$, so trübt sich das Rohr durch ausgeschiedene Kieselsäure (beim Trocknen des Rohres als weisser Ueberzug hervortretend) und Wasser dascheider saure Reaction an; häufig findet auch in dem Wasser Abscheidung gallertartiger Kieselsäure statt.

17. Kieselsäure. Ueber den Nachweis durch die Phosphorsalzperle s. S. 30. Bei Gegenwart von Fluor ist behufs Nachweis von Kieselsäure in der unter 16 angegebenen Weise zu verfahren. Der durch Ammoniumcarbonat erhaltene Niederschlag (s. oben) werde ausgewaschen, mit überschüssiger Salzsäure im Wasserbade zur Trockne verdampft, der Rückstand mit cone. Salzsäure durchfeuchtet und nach einigem Stehen mit Wasser ausgezogen. Etwa vorhandene Kieselsäure bleibt als weisses Pulver zurück. (Phosphorsalzperlenreaction.)

Soll in der zu untersuchenden Substanz auch der ev. Nachweis von schwefliger Säure, unterschwefliger Süure, salpetriger Säure, unterchloriger Säure, Chlorsäure, Bromsäure, Jodsäure, Ameisensäure, Bernsteinsäure, Aepfelsäure, Citronensäure, Benzoёsäure, Salicylsäure, sowie von Tïtan, Caesium, Rubidium, Thallium, Beryllium, Vanadin, Molybdän, Wolfram, Uran, Selen und Tellur geführt werden, so ist dies nach den in der ersten Abtheilung, bezüglich im Anhang angegebenen Reactionen oder
durch die Vorprüfung zu bewirken. 


\section{Anhang.}

\section{Reactionen einiger seltener Elemente.}

\section{Titan (Titansäure).}

a) Ammoniale, ätrende und kohlensaure Alkalien, sowie Schvefelammonium scheiden aus salzsaurer Lösung der Titansäureverbindungen weisse, gallertartige Orthotitansäure: $\mathrm{H}^{4} \mathrm{TiO}^{4}$, ab, die nach dem Auswasehen mit kaltem Wasser in Salzsäure löslich ist. Findet die Fallung durch obige Agentien in der Siedehitze statt, so scheidet sich weisse, in Salzsäure unlösliche Metatitansäure: $\mathrm{H}^{2} \mathrm{TiO}^{3}$, aus. Sehwefelwasserstoff ruft keine Fillung hervor.

b) Metallisches Zink oder Zinn scheiden aus der salzsauren Lösung dér Titansäure Titansesquioxyd ab, welehes zunächst mit violetter Farbe gelöst bleibt, allmälig sich aber als violettes Pulver absetzt.

c) Wasserstoffsuperoxyd ruft in salzsaurer oder schwefelsaurer Lösung eine intensiv gelbe bis tief orangefarbene Fürbung hervor.

d) Ferrocyankalium erzeugt in salzsaurer Lösung eine dunkelbraune Fällung.

e) Die Phosphorsalzperle wird in der Oxydationsflamme nicht gefärbt; bei lang anhaltendem Erhitzen in der Reductionsflamme tritt nach dem Erkalten Violettfärbung ein. Ein Zusatz von etwas Zinu beschleunigt die Färbung. Eisenhaltige Titansäure (z. B. Rutil, Titaneisen) färbt die Phosphorsalzperle in der reducirenden Flamme blutroth.

Unlösliche Titansäureverbindungen werden durch längeres Sehmelzen mit saurem Kaliumsulfat $(1: 6)$ aufgeschlossen. Durch Behandeln der kalten Schmelze mit viel kaltem Wasser, dem einige Tropfen Schwefelsäure zugesetzt sind, geht die Titansäure in Lösung und kann darin durch obige Reactionen erkannt werden; bei längerem Kochen scheidet sich aus obiger Lösung unlösliche Metatitansäure aus.

\section{Caesium und Rubidium.}

a) Platinchlorid, Weinsäure, Kieselfluorwasserstoffisäure und Ueberehlorsëure verhalten sich wie gegen die Kaliumsalze.

b) Die nicht leuchtende Flamme des Bunsen'schen Brenners wird durch Caesium - und Rubidiumsalze violett gefärbt; durch Kobaltglas betrachtet, verschwindet die Flammenfärbung nicht.

c) Das Spectrum der Caesiumflamme kennzeichnet sich durch zwei intensiv blane und eine weniger intensive, orangerothe Linie. Das Spectrum der Rubidiumflamme zeigt zwei rothe und zwei blauviolette Linien.

\section{Thallium.}

a) Schwefelwasserstoff scheidet aus neutraler Lösung der Thalliumsalze starker Säuren nur einen Theil des Thalliums als schwarzes Thalliumsulfür: TIS, ab; bei Anwesenheit von freien Mineralsäuren findet keine Fallung statt, wohl aber nach Zusatz von Natriumacetat im Ueberschuss.

Schmidt, Anleitung z. qualitativen Analyse. 
b) Sehwefelammonium fällt schwarzes Thalliumsulfür: $\mathrm{Tl}^{2} \mathrm{~S}$, unlöslich in einem Ueberschusse des Fuillungsmittels, leicht löslich in Salpetersäure, schwieriger löslich in Salzsäure und verdünnter Schwefelsäure. lium: $\mathrm{TICl}$.

c) Salnsäure und lösliche Chlormetalle fällen weisses Chlorthal-

d) Jodkalium scheidet gelbes Jodthallium: TLJ, ab.

e) Platinchlorid erzeugt einen gelben, krystallinischen Niederschlag $\left(\mathrm{Tl}^{2} \mathrm{PtCl}^{6}\right)$.

f) Ammoniak, ätrende und kohlensaure Alkalien rufen keine Fällung hervor.

g) Thallium und seine Salze färben die Flamme intensiv grün; im Spectrum zeigt die Thalliumflamme eine grüne Linie.

\section{Beryllium.}

a) Aetrende und kohlensaure Alkalien bewirken weisse Fallungen, die sich in einem grossen Ueberschusse des Fällungsmittels in der Kälte wieder lösen; beim Kochen letzterer Lösungen tritt von Neuem Fällung ein.

b) Sehwefelwasserstoff ruft keine Fällung hervor; Schwefelammonium fällt weisses Hydroxyd: $\mathrm{Be}(\mathrm{OH})^{2}$.

Natürliche Beryllverbindungen (Beryll, Chrysoberyll, Euklas etc.) sind durch Schmelzen mit der 4 fachen Menge Kalium-Natriumcarbonat aufzuschliessen. Die Schmelze ist dann zur Abscheidung der Kieselsäure mit Salzsänre im Uebersehuss einzudampfen, der Rückstand mit starker Salzsäure zu durchfeuchten und nach einiger Zeit schliesslich mit Wasser zu extrahiren. Letztere Lösung ist dann zur Prüfung auf Be ete. zu verwenden.

\section{Vanadin (Vanadinsäure).}

a) Schwefelwasserstoff und schweflige Säure reduciren die Vanadinsäure in saurer Lösung zu Vanadindioxyd: $\mathrm{VO}^{2}$, welches mit blauer Farbe gelöst bleibt.

b) Schwefelammonium erzeugt in der Lösung der Vanadinsïure und deren Salze einen braunen Niederschlag, welcher in gelbem Schwefelammonium mit brauner, in farblosem Schwefelammonium mit kirsehrother Farbe löslich ist. Durch Neutralisation mit Salzsäure scheidet sich aus letzterer Lösung braunes Schwefelvanadin ab.

e) Gerbsäure fällt die neutralen vanadinsauren Salze blauschwarz.

d) Zink ruft in der salzsauren Lösung der Vanadate eine blaue Fïrbung hervor.

e) Schüttelt man die angesäuerte Lösung eines vanadinsauren Salzes mit Wasserstoffsuperoxydlösung und Aether, so nimmt letzterer eine dunkelrothe Farbe an.

f) In der Borax - und in der Phosphorsalxperle lösen sich die Vanadinsäure und die Oxyde des Vanadins in der oxydirenden Flamme mit gelblicher Farbe auf. In der reducirenden Flamme färbt sich die Perle in der Hitze braun, beim Erkalten schön grün.

Zum Nachweis von Vanadin im Brauneisenstein, Eisenschlacken etc. schmelze man dieselben (in nicht zu kleiner Menge) im fein gepulverten Zustande mit Salpeter und Soda, ziehe die Schmelze mit wenig Wasser aus und weise in dieser ev. gelb gefärbten Lösung nach obigen Angaben das Vanadin nach.

Vanadinblei löst sich in Salpetersäure beim Kochen auf. Auf der Kohle liefert es ein Bleikorn, in der Phosphorsalzperle die Vanadinreaction. 


\section{Cer.}

Die Ceroxydsalxe sind ungefärbt; die wasserlöslichen besitzen süssen, etwas zusammenziehenden Geschmack und zeigen kein Absorptionsspectrum. Die Cerdioxydsalze sind gelb, gelbroth oder braun gefärbt.

a) Schwefelwasserstoff verursacht keine Fällung; Schwefelammonium scheidet weisses Cerhydroxyd: $\mathrm{Ce}^{2}(\mathrm{OH})^{6}, \mathrm{ab}$.

b) Kalihydrat fällt weisses, in einem Ueberschusse des Fällungsmittels lösliches Cerhydroxyd: $\mathrm{Ce}^{2}(\mathrm{OH})^{6}$, welches nach dem Auswaschen und Trocknen an der Luft eine gelbe Farbe annimmt. Streut man von dem hierbei entstandenen Cerdioxydhydrat etwas in eine Lösung von Strychnin in cone. Schwefelsäure $(1: 1000)$, so tritt eine intensiv blaue, bald in Rothviolett übergehende Färbung auf.

c) Oxalsäure scheidet weisses, allmälig krystallinisch werdendes Ceroxydoxalat $\mathrm{ab}$, welches in überschüssiger Oxalsäurelösung unlöslich ist. Bei Luftzutritt erhitzt, geht das Ceroxydoxalat in Cerdioxyd: $\mathrm{CeO}^{2}$, über, welches heiss orangeroth, kalt gelblichweiss gefärbt ist.

d) Kaliumsulfat (gesättigte Lösung) fällt weisses, in überschüssiger Kaliumsulfatlösung unlösliches Kaliumceroxydsulfat: $3 \mathrm{~K}^{2} \mathrm{SO}^{4}+$ $\mathrm{Ce}^{2}\left(\mathrm{SO}^{4}\right)^{3}$.

e) Natriumhypochlorit fällt gelbrothes Cerdioxydhydrat: $\mathrm{Ce}(\mathrm{OH})^{4}$, welches sich in heisser Salzsäure unter Chlorentwicklung löst.

f) Bleisuperoxyd in geringerer Menge zu einer Lösung eines Ceroxydsalzes in verdünnter Salpetersäure gesetzt, ruft, nachdem die Mischung einige Minuten gekocht ist, eine Gelbfärbung der Lösung (von gebildetem Cerdioxydsalz herrührend) hervor.

g) Wasserstoffsuperoxyd färbt die mit Ammoniumacetat versetzte Lösung der Ceroxydsalze braun; beim Schütteln der Mischung scheidet sich braunes, gallertartiges Basisch-Cerdioxydacetat aus. In verdünnten Lösungen tritt nur eine Gelbfärbung ein; beim Erwärmen findet jedoch auch hier Abscheidung von Basisch-Cerdioxydacetat statt.

h) Die Borax- und Phosphorsalxperle lösen die Cerverbindungen in der Oxydationsflamme mit gelbrother Farbe, die jedoch beim Erkalten verschwindet. In der Reduktionsflamme resultiren farblose Perlen.

Cerit und Orthit werden im fein gepulverten Zustande durch Digestion mit conc. Schwefelsäure, unter Abscheidung von Kieselsäure, gelöst.

\section{Molybdän.}

a) Schwefelwasserstoff erzeugt in geringer Menge in saurer Molybdänsäurelösung eine Blaufärbung, in grösserer Menge einen braunen, in Schwefelammonium löslichen Niederschlag $\left(\mathrm{MoS}^{3}\right)$. Die über dem braunen Niederschlage befindliche Flüssigkeit ist in Folge unvollständiger Fällung meist blau gefärbt. Eine vollständige Fällung als $\mathrm{MoS}^{3}$ tritt ein, wenn zur Molybdänsäurelösung erst Schwefelammonium und dann Salzsäure zugefügt wird.

b) Betupft man die Molybdänsäure oder deren Salze auf einem muldenförmig gebogenen Platinbleche mit cone. Schwefelsüure, erhitzt hierauf bis zum lebhaften Verdampfen der Schwefelsäure, lässt alsdann erkalten und haucht schliesslich wiederholt auf das Platinblech, so nimmt die Schwefelsäure eine blaue Färbung an.

c) Sehwefeleyankalium färbt die salzsaure Lösung der Molybdänsäure und der Molybdate gelb, auf Zusatz von Zink tritt eine schön rothe Färbung ein. Aether entzieht der rothen Flüssigkeit die färbende Verbindung mit orangerother, an der Luft carminroth werdender Farbe. 
d) Natriumphosphat erzengt bei mässiger Erwärmung $\left(40-50^{\circ} \mathrm{C}\right.$.) in stark salpetersaurer, die Molybdänsäure im Ueberschuss enthaltender Lösung eine gelbe, krystallinische Fällung (vgl. S. 27).

e) Zink ruft in salzsaurer Lösung zunächst eine Blaufärbung hervor, die allmälig in Grün und endlich in Braun übergeht.

f) Die Phusphorsalzperle wird in der reducirenden Flamme grün, die Boraxperle dagegen braun gefärbt. Beide Färbungen verschwinden wieder nahezu in der Oxydationsflamme.

Molybdänglañ liefert in der Phosphorsalzperle Molybdänreaction, färbt die Flamme zeisig - grün und giebt mit Soda auf der Kohle geschmolzen Hepar. Derselbe löst sich in Königswasser und nach dem Rösten in Ammoniak.

Gelbbleierz liefert auf der Kohle ein Bleikorn und in der Phosphorsalzperle Molybdänreaction. Dasselbe wird durch Digestion mit Salpetersäure, meist unter Abscheidung von Molybdänsäure, zersetzt.

\section{Wolfram.}

a) Schwefelwasserstoff fällt die saure Lösung der Wolframverbindungen nicht. Vermischt man dieselben aber mit Schwefelammonium und darauf mit Salzsüure, so scheidet sich braunes, in Schwefelammonium lösliches Sehwefelvolfram: WS ${ }^{3}, a b$. Die über dem Niederschlage befindliche Flüssigkeit zeigt meist eine blaue Farbe.

b) Säuren fallen aus der Lösung der Wolframate weisse Wolframsäure, die sich beim Kochen gelb färbt, ohne sich im Ueberschuss der Säure zu lösen.

c) Zinnchlorïr bewirkt in der Lösung der Wolframate einen gelben Niederschlag, der nach dem Ansäuern mit Salzsïure und Kochen sich schön blau färbt.

d) Zink ruft bei der durch Salzsäure abgeschiedenen Wolframsäure allmälig eine Blaufärbung hervor, die schliesslich in Braun übergeht.

e) Die Verbindungen des Wolframs, ertheilen der Phosphorsal:perle in der reducirenden Löthrohrflamme, namentlich auf Zusatz von etwas Stanniol, eíne tiefblaue Fürbung, die in der oxydirenden Löthrohrflamme wieder versehwindet. Bei Anwesenheit von Eisen zeigt die Perle eine blutrothe Färbung, die jedoch auf Zusatz von Stanniol ebenfalls in Blau übergeht. Die Boraxperle wird in der oxydirenden Flamme durch Wolframverbindungen nicht gefärbt, in der reducirenden Flamme tritt Gelbfärbung ein.

Wolframit und Scheelit liefern in der Phosphorsalzperle die Wolframreaction und scheiden bei der Digestion mit Königswasser gelbe Wolframsäure $a b$.

\section{Uran.}

a) Schwefelwasserstoff fält die Uransalze nicht; Schwefelammonium scheidet braunschwarzes Uranoxysulfid: UO'S, ab, welches in verdünnten Säuren und in Ammoniumcarbonat löslich ist. Bei Gegenwart von viel Ammoniumcarbonat werden daher die Uransalze durch Schwefelammonium nicht gefällt.

b) Ammoniale und ätzende Alkalien fällen aus Uranoxydsalzen gelbes, in einem Ueberschusse des Fällungsmittels unlösliches Alkaliuranat.

c) Ammoniumearbonat, Kalium - und Natriumbicarbonat rufen gelbe Fällungen hervor, die sich in einem Ueberschusse des Fällungsmittels wieder lösen. Beim Kochen letzterer Lösung tritt von Neuem Fällung ein. 
d) Ferrocyankalium ruft eine tief rothbraune Fällung hervor.

e) Die Phosphorsalz - und die Boraxperle lösen die Uranverbindungen in der oxydirenden Flamme mit gelber, beim Erkalten gelbgrün werdender Farbe. In der reducirenden Flamme geht die Färbung in Grün über.

Uranpecherz liefert in der Phosphorsalzperle die Uranreaction; es löst sich beim Kochen in Salpetersäure.

\section{Selen.}

a) Alle Selenverbindungen entwickeln beim Schmelzen mit wasserfreiem Natriumcarbonat auf der Kohle einen Geruch, der an faulen Rettig erinnert, und liefern eine Schmelze, welche blankes Silber schwärzt und mit Säuren übergossen, übelriechendes Selenwasserstoffgas entwickelt.

b) Selen (freies) löst sich in conc. Schwefelsäure mit grüner Farbe; durch Wasser wird es aus dieser Lösung als rothes Pulver wieder gefällt.

c) Selen (freies) verbrennt unter Entwicklung eines weissen Rauches mit blauer Flamme und verbreitet dabei einen Geruch nach faulem Rettig.

d) Schwefelwasserstoff fällt aus der wässerigen Lösung der selenigen Säure oder der angesäuerten Lösung der Selenite gelbes Schwefelselen: $\mathrm{SeS}^{2}$, welches löslich in Schwefelammonium ist.

e) Schweflige Säure, Zinnchlorür und andere Reductionsmittel scheiden aus der Lösung der selenigen Süure und der Selensäure, sowie der Selenite und der Selenate allmälig rothes Selen ab, welches beim Kochen schwarz wird.

f) Selensäure und Selenate werden durch Kochen mit Salzsäure unter Chlorentwicklung zu seleniger Säure reducirt.

g) Selensäure und Selenate werden durch Schwefelwasserstoff nicht crefällt. Chlorbaryum fällt weisses Baryumselenat: $\mathrm{BaSeO}^{4}$, unlöslich in Wasser und in verdünnten Säuren, löslich in conc. Salzsäure unter Entwicklung von Chlor.

\section{Tellur.}

a) Alle Tellurverbindungen liefern auf der Kohle in der inneren Löthrohrflamme einen weissen Beschlag; bläst man mit der inneren Löthrohrflamme auf den Beschlag, so verschwindet er unter Grünfärbung der Flamme. Mit Kaliumcarbonat auf der Kohle geschmolzen liefern die Tellurverbindungen Tellurkalium: $\mathrm{K}^{2} \mathrm{Te}$, welches sich in Wasser mit rother Farbe löst und mit Salzsäure übergossen, unangenehm riechenden Tellurwasserstoff liefert.

b) Tellur (freies) löst sich in conc. Schwefelsäure mit carminrother Farbe; Wasser scheidet es mit schwarzgrüner Farbe wieder aus. An der Luft erhitzt, verbrennt das Tellur ohne Geruch mit blauer Flamme zu weissem Tellurigsäureanhydrid: $\mathrm{Te}^{2}$.

c) Aus salzsaurer Lösung der tellurigen Säure und der Tellurite fällt Schwefelwasserstoff schwarzbraunes, in Schwefelammonium lösliches Schwefeltellur: TeS ${ }^{2}$; schweflige Säure und Zinnchlorür scheiden schwarzes Tellur ab.

d) Tellursäure und Tellurate werden beim Kochen mit Salzsäure unter Chlorentwicklung zu telluriger Säure reducirt. 


\section{Säuren.}

\section{Ameisensäure, Formiate.}

a) Quecksilberchlorid ruft beim Erwärmen eine weisse Trübung von ausgeschiedenem Quecksilberchlorïr hervor.

b) Fein vertheiltes gelbes Quecksilberoxyd wird beim Erwärmen unter Kohlensäureentwicklung grau gefärbt (Ausscheidung von Quecksilber).

c) Silbernitrat wird beim Erwärmen geschwärzt.

d) Conc. Schvefelsäure ruft beim Erwärmen Entwicklung von Kohlenoxyd hervor (mit bläulicher Flamme brennbar).

\section{Bernsteinsäure, Succinate.}

a) Die freie Bernsteinsäure kennzeichnet sich zunächst durch ihre Flüchtigkeit (ohne Abscheidung von Kohle); durch den stechenden Geruch ihres Dampfes und durch ihren Schmelzpunkt $\left(184^{\circ} \mathrm{C}\right.$.)

b) Neutrale Eisenoxydsalxe rufen in Bernsteinsäurelösung sofort oder nach einiger Zeit einen voluminösen, braunen Niederschlag hervor, ohne dass jedoch alles Eisenoxydsalz gefällt wird. Letzteres ist der Fall, sobald die Bernsteinsäure zuvor mit Ammoniak neutralisirt wird.

c) Bernsteinsäure und ihre Salze werden durch Kallwwasser nicht gefällt; erst auf Zusatz von Alkohol scheidet sich voluminöses Calciumsuccinat aus.

d) Bleiacetat fällt Bleisuccinat, welches sowohl in freier Bernsteinsäure, als auch in einem grossen Ueberschuss von Bleiacetat löslich ist.

\section{Aepfelsäure, Malate.}

a) Kalkwasser ruft weder in der Kälte noch beim Erhitzen eine Fällung hervor.

b) Bleiacetat fallt aus der Lösung der Aepfelsäure und deren Salze weisses, nach längerem Stehen krystallinisch werdendes Bleimalat; beim Kochen wird letzteres zum Theil gelöst, zum Theil schmilzt es harzartig zusammen.

c) Durch Erhitzen auf $150^{\circ} \mathrm{C}$. wird die Aepfelsäure in die schwer lösliche, gut krystallisirende Fumarsäure übergeführt. Die Mehrzahl der äpfelsauren Salze geht gegen $200^{\circ}$ C. in fumarsaure Salze über.

\section{Citronensäure, Citrate.}

a) Kalkwasser, bis zur alkalischen Reaction zugesetzt, ruft in der Kälte keine Fällung hervor, beim Kochen scheidet sich Calciumeitrat aus, welches sich beim Erkalten der Mischung wieder auflöst.

b) Bleiacetat fällt weisses Bleicitrat, löslich in Salpetersäure, Ammoniak und Alkalicitrat.

c) Conc. Schwefelsäure löst Citronensäure und Citrate bei mässigem Erwärmen (unter $90^{\circ}$ C.) unter lebhafter Entwicklung von Kohlenoxyd und Kohlensäureanhydrid ohne Bräunung auf.

d) Bei raschem Erhitzen an der Luft findet Verkohlung statt unter Entwicklung eines eigenthümlichen brenzlichen Geruchs.

\section{Benzoësäure, Benzoate.}

a) Die freie Benzoësäure kennzeichnet sich zunächst durch das Aeussere, durch die leichte Sublimirbarkeit, durch den Schmelzpunkt $\left(120^{\circ}\right.$ C.) und meist auch dureh einen eigenthümlichen Geruch (von kleinen Beimengungen aus dem Darstellungsmaterial herrührend). 
b) Durch Kalkwasser tritt weder in der Kalte noch in der Wärme eine Fállung ein.

c) Bleiacetat fällt Benzoësäurelösung nicht, wohl aber die der Benzoate.

d) Eisenchlorid scheidet aus der Lösung der Benzoësäure und der Benzoate voluminöses, gelbrothes Ferribenzoat aus.

\section{Salicylsäure, Salicylate.}

a) Eisenoxydsalke rufen eine schön violette Färbung hervor.

b) Kupfersulfat färbt die Lösung der Salicylsäure und der Salicylate schön grün; freie Mineralsäuren und ätzende Alkalien hindern die Reaction.

c) Bleiacetat fällt Salicylsäurelösung nicht, wohl aber die der Salicylate; der Niederschlag löst sich in Essigsäure und in einem Ueberschusse des Fällungsmittels, nicht dagegen in Ammoniak.

d) Mit Aetzkalle im Glühröhrchen erhitzt, tritt Phenolgeruch auf. 


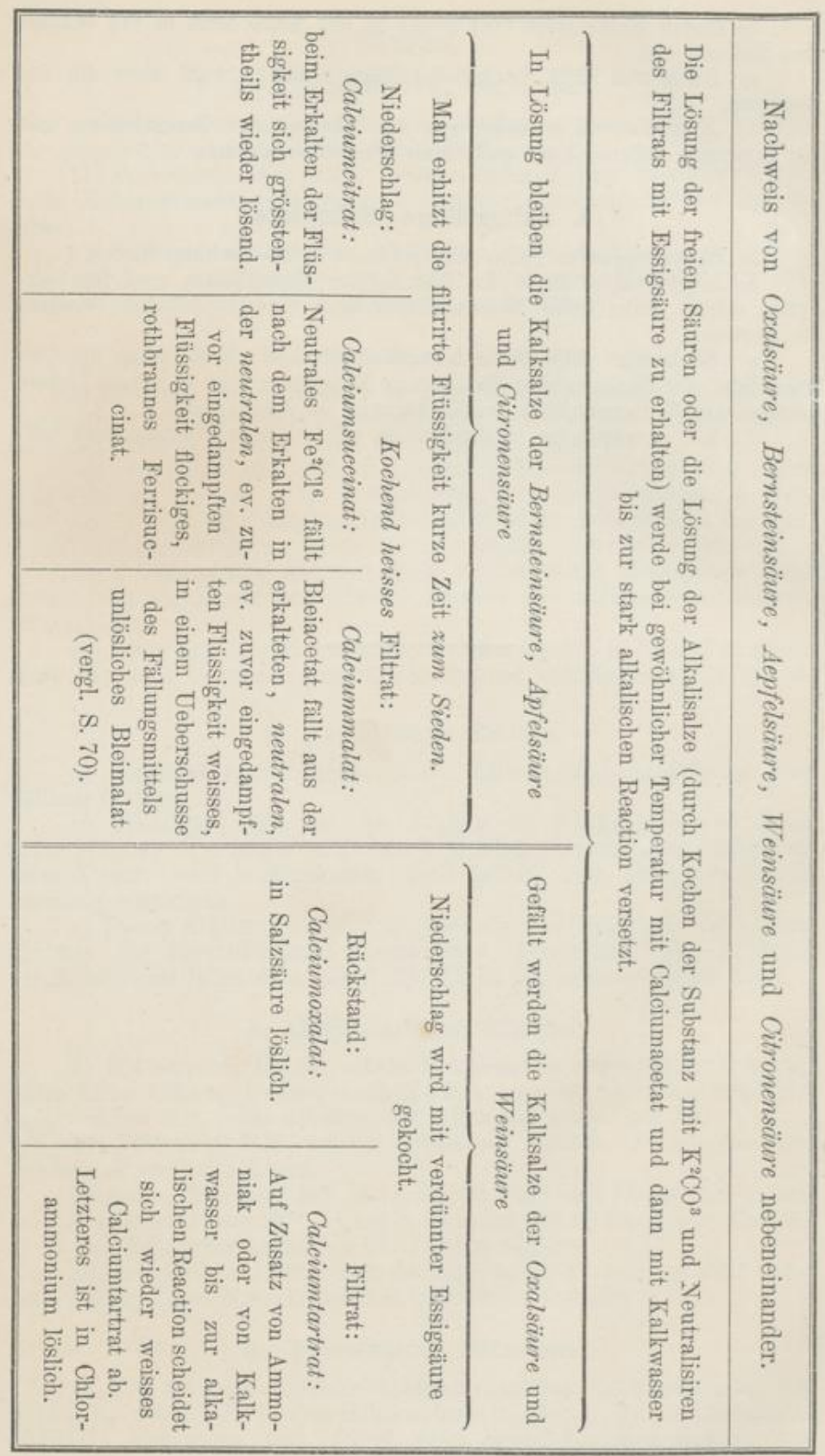




\section{Analyse}

\section{von Substanzen, Mineralien etc.,}

welche die selteneren Elemente enthalten:

Ti, Tl, W, Mo, Se, Te, U, Be, Ce, La, Di, Th, Zr, Y, Jr,

$\mathrm{Pd}, \mathrm{Ru}, \mathrm{Os}, \mathrm{Jn}, \mathrm{Ga}$ etc.

Die Mehrzahl obiger Elemente wird sich schon durch die Färbung der Flamme, sowie durch das Verhalten in der Phosphorsalzperle bemerkbar machen: Färbung in der oxydirenden und in der reducirenden Löthrohrflamme, in letzterer häufig nach Zusatz von etwas Zinnfolie (vgl. S. 42 u. f.)

Die Auflösung bezüglich Aufschliessung geschieht im Allgemeinen in der auf S. 47 u. f. angegebenen Weise. Auch die weitere Untersuchung der erzielten Lösungen ist im Allgemeinen die systematische des üblichen Ganges.

Ist dureh die Vorproben die Anwesenheit eines Titanits oder titansäurehaltigen Minerals wahrscheinlich gemacht, so schliesse man die sehr fein gepulverte Substanz durch lang anhaltendes Schmelsen mit $\mathrm{KHSO}^{4}(1: 6)$ auf, behandle die Schmelze mit vielem kalten oder lauwarmen Wasser, dem einige Tropfen $\mathrm{H}^{2} \mathrm{SO}^{4}$ zugesetzt sind, und prüfe die erzielte Lösung auf Titansäure nach S. 65. Durch anhaltendes Kochen ist dann die Titansäure abzuscheiden und das Filtrat in der üblichen Weise auf andere Basen zu prüfen.

Um Titansäure in Silicaten nachzuweisen, schliesse man durch Schmelzen mit Natrium-Kaliumearbonat auf und scheide die Kieselsäure ab (vgl. S, 50).

Fin Theil der Titansäure findet sich dann bei der abgeschiedenen Kieselsäure, der andere geht in die salzsaure Lösung und fällt daraus auf Zusatz von Ammoniak (mit Fe, Al ete.).

Um die Titansäure in letzterem Niedersehlag zu finden, schmelze man ihn mit $\mathrm{KHSO}^{4}$ und verfahre, wie oben erörtert ist.

Von der Kieselsäure lässt sich die Titansäure durch wiederholtes Erhitzen mit Flusssïure und Schwefelsäure, oder durch schwaches Glühen mit Fluorammonium trennen. Kieselsäure entweicht hierbei als Fluorsilicium, Titansäure bleibt zurück.

\section{Gruppe A.}

\section{Salzsäureniederschlag.}

Ausser $\mathrm{Pb}, \mathrm{Ag}$ und $\mathrm{Hg}$ (Mercuroverbindungen) können durch $\mathrm{HCl}$ noch gefallt werden:

a) Aus neutraler oder schwach salpetersaurer Lösung: Tl.

b) Aus neutraler oder schwach alkalischer Lösung: Wolframsäure (unter Umständen auch $\mathrm{SiO}^{2}$ und $\mathrm{MoO}^{3}$ ); $\mathrm{WO}^{3}, \mathrm{MoO}^{3}$ und $\mathrm{SiO}^{2}$ werden auch durch $\mathrm{HNO}^{3}$ gefällt. Die Kennzeichnung von $\mathrm{Pb}$ und $\mathrm{Hg}$ geschieht in der üblichen Weise, ebenso auch die des $\mathrm{Ag}$, wenn kein Wolfram vorhanden ist. 


\begin{tabular}{|c|c|c|}
\hline Thallium. & Wolfram. & Molybdän. \\
\hline $\begin{array}{l}\text { Weisser, anfangs kä- } \\
\text { siger, allmälig pulvri- } \\
\text { ger, lichtbeständiger } \\
\text { Niedersohlag: TiCl. } \\
\text { Grünfärbung der } \\
\text { Flamme. Die heisse } \\
\text { wässrige Lösung giebt } \\
\text { mit KJ und H² } \mathrm{H}^{2} \mathrm{tCl}^{6} \\
\text { gelbe Fällungen. } \\
\text { Vergl. S. } 65 \text {. Zur wei- } \\
\text { terenCharakterisirung } \\
\text { benutze man das Spec- } \\
\text { troskop. }\end{array}$ & 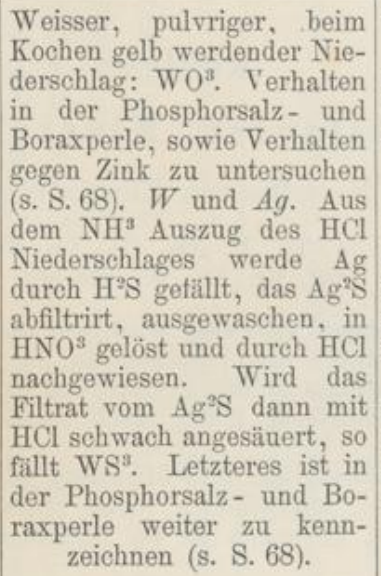 & $\begin{array}{l}\text { Weisser, krystalli- } \\
\text { nischer Nieder- } \\
\text { schlag: MoO }{ }^{3} \text {. In } \\
\text { der Phosphorsalz- } \\
\text { und Boraxperle zu } \\
\text { kennzeichnen } \\
\text { (s. S. 68). } \\
\text { Wenig } \mathrm{H}^{2} \mathrm{~S} \text { färbtdie } \\
\text { saure Lösung blau. } \\
\text { In NH } \mathrm{NH}^{3} \text { gelöst, die } \\
\text { Lösung in über- } \\
\text { schüssige HNO ge- } \\
\text { gossen, venig } \\
\text { Na }{ }^{2} \mathrm{HPO} \mathrm{O}^{4} \text { zugefügt } \\
\text { undauf50 erwärmt: } \\
\text { gelber, krystallini- } \\
\text { scher Niederschlag. }\end{array}$ \\
\hline
\end{tabular}

\section{Gruppe B.}

Schwefelwasserstoff-Niederschlag.

Ausser den auf Tab. I angegebenen Elementen werden durch $\mathrm{H}^{2} \mathrm{~S}$ in saurer Lösung noch gefällt:

Mo, Se, Te, Pd, Jr, Os, Ru, Rh.

(Bei Gegenwart von V, Mo und auch W pflegt die über dem $\mathrm{H}^{2} \mathrm{~S}$-Niederschlage befindliche Flüssigkeit blau gefärbt zu sein.)

Nach vollständiger Ausfällung werde der $\mathrm{H}^{2} \mathrm{~S}$-Niederschlag abfiltrirt, ausgewaschen und mit gelbem Schwefelammonium digerirt; [zunächst eine Probe des Niederschlages, und nur wenn etwas in Lösung geht, die ganze Menge. Vgl. Tab. I].

a) In $\left(\mathrm{NH}^{4}\right)^{2} \mathrm{~S}$ sind löslich: $\mathrm{As}^{2} \mathrm{~S}^{3}, \mathrm{Sb}^{2} \mathrm{~S}^{3}, \mathrm{SnS}^{2}, \mathrm{Au}^{2} \mathrm{~S}^{3}, \mathrm{PtS}^{2}, \mathrm{JrS}^{2}$, $\mathrm{MoS}^{3}, \mathrm{SeS}^{2}, \mathrm{TeS}^{2}$.

b) In $\left(\mathrm{NH}^{4}\right)^{2} \mathrm{~S}$ sind unlöstich: $\mathrm{HgS}, \mathrm{CuS}, \mathrm{PbS}$, CdS, $\mathrm{Bi}^{2} \mathrm{~S}^{3}, \mathrm{PdS}$, $\mathrm{OsS}^{4}, \mathrm{Ru}^{2} \mathrm{~S}^{3}, \mathrm{Rh}^{2} \mathrm{~S}^{3}$.

\section{a) In $\left(N^{4}\right)^{2} S$ unlöslicher Theil.}

Da Pd, Ru, Rh, Os nur bei der Analyse der Platinmetalle in Frage kommen (worüber Specialwerke zu befragen sind), so ist dieser Theil des $\mathrm{H}^{2} \mathrm{~S}$-Niederschlages direct nach Tab. I zu untersuchen.

b) In $\left(\mathrm{NH}^{4}\right)^{2} S$ löslicher Theil.

a) Bei Abwesenheit von Pt, Au und Jr.

Man trockne den durch $\mathrm{HCl}$ aus der Schwefelammonium-Lösung abgeschiedenen Niederschlag, mische ihn innig mit je der gleichen Menge $\mathrm{Na}^{2} \mathrm{CO}^{3}$ und $\mathrm{NaNO}^{3}$ und trage das Gemenge in kleinen Portionen in einen Porzellantiegel ein, in welchem 2 Theile $\mathrm{NaNO}^{3}$ bei mässiger Wärme zum Schmelzen gebracht sind. Ist Alles oxydirt, so giesse man die Schmelze in einen Porzellansoherben, weiche sie nach dem Erhalten mit kaltem Wasser auf, filtrire das Ungelöste $\left(\mathrm{NaSbO}^{3}\right.$ und $\left.\mathrm{SnO}^{2}\right) \mathrm{ab}$, 
wasche es mit Wasser und Alkohol zu gleichen Theilen aus, löse es in $\mathrm{HCl}$ und untersuche die Lösung nach Tab. II, $\beta$. auf $S b$ und $\mathrm{Sn}$.

Die Temperatur der Schmelze darf nicht zu hoch gesteigert und das Schmelzen nicht zu lange ausgedehnt werden, um die Bildung von wasserlöslichem $\mathrm{Na}^{2} \mathrm{SnO}^{3}$ zu verhüten.

Das Filtrat von $\mathrm{NaSbO}^{3}$ und $\mathrm{SnO}^{2}$, oder bei deren Abwesenheit, die Lösung der Schmelze, welche ev. $\mathrm{Na}^{3} \mathrm{AsO}^{4}, \mathrm{Na}^{2} \mathrm{MoO}^{4}, \mathrm{Na}^{2} \mathrm{SeO}^{4}$ und $\mathrm{Na}^{2} \mathrm{TeO}^{4}$ enthält, werde eingedampft, in 3 Theile getheilt und diese auf As, Se und $\mathrm{Te}$, sowie auf $\mathrm{Mo}$ in nachstehender Weise geprüft:

\begin{tabular}{|c|c|c|}
\hline $\begin{array}{l}\text { I. Theil: } \\
\text { Arsen. }\end{array}$ & $\begin{array}{l}\text { II. Theil: } \\
\text { Selen, Tellur. }\end{array}$ & $\begin{array}{l}\text { III. Theil: } \\
\text { Molybdän. }\end{array}$ \\
\hline $\begin{array}{l}\text { Die Lösung werde mit } \\
\text { HNO sauer gemacht } \\
\text { und a) mit Ammon- } \\
\text { molybdat-Lösung im } \\
\text { Ueberschuss erwärmt: } \\
\text { Gelber, krystallini- } \\
\text { scher Niederschlag. } \\
\text { b) mit AgNO }{ }^{3} \text {-Lösung } \\
\text { versetzt und mit Am- } \\
\text { moniak geschichtet: } \\
\text { Rothbraune Zone. } \\
\text { c) mit Ammoniak und } \\
\text { Magnesiamixtur ver- } \\
\text { setzt: allmälig kry- } \\
\text { stallinischer Nieder- } \\
\text { schlag, ev. nach 24 } \\
\text { Stunden zu sammeln, } \\
\text { mit NH auszuwa- } \\
\text { schen, in verdünnter }^{3} \text { H'SO }^{2} \text { zu lösen und } \\
\text { mit viel HS-Wasser } \\
\text { (erwärmen), oder mit } \\
\text { Bettendorf'schem } \\
\text { Reagenz, oder im } \\
\text { Marsh'schen Apparat } \\
\text { zu prüfen. }\end{array}$ & $\begin{array}{l}\text { Die Lösung werde mit starker } \\
\text { Salzsäure einige Zeit gekocht: } \\
\text { Bildung von } \mathrm{H}^{2} \mathrm{Se} \mathrm{O}^{3} \text { und } \mathrm{H}^{2} \mathrm{TeO} \\
\text { unter Chlorentwicklung. Dann } \\
\text { erwärme man die Flüssigkeit mit } \\
\text { schwefliger Säure und lasse sie } \\
\text { einige Zeit lang stehen. } \\
\text { Selen: allmälig rothe Abschei- } \\
\text { dung: Se. } \\
\text { Tellur: allmälig schwarze Ab- } \\
\text { scheidung: Te. } \\
\text { Se und Te sind ev. nach S. } 69 \\
\text { weiter zukennzeichnen. Trennung } \\
\text { des Se von Te. Man sammle den } \\
\text { durch SO }{ }^{2} \text { erzeugten Niederschlag, } \\
\text { trockne ihn, schmelze ihn mit } \\
\text { KCN, löse die Schmelze in Wasser } \\
\text { und setze die klare Lösung in einer } \\
\text { Schale der Luft aus: allmälige Ab- } \\
\text { scheidung von schwarzem Te. Se } \\
\text { bleibt hierbei in Lösung und kann } \\
\text { aus dem Filtrat vom ausgeschie- } \\
\text { denen Te durch HCl allmälig } \\
\text { als rothes Pulver abgeschieden } \\
\text { werden. }\end{array}$ & $\begin{array}{l}\text { Die Lösung } \\
\text { werde mit HCl } \\
\text { oder HNO }{ }^{3} \text { an- } \\
\text { gesäuert und } \\
\text { dann wie S. } 67 \\
\text { u.f. angegeben } \\
\text { ist, auf Molyb- } \\
\text { dän geprüft. }\end{array}$ \\
\hline
\end{tabular}

B) Bei vermuthlicher Anwesenheit von Pt, Au und Jr.

Man mische den trocknen, ev. die Sulfide des As, Sb, Sn, Mo, Se, $\mathrm{Te}, \mathrm{Pt}, \mathrm{Au}, \mathrm{Jr}$ enthaltenden Niedersehlag innig mit 1 Theil $\mathrm{NH}^{4} \cdot \mathrm{NO}^{3}$ und 5 Theilen $\mathrm{NH}^{4} \cdot \mathrm{Cl}$ und erhitze das Gemisch in einem trocknen Reagenzglase, oder besser in einem Porzellanschiffchen, welches sich in einem horizontal liegenden Glasrohr $(1,5 \mathrm{~cm}$ w้eit, $30-40 \mathrm{~cm}$ lang) befindet, in einem langsamen Luftstrome. Als Sublimationsrückstand verbleiben: $P t, A u, J r$ als Metalle; während $A s, S b, S n, M o, S e$ und $T e$ sich in dem entstandenen Sublimat befinden. $P t, A u$ und $J r$ werden durch Zerschneiden des Reagenzglases oder durch Herausnehmen des Schiffchens von dem Sublimate getrennt, in Königswasser gelöst und die Lösung nach Tab. II auf $P t$ und $A u$ geprüft; $J r$ bleibt hierbei im Wesentlichen zurück. Das Sublimat, welches ev. As, Sb, Sn, Mo, Se, Te enthält, wird in Salzsäure gelöst und werden aus der Lösung die Elemente als Schwefelverbindungen durch $\mathrm{H}^{3} \mathrm{~S}$ abgeschieden. Die weitere Untersuchung der letzteren geschieht dann nach $c$ ) s. S. 74 . 


\section{Gruppe C.}

Schwefelammoniumniederschlag.

Aus alkalischen Lösungen werden bei Gegenwart von $\mathrm{NH}^{4} \mathrm{Cl}$ ausser den auf Tab. III angegebenen Elementen gefällt:

als Sulfide: $U, T l, J n$ und $G a$.

als Hydroxyde: $\mathrm{Be}, \mathrm{Th}, \mathrm{Zr}, \mathrm{Y}, \mathrm{Ce}, \mathrm{La}, \mathrm{Di}, \mathrm{Ta}, \mathrm{Nb}, \mathrm{Er}$.

Der Fall, dass alle diese Elemente gleichzeitig nebeneinander vorhanden sind, kommt in praxi nie vor, vielmehr wird es sich immer nur um Scheidung gewisser zu einander in Beziehung stehender oder gemeinsam vorkommender Elemente handeln.

Der gut ausgewaschene Schwefelammoniumniederschlag werde mit kalter Salzsüure $(5 \% \mathrm{HCl})$ im Deberschuss geschüttelt; es bleiben CoS und NiS im Wesentlichen ungelöst (s. Tab. III). Die erzielte salzsaure Lösung werde hierauf mit $\mathrm{HNO}^{3}$ gekocht (um Ferrosalze zu oxydiren), alsdann mit $\mathrm{NH}^{3}$ übersättigt und der entstehende Niederschlag (c) sofort von der Flüssigkeit (d) abfiltrirt (s. Tab. III).

1. Die Lösung d kann enthalten: Mn, Zn, Ga und TI.

Die Trennung geschieht nach der Tab. III; Ga und Tl verbleiben hierbei mit dem Zink in Lösung und sind ev. durch das Spectroseop nachzuweisen. $T l$ kann nach dem Neutralisiren der alkalischen Lösung mit $\mathrm{HNO}^{3}$ und Eindampfen ev. auch durch KJ nachgewiesen werden (s. \$.66). Der Nachweis des Tl kann auch direkt in einer Probe des $\left(\mathrm{NH}^{4}\right)^{2} \mathrm{~S}$-Niederschlages geführt werden. (Lösen in verdünnter $\mathrm{H}^{2} \mathrm{SO}^{4}$, gelinde erwärmen, bis HS entfernt ist, dann mit $\mathrm{NH}^{3}$ annähernd neutralisiren und mit KJ prüfen.)

2. Der Niederschlag $c$ lann enthalten: Die Hydroxyde des $\mathrm{Fe}$, $\mathrm{Cr}, \mathrm{Al}, \mathrm{Be}, \mathrm{U}, \mathrm{Jn}, \mathrm{Ce}, \mathrm{La}, \mathrm{Di}, \mathrm{Y}, \mathrm{Fr}, \mathrm{Ta}, \mathrm{Nb}, \mathrm{Th}, \mathrm{Zr}$ und das Phosphat des $C a$; die Phosphate des $B a$, Sr und $M g$, ebenso Oxalate des $C a, B a$ und $S r$ dürften im Verein mit obigen Elementen in praxi kaum vorkommen. $J n$ ist spectroseopisch nachzuweisen.

Der Niederschlag werde mit kalter, cone. Kalilauge im Ueberschuss geschüttelt, die Mischung etwas mit $\mathrm{H}^{2} \mathrm{O}$ verdünnt und filtrirt:

In Lösung gehen: $\mathrm{Al}^{2}(\mathrm{OH})^{6}$, $\mathrm{Be}(\mathrm{OH})^{2}$ und $\mathrm{Cr}^{2}(\mathrm{OH})^{6}$. Die Lösung werde mit $\mathrm{H}^{2} \mathrm{O}$ verdünnt und längere Zeit gekocht; es werden abgeschieden: $\mathrm{Cr}^{2}(\mathrm{OH})^{6}$ und $\mathrm{Be}(\mathrm{OH})^{2}$. $\quad \mathrm{Al}^{2}(\mathrm{OH})^{6}$ bleibt in Lösung und kann durch conc. $\mathrm{NH}^{4} \mathrm{Cl}$ - Lösung aus der filtrirten Flüssigkeit gefallt werden.

Trennung von $\mathrm{Cr}$ und Be. Der Niederschlag werde mit 2 Theilen $\mathrm{KClO}^{3}$ und 2 Theilen $\mathrm{K}^{2} \mathrm{CO}^{3}$ im Platintiegel geschmolzen, die Schmelze mit Wasser aufgeweicht und die Lösung mit $\mathrm{HNO}^{3}$ angesäuert. $\mathrm{Be}$ wird durch $\mathrm{NH}^{3}$ im geringen Ueberschuss gefällt; $\mathrm{Cr}$ bleibt mit gelber Farbe gelöst.
Ungelöst bleiben: die Hydroxyde des $\mathrm{Fe}, \mathrm{Ur}$ und der seltneren Elemente, ebenso $\mathrm{Ca}^{3}\left(\mathrm{PO}^{4}\right)^{2}$ [ev. auch etwas $\mathrm{Cr}^{2}(\mathrm{OH})^{6}$ und $\left.\mathrm{Al}^{2}\left(\mathrm{OH}^{6}\right)\right]$. Der Niederschlag werde wiederholt längere Zeit mit cone. Ammoncarbonatlösung kalt geschüttelt.

Es bleiben ungelöst: $\mathrm{Fe}^{2}(\mathrm{OH})^{6}$, $\mathrm{Ca}^{3}\left(\mathrm{PO}^{4}\right)^{2} \mathrm{u}$. ev, auch etwas $\mathrm{Cr}^{2}(\mathrm{OH})^{6}$ und $\mathrm{Al}^{2}(\mathrm{OH})^{6}$. [Ueber deren Trennung s. Tab. III und IV.]

Gelöst verden: die Hydroxyde des Ur, Ce, La, Di, Y, Er, Ta, Nb, Zr, u. Th. Ur. Eine Probe dieser Lösung werde mit $\mathrm{HCl}$ angesäuert und mit $\mathrm{K}^{4} \mathrm{Fe}(\mathrm{CN})^{6}$ versetzt: braunrother Niederschlag. Der Rest derLösung werde zum Kochen erhitzt: $T h, Z r, Y$ werden abgeschieden.

Aus dem eingeengten Filtrate scheidet conc. Oxalsäurelösung im Ueberschuss: $\mathrm{Ce}, \mathrm{La}, \mathrm{Di} \mathrm{ab}$. (Nach längerem Stehen auch Ur.) 


\section{Gruppe D und E.}

Das Filtrat vom $\left(\mathrm{NH}^{4}\right)^{2} \mathrm{~S}$-Niederschlage kann bei brauner oder braunrother Färbung ausser den alkalischen Erden ete. noch $N i, V$ und $W$ enthalten. Man säure dasselbe mit $\mathrm{HCl}$ schwach an, filtrire den Niedersehlag $a b$, wasche ihn aus und schmelze ihn nach dem Trocknen mit $\mathrm{KNO}^{3}$ und $\mathrm{Na}^{2} \mathrm{CO}^{3}$. Nach dem Aufweichen mit Wasser bleibt $\mathrm{NiO}$ ungelöst. Die Lösung werde mit soviel festem $\mathrm{NH}^{4} \mathrm{Cl}$ versetzt, dass noch etwas ungelöst bleibt. $V$ wird nach einiger Zeit als Ammoniumvanadat abgeschieden; dasselbe werde gesammelt und nach S. 66 gekennzeichnet. Das Filtrat von Ammoniumvanadat werde mit $\mathrm{HCl}$ im Ueberschuss eingedampft, der Rückstand mit Wasser ausgezogen und das Ungelöste in der Phosphorsalz - und Boraxperle auf $W$ geprüft. Das Filtrat hiervon ist alsdann in der üblichen Weise nach Gruppe $D$ auf $C a, B a$ und $S r$, sowie nach Gruppe $E$ auf $M g, K, N a, L i$ zu prüfen. $R b$ und $C s$, welche ev. mit den Alkalien nach Gruppe $E$ zurückbleiben, sind spectroscopisch nachzuweisen.

\section{Unlöslicher Rückstand.}

Bei Berücksichtigung der seltneren Elemente kann der in Königswasser unlösliche Rückstand noch enthalten die Sauerstoffverbindungen des $\mathrm{Be}, \mathrm{Ti}, \mathrm{W}, \mathrm{Mo}, \mathrm{Th}, \mathrm{Zr}, \mathrm{Ce}, \mathrm{Ta}, \mathrm{Nb}$ und die Platinmetalle $\mathrm{Jr}$, Os, $\mathrm{Ru}, \mathrm{Rh}$. In vielen Fällen wird dann die Phosphorsalzperle in der reducirenden Flamme blau, violett oder blutroth (bei Gegenwart von $\mathrm{Fe}$ ), namentlich unter Zusatz von etwas Stanniol, gefärbt werden. Man schliesse zunächst durch anhaltendes Schmelzen im Silbertiegel mit KOH und $\mathrm{KNO}^{3}$ auf und extrahire die Schmelze mit heissem Wasser. Das Ungelöste schliesse man mit KHSO ${ }^{4}(1: 6)$ auf und löse in viel Wasser. Die Lösungen sind nach obigen Angaben weiter zu prüfen. 


\section{Register.}

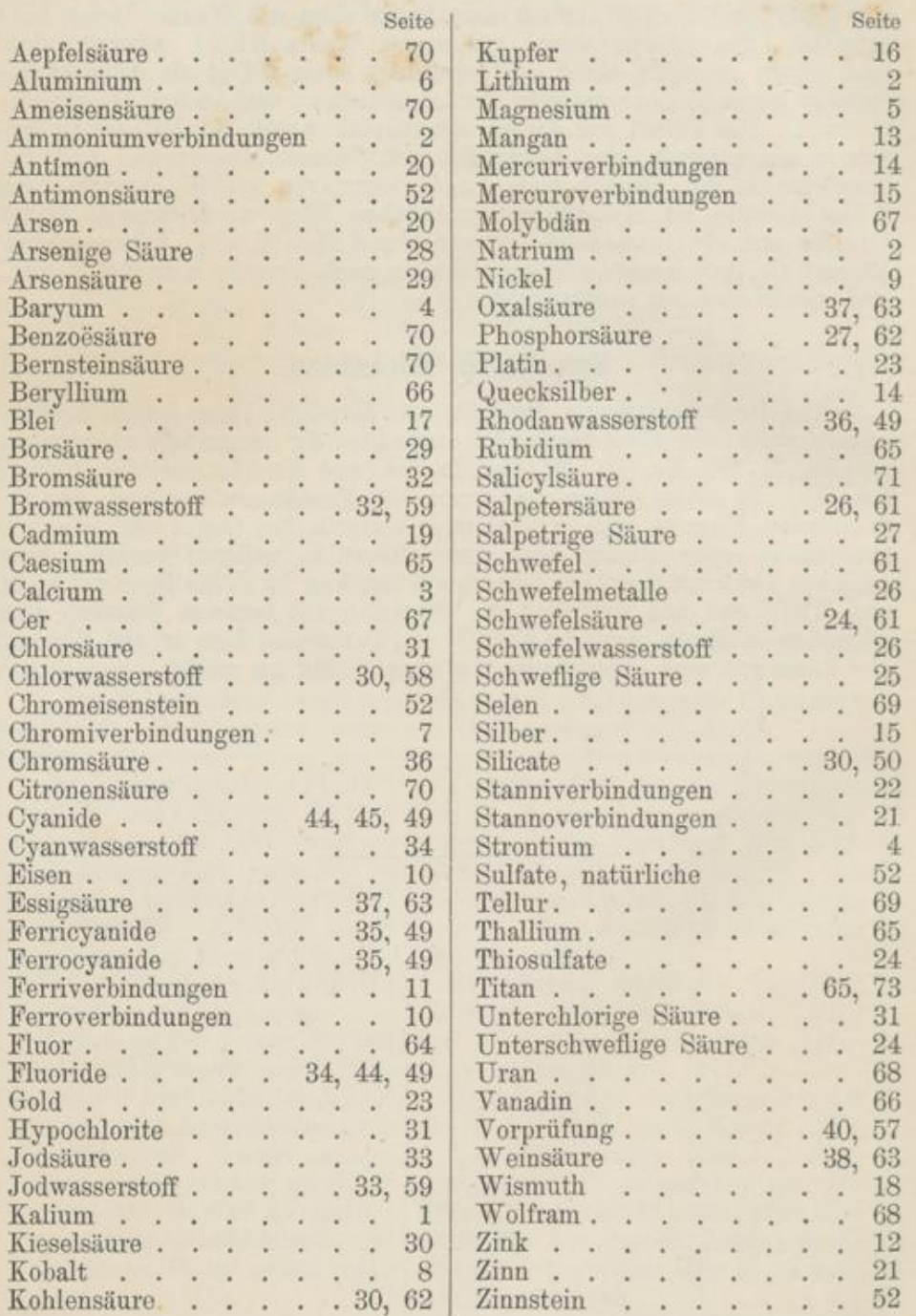




\title{
Die \\ Pharmacie bei den alten Culturvölkern.
}

\author{
Historisch-kritische Studien \\ von
}

\section{Dr. J. Berendes,}

Apotheker.

Mit einem Vorworte von

Professor Dr. H. Beckurts in Braunschweig.

Zwei Bände in hochfeiner Ausstattung mit einer Tafel und einer Karte.

Geheftet: $\mathscr{k}$ 17, in einen eleganten Halbfranzband gebunden: $\mathbb{K}: 20$.

\section{Auszug aus der Vorrede}

des Herrn Professors Dr. H. Beckurts in Braunsehweig.

Als ein Teil der Culturgesehichte ist die Geschichte der Pharmacie für jeden Apotheker von grofser Bedeutung, weil er aus ihr erfährt, welchen Entwickelungsgang seine Wissenschaft genommen hat. Aber auch kaum kann es Anziehenderes für den gebildeten Apotheker geben, als in seinen Mufsestunden sich der Betrachtung hinzugeben, wie das, was wir als unsere tägliche Beschäftigung betreiben, sich aus den kleinsten Anfängen zur hentigen Vollendung entwickelt hat, welche Leistungen der Pharmaeie schon vor Jahrtausenden mit den im Vergleich zur Gegenwart primitivsten Hilfsmitteln zu verzeichnen sind; einen Blick zu werfen in das Laboratorium der Alten und zu erfahren, welche Zwecke unsere Vorgänger in grauer Vorzeit verfolgten, und welchen Zielen sie zustrebten; zu sehen, wie so manches im Laufe der Zeit beiseite gesetzt wurde, um später seinem unsprünglichen Dienste wieder gewidmet zu werden.

Verdienen nun alle auf das Studium der geschichtlichen Entwickelung der Pharmacie gerichteten Bestrebungen, dafs wir sie durch Zuwendung unseres Interesses unterstützen, so dürfte die vorliegende, auf höchst mühevollen Studien beruhende Leistung auf diesem Gebiete dies im hervorragenden Grade wert sein. Der Inhalt der Arbeit wird zur Verbreitung unserer Kenntnisse der Geschichte der Pharmacie beitragen und zu neuen Studien auf diesem interessanten Gebiete anregen; er wird den Sinn für eine ideale Auffassung des pharmaceutischen Berufes wachrufen und erhalten, und dadurch belebend auf eine auf wissenschaftlicher Grundlage beruhende Entwickelung der heutigen Pharmacie einwirken. Möge eine recht weite Verbreitung des Werkes diesem Zwecke förderlich sein, und dadurch dem Verfasser die beste Anerkennung seiner verdienstvollen Thätigkeit zu teil werden. 
Verlag von Tausch \& Grosse in Halle a. S.

\title{
Der angehende Apotheker.
}

\author{
Lehrbuch
}

der

\section{pharmazeutischen Hilfswissenschaften}

\author{
zum Gebrauch für den Unterricht der Eleven
}

von

\section{Dr. J. Berendes,}

Apotheker.

Zweite vermehrte und verbesserte Auflage. 1895.

I. Band: Physile und Chemie. 590 Seiten. gr. $8^{0}$ mit 146 Holzschnitten und 1 farbigen Spektraltafel. Grebunden $\mathscr{N}$. 7,50.

II. Band: Botanik, Pharmaliognosie, sperielle Pharmazie. 514 S. gr. $8^{0}$ mit 486 Holzschnitten. Gebunden $\mathscr{K}$. 8,50.

Jeder Band ist einzeln käuflich.

Pharmaceutische Rundschau: Die Ausstattung des Werkes ist in jeder Weise eine solide und schöne, die A bbildungen und besonders der gröfsere Teil der botanischen und pharmakognostischen sind von einer Sauberkeit und Schönheit, wie sie in solchen Lehrbüchern, selbst bei der bekannten Vortreftlichkeit deutscher Illustration, nicht oft gefunden werden. Möge das schöne, anregend geschriebene und mit praktischem Sinne verfafste Werk verdiente Verbreitung finden.

Apotheker-Zeitung: Klar geschrieben, übersichtlich dargestellt, bietet das Werk nicht nur das nötige Wissensquantum für den angehenden, sondern auch eine Menge Stoff für den fertigen Apotheker, der sich den gesetzlich vorgeschriebenen gründlichen Unterricht seiner Lehrlinge am Herzen liegen läfst.

Pharmaceutische Centralhalle: Die Vorzüge dieses Werkes - speziell sei noch die fleifsige Behandlung des Stoffes erwähnt - versprechen eine bereitwillige Aufnahme unter den jungen Fachgenossen.

Pharmaceutische Wochenschrift: So ist denn auch der zweite Band dieses Werkes von der ersten bis letzten Seite in jeder Beziehung als vorzüglich zu bezeichnen; nicht nur unsern angehenden Kollegen, sondern auch unseren älteren Fachgenossen möchten wir das ganze Buch zu recht fleifsiger Benutzung empfehlen.

Süddeutsche Apotheker-Zeitung: Alles in Allem genommen, ,Der angehende Apotheker" bildet eine wertvolle Bereicherung des pharmazeutischen Bücherstandes, seine Anschaffung und, Nota bene, recht fleilsige Benutzung kann der heranwachsenden Jugend des Standes wärmstens empfohlen werden.

Halle a. S., Buchdruckerei des Waisenhauses. 
olz-

50.

$1 \mathrm{~S}$.

eder

sere 


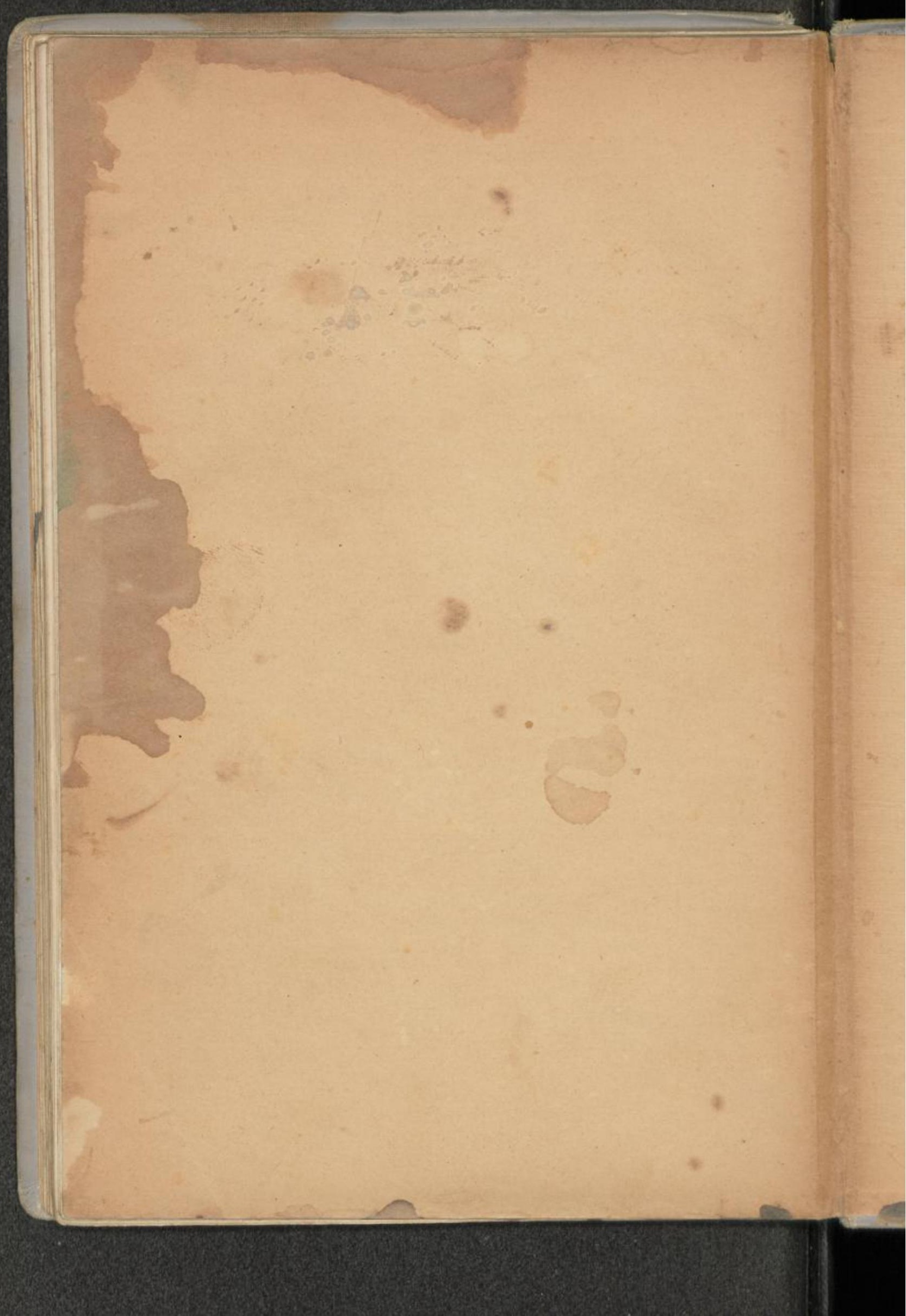





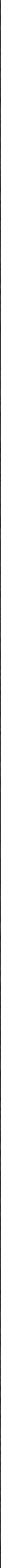

